

\section{ASSESSING WATER QUALITY IN LAKE NAIVASHA}

Jane Njeri Ndungu 


\section{Thesis committee members:}

$\begin{array}{ll}\text { Prof. dr. G.P.M.R Dewulf } & \begin{array}{l}\text { University of Twente, Chairman and } \\ \text { Secretary }\end{array} \\ \text { Prof. S.J.M.H.Hulscher } & \text { University of Twente, Promotor } \\ \text { Prof. Jude Mathooko } & \text { Egerton University, Promotor } \\ \text { Dr.ir. D.C.M.Augustijn } & \text { University of Twente, Co-promotor } \\ \text { Prof Prof. dr. W. M Mooij, } & \text { NIOO-KNAW } \\ \text { Prof. M.E McClain } & \text { UNESCO-IHE } \\ \text { Prof. A. van der Veen } & \text { University of Twente } \\ \text { Dr.ir. C.M.M. Mannaerts (UHD) } & \text { University of Twente }\end{array}$

The work described in this thesis was performed at the Department of Water Engineering and Management, Faculty of Engineering Technology and Faculty of Geoinformation and Earth Observation (ITC), University of Twente, P.O. Box 217, 7500 AE Enschede, The Netherlands.

Copyright (C) 2014, , All rights reserved.

ISBN: $978-90-365-3700-1$

DOI $10.3990 / 1.9789036537001$ 


\title{
ASSESSING WATER QUALITY IN LAKE NAIVASHA
}

\author{
DISSERTATION
}

to obtain

the degree of doctor at the University of Twente, on the authority of the rector magnificus, prof.dr. H. Brinksma, on account of the decision of the graduation committee,

to be publicly defended

on $27^{\text {th }}$ June 2014 at $12: 45$ hours

by

Jane Njeri Ndungu

Born on the $3^{\text {rd }}$ July 1979

in Kiambu, Kenya 
This dissertation has been approved by:

Prof.dr. S.J.M.H.Hulscher, promoter

Prof. Jude Mathooko, promoter

Dr. Ir. D.C.M.Augustijn, Co-promoter 


\section{Preface}

This study was part of the EOIA ("An Earth Observation- and Integrated Assessment approach to the Governance of Lake Naivasha") Project together with four other PhD components executed collaboratively between University of Nairobi, Egerton University and the University of Twente. The overall project goal was to integrate hydrology, limnology, biodiversity, social economics and governance to highlight the interdependencies between policies, activities and aspirations in order to identify constraints and explore mutually acceptable alternatives. This study stipulates how the limnological part of the project was executed. The information provided through this study could aid in sustainable governance of Lake Naivasha: a critical but severely threatened ecosystem. 


\section{Acknowledgements}

This work would not have been a success without the contribution of various institutions and individuals in Netherlands, Kenya and United States of America. It's difficult for me to mention them all in this acknowledgement but I want to take this opportunity to express my appreciation to a few who played a key role.

First and foremost, my deepest respect and utmost gratitude goes to my promoter Prof. Suzanne Hulscher. Your exceptional generous support and apt guidance provided an endless enthusiasm that kept me going all through. The intuitive solution oriented research approach and conscientious working style in you amazingly inspired me a lot. Your precise and realistic timelines left me wondering how you intuitively got it right. The scientific attitude learnt from you will be amplified over my entire career and am truly indebted to you.

I would also like to convey my sincere gratitude to my second promoter Prof. Jude Mathooko. Your invaluable guidance and thorough revisions of my dissertation would not go unmentioned. I have benefited a lot from your scientific experience and I truly appreciate your generous and unconditional support. Your immeasurable goodwill in liaison to Prof. Suzanne Hulscher is what has made me proud to graduate without delays. I truly appreciate, and again I say thank you very much.

Special appreciation goes to my assistant promoter Dr. Denie Augustijn for the enthusiastic and tireless effort to shape my research. Your unwavering support and encouragement throughout the study period together with many fruitful critics helped to substantially improve this work. I have benefited a lot and I feel privileged to have worked under your stewardship during especially during this challenging but rewarding phase in my career. Your meticulous working style will immensely shape my entire career. You were patient with me through the research hurdles and I am sincerely grateful.

I would like to extend the much deserved gratitude Dr. Nzula Kitaka (Associate professor) who supported me a lot during my research. Your constructive scientific comments contributed a lot to the quality of this research. Your comments instilled important lessons that I will truly treasure in my entire life. I feel indebted and will forever remain grateful to the invaluable contribution in steering my PhD into a cheerful conclusion.

I gratefully acknowledge Prof. Bruce Monger from Cornell University in the United States of America. Your encouragement, inspiration and devotion to unconditional and thorough revision to the remote sensing part of my 
research contributed a lot to the success this work. Thank very much for your patience in teaching me the IDL programming which I treasure very much.

The work would not have been completed without the support and the contribution from the Water Resource Management Authority (WRMA), Kenya; Fisheries Department (FiD), Kenya; the Kenya Marine and Fisheries Research Institute (KMFRI) and Egerton University, Kenya. Special gratitude goes to Mr. John Njungo, Ms Beatrice and Mr. Dominic Wambua from WRMA for their instrumental assistance provided during my fieldwork in Naivasha. I would like thank Mr. Muchai from FiD who was the coxswain all through data collection period. I would like to thank Dr. Fulanda as well. Your support and contribution gave me a reason to move on. Thank so much. I would also wish to acknowledge Christopher Aura for the valuable contribution and support. Thank you so much Achille-Tâm Guilchard from France for the help accorded during your attachment period in the University of Twente.

I gratefully acknowledge the WOTRO Science for Global Development for funding this research work. My sincere gratitude also goes to the administrative assistance provided by International Institute for Geoinformation and Earth Observation (ITC) particularly through Prof. Anne van der Veen, Drs. Robert Becht, and Dr. Pieter van Oel. My sincere thanks go to Ms. Loes Colenbrander, Petra, Marion Pierik, Marie Chantal Metz, Theresa van den Boogaard, Bettine Geerdink of ITC for timely administrative assistance. Thanks to you Tina Butt-Castro for being a great friend. The time we shared, motherly advice, nice dinners would not go unmentioned. Thanks Carla Gerritsen and Marga of ITC library. The entire ITC helpdesk staff had solutions to all my computer problems. Thank you so much.

Special gratitude goes to Water and Engineering Department where I worked from, on Mondays and Fridays. My profound gratitude goes to Brigitte, Anke, and Joke; you made me feel at Home in WEM department. Thanks a lot. I recognize the PhD colleagues in WEM, Erik, Suleyman, among others. Special gratitude goes to Wen Long for the assistance he gave especially in modelling. I appreciate Dr. Wijnberg's, constructive statistical discussion which helped shape my work. Thanks Zhuo La, and Basma, with whom I shared an office. I appreciate your friendship which made our office warm. I would like to appreciate all the ITC PhD colleagues whom we interacted. The list is inexhaustible and therefore I will just mention a few. Special gratitude goes Dawit, Job, Francis, Akwany, and Vincent, with whom we shared an office in ITC. You all gave me a reason to move on and am indeed grateful. I wish recognize my friend Clarisse Kagoyire who consistently encouraged me particularly when things did not seem to work. Thanks Sonia, Sam, Dr. Tagel, John, Jesper, Khuluse, Irma, Adrie, Kapongola, Zandieh, Alemie, Dr. Ali, Atkilt, Zhang, among others for the time we shared. 
Am indebted to thank the Kenyan community in Enschede, with whom we shared memorable get-togethers, politics, and jokes. You all made me feel part of a great family. Thank you all. Dr. Ngene, Dr. Kuria, Lilian Wamuyu, Lucy Chepkosgei, Martin Mwema, Salome, Eshitera, Aidan, Edicah, Faith, I appreciate your cordial friendship and the support during my PhD. The memorable time shared with Dr. Kinoti cannot go unmentioned. Your consistent encouragement each day was a constant reminder that the sky is the limit. I will forever be grateful and I truly treasure your friendship. 


\section{Executive summary}

Water quality in aquatic systems is important because it maintains the ecological processes that support biodiversity. However, declining water quality due to environmental perturbations threatens the stability of the biotic integrity and therefore hinders the ecosystem services and functions of aquatic ecosystems. This research aimed at studying the water quality in Lake Naivasha, Kenya. A myriad of environmental perturbations in Lake Naivasha's ecosystem have transformed the lake from a clear to muddy eutrophic turbid state, which has resulted in a decline in ecological quality, impacting heavily on fish population and tourism. Though there has been regular data collection on water levels and fish catches, little has been done in monitoring the water quality dynamics in Lake Naivasha. The specific objectives were to assess the overall water quality status; establish the trophic status; assess retrospectively the water quality condition in the last decade; study effect of succession of fish community; and investigate the mechanisms that influence the water quality dynamics in Lake Naivasha.

These objectives were achieved through coupling field measurements, geoinformation and earth observation, and system modelling. The field measurements were collected weekly from January to June and bi-weekly from July to November 2011 at seven locations in the lake. Water temperature, $\mathrm{pH}$, conductivity, Secchi depth, and turbidity were measured insitu while others were analysed from water samples in the laboratory. Geoinformation and earth observation was used in the retrieval of chlorophyll-a concentration from June 2002 to June 2012 from Moderate Resolution Imaging Spectroradiometer (MODIS-Aqua) satellite images. The modelling objective was achieved using Delft3D Flow module to simulate the hydrodynamics in Lake Naivasha.

Principal Component Analysis (PCA) and Cluster Analysis (CA) revealed spatial variability in physiochemical parameters, nutrients and main ions. Northern region, main lake, and Crescent Lake sectors of the lake were distinct. Water quality parameters association indicated that the quality of water is influenced by agricultural activities, and domestic effluent around Lake Naivasha. The Northern sector (close to rivers input) seemed to be influenced by agricultural activities. The North East sector of the Lake was dominated by domestic effluent and close association with the crescent lake which is influenced by natural mineral composition associated with its volcanic origin.

This study also indicated that Lake Naivasha lies between eutrophic and hypereutrophic state. In comparison to previous water quality studies, this study showed that a further deterioration of the trophic status. Discriminant 
analysis (DA) of the trophic state indices (TSI) revealed that the trophic state was indeed heterogeneous with three distinct sectors which include: the northern part of the lake, the mid and southern sector, and the Crescent Lake. Graphical representation of the deviations of chlorophyll-a (TSI-CHL) and total phosphorus (TSI-TP) trophic state indices indicated that the lake was predominantly phosphorus limited (TSI-CHL > TSI-TP). Further scrutiny revealed that close to Mouth of Malewa (river input), North East (near the waste water treatment plant effluent discharge point and Kihoto informal settlement) and Kamere Beach (near Kamere informal settlement), the turbidity constituents were mainly dominated by sediments or other organic matter rather than chlorophyll-a (TSI-CHL < TSI-SD (SD=Secchi depth )). In Crescent Lake, the TSI-CHL exceeded the TSI-SD (TSI-CHL > TSI-SD) which was an indication of the presence of algae species with a more filamentous or colonial structure than in the rest of the lake.

This study affirms the possibility of retrospective analysis of spatial variations and temporal trends in chlorophyll-a concentration's using MODIS-Aqua satellite data, and therefore provide data at times when routine ground measurements do not exist. The existence of a large inter-annual spatial variation in chlorophyll-a concentration over the lake was evident particularly in the monthly composite maps. The results portray a large temporal variability which was partly caused by seasonal influences such as climate (rainfall) and seasonal agricultural practices. This was also evident in the long-term trend variations that correlate to the lake level, which could explain dilution and concentration effects.

Investigation of the driving forces behind the spatial variability in water quality revealed that currents which might have been responsible for the transport of sediment and other constituents from the input rivers, were mainly wind-driven in Lake Naivasha. There exists mixing which could be responsible of substance (suspended particles, sollutes, and pollutants) redistribution in the Lake. This phenomenon could have enhanced proliferation of algal biomass through nutrient enrichment in the water column leading to high turbidity levels. Water quality modelling revealed that response of the lake ecosystem to reduction of pollutants is gradual and it would take 40 years to reach the equilibrium state if the loading remained constant. Ground water seepage could be the main reason behind the freshness of Lake Naivasha despite non-existence of a visible outlet.

Evaluation of the fish community succession revealed that the Cyprinus carpio had not only led to elimination of sight dependent feeders such as Tilapia zilli but also lead to an increase in chlorophyll-a concentration through nutrient enrichment from the lake sediment layer. Micropterus salmoides was found to be more tolerant to turbid conditions. In terms of fishermen 
revenue, Cyprinus carpio was quantitatively more lucrative although it has the least unit cost.

This study has demonstrated the usefulness of the integration of field measurements, geo-information and modelling in unmasking important water quality information in Lake Naivasha. 


\section{Table of Contents}

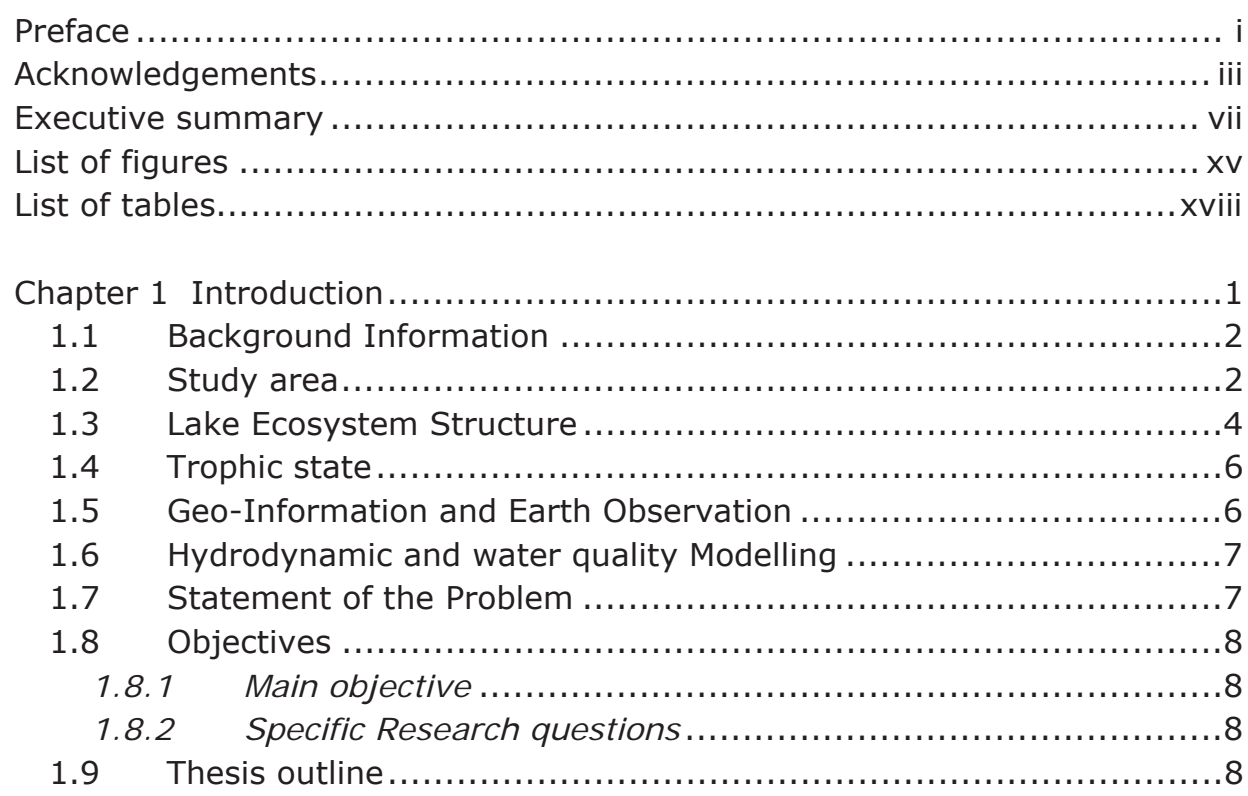

Chapter 2 A Multivariate analysis of Water Quality in Lake Naivasha, Kenya

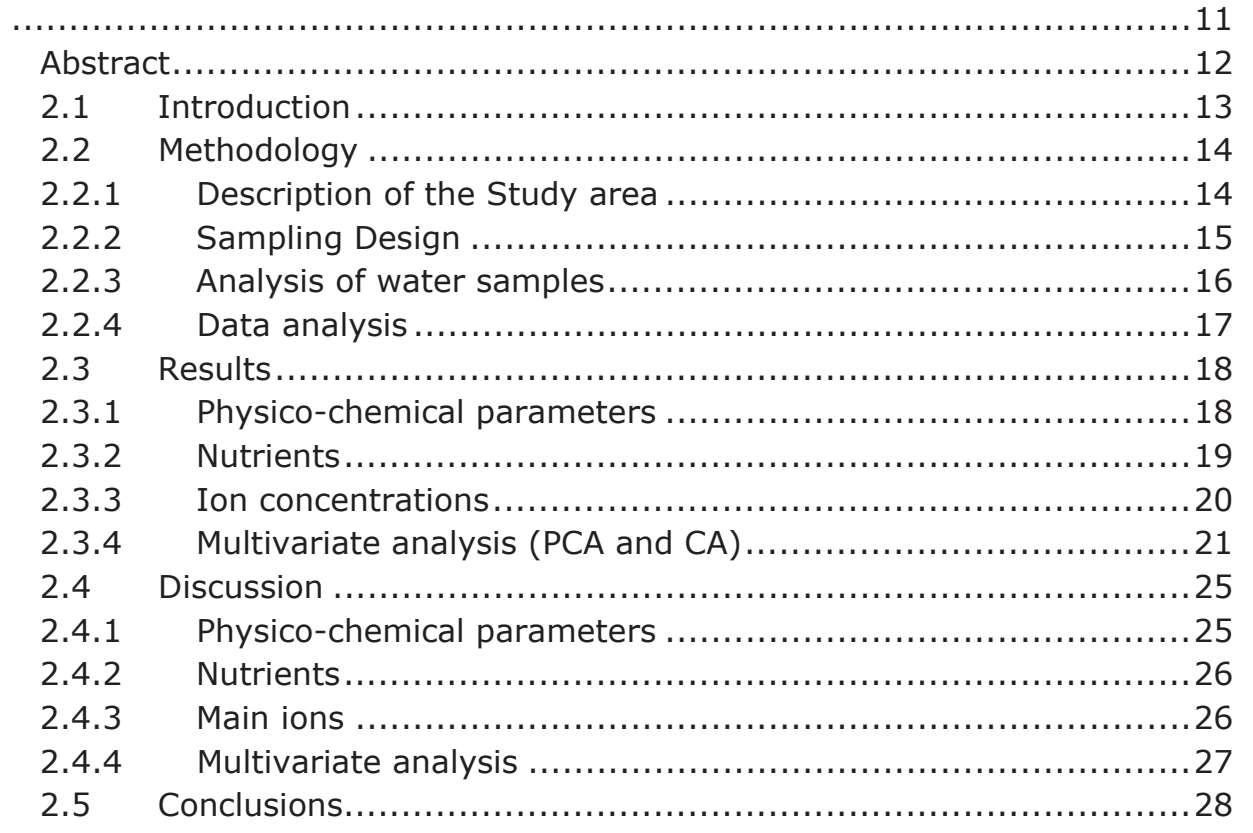

Chapter 3 Spatio-temporal Variations of the Trophic state in Lake Naivasha, Kenya. 


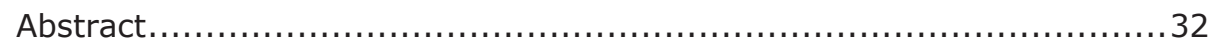

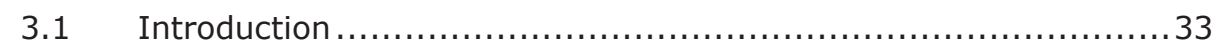

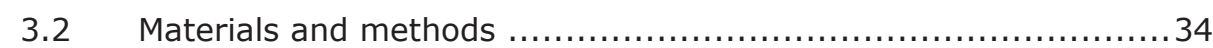

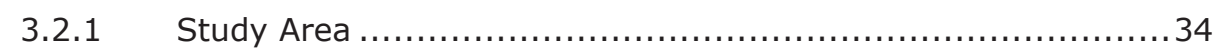

3.2.2 Sample collection and field measurements ..................... 35

3.2.3 Determination of the trophic state................................ 37

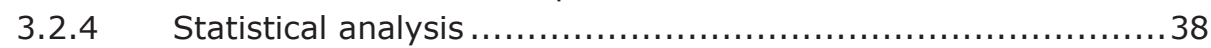

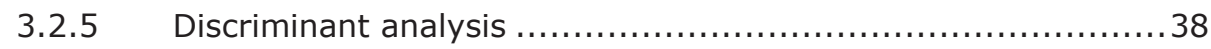

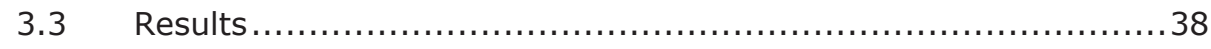

3.3.1 Trophic State Variation in reference to Total Phosphorus .......... 38

3.3.2 Trophic state variation in reference to Secchi depth ..............40

3.3.3 Trophic state variation in reference to chlorophyll-a..............42

3.3.4 Deviations between trophic state indices ........................ 42

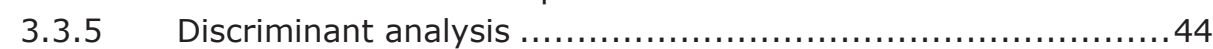

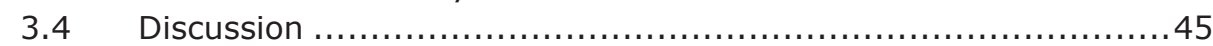

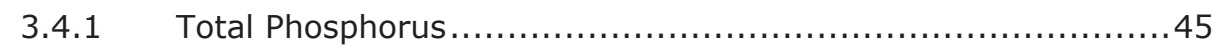

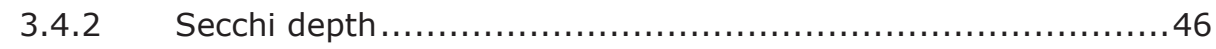

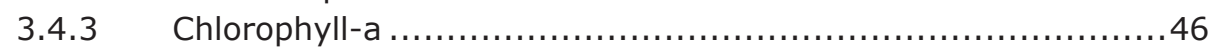

3.5 Conclusions..................................................... 49

Chapter 4 Evaluation of Spatio-temporal Variations of Chlorophyll-a in Lake

Naivasha, Kenya: Remote sensing approach .............................. 51

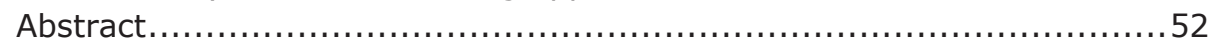

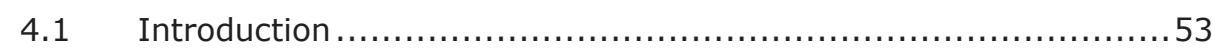

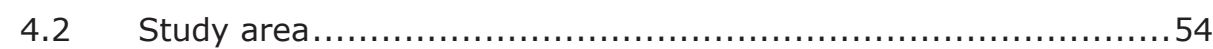

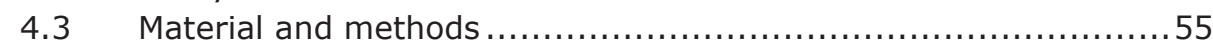

4.3.1 Field data collection and analysis ................................ 55

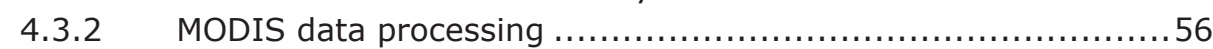

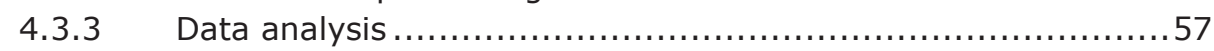

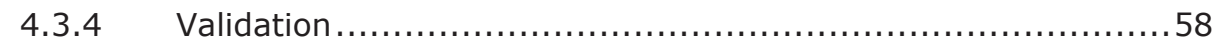

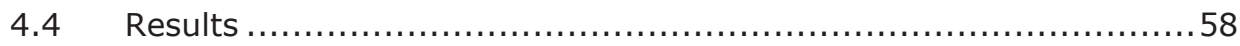

4.4.1 Spatio-temporal variation in chlorophyll-a concentration .........58

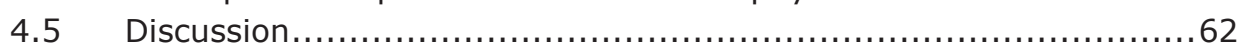

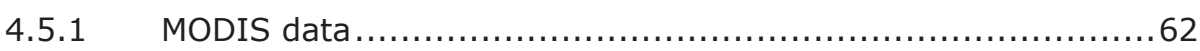

4.5.2 Spatio-temporal variations in chlorophyll-a......................63

4.5.3 Lake levels and chlorophyll-a concentration ......................64

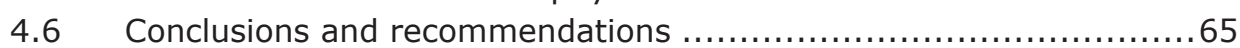

Chapter 5 Hydrodynamics and water quality analysis in Lake Naivasha ....67 67

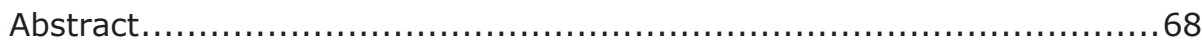

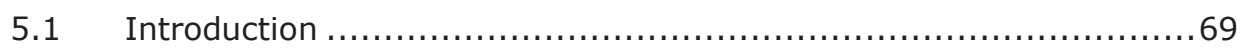

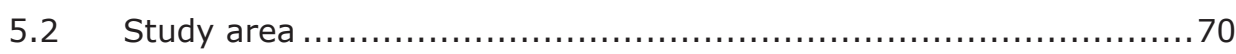

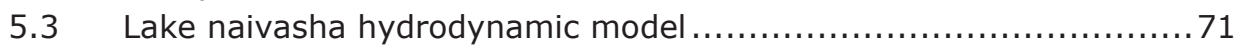

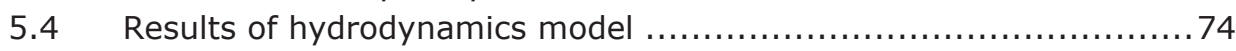


5.5 Idealised hydrodynamics model....................................... 78

$5.6 \quad$ Lake Naivasha water quality model ................................... 82

5.6.1 Water and mass balance......................................... 82

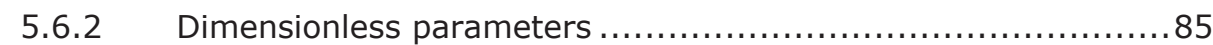

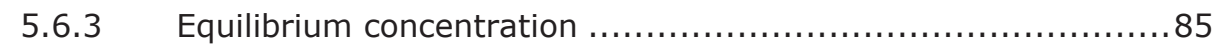

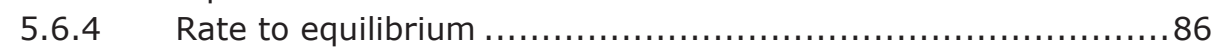

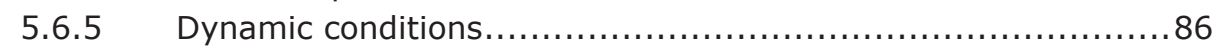

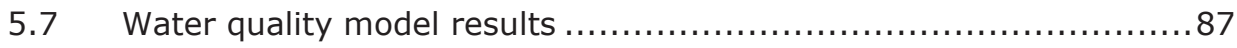

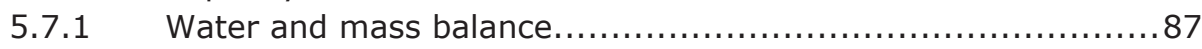

5.7.2 Equilibrium concentration of pollutants ........................... 88

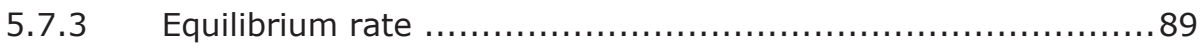

5.7 .4 Dynamic conditions.............................................. 90

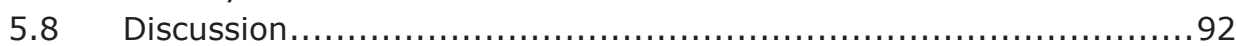

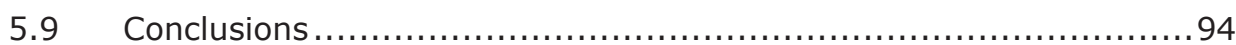

Chapter 6 Relationship between fish community succession, water quality and livelihood: case study in Lake Naivasha, Kenya...........................99

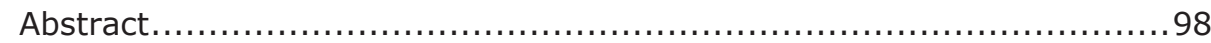

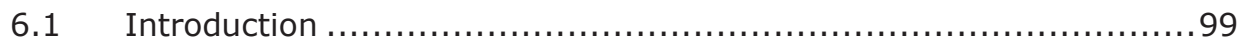

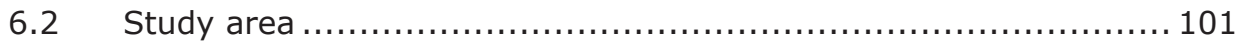

$6.3 \quad$ Materials and methods ................................................... 102

6.3.1 Data collection .................................................... 102

6.3.2 Data analysis .................................................... 103

6.3.3 Characteristics of the commercial fisheries in Lake Naivasha.. 103

$6.4 \quad$ Results ................................................................... 105

6.4.1 Commercial fisheries succession ............................... 105

6.4.2 Relationship between chlorophyll-a and commercial fisheries succession in Lake Naivasha....................................... 107

6.4.3 Revenue generation from fish catches ........................... 108

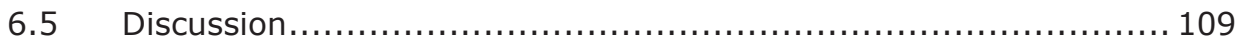

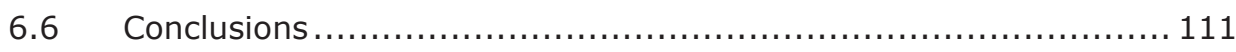

Chapter 7 Conclusions and Recommendations ............................... 113

7. Conclusions and Recommendations ...................................... 114

7.1 Conclusions.......................................................... 114

7.1.1 What is the status of water quality in Lake Naivasha? ........... 114

7.1.2 What is the status of the trophic state of Lake Naivasha? ...... 115

7.1.3 Does the current status of water quality of Lake Naivasha differ from the water quality of the past decades? ............... 115

7.1.4 What are the mechanisms that cause the spatio-temporal variability in Lake Naivasha's water quality? ..................... 116

7.1.5 What is the relationship between the fish community succession, livelihoods and the water quality of Lake Naivasha? 


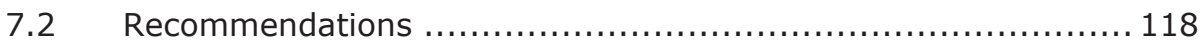

7.2.1 Scientific recommendations.................................. 118

7.2.2 Management recommendations ............................... 119

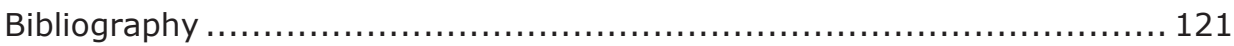

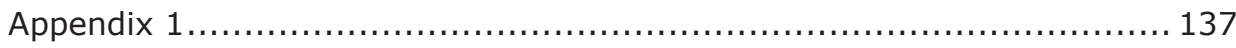

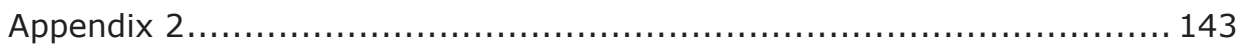

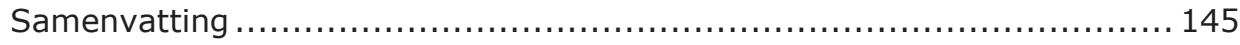

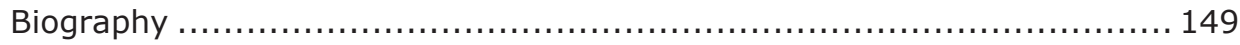




\section{List of figures}

Figure 1.1 Map showing the location of Lake Naivasha, its catchment area and the main input rivers

Figure 1.2 A simplified diagram of the interactions of the various factors that influence Lake Naivasha ecosystem services and functions.

Figure 2.1 Map showing Lake Naivasha, input rivers and the sampling sites used in this study.

Figure 2.2 Results of the principal component analysis (PCA) showing eigenvalues (histogram) and cumulative variability (line with markers) .....22 Figure 2.3 Results of the Principal Component Analysis (PCA) for various water quality parameters measured in Lake Naivasha from January to November 2011: (a) bi-plot of the correlation between the water quality parameters in this study; (b) correlation between the studied sites in respect to the water quality parameters. 24

Figure 2.4 Dendrogram of the dissimilarity between the four distinct areas of Lake Naivasha based on water quality parameters (dotted line denotes the truncation line that represents the stations that are somewhat homogeneous)

Figure 3.1 Location of Lake Naivasha catchment in Kenya (a), the extent of the catchment together with the major rivers that drain into the lake (b), the sampling sites and depth of the lake in October 2011 (c) ...................... 35 Figure 3.2 Time series plot of Total Phosphorus concentration and the corresponding TSI-TP from January to October 2011 in Lake Naivasha....... 39 Figure 3.3 Daily rainfall in Kijabe Farm (bar graph) and lake water levels measured at 2GB6 station (line graph) in 2011 (a), Malewa River discharge from the WRMA 2GB1 Gauging Station from June to November 2011 (b)...40 Figure 3.4 Time series plot of secchi depth and the corresponding TSI-SD from January to June 2011 in Lake Naivasha.... 41 Figure 3.5 Time series plot of chlorophyll-a concentration and the corresponding TSI-CHL from February to May 2011 in Lake Naivasha. .. Figure 3.6 A plot of the deviation of TSI-CHL from TSI-SD versus the deviation of TSI-CHL from TSI-TP (Y-axis denotes phosphorus limitation while $\mathrm{X}$-axis denotes the influence of chlorophyll-a on the turbidity).

Figure 3.7 A plot of the discriminant functions showing the different spatial clusters derived from all the studied sites in Lake Naivasha

Figure 4.1 Study area of Lake Naivasha catchment in Kenya (a), the extent of the catchment together with the major rivers that drain into the Lake (b), and the lake area including sampling sites (c) . ............................... 55

Figure 4.2 Flow diagram of the procedure to obtain chlorophyll-a concentrations maps. 
Figure 4.3 Monthly average of chlorophyll-a concentration maps from 2003 to

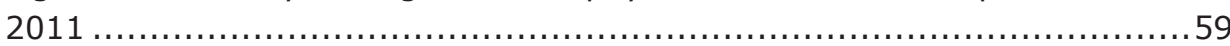

Figure 4.4 The time series of chlorophyll-a concentration based on MODIS data (dotted line) and lake water levels (line graph) in Lake Naivasha from

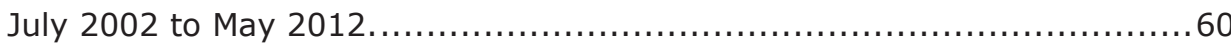

Figure 4.5 Decomposition of chlorophyll-a data into seasonal, trend and residual component

Figure 4.6 Comparison between the trends of de-seasoned chlorophyll-a (dashed line) concentration and de-seasoned lake water levels (solid line) from July 2002 to May 2009

Figure 5.1 Map showing the location of Lake Naivasha in Kenya, the

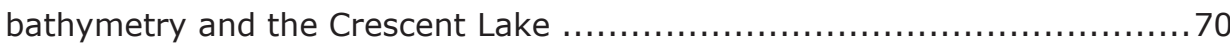
Figure 5.2 Wind rose plotted from the daily average wind speed $\left(\mathrm{ms}^{-1}\right)$ data

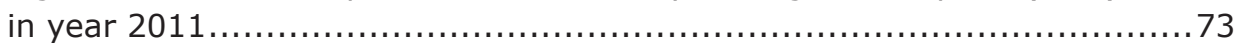
Figure 5.3 Cumulative frequencies of wind speed and discharge from Gilgil, Malewa and Karati rivers for 2011. 74

Figure 5.4 Map showing the spatial current movement pattern with; a) zero wind velocity and high discharge, b) high wind velocity, zero discharge, c) high wind velocity and high discharge, all at 45 degrees wind direction (actual

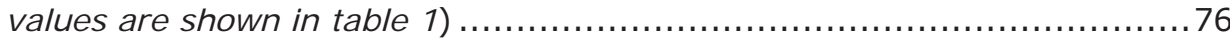
Figure 5.5 Map showing the spatial water movement pattern with; a) zero wind velocity and high discharge, b) high wind velocity, zero discharge, c) high wind velocity and high discharge, all at 90 degrees wind direction (actual values are shown in table 1 )

Figure 5.6 Map showing the spatial water movement pattern with; a) zero wind velocity and high discharge, b) high wind velocity, zero discharge, c) high wind velocity and high discharge, all at 135 degrees wind direction

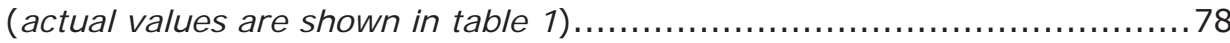

Figure 5.7 Schematic diagram of the idealized model ....................... 79 Figure 5.8 Current direction simulated with a wind blowing from the west. .80 Figure 5.9 Illustration of the horizontal transport current magnitude......... 80 Figure 5.10 Schematic overview of the processes affecting water quality in

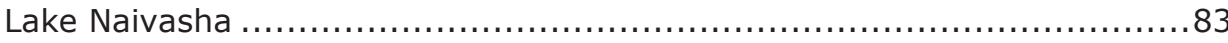
Figure 5.11 Relationship between the relative equilibrium concentration $\left(\mathrm{C}^{*}=\right.$ $\mathrm{C} / \mathrm{C}_{\text {in }}$ ) and the fraction of water lost to groundwater or by abstraction ( $\mathrm{F}$ ) given a constant volume in the lake. The red marker indicates the estimated equilibrium level for Lake Naivasha.

Figure 5.12 Approach to equilibrium concentration in Lake Naivasha.........90 Figure 5.13 Concentration as function of a dynamic lake level, starting with the equilibrium concentration of a closed water balance $\left(C_{e q}=2.35 \mathrm{mg} / \mathrm{l}\right) . .92$

Figure 6.1 Illustration of the relationship between fish and water quality .. 100 Figure 6.2 Map showing Lake Naivasha, and the input rivers. 102 
Figure 6.3 Pictures of the commercial fish species in Lake Naivasha.......... 104 Figure 6.4 Commercial fish monthly catches from 2003 to 2010 in Lake Naivasha. The solid line is the trend line. NB. June, July, and August months were excluded in the analysis because it is a closed season 106 Figure 6.5 Time series plot of the chlorophyll-a concentration and Lake water levels trends from January 2003 to April 2009. 107

Figure 6.6 Figure illustrating the total annual income generated by each fisherman (a), average price per kilogram of each fish species (b), and the percentage income generated by each fish species ( 1 Euro 100 Kenya shillings) 109 


\section{List of tables}

Table 2.1 Mean and Range of physico-chemical parameters in the sampling sites of Lake Naivasha, Kenya during January through November, 2011....19 Table 2.2 Mean and range of nutrients concentrations measured in the sampling sites of Lake Naivasha, Kenya during January through November,

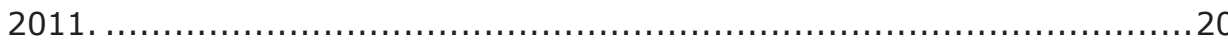

Table 2.3 Mean and range of main ions measured in the sampling sites of Lake Naivasha, Kenya, during January through November, $2011 \ldots \ldots \ldots \ldots \ldots . . .21$

Table 2.4 Eigenvectors of the principal components..............................22

Table 5.1: Table showing the scenario simulated with against the respective

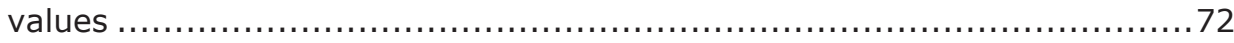
Table 5.2 Lake balance in pre-abstraction era. Based on Van Oel et al. (2013)

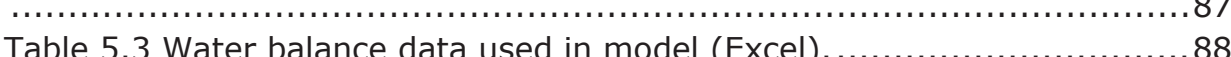

Table 5.4 Changes in water balance for the dynamic calculations. Orange box indicates that the loss is larger than input (lowering water table) while green box indicates that the inflow is larger than loss (increasing water tables)...91

Table 6.1 Summary of the characteristic of the commercial fish species in Lake Naivasha 105 Table 6. 2 Table showing the correlation coefficient between the commercial fish species and chlorophyll-a 108 
Chapter 1

Introduction 


\subsection{Background Information}

Water quality is the measure of the state or condition of water resources relative to the requirements of the biotic species and human needs. It is defined as the physical, chemical, biological and organoleptic (taste-related) characteristics of water (Johnson et al., 1997; United Nations, 2007). Water quality in aquatic systems is important because it maintains the ecological processes that support biodiversity. However, declining water quality due to environmental perturbations threatens the stability of the biotic integrity and therefore hinders the ecosystem services and functions of aquatic ecosystems.

Lake Naivasha is one of the tropical aquatic ecosystems that are facing human-induced changes as a result of land- and water-use transforming it from clear state dominated by macrophytes, to turbid state dominated by algae. The environmental perturbations include: species invasion, poor agricultural systems on the catchment that lead to soil erosion, changes in hydrology due to water abstraction for horticulture, domestic use, and industrial use (such as cooling turbines in geothermal power generation). These challenges necessitate remedial actions to enable implementation of conservation measures in Lake Naivasha.

An understanding of the processes and mechanisms that influence the water quality dynamics is fundamental in order to arrive at informed management decisions for sound conservation measures (Scheffer, 1998). This study aims at providing an insight in the spatio-temporal water quality dynamics and the interrelationships of the water quality parameters with biological components, particularly fish population, in Lake Naivasha. The hydrodynamics in the lake are also investigated in this study as one of the mechanisms that could lead to spatial differences in water quality parameters. Statistical, remote sensing and modeling approaches have been applied to achieve the goal of this study. This study demonstrates integration of ground measurements, remote sensing, and modeling to enhance the understanding of water quality in aquatic systems.

\subsection{Study area}

Lake Naivasha is a shallow endorheic fresh water lake situated on the floor of the Eastern Rift Valley in Kenya at $1885 \mathrm{~m}$ above sea level. It lies at latitude $0046^{\prime} \mathrm{S}$ and longitude $3622^{\prime} \mathrm{E}$ (Figure 1.1). The entire lake consists of a main lake, Oloidien that is now separated from the main lake due to decline in water levels, and Sonachi Crater Lake which is the smallest. The lake's catchment area is $3401 \mathrm{~km}^{2}$. The main inputs into the lake are mainly from Malewa river that accounts for $80 \%$ of the lakes discharge and Gilgil river which accounts for the $10 \%$ of the total discharge into the lake. The rest 
comes from other insignificant rivers around the lake such as Karati. The mean temperature around Lake Naivasha is approximately $25^{\circ} \mathrm{C}$. December - March is the hottest period $\left(30^{\circ} \mathrm{C}\right)$ while July is the coldest month $\left(23^{\circ} \mathrm{C}\right)$.

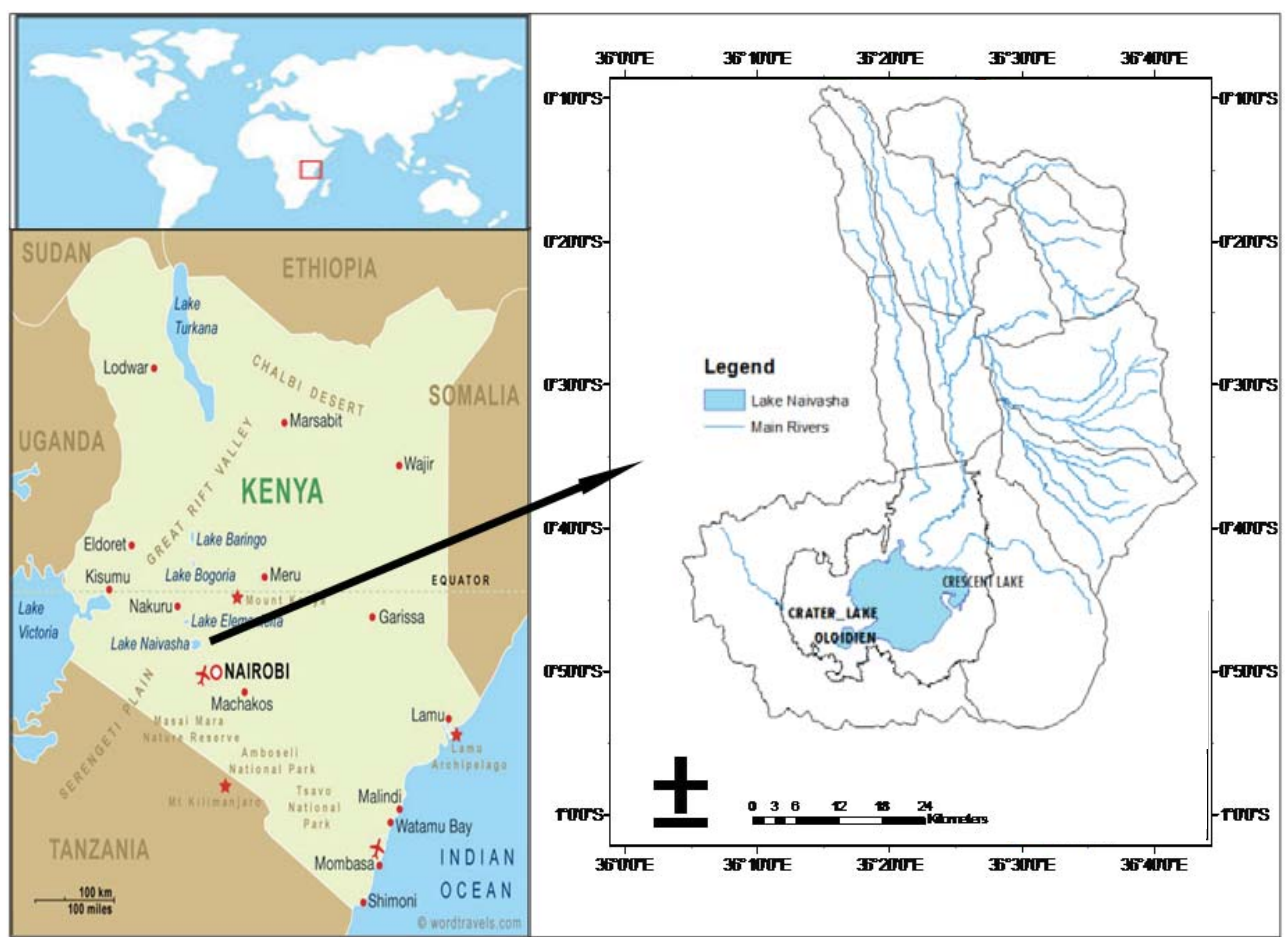

Figure 1.1 Map showing the location of Lake Naivasha, its catchment area and the main input rivers

The Lake was once one of the most treasured tourist sites in the world due to biodiversity richness leading to subsequent designation as a Ramsar site in 1995 (Ramsar, 1996). Beadle (1932) described Lake Naivasha as full of floating leaved lilies and submerged macrophytes which is an indication of a clear state. The water lilies have now disappeared while the submerged macrophytes fluctuates between presence and absence due to increase in turbidity (Britton et al., 2007). Introduction of alien species such as Louisiana red swamp crayfish (Procambarus Clarkii) (Smart et al., 2002), which feeds on the submerged plants, and common carp (Cyprinus Carpio) (Hickley et al., 2004) has threatened Lake Naivasha's ecological balance in the past decades with more impacts being experienced since 1970s and 1980s (!!! INVALID CITATION !!!). The common carp, which is a bottom feeder, contributes much to the turbidity of Lake Naivasha as it burrows triggering the re-suspension process. 
The lake water levels are also known to affect the dynamism of turbidity: a decline in water levels leads to an increase in turbidity. The water levels are a function of the inflow from the two main rivers (Malewa and Gilgil), precipitation, ground water recharge, and outflow through ground water seepage, water abstractions, and evapotranspiration. Lake Naivasha lake levels were highest in 1890s and lowest in 1940s (Becht and Harper, 2002). Gitonga's (1999) study of the water level also revealed a minimum in the 1940s. Tarafdar and Harper (2008) presented the lake levels from 1950 to year 2000 in two phases [1951-1980 (period I) and 1981-2000 (period II)]. The second phase appeared to be affected by increased human consumption (Van Oel et al., 2013).

Emergence of uncontrolled horticultural farms in the late 1980 s has led to urbanization problems such as rapid informal settlements for the growing population and large water abstractions for irrigation; thus exerting agricultural and domestic pollution pressures on Lake Naivasha. Changes in land use upstream have resulted in fluctuations in the inflow and increase in agrochemicals leading to pollution and therefore exerting more pressure on the ecosystem and society (Ballot et al., 2009). A series of environmental tragedies, with the most recent being the death of over 1000 fish due to lack of oxygen in February 2010 (Morara, 2010), continue to deteriorate the health of lake Naivasha. Limnologically, Lake Naivasha was classified as eutrophic around 1997-1998 period (Kitaka et al., 2002). Consequently, biodiversity shift was observed since 1980s, particularly in the phytoplankton community (Hubble and Harper, 2002). A positive effect of eutrophication is that it increases fisheries productivity (Payne, 1984), but excess nutrients can also lead to proliferation of algal blooms that decrease transparency limiting the foraging behaviour of all the aquatic organisms that depend on vision to identify their prey.

\subsection{Lake Ecosystem Structure}

An important principle which is vital in understanding the aquatic ecosystem structure and functions is that there are no barriers limiting the interaction of various physical, biological as well as chemical factors. Figure 1.2 below represents the interaction of the various components that may positively or negatively affect water quality either directly or indirectly in Lake Naivasha. For easy in understanding the diagram, we focus on the turbidity as one of the water quality indicators. The main causes of turbidity in Lake Naivasha include excess sediment input from eroded catchment soils, eutrophication, increased algal biomass and re-suspension from the benthic layer as a result of water movements and/or barrowing fish community such is the Cyprinus carpio. 


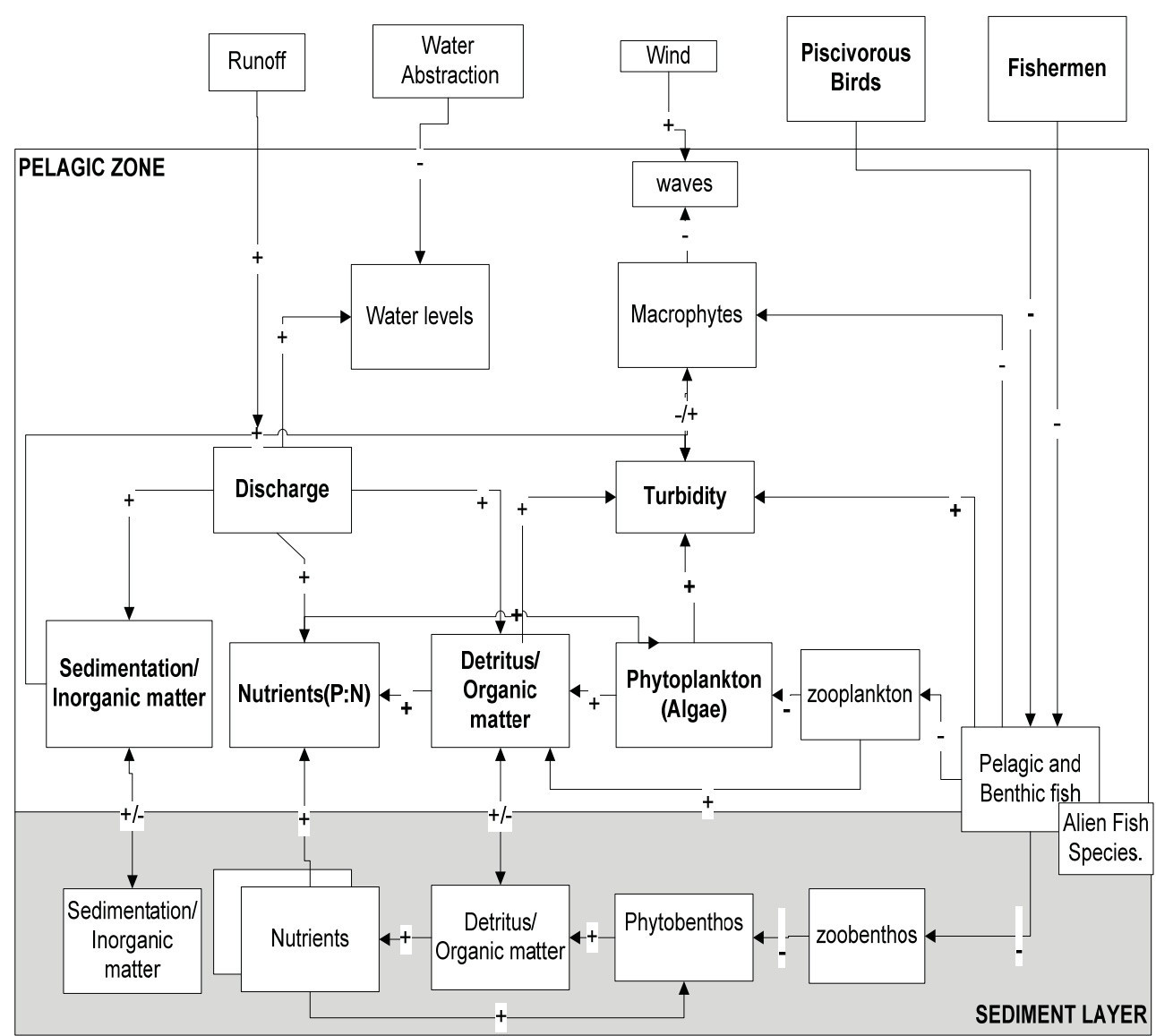

Figure 1.2 A simplified diagram of the interactions of the various factors that influence Lake Naivasha ecosystem services and functions.

The main input into Lake Naivasha comes from Malewa and Gilgil rivers whose catchments amounts up to around $90 \%$ of the discharge into Lake Naivasha. Apart from contributing to the water levels of Lake Naivasha, the discharge from the rivers contains organic matter/detritus, inorganic matter/sediments comprising of fine particles and nutrients ( $P$ and $N$ ). Organic matter/ detritus significantly plays a role in the transport of phosphorus (P) (Kitaka et al., 2002), since as the detritus decompose, phosphorus is released into the water column. $\mathrm{P}$ is one of the limiting factors in primary production in an aquatic ecosystem and therefore excess loads lead to proliferation of algal blooms. As organic components decompose availability of dissolved oxygen in the water column is compromised (Scheffer et al., 1993).

The concentration of algae/phytoplankton (quantified as chlorophyll-a) together with particulate matter have a functional relationship with the water 
transparency, which translates to the turbidity of the aquatic ecosystem (Scheffer et al., 1993). Aquatic vegetation/macrophytes play a special role in stabilizing the benthic layer and dissipating wave energy. In the absence of vegetation, currents/waves may enhance the re-suspension of sediment and particulate matter. The fish community may also increase re-suspension during their movement as they feed on the macrophytes and the zooplankton both in the benthic as well as pelagic zone (Britton et al., 2007). Total Suspended Solids (TSS) contribute to turbidity levels and play a role in transport of toxic pollutants and nutrients. Presence of TSS in the water column may lead to clogging of fish gills, fills spawning and breeding grounds, and smothers benthic communities. Peeters et al. (2009) noted that physical and chemical variables associated with light regime and nutrients significantly determine ecological quality of shallow lakes, more than biological variables. They therefore concluded that water transparency expressed as Secchi depth predicts the ecological quality of shallow lakes quite well.

\subsection{Trophic state}

The trophic state of a lake is a measure of the biological productivity (level of ecological water quality), that is, the mass of plants and animals in a lake. The diversity of the plants and animals in the water is also determined by the water quality of the aquatic ecosystems and therefore serves as water quality indicator. Clear lakes are characterized by high diversity of plants and animals in comparison to turbid lakes. The parameters used in determining the trophic state include: total nitrogen, total phosphorus, chlorophyll-a and clarity. The level of ecological water quality can be expressed by the trophic state index based on the trophic state parameters. Total nitrogen and total phosphorus are the nutrients that limit the growth of algae in lakes. Excess nutrient input is referred to as eutrophication and results in proliferation of algal blooms. The higher the concentrations of nutrients, the higher the trophic state index of the lake. The trophic state is grouped into oligotrophic, mesotrophic, eutrophic, and hypereutrophic depending on the value of the trophic state index.

\subsection{Geo-Information and Earth Observation}

Information on the spatio-temporal heterogeneity information in water quality is crucial in making sound judgment on whether to apply local or holistic management options. However, spatial heterogeneity of water quality in lakes is difficult to determine through conventional means. Remote sensing technology has the potential to represent a true synoptic view of the water quality. The principles applied are absorption and reflectance of light. Water constituents that are considered optically significant are total suspended sediments, colored dissolved organic matter commonly known as gelbstof, 
and chlorophyll-a (Mobley, 2004). Traditionally, remote sensing of water quality was commonly applied in oceans. This is due to limitations in spatial resolutions of the existing satellite data and high light reflectance in fresh water systems. However, several studies have tried to overcome this challenge by adopting the principles used in ocean color to fresh water with modifications in trying to overcome the high reflectance of light that is attributed to suspended solids and the shallow bottom. Advances have also been made in improvement of spatial as well as spectral resolutions. Research has shown the applicability of deducing turbidity level from beam attenuation. Larson et al. (2007) successfully attempted to predict Secchi depth from beam attenuation. Gelda and Effler (2007) used the beam attenuation to measure turbidity in Schoharie Reservoir located in the Catskill Mountains of southeastern New York. Maximum attenuation depth shifts from lower to higher wavelengths (the red) with an increase in depth (Liu and Li, 2009). Different researchers have used various satellite data to retrieve turbidity parameters such as chlorophyll-a, TSS and colored dissolved organic matter. Lepistö et al.,(2010) successfully applied Medium Resolution Imaging Spectrometer (MERIS) satellite data in spatial mapping the water quality in Pyhäjärvi Lake in Finland. Tyler et al. (2006) and Dekker et al. (2002) used Landsat Thematic Mapper (TM) imagery and SPOT to sufficiently estimate TSS in shallow waters. Moderate Resolution Imaging Spectroradiometer (MODIS) has also been used to map sediments in lakes such as Poyang Lake in China (Cui et al., 2009). In this study, we explore the use of $500 \mathrm{~m}$ resolution Moderate Resolution Imaging Spectroradiometer Aqua (MODISAqua) satellite data in studying the spatio-temporal changes in the chlorophyll-a concentration in Lake Naivasha.

\subsection{Hydrodynamic and water quality Modelling}

Hydrodynamic modeling aids in simulation of complex water transport patterns. They are used in predicting sediment transport as well as the solutes/contaminants. Hydrodynamic modeling is built upon numerical solutions of momentum and mass conservation equations in fluids. Researches in tropical lake hydrodynamics have been carried out in other lakes (Hamilton and Schladow, 1997; Jin et al., 2000; Simons, 1974; Teeter et al., 2001). However, there are no other studies on hydrodynamic that have been carried out in Lake Naivasha before. This study aimed at modelling the hydrodynamics as one of the mechanisms that result in spatial heterogeneity of turbidity in Lake Naivasha. The effect of water balance on the pollutant concentration is also assessed using stirred-tank reactor model.

\subsection{Statement of the Problem}

Amalgamation of physical and biological processes that result from a myriad of environmental perturbations in Lake Naivasha's ecosystem have 
transformed the lake from a clear to muddy eutrophic turbid state, which has resulted in a decline in ecological quality, impacting heavily on fish population and tourism. Cases of fish kills have been observed which may be attributed to deterioration of the quality of the water, turbidity being one of the factors contributing significantly towards it. Though there has been regular data collection on water levels and fish catches, little has been done in monitoring the water quality dynamics in Lake Naivasha. The interrelationship between progressive water quality dynamics and the fish community succession studies in Lake Naivasha is lacking. Studies on the hydrodynamics were also not yet done before this study. This project targets the bridging of this gap.

\subsection{Objectives}

\subsubsection{Main objective}

The main objective of this research was to assess the spatio- temporal water quality dynamics and its influence on the lake Naivasha ecosystem. This information was mainly useful in providing an insight on the spatio-temporal turbidity dynamics and therefore facilitate informed decision making and implementation of sound management options.

\subsubsection{Specific Research questions}

1. What is the status of water quality in Lake Naivasha?

2. What is the status of the trophic state of Lake Naivasha?

3. Does the current status of water quality of Lake Naivasha differ from the water quality of the past decades?

4. What are the mechanisms that cause the spatio-temporal variability in Lake Naivasha's water quality?

5. What is the relationship between the fish community succession, livelihoods and the water quality of Lake Naivasha?

\subsection{Thesis outline}

This study is comprised of seven chapters.

Chapter two gives the status of the water quality in reference to the physicochemical parameters, nutrients, and the main ions in Lake Naivasha. Principal Component Analysis and Cluster Analysis are used to assess the spatial heterogeneity of the water quality and decipher the possible pollution sources based on water quality parameter's association.

Chapter three assesses the eutrophication status in Lake Naivasha. Spatiotemporal dynamics in the trophic state of Lake Naivasha as well as the possible causes of turbidity in different locations in the lake are evaluated. 
Chapter four gives a retrospective spatio-temporal analysis of the status of the water quality. Chlorophyll-a is estimated from MODIS-Aqua satellite data as a water quality proxy. The spatio-temporal trend of the chlorophyll-a concentrations in the lake from June 2002 to June 2012 was also considered in this study.

In Chapter five, Hydrodynamic and water quality models are presented. A description of the way the models were set up is provided. The currents movement and the influence of water balance on pollutant concentration in Lake Naivasha as simulated by the models is presented. The major driving forces in water movement and the associated substances are also evaluated.

Chapter six Lake Naivasha provides information on the main fish species in the commercial fisheries in Lake Naivasha. The progressive trend of the commercial fisheries is assessed. This chapter also explains the relationship of the catches with environmental variables particularly Chlorophyll-a and water levels.

Chapter seven summarizes the major conclusions and gives recommendations. Future work based on the outcomes of this study is also mentioned. 


\section{Chapter 2}

\section{A Multivariate analysis of Water Quality in Lake Naivasha, Kenya1}

1 This chapter is based on: Ndungu, J.N., Augustijn, D.C.M., Hulscher, S.J.M.H., Bernard Fulanda, Kitaka, N. \& Mathooko, J.M. Multivariate approach in the assessment of the status of water quality in Lake Naivasha. Accepted in Marine and Fresh Water Research Journal. 


\begin{abstract}
Water quality information in aquatic ecosystems is crucial in setting up guidelines for resource management. This study explores the water quality status and pollution sources in Lake Naivasha, Kenya. Water quality parameters analysis of seven sampling sites was done from water samples collected weekly from January to June and biweekly from July to November in 2011. Principal Component Analysis (PCA) and Cluster Analysis (CA) were used to analyze the dataset. PCA showed that four principal components (PCA-1 to PCA-4) explained $94.2 \%$ of the water quality variability. PCA-1 and PCA-2 bi-plot suggested that turbidity in the lake correlated directly to nutrients and iron with close association with the sampling site close to the mouth of Malewa River. Three distinct clusters were discerned from the CA analysis: Crescent Lake, a more or less isolated crater lake, the Northern region of the lake, and the main lake. The pollution threat in Lake Naivasha includes agricultural and domestic sources. This study provides a valuable dataset on the current water quality status of Lake Naivasha which is useful for formulating effective management strategies to safeguard ecosystem services and secure the livelihoods of the riparian communities around Lake Naivasha, Kenya.
\end{abstract}




\subsection{Introduction}

Lakes and reservoirs are important sources of surface water and livelihoods to many rural and urban communities. However, declining water quality in freshwater lakes and reservoirs is an increasing problem that threatens the ecosystem services to the riparian communities, especially in developing countries. One of the major causes of the decline in the quality of water is nutrient enrichment; mainly phosphorus and nitrogen. As a result, massive algal blooms may occur causing a shift from clear to a turbid state in shallow lakes and reservoirs (Kitaka et al., 2002; Lung'Ayia et al., 2000; Mugidde et al., 2005). Consequently, significant changes in the biological structure of the lakes and reservoirs occur which are a major threat to the sources of livelihoods to the riparian fisher folks (Harper, 1992).

Lake Naivasha is an important inland freshwater lake, especially within the Rift Valley because of the salty nature of the majority of the other water resources in the area. The lake harbours unique faunal and floral biodiversity, leading to it being declared a wetland of international importance in 1994 under the Ramsar Convention (LNRA, 1999). The lake is a source of livelihood and supports many socio-economic activities such as a multibillion horticultural industry, tourism, fishing, and domestic water sources (Becht and Harper, 2002; Kundu et al., 2010). Though still artisanal, the fishing industry within the lake employs over 1000 fishermen and provides a source of protein for people living within the nearby towns (Kundu et al., 2010). However, myriad of environmental perturbations in Lake Naivasha's ecosystem have transformed the lake from a clear to muddy eutrophic turbid state, which has resulted in a decline in ecological quality, impacting heavily on fish population and tourism (Hubble and Harper, 2001a; Mergeay, 2004). Sustainable lake management calls for reliable data and information on the water quality. However, the quality varies in time and space. The main causes of the variation include anthropogenic activities, season related fluctuations in inflow of nutrients and other substances, and natural variations attributed to biogeochemical processes. Therefore, the need for continuous assessment of the lake water quality is inevitable and calls for continuous monitoring of the lake. This notwithstanding, monitoring programs often result in huge and complex data matrices consisting of many physico-chemical parameters thus calling for multivariate approaches to the analysis and interpretation of the data.

Application of multivariate statistical techniques for analysis of environmental data has increased in the last decades (Alberto et al., 2001; Lee et al., 2006; Reghunath et al., 2002; Tariq et al., 2005; Vega et al., 1998). The techniques include: Cluster Analysis (CA), Principal Component Analysis $(P C A)$, Factor Analysis (FA), and Discriminant Analysis (DA). Several studies 
have demonstrated the usefulness of multivariate approaches in aiding the interpretation of large complex water quality datasets (Kazi et al., 2009; Shrestha and Kazama, 2007; Singh et al., 2004). Despite the numerous management challenges, the multivariate techniques have not been used in the assessment of water quality in many lakes in developing countries including Lake Naivasha. The main aim of this study was therefore to provide information for a basin-wide ecosystem management of Lake Naivasha. Specifically, the objectives of the study were to: i) assess the status of water quality in relation to physico-chemical parameters, nutrients, and major ions in Lake Naivasha, ii) assess correlations between the different water quality parameters using multivariate analysis, iii) evaluate any similarities/dissimilarities between the different regions of the lake, and iv) decipher the pollution sources based on physico-chemical parameter associations. This paper shows the mean concentrations of physico-chemical parameters, nutrients and ions in Lake Naivasha. It also gives the correlations between the water quality parameters as analyzed using PCA and explains the differences between the different regions as indicated by the CA. Probable pollution sources are also discussed.

\subsection{Methodology}

\subsubsection{Description of the Study area}

The description of Lake Naivasha has been provided in several publications (Ndungu et al., 2013a; Ndungu et al., 2013b; Stoof-Leichsenring et al., 2011). Therefore, only a brief description will be provided. Lake Naivasha is a shallow endorheic freshwater lake lying in the Kenyan Rift Valley at 1,890 metres above sea level in a complex geological arrangement of volcanic rocks and sedimentary deposits. Straddling at latitude $00^{\circ} 46^{\prime} \mathrm{S}$ and longitude $36^{\circ}$ $22^{\prime} \mathrm{E}$, the lake is fed by ephemeral streams and two major perennial rivers namely the Malewa and Gilgil Rivers; and other semi-permanent ones such as Karati River (Figure 2.1). To the northeast lies Crescent Lake, a crater lake with a depth of up to $20 \mathrm{~m}$ which occasionally separates from the main lake during low water levels (Childress et al., 2002). Lake Naivasha lacks a visible outlet but the lake's water is fresh due to a likely underground outflow (Åse, $1987)$. During the rainy season, the main lake occupies about $150 \mathrm{~km}^{2}$ but shrinks to about $100 \mathrm{~km}^{2}$ during the dry season (LNRA, 1999).

The weather in the area is typically tropical with mean temperatures of $25^{\circ} \mathrm{C}$. Precipitation is bi-modal in March/April/May and in October/November at an average of $650 \mathrm{~mm}$ year $^{-1}$. However, the eastern part of the catchment covering the Nyandarua Range receives a higher precipitation often reaching 2,400 $\mathrm{mm}_{\text {year }}{ }^{-1}$ (Stoof-Leichsenring et al., 2011). 


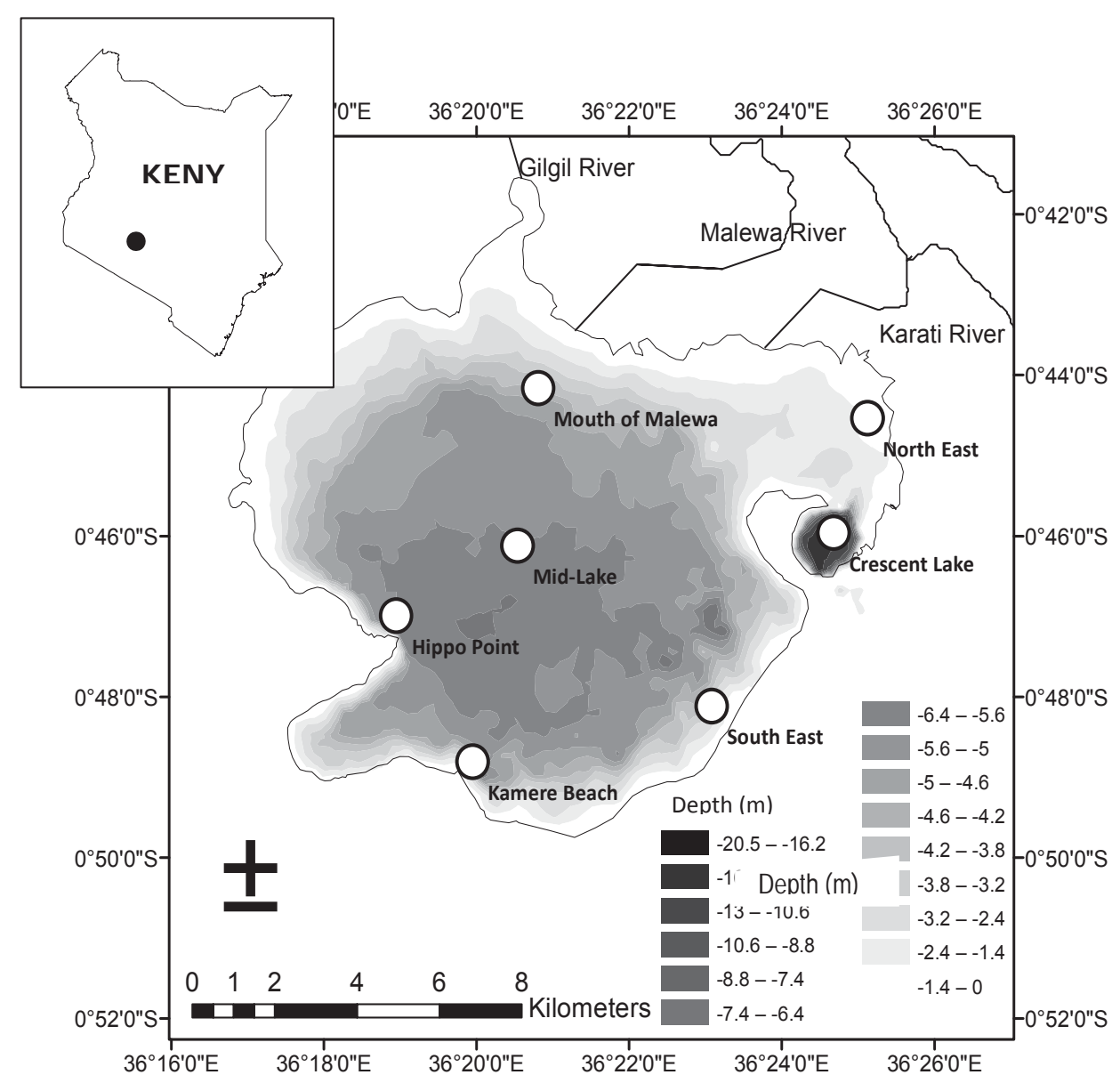

Figure 2.1 Map showing Lake Naivasha, input rivers and the sampling sites used in this study.

\subsubsection{Sampling Design}

Water samples were collected weekly from January to June and bi-weekly from July to November 2011. Sampling was conducted at seven pre-defined stations (Figure 2.1). Two sites were located in the northern side of the lake, one sited in the plume area of the Malewa River (Mouth of Malewa site) and the other in an area close to the municipal effluent discharge point (North East site). One site was at the central part of the lake (Midlake) while three other sites, which included Hippo Point, Kamere Beach and South East, were located in the southern side of the lake. Hippo Point was at the deepest point of the main lake and Kamere Beach was close to an informal settlement, whilst South East was set close to a sector where a large fish kill was 
experienced in February 2010. The seventh sampling site was set at Crescent Lake.

Water temperature, $\mathrm{pH}$, conductivity, and turbidity were measured in-situ during each sampling ocassion using pHTestr 30, ECTestr ${ }^{\mathrm{TM}} 11+$, and Oakton $\AA$ waterproof turbidity portable meters. Triplicate water samples were collected at about $10 \mathrm{~cm}$ below the surface and chilled in ice on site and transported to the laboratory for analysis. The parameters analysed were physico-chemical parameters (total dissolved solids (TDS), total suspended solids (TSS), total hardness (TH), and total alkalinity (TA)), nutrients (ammonium nitrogen $\left(\mathrm{NH}_{4}-\mathrm{N}\right)$, nitrate nitrogen $\left(\mathrm{NO}_{3}-\mathrm{N}\right)$, nitrite nitrogen $\left(\mathrm{NO}_{2}-\mathrm{N}\right)$, orthophosphates $\left(\mathrm{PO}_{4}{ }^{3-}-\mathrm{P}\right)$, and total phosphorus $\left.(\mathrm{TP})\right)$, and the main ions (calcium $\left(\mathrm{Ca}^{2+}\right)$, magnesium $\left(\mathrm{Mg}^{2+}\right)$, Iron $\left(\mathrm{Fe}^{2+}\right)$, manganese $\left(\mathrm{Mn}^{2+}\right)$, chloride $\left(\mathrm{Cl}^{-}\right)$, and sulphate $\left.\left(\mathrm{SO}_{4}{ }^{2-}\right)\right)$.

\subsubsection{Analysis of water samples}

\subsubsection{Physico-chemical parameters}

The TDS was measured directly using ECTestr ${ }^{\mathrm{TM}} 11+$ meter, while TSS was determined through the EPA gravimetric method where $100 \mathrm{ml}$ of water was filtered onto pre-weighed $0.4 \mathrm{GF} / \mathrm{C}$ micron filters and dried in an oven to constant weight. The TSS was calculated as the difference between the weight of the filter and the final dry weight. Total hardness was determined using the ethylene-diamine tetra-acetic acid (EDTA) method while total alkalinity was determined using the titration method which utilizes the phenolphthalein indicator and N/50 sulphuric acid (APHA, 2005).

\subsubsection{Nutrients}

Nitrogen as $\mathrm{NH}_{4}-\mathrm{N}, \mathrm{NO}_{3}-\mathrm{N}$, and $\mathrm{NO}_{2}-\mathrm{N}$ was determined through colorimetric methods as described in APHA (2005). The Salicylate Method was used to determine $\mathrm{NH}_{4}-\mathrm{N}$, while $\mathrm{NO}_{3}-\mathrm{N}$ and $\mathrm{NO}_{2}-\mathrm{N}$ were determined using the Cadmium Reduction Method. TP was determined using the Molybdenum blueascorbic acid method where duplicate volumes of $50 \mathrm{ml}$ samples were digested with persulphate in an autoclave for 30 minutes. The digested sample was then topped up with distilled water to $50 \mathrm{ml}$; the absorbance was read within $30 \mathrm{~min}$. to $1 \mathrm{hr}$. at $880 \mathrm{~nm}$ wavelength using ultra violet UVmini1240 spectrophotometer in $1 \mathrm{~cm}$ cells. The TP concentration was then determined using standard calibration curves. $\mathrm{PO}_{4}{ }^{3-}-\mathrm{P}$ was also determined through Molybdenum blue-ascorbic acid method by adding phenolphthalein indicator followed by drop-wise addition of $5 \mathrm{~N}$ sulphuric acid to discharge the red color if it develops when the phenolphthalein indicator is added. $8.0 \mathrm{ml}$ of a solution made from a combination of $5 \mathrm{~N}$ sulphuric acid, ammonium molybdate, and ascorbic acid as description in APHA (2005) was then added 
and mixed thoroughly. After $10 \mathrm{~min}$ and not more than $30 \mathrm{~min}$ the absorption of each sample was measured at $880 \mathrm{~nm}$ wavelength using a reagent blank as reference solution. The $\mathrm{PO}_{4}{ }^{3-}-\mathrm{P}$ concentrations were then determined using calibration curves.

\subsubsection{Main ions in water}

$\mathrm{Ca}^{2+}$ and $\mathrm{Mn}^{2+}$ were determined using the EDTA method and pan-method, respectively (APHA, 2005). $\mathrm{Fe}^{2+}$ and $\mathrm{Cl}^{-}$were determined through the $\mathrm{HACH}$ portable spectrophotometer procedures namely, FerroVer and Silver Nitrate Methods, respectively. The $\mathrm{SO}_{4}{ }^{2-}$ concentrations were determined using SulfaVer ${ }^{\circledR} 4$ turbidimetric method as described in the $\mathrm{HACH}$ DR2800 series Manual (2005).

\subsubsection{Data analysis}

The multivariate analysis of the data using Principle Component Analysis (PCA) and Cluster Analysis ( $C A$ ) enabled the identification of the sources of constituents and the distinguishing of the natural and anthropogenic contributions of pollutants into the lake system based on the level of association of the variables. The PCA and CA employed correlation $(a=0.05)$ matrices on the variables in order to establish possible associations and input sources among polluting elements as described by Delgado, Nieto et al. (2010). In PCA, the eigenvalues of the principal components are a measure of their associated variances (Meglen, 1992; Mellinger, 1987; Wenning and Erickson, 1994). Correlation of principal components and original variables is given by loadings. This treatment provides a small number of factors that usually account for approximately the same amount of information as the original set of observations. CA uncovers intrinsic structure or underlying behaviour of a data set without making priori assumptions about the data. It further classifies objects of the system into categories (clusters) based on their similarity. In hierarchical CA, the distance between samples is used as a measure of similarity. In the present analysis hierarchical agglomerative CA was performed on the normalized data by means of the complete linkage (furthest neighbour), average linkage (between and within groups) and Ward's (1963) Euclidean distance method. The outputs were displayed as biplots in which the plotted points for sites were related to water quality parameters presented as rays. Both PCA and CA were done using XLSTAT 2013.2.04 package for Microsoft Excel. 


\subsection{Results}

\subsubsection{Physico-chemical parameters}

Several physico-chemical parameters were considered in this study which included temperature, $\mathrm{pH}$, conductivity, turbidity, total dissolved solids (TDS), total suspended solids (TSS), total hardness (TH), and total alkalinity (TA) (Table 2.1). The temperatures in the study sites ranged from 18.1$29.6^{\circ} \mathrm{C}$ over the study duration. Crescent Lake recorded the lowest mean temperature $\left(22.4^{\circ} \mathrm{C}\right)$ followed by the North East site $\left(22.5^{\circ} \mathrm{C}\right) . \mathrm{pH}$ ranged from 7.2-9.5 with the Mouth of Malewa showing the highest variations (Standard Deviation $=0.57$ ) during the study period. Mouth of Malewa showed the lowest mean conductivity $\left(251 \mu \mathrm{S} \mathrm{cm}{ }^{-1}\right)$ while Crescent Lake and Northeast recorded the highest mean values of 421 and $358 \mu \mathrm{S} \mathrm{cm}^{-1}$, respectively. The turbidity was lowest at Crescent Lake (Mean $=10.05$ NTU) and highest at Mouth of Malewa (67.17 NTU) and the North East (43.94 NTU). TSS covered a wide range of $1.0-432.0 \mathrm{mg} \mathrm{L}^{-1}$ with highest and lowest values recorded at Kamere Beach and Crescent Lake, respectively. TDS ranged from 37.0-415.0 $\mathrm{mg} \mathrm{L}^{-1}$ with the low limit in Mouth of Malewa and the high limit at Crescent Lake. TH ranged from 0-120.0 mg $\mathrm{CaCO}_{3} \mathrm{~L}^{-1}$. The Mouth of Malewa, Hippo Point and Kamere Beach stations recorded the lowest values of $\mathrm{TH}$, while the highest values were recorded at the Crescent Lake and Midlake stations. TA ranged between $20-220 \mathrm{mg} \mathrm{CaCO}_{3} \mathrm{~L}^{-1}$ with lowest values at Kamere Beach, Midlake and Mouth of Malewa. Crescent Lake and North East recorded the highest values for TA. 
Table 2.1 Mean and Range of physico-chemical parameters in the sampling sites of Lake Naivasha, Kenya during January through November, 2011.

\begin{tabular}{|c|c|c|c|c|c|c|c|c|}
\hline & & $\begin{array}{c}\text { Crescent } \\
\text { lake }\end{array}$ & $\begin{array}{l}\text { Hippo } \\
\text { Point }\end{array}$ & $\begin{array}{c}\text { Kamere } \\
\text { Beach }\end{array}$ & $\begin{array}{c}\text { South } \\
\text { East }\end{array}$ & Midlake & $\begin{array}{c}\text { Mouth of } \\
\text { Malewa }\end{array}$ & North East \\
\hline \multicolumn{9}{|l|}{ Temperature } \\
\hline \multirow[t]{3}{*}{$\left({ }^{\circ} \mathrm{C}\right)$} & Mean & 22.4 & 23.3 & 24.0 & 24.4 & 24.4 & 22.9 & 22.5 \\
\hline & & $18.9-$ & $18.1-$ & $19.0-$ & $18.7-$ & $19.6-$ & & \\
\hline & Range & 26.6 & 29.6 & 28.1 & 29.3 & 29.0 & $18.1-28.4$ & $18.2-26.7$ \\
\hline \multirow[t]{3}{*}{$\mathrm{pH}$} & Mean & 8.51 & 8.98 & 8.93 & 8.84 & 8.95 & 8.13 & 8.01 \\
\hline & & & $7.98-$ & $7.85-$ & & & & \\
\hline & Range & $7.97-8.95$ & 9.28 & 9.27 & $7.97-9.5$ & $8.16-9.3$ & $7.20-9.28$ & $7.26-9.11$ \\
\hline \multicolumn{9}{|l|}{ Conductivity } \\
\hline \multirow[t]{2}{*}{$(\mu \mathrm{S} / \mathrm{cm})$} & Mean & 421 & 276 & 271 & 268 & 271 & 251 & 358 \\
\hline & Range & $384-526$ & $226-322$ & 216- 310 & $159-313$ & 225- 307 & $74-305$ & $289-392$ \\
\hline \multicolumn{9}{|l|}{ Turbidity } \\
\hline \multirow[t]{3}{*}{ (NTU) } & Mean & 10.05 & 22.83 & 23.06 & 25.50 & 23.47 & 67.17 & 43.94 \\
\hline & & $2.17-$ & $6.76-$ & $7.04-$ & $7.30-$ & $6.85-$ & $4.94-$ & $5.97-$ \\
\hline & Range & 16.40 & 51.50 & 57.50 & 60.80 & 47.10 & 282.00 & 124.00 \\
\hline \multirow[t]{2}{*}{ TDS (mg L-1) } & Mean & 205 & 144 & 138 & 140 & 138 & 124 & 175 \\
\hline & Range & $120-415$ & $110-274$ & $84-200$ & $112-177$ & $110-263$ & $37-160$ & $132-240$ \\
\hline TSS (mg L-1) & Mean & 18 & 48 & 82 & 32 & 29 & 56 & 34 \\
\hline $\begin{array}{l}\text { Total Hardness } \\
\text { (TH) }\end{array}$ & Range & $1-101$ & $4-152$ & $1-432$ & $4-124$ & $2-112$ & $1-211$ & $3-93$ \\
\hline \multirow[t]{2}{*}{$\left(\mathrm{mg} \mathrm{CaCO}_{3} \mathrm{~L}^{-1}\right)$} & Mean & 48 & 26 & 27 & 32 & 30 & 27 & 41 \\
\hline & Range & $0-118$ & $0-62$ & $0-62$ & $0-74$ & $0-108$ & $0-62$ & $0-120$ \\
\hline \multicolumn{9}{|l|}{$\begin{array}{l}\text { Total Alkalinity } \\
\text { (TA) }\end{array}$} \\
\hline \multirow[t]{2}{*}{$\left(\mathrm{mg} \mathrm{CaCO}_{3} \mathrm{~L}^{-1}\right)$} & Mean & 153 & 107 & 99 & 101 & 99 & 96 & 138 \\
\hline & Range & $68-220$ & $72-180$ & $20-144$ & $38-204$ & $50-140$ & $32-136$ & $68-192$ \\
\hline
\end{tabular}

\subsubsection{Nutrients}

Nutrients analyzed in the present study were nitrogen (as $\mathrm{NH}_{4}-\mathrm{N}, \mathrm{NO}_{3}-\mathrm{N}$ and $\mathrm{NO}_{2}-\mathrm{N}$ ) and phosphorus (as $\mathrm{PO}_{4}{ }^{3-}-\mathrm{P}$ and TP) (Table 2). $\mathrm{NH}_{4}-\mathrm{N}$ concentration ranged from $0-0.51 \mathrm{mg} \mathrm{L}^{-1}$ and was highest in the Mouth of Malewa and North East while the South East and Midlake sites recorded the lowest values. The mean NO3-N concentration ranged from $0.17-0.25 \mathrm{mg} \mathrm{L}^{-1}$. The highest mean $\mathrm{NO}_{3}-\mathrm{N}$ was recorded at Mouth of Malewa followed by North East while Kamere Beach recorded the lowest values. $\mathrm{NO}_{2}-\mathrm{N}$ ranged from $0-0.09 \mathrm{mg} \mathrm{L}^{-1}$ with lowest concentrations recorded at Hippo Point while the South East recorded the highest values. $\mathrm{PO}_{4}{ }^{3-}-\mathrm{P}$ ranged from $0-0.08 \mathrm{mg} \mathrm{L}^{-1}$ and showed similar concentrations for all the sampling sites. However, the mean TP, which ranged $0.06-0.082 \mathrm{mg} \mathrm{L}^{-1}$ was highest at the Mouth of Malewa, South East and the North East. 
Table 2.2 Mean and range of nutrients concentrations measured in the sampling sites of Lake Naivasha, Kenya during January through November, 2011.

\begin{tabular}{|c|c|c|c|c|c|c|c|c|}
\hline & & $\begin{array}{l}\text { Crescent } \\
\text { lake }\end{array}$ & $\begin{array}{l}\text { Hippo } \\
\text { Point }\end{array}$ & $\begin{array}{l}\text { Kamere } \\
\text { Beach }\end{array}$ & $\begin{array}{l}\text { South } \\
\text { East }\end{array}$ & Midlake & $\begin{array}{l}\text { Mouth of } \\
\text { Malewa }\end{array}$ & $\begin{array}{l}\text { North } \\
\text { East }\end{array}$ \\
\hline $\mathrm{NH}_{4}-\mathrm{N}\left(\mathrm{mg}^{-1}\right)$ & $\begin{array}{l}\text { Mean } \\
\text { Range }\end{array}$ & $\begin{array}{l}0.057 \\
0.010- \\
0.250\end{array}$ & $\begin{array}{l}0.068 \\
0.000- \\
0.510\end{array}$ & $\begin{array}{l}0.055 \\
0.010- \\
0.240\end{array}$ & $\begin{array}{l}0.045 \\
0.010- \\
0.160\end{array}$ & $\begin{array}{l}0.048 \\
0.000- \\
0.220\end{array}$ & $\begin{array}{l}0.085 \\
0.010- \\
0.300\end{array}$ & $\begin{array}{l}0.083 \\
0.010- \\
0.400\end{array}$ \\
\hline $\mathrm{NO}_{3}-\mathrm{N}\left(\mathrm{mg} \mathrm{L}^{-1}\right)$ & $\begin{array}{l}\text { Mean } \\
\text { Range }\end{array}$ & $\begin{array}{l}0.186 \\
0.100- \\
0.800\end{array}$ & $\begin{array}{l}0.181 \\
0.050- \\
0.700\end{array}$ & $\begin{array}{l}0.167 \\
0.100- \\
0.600\end{array}$ & $\begin{array}{l}0.189 \\
0.060- \\
0.800\end{array}$ & $\begin{array}{l}0.202 \\
0.020- \\
0.600\end{array}$ & $\begin{array}{l}0.247 \\
0.100- \\
1.100\end{array}$ & $\begin{array}{l}0.230 \\
0.100- \\
0.700\end{array}$ \\
\hline $\mathrm{NO}_{2}-\mathrm{N}\left(\mathrm{mg} \mathrm{L}^{-1}\right)$ & $\begin{array}{l}\text { Mean } \\
\text { Range }\end{array}$ & $\begin{array}{l}0.012 \\
0.002- \\
0.061\end{array}$ & $\begin{array}{l}0.010 \\
0.001- \\
0.015\end{array}$ & $\begin{array}{l}0.012 \\
0.001- \\
0.065\end{array}$ & $\begin{array}{l}0.014 \\
0.001- \\
0.085\end{array}$ & $\begin{array}{l}0.013 \\
0.001- \\
0.071\end{array}$ & $\begin{array}{l}0.013 \\
0.002- \\
0.062\end{array}$ & $\begin{array}{l}0.013 \\
0.001- \\
0.059\end{array}$ \\
\hline $\mathrm{PO}_{4}{ }^{3-} \mathrm{P}\left(\mathrm{mg} \mathrm{L}^{-1}\right)$ & $\begin{array}{l}\text { Mean } \\
\text { Range }\end{array}$ & $\begin{array}{l}0.021 \\
0.001- \\
0.079\end{array}$ & $\begin{array}{l}0.025 \\
0.001- \\
0.079\end{array}$ & $\begin{array}{l}0.023 \\
0.001- \\
0.077\end{array}$ & $\begin{array}{l}0.023 \\
0.003- \\
079\end{array}$ & $\begin{array}{l}0.022 \\
0.000- \\
0.079\end{array}$ & $\begin{array}{l}0.022 \\
0.001- \\
0.079\end{array}$ & $\begin{array}{l}0.022 \\
0.004- \\
0.079\end{array}$ \\
\hline $\begin{array}{l}\text { Total } \\
\text { Phosphorus } \\
\left(\mathrm{mg} \mathrm{L}^{-1}\right)\end{array}$ & $\begin{array}{l}\text { Mean } \\
\text { Range }\end{array}$ & $\begin{array}{l}0.061 \\
0.031- \\
0.174\end{array}$ & $\begin{array}{l}0.066 \\
0.030- \\
0.176\end{array}$ & $\begin{array}{l}0.065 \\
0.032- \\
0.192 \\
\end{array}$ & $\begin{array}{l}0.075 \\
0.027- \\
0.410\end{array}$ & $\begin{array}{l}0.064 \\
0.030- \\
0.179\end{array}$ & $\begin{array}{l}0.082 \\
0.031- \\
0.342 \\
\end{array}$ & $\begin{array}{l}0.074 \\
0.042- \\
0.192\end{array}$ \\
\hline
\end{tabular}

\subsubsection{Ion concentrations}

$\mathrm{Ca}^{2+}, \mathrm{Mg}^{2+}, \mathrm{Fe}^{2+}, \mathrm{Mn}^{2+}, \mathrm{Cl}^{-}$and $\mathrm{SO}_{4}{ }^{3-}$ were the main ions which were analyzed and their details are summarized in Table 3. $\mathrm{Ca}^{2+}$ concentration ranged between 0 and $43.2 \mathrm{mg} \mathrm{L}^{-1}$ and was highest at Crescent Lake and North East while Hippo Point recorded the lowest values. $\mathrm{Mg}^{2+}$ concentration ranged from 0.0-24.0 $\mathrm{mg} \mathrm{L}^{-1}$ with lower values at Kamere Beach, Midlake and Mouth of Malewa. The South East recorded highest $\mathrm{Mg}^{2+}$ concentration at $24.0 \mathrm{mg} \mathrm{L}^{-1} . \mathrm{Fe}^{2+}$ concentrations were lowest at the Crescent Lake at $0.01 \mathrm{mg}$ $\mathrm{L}^{-1}$ while the Mouth of Malewa site recorded the highest values at $1.98 \mathrm{mg} \mathrm{L}^{-1}$. $\mathrm{Cl}^{-}$concentration ranged between 4 and $64 \mathrm{mg} \mathrm{L}^{-1}$ with lower values at South East, Midlake, Mouth of Malewa, and North East. Crescent Lake and Hippo Point recorded higher values. Generally, $\mathrm{SO}_{4}{ }^{3-}$ concentrations were highest at Hippo Point and the Kamere Beach stations which recorded $16 \mathrm{mg} \mathrm{L}^{-1}$ while the Crescent Lake and Mouth of Malewa recorded lower values at $4 \mathrm{mg} \mathrm{L}^{-1}$. 
Table 2.3 Mean and range of main ions measured in the sampling sites of Lake Naivasha, Kenya, during January through November, 2011.

\begin{tabular}{|c|c|c|c|c|c|c|c|c|}
\hline & & $\begin{array}{l}\text { Crescent } \\
\text { lake }\end{array}$ & Hippo Point & $\begin{array}{l}\text { Kamere } \\
\text { Beach }\end{array}$ & South East & Midlake & $\begin{array}{l}\text { Mouth of } \\
\text { Malewa }\end{array}$ & North East \\
\hline $\begin{array}{l}\mathrm{Ca}^{2+} \\
(\mathrm{mg} \\
\left.\mathrm{L}^{-1}\right)\end{array}$ & Mean & 25.5 & 14.6 & 15.2 & 16.3 & 15.5 & 15.8 & 22.6 \\
\hline $\mathrm{Mg}^{2+}$ & Range & $16.0-43.2$ & $4.8-24.0$ & $8.0-20.6$ & $6.4-28.8$ & $8.0-22.4$ & $0.0-32.0$ & $8.0-33.6$ \\
\hline$\left.L^{-1}\right)$ & Mean & 1.5 & 0.7 & 1.1 & 2.3 & 1.2 & 1.3 & 1.7 \\
\hline $\mathrm{Fe}^{2+}$ & Range & $0.0-7.6$ & $0.0-3.8$ & $0.0-4.3$ & $0.0-24.0$ & $0.0-8.2$ & $0.0-7.7$ & $0.0-8.6$ \\
\hline ') & Mean & 0.32 & 0.48 & 0.42 & 0.47 & 0.53 & 1.05 & 0.59 \\
\hline $\mathrm{Mn}^{2+}($ & Range & $0.06-1.03$ & $0.17-1.19$ & $0.18-0.90$ & $0.04-1.46$ & $0.15-1.22$ & $0.31-1.98$ & $0.01-1.03$ \\
\hline & Mean & 0.126 & 0.206 & 0.229 & 0.236 & 0.312 & 0.292 & 0.236 \\
\hline & Range & $0.044-0.361$ & $0.091-0.387$ & $0.110-0.371$ & $0.054-0.718$ & $0.099-2.880$ & $0.150-0.690$ & $0.059-0.490$ \\
\hline $\mathrm{Cl}^{-}$ & Mean & 21 & 22 & 19 & 18 & 18 & 18 & 18 \\
\hline $\mathrm{SO}_{4}{ }^{3-}$ & Range & $4-32$ & $14-64$ & $12-43$ & $14-22$ & $12-48$ & $8-45$ & $14-22$ \\
\hline$\left.L^{-1}\right)$ & Mean & 1 & 2 & 2 & 1 & 1 & 3 & 1 \\
\hline & Range & $0-4$ & $0-16$ & $0-16$ & $0-10$ & $0-4$ & $0-13$ & $0-7$ \\
\hline
\end{tabular}

\subsubsection{Multivariate analysis (PCA and CA)}

PCA performed on the correlation matrix of means of the analyzed water quality parameters by site showed that four principal components (PCs) represented about $94.2 \%$ of the total variation in the entire dataset. The actual eigenvalue and the percentage cumulative variability are shown in Figure 2.2 and Table 2.4 summarizes the corresponding eigenvectors. The first PC accounted for $41.3 \%$ of the variations between sites and comprised of the following parameters: TDS, conductivity, $\mathrm{TA}, \mathrm{TH}, \mathrm{Ca}^{2+}, \mathrm{Cl}^{-}$, and $\mathrm{Mg}^{2+}$. The second PC accounted for $29.8 \%$ of the variation with temperature, $\mathrm{pH}$, TSS, orthophosphates and $\mathrm{Cl}^{-}$as the associated parameters. The third PC explained $18 \%$ of the total variations between sites comprising ions $\left(\mathrm{Ca}^{2+}\right.$, $\mathrm{Mn}^{2+}$ and $\left.\mathrm{Mg}^{2+}\right)$, nutrients $\left(\mathrm{NO}_{2}-\mathrm{N}\right.$ and TP), and the physico-chemical parameters ( $\mathrm{pH}$ and temperature). Further, $5 \%$ of the total variation was explained by the $4^{\text {th }} \mathrm{PC}$ whilst $5.8 \%$ of the site variations were explained by the $5^{\text {th }}$ and $6^{\text {th }}$ PCs. 


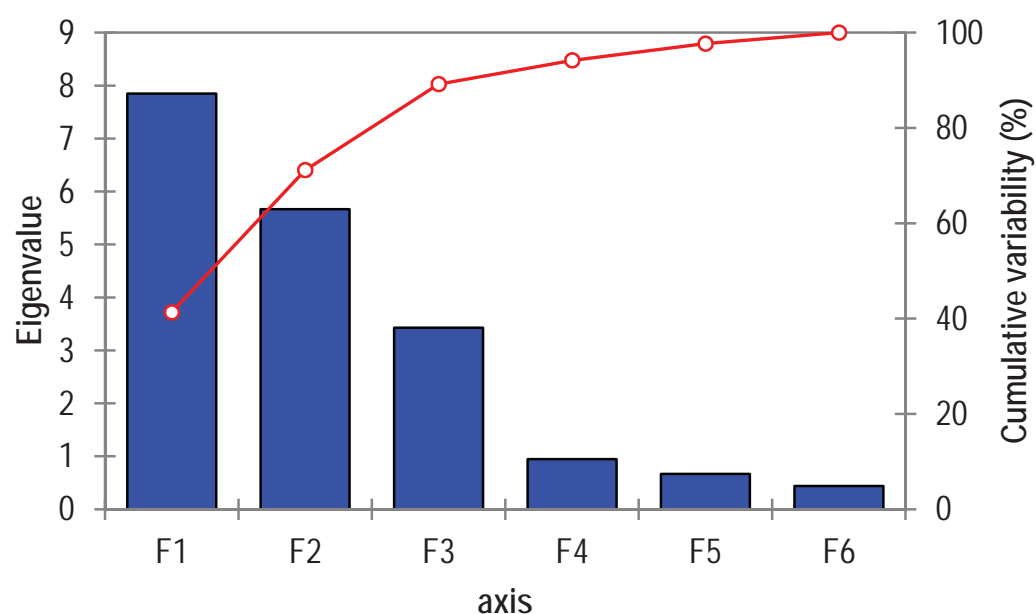

Figure 2.2 Results of the principal component analysis (PCA) showing eigenvalues (histogram) and cumulative variability (line with markers).

Table 2.4 Eigenvectors of the principal components

\begin{tabular}{|c|c|c|c|c|c|c|}
\hline & $\mathrm{F} 1$ & $\mathrm{~F} 2$ & F3 & $\mathrm{F} 4$ & F5 & F6 \\
\hline Turbidity & -0.233 & -0.309 & -0.092 & -0.033 & 0.027 & -0.021 \\
\hline $\mathrm{pH}$ & -0.025 & 0.411 & 0.080 & 0.00011 & -0.116 & 0.137 \\
\hline Temperature & -0.177 & 0.266 & 0.320 & -0.00005 & -0.008 & -0.002 \\
\hline Conductivity & 0.339 & -0.125 & -0.041 & -0.023 & 0.072 & -0.032 \\
\hline $\mathrm{NH}_{4}-\mathrm{N}$ & -0.071 & -0.313 & -0.323 & -0.045 & -0.043 & -0.324 \\
\hline $\mathrm{NO}_{3}-\mathrm{N}$ & -0.117 & -0.378 & -0.012 & -0.198 & -0.260 & 0.013 \\
\hline $\mathrm{NO}_{2}-\mathrm{N}$ & -0.071 & -0.216 & 0.445 & 0.079 & 0.099 & 0.057 \\
\hline $\mathrm{PO}_{4}^{3-}-\mathrm{P}$ & -0.125 & 0.172 & -0.276 & 0.506 & -0.404 & -0.472 \\
\hline TP & -0.224 & -0.291 & 0.022 & 0.354 & -0.066 & 0.024 \\
\hline TSS & -0.215 & 0.107 & -0.209 & 0.024 & 0.770 & -0.246 \\
\hline $\mathrm{Fe}^{2+}$ & -0.251 & -0.269 & -0.098 & -0.131 & -0.079 & 0.306 \\
\hline $\mathrm{Mn}^{2+}$ & -0.293 & -0.057 & 0.178 & -0.410 & -0.179 & -0.197 \\
\hline $\mathrm{Mg}^{2+}$ & 0.042 & -0.158 & 0.406 & 0.537 & -0.004 & 0.094 \\
\hline TA & 0.322 & -0.171 & 0.073 & 0.025 & 0.047 & 0.016 \\
\hline $\mathrm{Ca}^{2+}$ & 0.308 & -0.208 & 0.010 & 0.011 & 0.111 & 0.000 \\
\hline TA & 0.327 & -0.152 & -0.069 & 0.026 & 0.006 & -0.145 \\
\hline $\mathrm{Cl}^{-}$ & 0.180 & 0.160 & -0.376 & -0.048 & -0.232 & 0.414 \\
\hline $\mathrm{SO}_{4}{ }^{3-}$ & -0.229 & -0.080 & -0.312 & 0.302 & 0.182 & 0.501 \\
\hline TDS & 0.348 & -0.089 & -0.036 & 0.025 & 0.033 & -0.049 \\
\hline
\end{tabular}


The bi-plot of the $1^{\text {st }}$ and $2^{\text {nd }}$ PCs showed that turbidity in Lake Naivasha was closely associated with the nutrients $\left(\mathrm{NH}_{4}-\mathrm{N}, \mathrm{NO}_{3}-\mathrm{N}, \mathrm{NO}_{2}-\mathrm{N}\right.$ and $\left.\mathrm{TP}\right)$, and $\mathrm{Fe}^{2+}$ and showed inverse relation to $\mathrm{Cl}^{-}$(Figure 2.3a). Most of these parameters mainly characterized the Mouth of Malewa (Figure 2.3b). Crescent Lake's distinctiveness was attributed to TDS, conductivity, TA, TH and $\mathrm{Ca}^{2+}$. The parameter influencing the distinction in the North East site was mainly $\mathrm{Mg}^{2+}$, while Hippo Point, Kamere Beach, Midlake and South East sites were influenced by $\mathrm{pH}$, temperature, orthophosphate, and TSS, respectively.

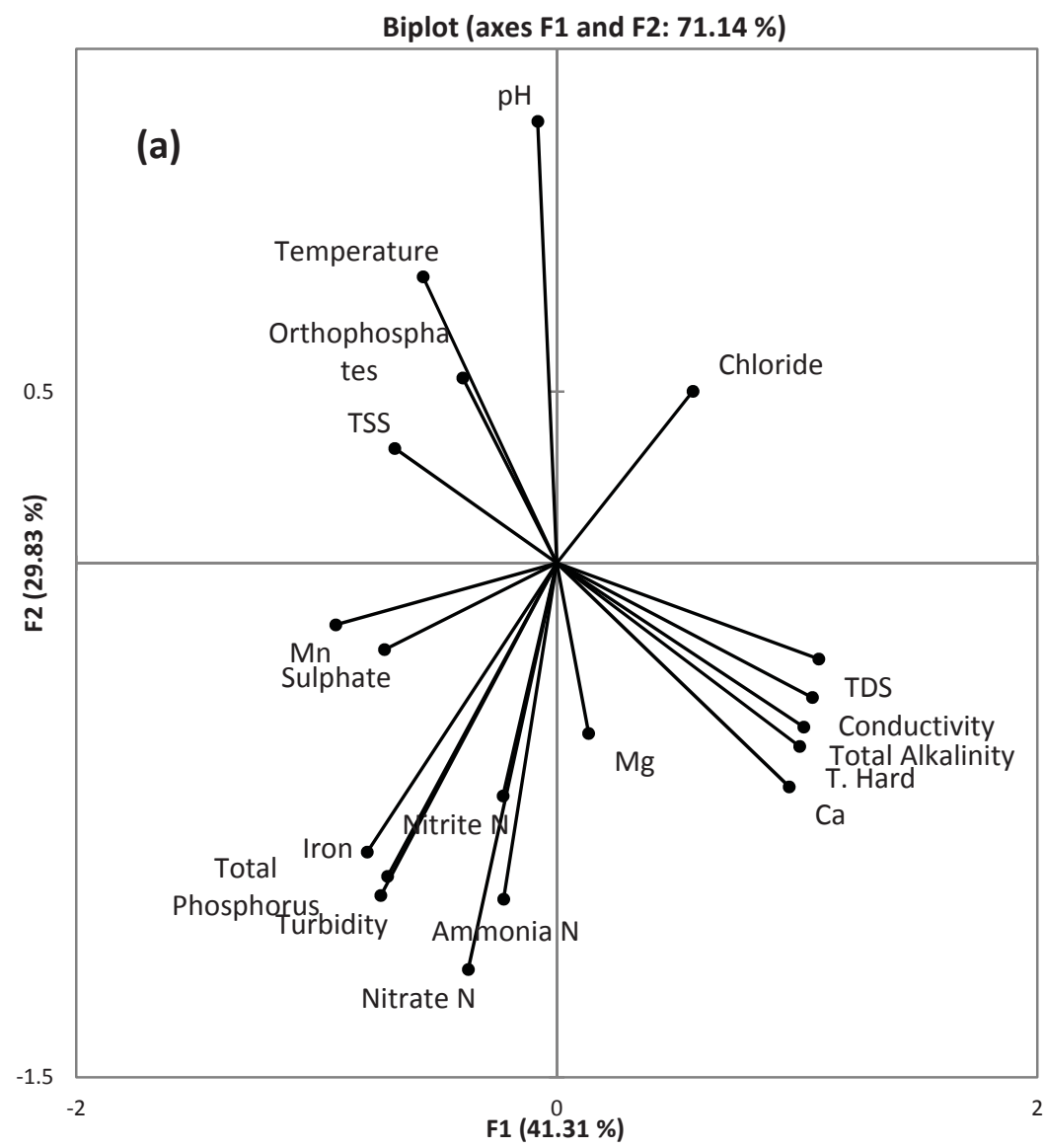




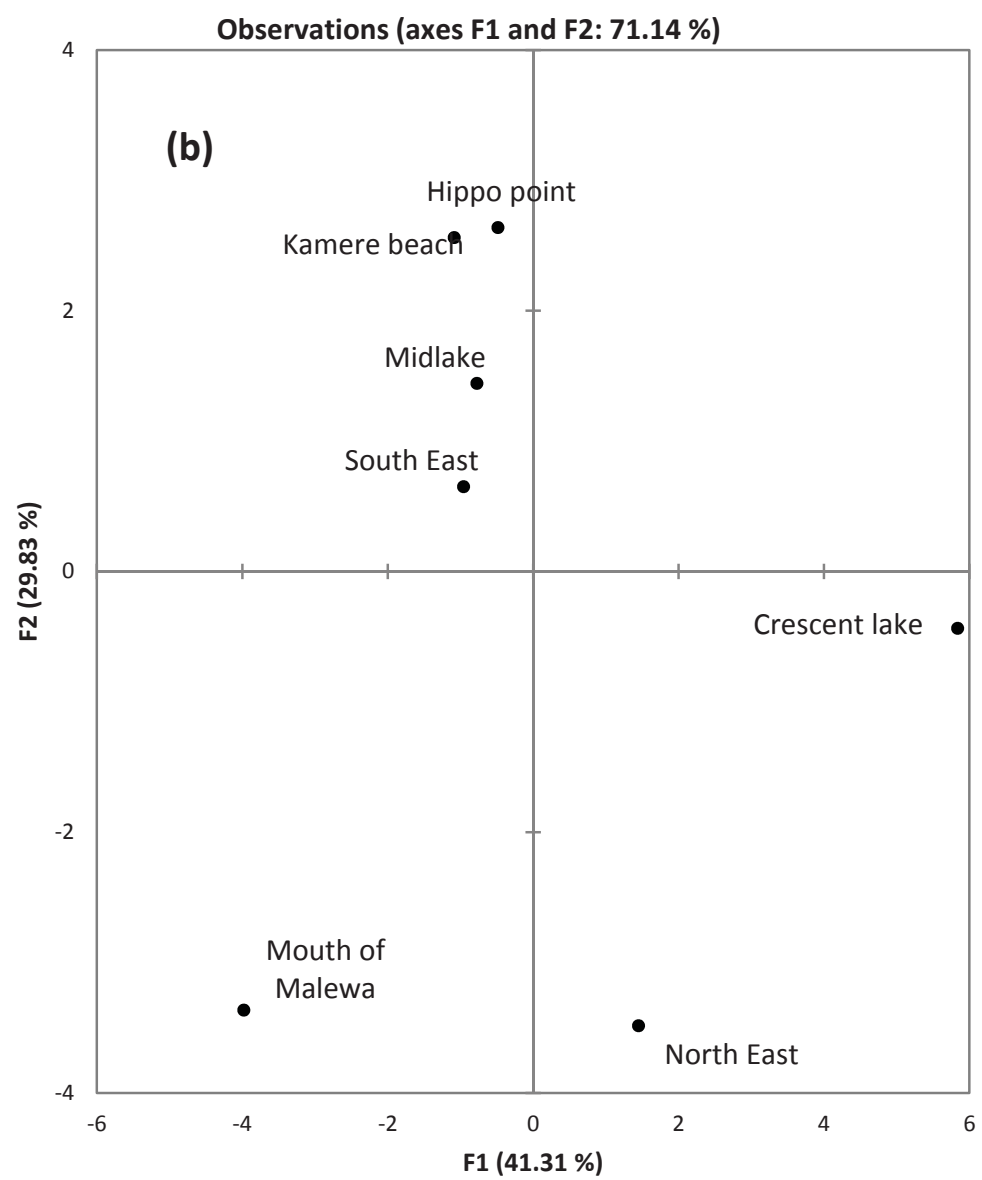

Figure 2.3 Results of the Principal Component Analysis (PCA) for various water quality parameters measured in Lake Naivasha from January to November 2011: (a) bi-plot of the correlation between the water quality parameters in this study; (b) correlation between the studied sites in respect to the water quality parameters.

Figure 2.4 showing the results of $\mathrm{CA}$, indicates that the sampling sites varied and distinctly clustered into three distinct regions as follows: Northern region (Mouth of Malewa and North East), ii) Crescent Lake, iii) Main lake (Kamere Beach, Midlake, Hippo Point and the South East). 


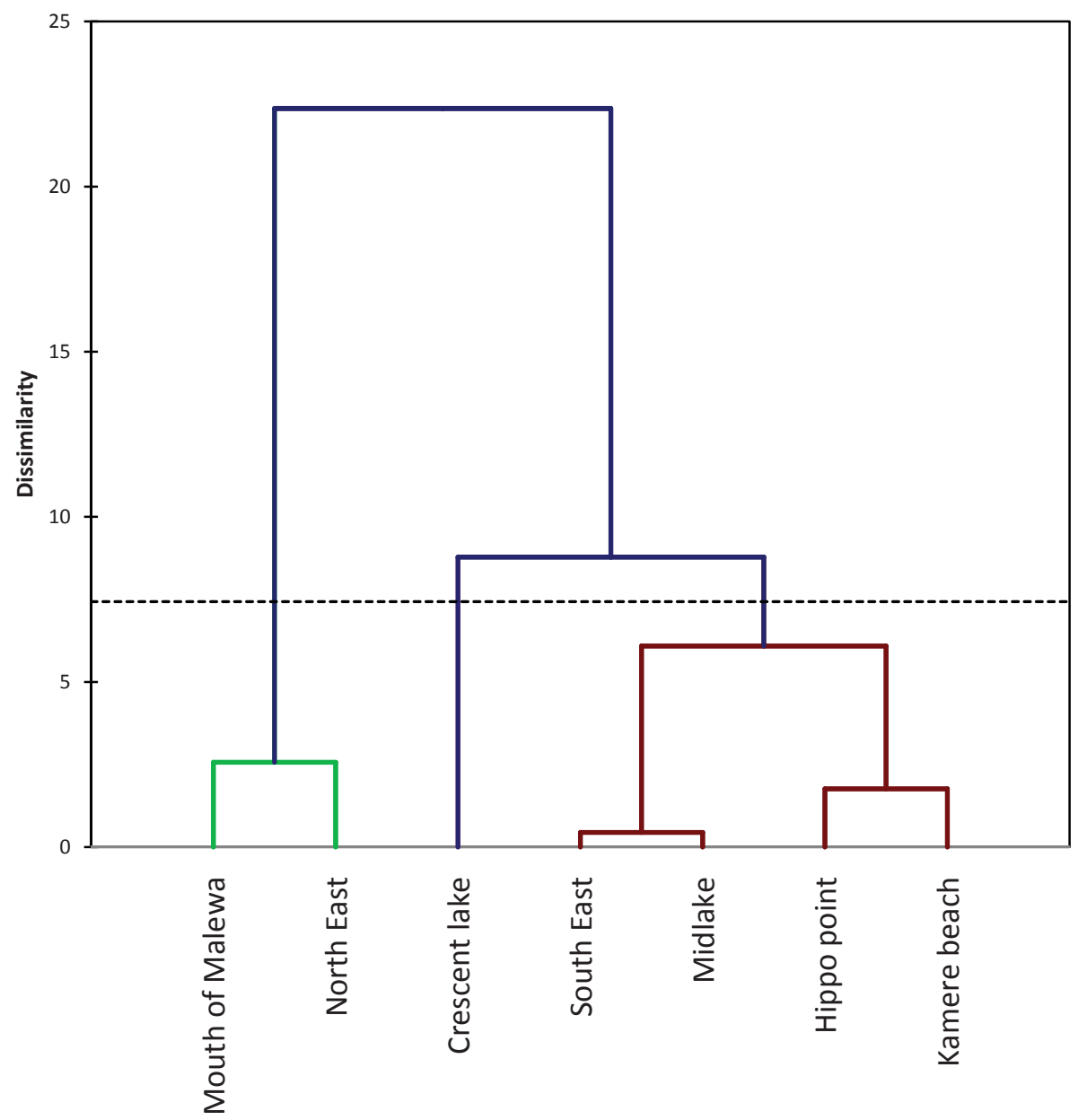

Figure 2.4 Dendrogram of the dissimilarity between the four distinct areas of Lake Naivasha based on water quality parameters (dotted line denotes the truncation line that represents the stations that are somewhat homogeneous)

\subsection{Discussion}

\subsubsection{Physico-chemical parameters}

Being a shallow tropical lake situated very close to the equator, the mean water temperature in Lake Naivasha did not vary much between the sites. However, Crescent Lake showed lower temporal variability in comparison to the rest of the sites because of the deep water in this site which translates to relatively larger water mass which takes longer to warm up and cool down. The $\mathrm{pH}$ is relatively high which is common for lakes of volcanic origin 
(Chernet et al., 2001; Costantini et al., 2007). The pH at Mouth of Malewa and Northeast is somewhat lower in comparison to the other sites which can be attributed to the high influx of fresh water from the Malewa, Gilgil and Karati Rivers (Gaudet, 1979; Stoof-Leichsenring et al., 2011). The range of conductivity in lake Naivasha seems to have widened from $282-374 \mu \mathrm{cm}^{-1}$ as measured by Ballot, Kotut et al. (2009) in 2001-2005 years to 74-526 $\mu \mathrm{S}$ $\mathrm{cm}^{-1}$ in the present study. Turbidity and TSS were generally high at Mouth of Malewa due to the effect of surface runoff from the agriculturally rich catchment area. The Kamere Beach site recorded high turbidity which was attributed to the discharges from the Kamere informal settlements. Being a crater lake, Crescent Lake recorded the highest TDS, probably due to its volcanic origin which is often associated with high concentrations of dissolved minerals (Ayenew, 2005). Furthermore, Crescent Lake station also recorded the highest levels of $\mathrm{TH}$ and $\mathrm{TA}$, suggesting the presence of high concentrations of ions associated with the volcanic geology.

\subsubsection{Nutrients}

The mean concentrations as well as seasonal variations of $\mathrm{NH}_{4}-\mathrm{N}, \mathrm{NO}_{3}-\mathrm{N}$ and TP were highest in the Mouth of Malewa and North East sites compared to the other sites. Presence of $\mathrm{NH}_{4}-\mathrm{N}$ is an indication of domestic waste pollution while the other nutrients are closely associated with agricultural effluents from surface runoff into the rivers (Kazi et al., 2009) .This suggests that Lake Naivasha is experiencing high influxes of phosphorus and nitrogen from exogenous sources. Nitrites and orthophosphates concentrations showed little variation between the sampled sites. However, the turnover rate of orthophosphates in phosphorus limited aquatic environment is extremely rapid, making TP the most informative measurement of phosphorus in surface waters (Wetzel, 2001). In Lake Naivasha the mean phosphorus loading was estimated to be $0.6 \mathrm{~g} \mathrm{~m}^{-2} \mathrm{yr}^{-1}$ in 1997-1998 (Kitaka et al., 2002). During this study, total phosphorus loading data were not collected. However, the trophic state was found to have deteriorated based on comparative assessment of total phosphorus trophic state index (TSI-TP) of 1998-1997 and 2011 in the lake (Ndungu et al., 2013a).

\subsubsection{Main ions}

The concentration of $\mathrm{Mg}^{2+}$ was about half the $\mathrm{Ca}^{2+}$ concentrations; a phenomenon observed in other parts of the world (Grochowska and Tandyrak, 2009). Both cations were generally higher in the Crescent Lake and North East sites, explaining the high TH, TA and conductivity at these two sites. Studies in other parts of the world have expressed similar association between $\mathrm{Ca}^{2+}$ and $\mathrm{Mg}^{2+}$, and $\mathrm{TH}, \mathrm{TA}$ and conductivity (Prepas et al., 2001). The volcanic origin of Crescent Lake and the proximity of the North East site to this satellite lake could plausibly explain the high $\mathrm{Ca}^{2+}$ and 
$\mathrm{Mg}^{2+}$ concentrations in the two sites. $\mathrm{Fe}^{2+}$ concentrations were generally high at the Mouth of Malewa site which is an indication that the high levels of $\mathrm{Fe}^{2+}$ in the lake were mainly emanating from surface runoff from the iron-rich catchment soils. The higher temporal variations $(S D=0.44)$ of $\mathrm{Fe}^{2+}$ in the Mouth of Malewa sampling site compared to other studied sites may also be explained by the inflow variations between the wet and dry seasons. Lower $\mathrm{Fe}^{2+}$ concentrations were recorded in the Crescent Lake which may be attributed to limited exchange of the river water into the area; and the occasional disconnection between the Crescent Lake and the main lake. The range of $\mathrm{Fe}^{2+}$ concentrations observed in this study $\left(40-1980 \mu \mathrm{g} \mathrm{L}^{-1}\right)$ falls within the range found in Ethiopian Rift Valley lakes $\left(3.2-4699 \mu \mathrm{g} \mathrm{L}^{-1}\right.$ ) (Zinabu and Pearce, 2003). However, $\mathrm{Mn}^{2+}$ concentrations observed in this study were found to be higher than observed in Kenyan and Ethiopian Rift Valley lakes (Ochieng et al. 2007, Zinabu and Pearce 2003). Ochieng Lalah et al. (2007) measured $\mathrm{Mn}^{2+}$ in Lake Naivasha sediment but could not detect dissolved $\mathrm{Mn}^{2+}$ in the water samples collected.

\subsubsection{Multivariate analysis}

PCA associated water turbidity with nutrients $\left(\mathrm{NH}_{4}-\mathrm{N}, \mathrm{NO}_{3}-\mathrm{N}, \mathrm{NO}_{2}-\mathrm{N}\right.$ and TP), $\mathrm{SO}_{4}{ }^{2-}, \mathrm{Mn}^{2+}$ and $\mathrm{Fe}^{2+}$, which were the key parameters characterizing the Mouth of Malewa sampling site (Figure 2.3), which suggests an influence of agricultural activities in the catchment. The North East region of the lake was associated with $\mathrm{NH}_{4}-\mathrm{N}$ and $\mathrm{Mg}^{2+}$. The association with $\mathrm{NH}_{4}-\mathrm{N}$ can be explained by the close proximity to the Naivasha municipal treatment plant and Kihoto informal settlements which are sources of fresh organic material with high ammonium content. The high influence of $\mathrm{Mg}^{2+}$ in the characterization may be indicative for interaction with Crescent Lake, whose natural mineral composition is associated with its volcanic origin. TDS, conductivity, TA, TH and $\mathrm{Ca}^{2+}$ were more associated with Crescent Lake than with the other sites of the lake. Kilham (1990) also found close association of chemical composition of African lakes with volcanic rocks. Gaudet and Melack (1981) also associated African waters with the chemical composition of the underlying rocks. $\mathrm{Cl}^{-}$seems to have no close association to any site which means that the $\mathrm{Cl}^{-}$concentration is not a strong discriminating parameter between the studied sites.

Cluster analysis resulted in three major regions: i) Northern region (Mouth of Malewa, and the North East), ii) Crescent Lake, iii) Main-lake (Kamere Beach, Midlake, Hippo Point and the South East). This grouping agrees with the results of discriminant analysis done on the trophic state variables (Ndungu et al., 2013a). The Northern region is more influenced by external discharge which consists of runoff from the agricultural activities in the catchment, urban waste water from the Naivasha municipal treatment plant and Kihoto 
informal settlement. Crescent Lake is a volcanic crater lake and therefore expected to have the chemical composition of the leached underlying volcanic rocks (Gaudet and Melack, 1981). The main lake receives the external input from the northern region but it is characterized by wind driven mixing (confirmed by a hydrodynamic study which is to be published later) making it quite homogeneous.

Other water quality studies that applied PCA and CA analysis found the techniques helpful in the interpretation of large datasets. Kazi, Arain et al.(2009) used PCA and CA in the analysis of water quality in Manchar Lake in Pakistan and found the techniques useful in apportionment of pollution sources based on parameter association. Though Kazi, Arain et al.(2009) used 36 parameters, their findings agree with the present study particulary in the association of the nutrients with catchment runoff, and $\mathrm{NH}_{4}$ with domestic wastes. Magyar, Hatvani et al. (2013) used PCA and CA as well but the study had 33 sampling sites 13 physiochemical and biological water quality parameters which helped in identifying the underlying processes responsible for the heterogeneity in different parts of Lake Neusiedler See in Hungary. The study also found the river input region to be significantly different. Sheela, Letha et al. (Sheela et al., 2012) applied PCA and Cluster analysis to identify the factors influencing the water quality in the different seasons in Akkulam-Veli Lake in India. The study revealed that organic pullution was more significant during the dry season as compared to the rainy season and decrease during the rainy season because of precipation and tidal influence which cause dilution. PCA and CA have also been applied in water quality studies in other lakes (Simeonov et al., 2010; Wenchuan et al., 2001).

\subsection{Conclusions}

The present study aimed at assessing the status of the water quality in Lake Naivasha. Concentrations of different physico-chemical parameters, nutrients, and the main ions were determined through field measurements. Turbidity was high in Mouth of Malewa in comparison to other studied sites implying presence more suspended particles around the river input region (Mouth of Malewa). Nutrients concentrations were high in the region around the river inputs and effluent of the waste water treatment (Mouth of Malewa, North East). Main ions were found to be high in Crescent Lake, which is a more or less isolated volcanic crater lake, due to the influence of underlying volcanic rocks.

The use of Principal Component Analysis (PCA) and Cluster Analysis (CA) to provide an insight on water quality in Lake Naivasha showed the usefulness of such multivariate analysis in establishing the characteristics of different regions in aquatic ecosystems based on numerous water quality parameters. 
Three distinct regions were observed which include: Northern region (Mouth of Malewa and North East), ii) Crescent Lake, iii) Main Lake (Kamere Beach, Midlake, Hippo Point and the South East). Apart from provision of the distinction between the studied sites, water quality parameter associations provided information on the factors that influence the water quality of Lake Naivasha which include agricultural activities and domestic effluent. The Northern region (Mouth of Malewa and North East) of the Lake was dominated by the agricultural activities in the catchment and domestic effluent. In Crescent Lake, natural mineral composition associated with its volcanic origin played a major role. The main lake is the recipient of the Northern region effects but is somewhat well mixed. This information is fundamental especially in setting guidelines for effective ecosystem management particularly in the control of eutrophication. 


\section{Chapter 3}

\section{Spatio-temporal Variations of the Trophic state in Lake Naivasha, Kenya ${ }^{2}$}

\footnotetext{
2 This Chapter is based on: Ndungu, J., Augustijn, D.C.M., Hulscher, S.J.M.H., Kitaka, N. and Mathooko, J. (2013) Spatio-temporal variations in the trophic status of Lake Naivasha, Kenya. Lakes \& Reservoirs: Research \& Management 18(4), 317-328.
} 


\begin{abstract}
The spatio-temporal dynamics of the trophic state of a lake is crucial in defining its water quality as well as biodiversity. Accordingly, this study focuses on spatio-temporal variations of the trophic state and the possible causes of the heterogeneous turbidity in Lake Naivasha, Kenya. The trophic state oscillated between eutrophic and hypereutrophic being found to be more eutrophic than recorded in previous studies indicating a progressive deterioration of the lake's water quality. Inferences from graphical representation of the deviations of total phosphorus and secchi-depth from chlorophyll-a trophic state indices revealed that the lake is predominantly phosphorus limited. Furthermore, the turbidity in the northern part of the lake is dominated by suspended sediment and dissolved coloured material. Discriminant analysis resulted in identification of three distinct trophic state regions in Lake Naivasha, namely the northern region, the mid and southern part, and the more or less isolated Crescent Lake. The results of this study provide a good basis for further investigation of the current loading magnitude of both nutrients and sediments inorder to facilitate sustainable management to ensure community integrity and ecosystem functions of the lake.
\end{abstract}




\subsection{Introduction}

Understanding the trophic state of degrading aquatic ecosystems undergoing degradation is an important scientific basis of sustainable resource use management because it defines the foundation of community integrity and ecosystem function. It is also important to understand the constituents contributing to the water column turbidity in such systems. This knowledge provides an insight in identifying the appropriate remedial action for restoring of degraded aquatic systems. Carlson \& Havens (2005) established a graphical representation of deviations of total phosphorus and secchi-depth from chlorophyll-a trophic state indices, based on different lakes in the United States. This approach has since been adopted in Europe (Matias and Boavida, 2005) and China (James et al., 2009). In contrast, it has not been widely adopted for use in assessing the highly turbid waters in Africa, which are highly vulnerable to degradation from human activities. Thus, information from developing countries on this approach could provide insight regarding the global trends of lake trophic status.

Over the last few decades, human-induced changes in land- and water-use have resulted in environmental perturbations in Lake Naivasha ecosystem, transforming its waters from a clear oligotrophic state dominated by macrophytes, to turbid eutrophic state dominated by algae (Harper, 1992). Multiple stressors, including rapid siltation of the lake from sediments discharged by the main inflow rivers, runoff from the surrounding agro-based farms and huge irrigation water demands for agriculture poses a significant threat to the sustainability of Lake Naivasha (Harper et al., 2011b; Mergeay, 2004; Stoof-Leichsenring et al., 2011; Tarras-Wahlberg et al., 2002). Other factors contributing to the Lake's deterioration conflicts between conservation and exploitation its resources, rapid urbanization, untreated waste disposal into the lake from Naivasha town, introduction of invasive species and climate change (Becht and Harper, 2002; Britton et al., 2010; Grey and Jackson, 2012; Jackson et al., 2012; Kitaka et al., 2002). With an ever increasing intensity of the exploitation of the lake catchment and resources, monitoring of the water quality variables is imperative to obtain insight into the temporal and spatial variations associated with its prevailing trophic state. Despite an observable major shift from a clear oligotrophic to turbid eutrophic state, little has been carried out to evaluate the main constituents of turbidity in different regions of the lake. Although several studies have been undertaken to address such issues (Becht and Harper, 2002; Harper, 1992; Harper et al., 2011b; Hickley and Harper, 2007; Hickley and Harper, 2002; Kalff, 1983; Kitaka et al., 2002; Kundu et al., 2010) none have illustrated the spatio-temporal dynamism of the trophic state of the lake or the constituents of its turbidity. 
This study focuses on evaluating spatio-temporal dynamics associated with trophic state of Lake Naivasha, as well as the possible causes of turbidity in different locations in the lake, as proposed by Carslon and Havens (2005). The trophic state in Lake Naivasha, was determined with the use of Carlson's Trophic State Index (TSI) (Carlson, 1977). Determination of TSI was based on fieldwork conducted in year 2011 whereby total phosphorus, secchi depth and chlorophyll-a data were collected from seven different locations in the lake. The spatio-temporal heterogeneity of the water quality in the lake was ascertained using discriminant analysis as well as through two way analysis of variance of the trophic state variables.

\subsection{Materials and methods}

\subsubsection{Study Area}

Lake Naivasha is a shallow endorheic freshwater lake situated on the floor of the Eastern Rift Valley in Kenya at 1885 m above sea level (Figure 3.1). The lake basin total area is $3416 \mathrm{~km}^{2}$ (LP DAAC, 2011) and with the lake itself covering only $5 \%$ of the total catchment area. In addition to the main freshwater lake, the basin contains two smaller saline lakes; Lake Oloidien, which used to be connected to the main lake, and Sonachi Crater Lake. The main water inputs into the lake are from the Malewa River, which accounts for $80 \%$ of the discharge into the lake, and has a catchment area of 1700 $\mathrm{km}^{2}$, and the Gilgil River which accounts for $10 \%$ of the total discharge into the lake with a catchment area of $400 \mathrm{~km}^{2}$ (De-Jong, 2011). The remaining water inflow comes is from other less significant rivers around the lake (e.g. Karati River) and through seepage. Without considering the water withdrawn for agricultural irrigation, the annual surface water inflow is estimated to be $217.4 \times 10^{6} \mathrm{~m}^{3}$ (Becht and Harper, 2002). The lake area is estimated to 150 $\mathrm{km}^{2}$, under dry conditionsThe mean area is estimated to be approximately $120 \mathrm{~km}^{2}$ (( $\AA$ se, 1987)). Although the Crescent Lake is connected to the main lake, its characteristics are distinct from the main lake (Hubble and Harper, 2000). 


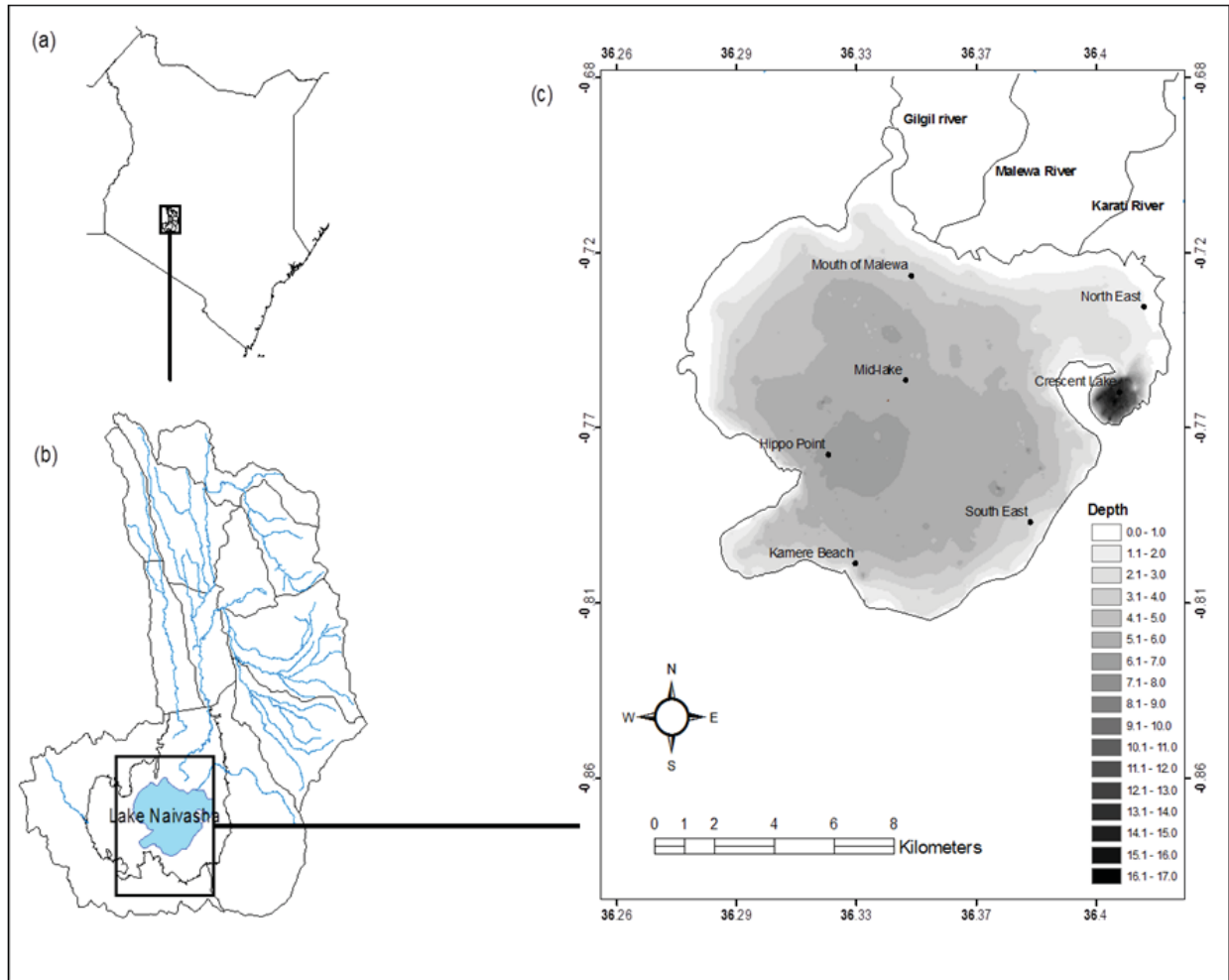

Figure 3.1 Location of Lake Naivasha catchment in Kenya (a), the extent of the catchment together with the major rivers that drain into the lake (b), the sampling sites and depth of the lake in October 2011 (c).

The mean temperature around Lake Naivasha is approximately $25^{\circ} \mathrm{C}$ with a maximum temperature of $30^{\circ} \mathrm{C}$. The area receives bimodal annual rainfall with long rains in March/April and short rains in October/November. The average rainfall around the lake is approximately $650 \mathrm{~mm}$ year ${ }^{-1}$, while the upper catchment receives much more rainfall of up to approximately 2,400 $\mathrm{mm}$ year $^{-1}$ (Stoof-Leichsenring et al., 2011).

\subsubsection{Sample collection and field measurements}

Triplicate surface water samples were collected in 2011 from seven sampling sites in Lake Naivasha (Figure 3.1). Two sites were located in the northern side of the lake, one being close to the Malewa River inlet covering the plume area (rivermouth) and the other located close to where the municipality discharges the effluent of the waste water treatment plant and Kihoto informal settlement (north-east). One sampling site was located in the middle of the lake (mid-lake). Three more sites were located in the southern side of the lake including Hippo Point (the deepest point in the main lake); Kamere beach (close to Kamere informal settlement), South-east site (located close 
to the flower farms located on the South-eastern edge of the lake). Crescent Lake, located on the eastern side of the main lake was also sampled. The collected water samples were transported to the laboratory in a cooler box for nutrient analysis (total phosphorus and total nitrogen) and chlorophyll-a. In situ Secchi depth was measured from January to June 2011 using a 20$\mathrm{cm}$-diameter Secchi disk.

Ancillary data, including the lake depth and level, rainfall, temperature, radiation and discharge, were collected to aid in the interpretation of the trophic state variables. The depth measurements were taken in October 2011using a Garmin Fishfinder 300C Sounder. The echosounder was configured to take a depth measurement every 30 seconds, with the boat moved at a speed of $<10 \mathrm{~km} \mathrm{hr}^{-1}$. A total of 3867 depth measurements were recorded along various tracks across the lake. The depth measurements were interpolated through ordinary kriging at a grid cell size of 50 by 50 to obtain the lake bathymetry. Lake level data from national water level 2GB6 station, which is located close to Crescent Lake, were also acquired. Rainfall data were obtained from Kijabe farm which is also located close to Cresecent Lake. Discharge data from the Malewa River were acquired from the Water Resources Management Authority (WRMA) 2GB1 gauging station which is about $20 \mathrm{~km}$ away upstream from the lake. Discharge data were only available from June to November 2011. Temperature information was noted during sample collection while radiation information was acqured from Oserian flower farm. Total Nitrogen (TN) concentration data were also collected as ancilary data to aid in the interpretation of the lake trophic state. The TN was determined using persulfate digestion method which involves adding persulfate reagent powder into the hydroxide reagent, followed by addition of $2 \mathrm{ml}$ of the sample. A distilled water blank was treated in a similar manner. Both the water samples and the blank were then digested for 30 minutes and left to cool. The solution was subsequently acidified after cooling. The absorption was then measured using a UVmini-1240 UV-VIS Spectrophotometer at $220 \mathrm{~nm}$ wavelength. The concentration was then determined using calibration curves. The TN samples were also analysed weekly from January to June and bi-weekly from July to November 2011.

\subsubsection{Total phosphorus}

Total phosphorus (TP) was determined with molybdenum blue-ascorbic method (APHA, 2005), after digestion of $50 \mathrm{~mL}$ duplicate samples with persulfate. After color development, the sample absorbance was read in 30 minutes to $1 \mathrm{hr}$ at $880 \mathrm{~nm}$ wavelength, using a UVmini-1240 UV-VIS Spectrophotometer in $1 \mathrm{~cm}$ cells. The TP concentration was then determined using standard calibration curves. The analysis was carried out weekly from January to June and bi-weekly from July to November 2011. 


\subsubsection{Chlorophyll-a}

Chlorophyll-a was determined with acetone extraction method, where $100 \mathrm{~mL}$ volume of a water sample was filtered with an electric filtration unit through prewashed Whatman GF/F $0.47 \mu \mathrm{m}$ diameter filters. Extraction was carried overnight using $10 \mathrm{~mL}$ of $90 \%$ acetone. Chlorophyll-a absorption was then determined using Thermo Scientific GENESYS ${ }^{\text {TM }} 10 \mathrm{~S}$ Bio UV/Visible Spectrophotometer by measuring the absorbance at 663 and 750 (blank) nanometers wavelength after zeroing using acetone. The formulae by Talling and Driver (1961) were used to calculate the chlorophyll-a concentration. The chlorophyll-a analysis was carried out weekly from February to May 2011.

\subsubsection{Determination of the trophic state}

The trophic state classification of Carlson (1977) was used in this study. This method transforms the trophic state variables (total phosphorus, chlorophylla and secchi depth) to a Trophic State Index (TSI) ranging from approximately 0 to 100 which represents the trophic state of a lake. The trophic state values range from oligotrophic ( $<40)$, mesotrophic (40-50), eutrophic (50-70), and hypereutrophic (>70) states, respectively (Carlson and Simpson, 1996).

The TSI of the different trophic state variables were derived using the following equations (Carlson, 1977):

$\mathrm{TSI}-\mathrm{TP}=14.42 \ln (\mathrm{TP})+4.15$

$\mathrm{TSI}-\mathrm{SD}=60-14.41 \ln (\mathrm{SD})$

$\mathrm{TSI}-\mathrm{CHL}=30.6+9.81 \ln (\mathrm{CHL})$

Where: TSI-TP = trophic state index referenced to total phosphorus, $($ TP $)=$ represent total phosphorus $(\mu \mathrm{g} / \mathrm{L}), \mathrm{TSI}-\mathrm{SD}=$ trophic state index referenced to secchi depth, SD = represents secchi depth in meters, TSI-CHL = trophic state index referenced to chlorophyll-a, CHL $=$ chlorophyll-a $(\mu \mathrm{g} / \mathrm{L})$, while In = natural logarithm.

The index variables with this method are interrelated, as exemplified by the regression models that produce the same index value for the trophic state variables. Thus, the trophic state is determined by a single variable from which the values of the other variables are inferred. Deviations from the inferred values result from the differences in the characteristics of the water system (Carlson and Havens, 2005). 


\subsubsection{Statistical analysis}

Two way analysis of variance (ANOVA) was conducted to test the differences between, and within, sampling sites at $95 \%$ confidence interval. The differences between sites were examined to determine the spatial variation while the differences within sites addressed the the temporal variation. The spatial variation was further ascertained using the discriminant analysis technique.

\subsubsection{Discriminant analysis}

The spatial variability of water quality in Lake Naivasha was determined with the use of discriminant analysis (DA) technique in PASW Statistics 18.Ink software. The DA was conducted on the seven studied sampling sites in 2011, under the prior assumption that all the sites were spatially different. In this case, discriminant functions represent a combination of discriminant scores that maximally separates the sampling sites based on the trophic state variables. The first discriminant function accounts for almost all the variance between the sites. The second discriminant function accounts for the variance that is not explained by the first discriminant function, and so on, till the last variable is considered (Kannel et al., 2011). Discriminant analysis was chosen because it is capable of separating the differences between the sampling sites by assigning scores (discriminant scores) indicating the strength of the separation between the sites (Kannel et al., 2011). High discriminant scores denote high contribution in separation of the sampling sites. Total phosphorus, secchi depth, chlorophyll-a, and total nitrogen were the water quality variables selected for the discriminant analysis because of their relevance to the trophic state determination. The goodness-of-fit in the classification of sampling sites into groups of similar characteristics was checked from the Wilks' lambda, which tests the null hypothesis that the classified groups have equal means. The closer the value of the Wilks' lambda to zero, the higher the discrimination between the sites (Kannel et al., 2011).

\subsection{Results}

\subsubsection{Trophic State Variation in reference to Total Phosphorus}

The total phosphorus (TP) concentration in Lake Naivasha ranged between 0.027 and $0.41 \mathrm{mg} \mathrm{L}^{-1}$. This corresponds to TSI values of 52 and 91, respectively. Two-way ANOVA between the means of the seven sampling sites indicated a significant spatial variation $(F=13.3, P<0.001)$. However, there were no temporal variations within the sites $(F=1.8, P>0.05)$. The TSI-TP value was indicative of a eutrophic state (TSI value between 50 and 70), with an exception of two peaks around March and August 2011 (Figure 
3.2). Both peaks were preceded by a higher TP concentration at the Mouth of Malewa sampling site, relative to the remaining sampling sites. During these peaks, Lake Naivasha shifted temporarily to a hypereutrophic state, with TSI values of above 80 and even higher (>90) in March 2011, particularly at the south-east sampling site. The north-east sampling site, which is located close to the Naivasha municipality treatment plant and Kihoto informal settlement, exhibited relatively high TP concentrations. A slight decreasing trend was observed towards November 2011.

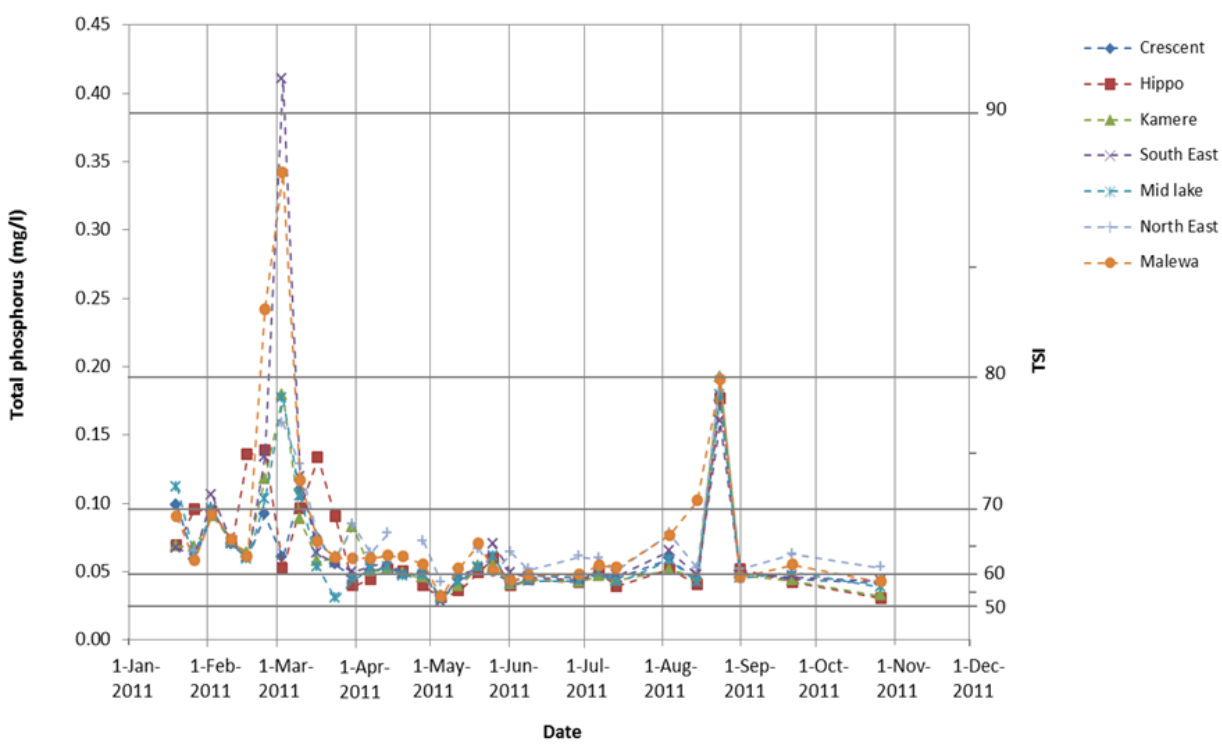

Figure 3.2 Time series plot of Total Phosphorus concentration and the corresponding TSI-TP from January to October 2011 in Lake Naivasha

The TP peaks coincided with intense rainfall that flushed nutrients into the river and towards the lake (Figure 3.3(a)). After the flush rainfall, the subsequent rainfall events did not correspond to high TP concentrations. The river discharge and lake water level increased after the flush rainfall (Figure 3.3 (a) and (b)). The lake water level increased towards November, coinciding with a decreased TP concentration. 

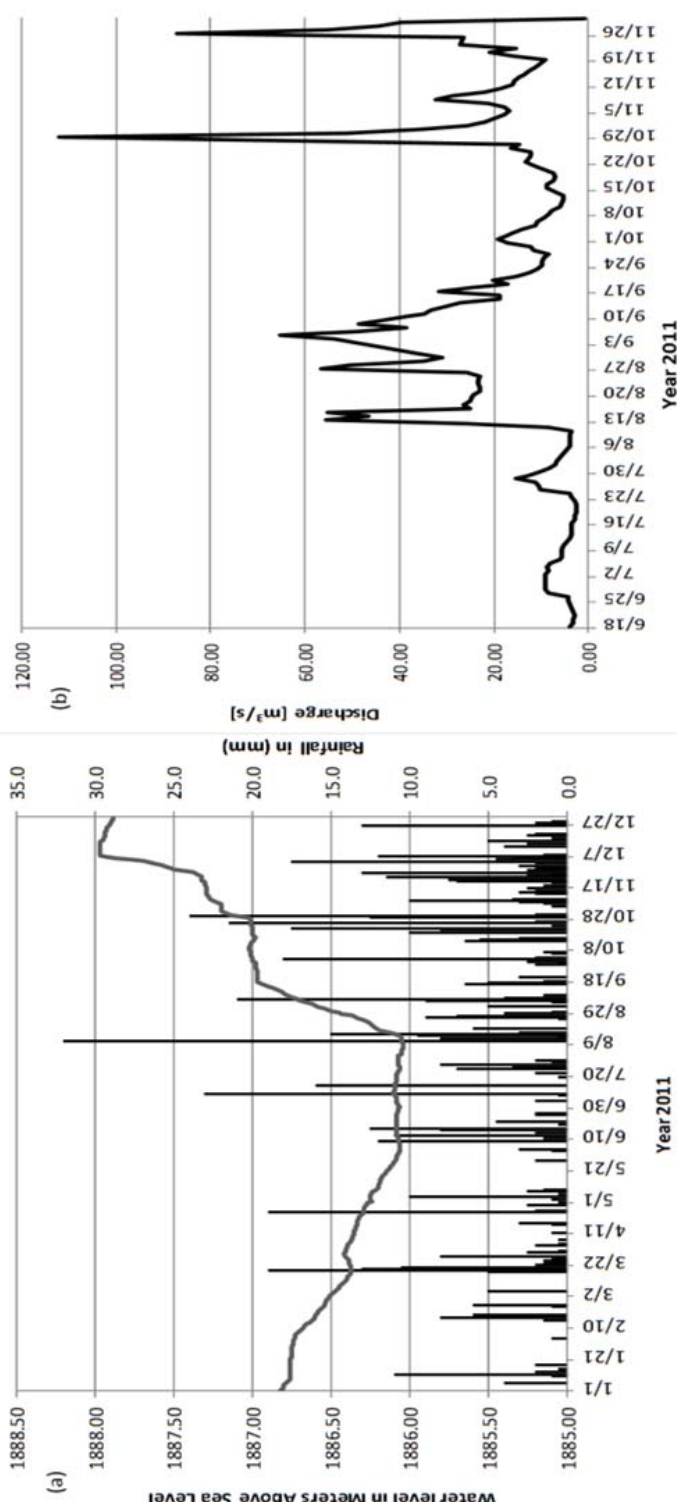

Figure 3.3 Daily rainfall in Kijabe Farm (bar graph) and lake water levels measured at 2GB6 station (line graph) in 2011 (a), Malewa River discharge from the WRMA 2GB1 Gauging Station from June to November 2011 (b).

\subsubsection{Trophic state variation in reference to Secchi depth}

A hypereutrophic state (TSI-SD $>70$ and Secchi depth $<0.5 \mathrm{~m}$ ) was observed for all the Lake Naivasha sampling sites, except for Crescent Lake, which was classified as eutrophic throughout this study (Figure 3.4). The Secchi depth in the main lake generally ranged between 10 and $75 \mathrm{~cm}$, while Crescent Lake 
exhibited a range between 50 and $120 \mathrm{~cm}$. The Mouth of Malewa sampling site exhibited the highest TSI-SD value, followed by the north-east sampling site. Both sites exhibited TSI values frequently exceeding 80. Crescent Lake exhibited the lowest TSI-SD values (i.e. largest Secchi depths), varying between 60 and 70 (indicating a eutrophic state) throughout the study period. All other sampling sites exhibited TSI-SD values mostly ranging between 70 and 80 .

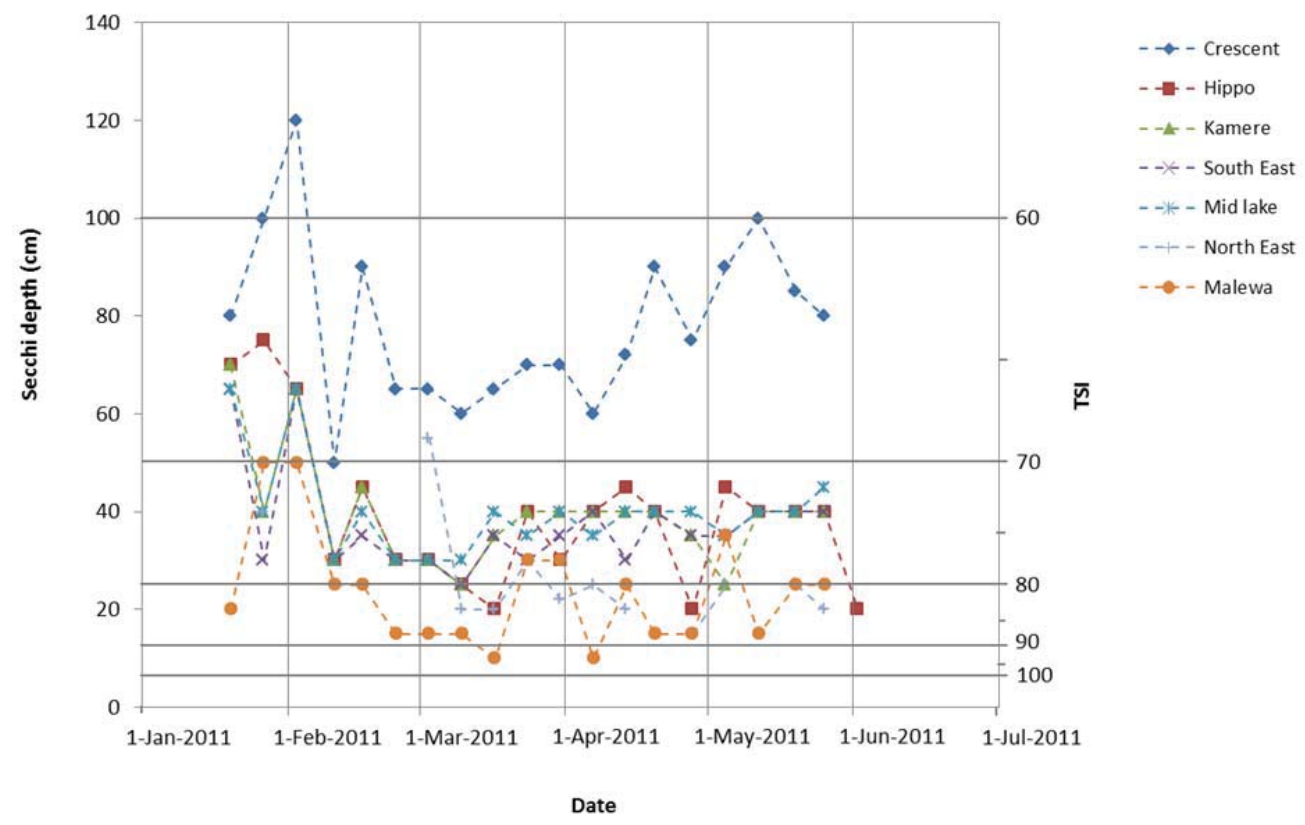

Figure 3.4 Time series plot of secchi depth and the corresponding TSI-SD from January to June 2011 in Lake Naivasha

A spatial variation in Secchi depth was noted among the sampling sites ( $\mathrm{F}=$ 3.8, $\mathrm{P}<0.001)$. Temporal differences between the sample sites also were evident $(F=46.3, P<0.05)$. Depth measurement interpolation indicated the northern part of the lake, where the Mouth of Malewa and north-east sites are located, appeared generally shallow, compared with the south edge (Figure 3.1). This part of the lake is near the locations where the catchment and Naivasha town run-off first reaches the lake. The Hippo Point is the deepest part of the main lake, being about $7 \mathrm{~m}$ deep. Crescent Lake, which exhibits different characteristics compared with the main lake, was as deep as $17 \mathrm{~m}$ during this study. 


\subsubsection{Trophic state variation in reference to chlorophyll-a}

The chlorophyll-a concentration ranged between 0.04 and $0.21 \mathrm{mg} \mathrm{L}^{-1}$. These values corresponded to TSI values of 67 and 83, respectively. However, most of the TSI-CHL values were between 70 and 80 , indicative of a hypereutrophic state. Analysis of variance (ANOVA) highlighted a highly significant temporal variation in TSI-CHL $(P<0.001)$, while the spatial variation was insignificant $(P>0.05)$. An increasing trend in the TSI-CHL could be discerned from February to June 2011 (Figure 3.5).

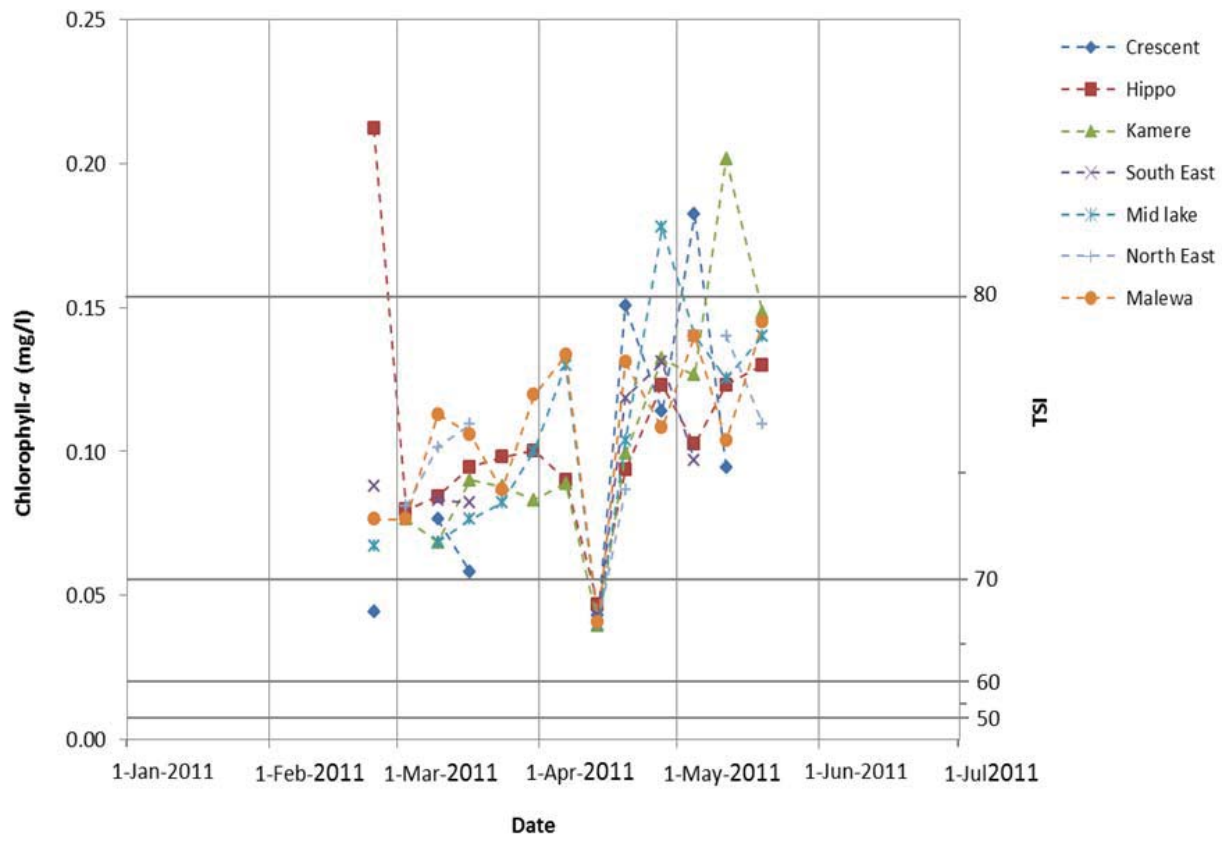

Figure 3.5 Time series plot of chlorophyll-a concentration and the corresponding TSICHL from February to May 2011 in Lake Naivasha.

\subsubsection{Deviations between trophic state indices}

Figure 3.6 provides a plot of the deviations between TSICHL and TSI-SD versus TSI-CHL and TSI-TP derived from chlorophyll-a, Secchi depth and total phosphorus data collected from February to May 2011. The Crescent Lake deviations of TSI-CHL from TSI-SD indicated positive values, denoting the presence of more chlorophyll-a than expected on the basis of the Secchi depth values. The Mouth of Malewa sampling site values were mainly negative, indicating less chlorophyll-a than indicated by Secchi depth measurements. All other sampling sites exhibited both negative and positive deviations of TSI-SD from TSI-CHL values. 


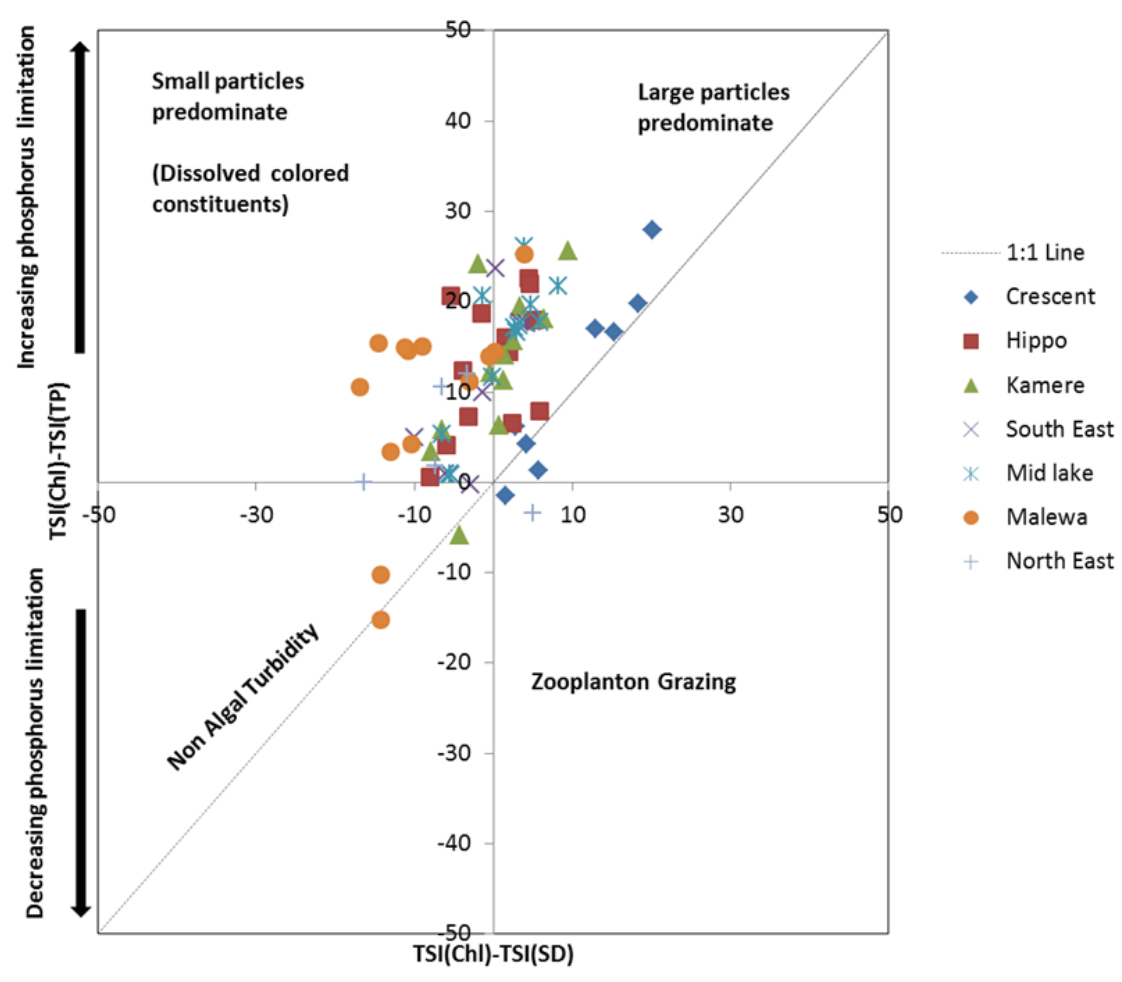

Figure 3.6 A plot of the deviation of TSI-CHL from TSI-SD versus the deviation of TSI$\mathrm{CHL}$ from TSI-TP ( $\mathrm{Y}$-axis denotes phosphorus limitation while $\mathrm{X}$-axis denotes the influence of chlorophyll-a on the turbidity).

The higher the positive values of the deviation between TSI-CHL and TSI-TP, the higher the phosphorus limitation on phytoplankton growth. The deviations of TSI-CHL from TSI-TP were predominantly positive. This represented more chlorophyll-a than indicated by TP concentrations, although there were a few negative values corresponding to peak phosphorus concentrations (Figure 3.2). The peak events fell in, or close to, the lower left corner (Figure 3.6), an indication of the chlorophyll-a concentration being lower than predicted by the TP and Secchi depth. Deviations of TSI-CHL from TSI-TP and TSI-SD that lie at, or near, the 1:1 linear line represent non-algal turbidity. The Mouth of Malewa, Crescent Lake, Kamere Beach and south-east sampling sites exhibited instances where the deviations fell on the 1:1 line, especially during the TP concentration peaks. Few points fell on the positive side of the $\mathrm{X}$-axis, and negative side of the $\mathrm{Y}$-axis, representing a situation wherein the chlorophyll-a concentration was higher than predicted from the Secchi depth, but lower than predicted from TP concentration. 


\subsubsection{Discriminant analysis}

The discriminant analysis (DA) resulted in four discriminant functions. The discriminant functions accounted for $96.6 \%, 1.9 \%, 1.4 \%$ and $0.1 \%$ of the variance between sampling sites, respectively. Discriminant function 1 and 2 had Wilks' lambda of 0.096 and 0.788 , respectively. The Wilks' lambda of discriminant function 1 was significant $(P<0.001)$, while that of discriminant function 2 was not significant $(P>0.05)$. Discriminant function 3 and 4 had non-significant Wilks' lambda $(P>0.05)$.

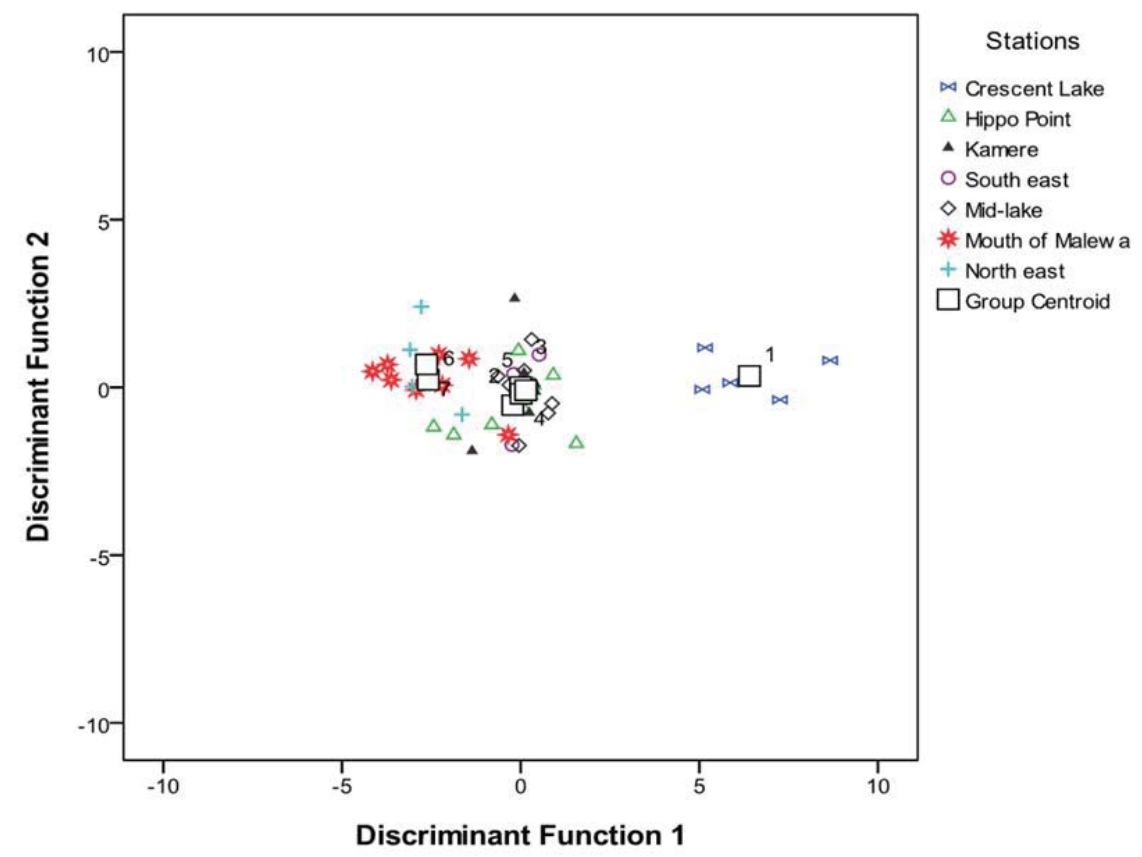

Figure 3.7 A plot of the discriminant functions showing the different spatial clusters derived from all the studied sites in Lake Naivasha

Discriminant analysis (DA) of the three clusters resulted in two discriminant functions (Figure 3.7). Discriminant function 1 had a significant Wilks' lambda $(\mathrm{P}<0.001)$, accounting for $98.7 \%$ variance between the clusters. Discriminant function 2 had non-significant Wilks' lambda ( $P>0.05$ ), accounting only for $1.3 \%$ of the total variance. The corresponding classification matrix of the discriminant analysis assigned $93.6 \%$ of the grouped sites in categories of similar characteristics. The northern sampling sites (Mouth of Malewa; north-east) formed one category. The second category included Hippo Point, mid-lake, Kamere, south-east sampling sites, all lying more towards the southern side of the lake, while the third category was distinctively constituted by Crescent Lake. 


\subsection{Discussion}

The present study examines the trophic state of the different sections of Lake Naivasha. Whereas several classification criteria for the trophic state exist (Galvez-Cloutier and Sanchez, 2007), this study utilized the Carlson (1977) TSI approach, which is based on the assumption that there is a close relationship between total phosphorus, chlorophyll-a and Secchi depth in phosphorus-limited lakes (Matthews et al., 2002). Total nitrogen is also sometimes used as an additional trophic state variable (Carlson and Havens, 2005; Carlson and Simpson, 1996; Kratzer and Brezonik, 1981). Although the TSI was developed for temperate lakes, the relationships appear not to be unique to these lakes (Mazumder and Havens, 1998), apparently being applicable for both temperate and tropical aquatic systems (Brezonik and Shannon, 1971; Kitaka et al., 2002; Lidia and Kobos, 2011; Matthews et al., 2002).

\subsubsection{Total Phosphorus}

The TSI-TP results suggested the Mouth of Malewa and north-east regions exhibit a higher trophic state, possibly due to exogenous influences such as the phosphorus influx. The exogenous effect is emphasized by the early phosphorus peak at the Mouth of Malewa sampling site, compared with the peaks for the other sites, which implies the increased phosphorus level emanated from the Malewa River inflow, being further distributed into the lake. Similar observations were recorded by Kitaka et al. (2002) between 1997 and 1998 for Lake Naivasha. Other external phosphorus loading sources, such as urban and lake fringe run-off, were affirmed by higher phosphorus levels (during off peak) at the north-east sampling site, which is located close to the Naivasha municipality treatment plant and the Kihoto informal settlement. Other studies have found a link between urban developments and the ecosystem health of Lake Naivasha (Becht et al., 2005). Although no phosphorus loading data were collected during the present study, the phosphorus concentration information provided substantial inference on the phosphorus loading sources. The results of the present study provide a good basis for further investigation of the current loading magnitude of both nutrients and sediments from the inferred loading sources.

Endogenous phosphorus loading emanating from internal processes, and mechanisms such as resuspension due to waves or fish, also can contribute to loading in lakes (Riley and Prepas, 1984; Søndergaard et al., 1992). The phosphorus concentrations in Lake Naivasha shifted back to an almost steady concentration of about $50 \mu \mathrm{g} \mathrm{L}^{-1}$ after the two peaks at all the sampling sites, implying limited endogenous phosphorus loading in the lake. Depending on the stable state in lake ecosystems, processes and mechanisms exist that maintain the system at its equilibrium (Scheffer, 1990), which could be 
responsible for the shift back to the steady concentration observed in Lake Naivasha. However, the TSI-TP declined towards the end of the year, following an increase in rainfall, discharge and subsequent water levels in Lake Naivasha probably due to a dilution effect. A similar dilution effect has been observed in other lakes, such as Lake Taihu in China (Chen et al., 2003).

\subsubsection{Secchi depth}

Verschuren (1999) attributed sedimentation to catchment run-off in lake Naivasha. This observation was affirmed by the present study because the TSI-SD was generally larger than the TSI-CHL at the Mouth of Malewa sampling site, indicating turbidity is dominated by constituents other than algae, likely attributable to the influence of the Malewa River discharge containing sediments emanating from catchment run-off. Other possible causes of the TSI-SD exceeding the TSI-CHL include a turbid effluent discharge from the municipal wastewater treatment plant, and the small-scale farming activities in the riparian zone near the Kihoto informal settlement around the northeast site. Crescent Lake exhibited a high Secchi depth, compared with the main lake, because of a limited connection of Crescent Lake to the main lake, especially during period with low lake water levels that may prevent suspended materials from reaching Crescent Lake. Other studies have indicated differences in Crescent Lake physio-chemical characteristics, compared with the main lake (Hubble and Harper, 2000). Shorter fetch lengths and larger depths may also enhance the settlement of suspended material, and limit resuspension (Carter, 1993; Håkanson, 1977; Pharo and Carmack, 1979), which may have resulted in less turbidity at the Crescent Lake sampling site, compared with the main lake.

\subsubsection{Chlorophyll-a}

There was a general increase in chlorophyll-a concentration from January towards May, as the lake water level decreased. This is not unique, because other studies also noted an inverse relationship between chlorophyll-a concentration and water levels (Wang et al., 2012). Lake Naivasha is situated close to the equator. Thus, the hours of daylight, as well as the temperatures, exhibit very little variability throughout the year. The percentage change in monthly solar radiation during the chlorophyll-a concentration data collection period (January to May 2011) was found to be only about $1 \%$. The water temperatures data collected from March to May 2011 also exhibited very little variability (average $23.3^{\circ} \mathrm{C}$, standard deviation = $\pm 2.1{ }^{\circ} \mathrm{C}$ ) and, therefore, could not be responsible for the change in the chlorophyll-a concentration. The concentration change from February to May can be attributed to several factors. February is usually planting season in the Lake Naivasha catchment area, and nutrients are washed into the lake 
with the first rainfall (see Fig. 2). At the same time, the rainfall period leads to clearer water, thereby promoting light penetration into the water column of the lake. The decreased lake level, however, may cause a concentration effect for the present algae. These three aspects can lead to increased chlorophyll-a concentrations from February to May. An inverse relationship between lake water level and chlorophyll-a concentration also was observed for the long-term chlorophyll-a data retrieved from MODIS-Aqua (Ndungu et al., 2013a).

In reference to Kitaka et al. (2002), the trophic state of Lake Naivasha has deteriorated from 1997-1998 to the present study. The average TSI-TP and TSI-CHL values of just below 60 (eutrophic) increased to 65 and 76, respectively, while the TSI-SD value increased from 66 to 82 . Although other studies (Ballot et al., 2009; Kalff, 1983) did not provide specific details regarding the time or location of sample collections, the TP values compared favourably. These changes are probably attributable to the ever-increasing multiple stressors, such as increased agricultural activities, urbanization and climate change (Becht et al., 2005; Harper et al., 2011a). Other studies have stipulated the trophic state is influenced by forcing factors such as eutrophication and sediment loads'. The effects of the forcing factors also can be modified by other accompanying factors such as season, agricultural activities in the catchments, algal grazing and mixing depth which, in turn, can play a role in the prevailing water transparency status (Matias and Boavida, 2005).

In an ideal situation, the TSI-TP, TSI-SD and TSI-CHL values are meant to be equal. In reality, however, they differ(Carlson, 1977). The differences in the indices are basically attributable to the characteristics of the water system, which can exhibit different turbidity constituents. The deviation of the TSI-SD from TSI-CHL indicates the influence of chlorophyll-a on the turbidity of the water system, while the deviation of the TSI-TP from TSI-CHL denotes the level of phosphorus limitation (Carlson and Simpson, 1996). Comparison of the graphical representation illustrated by Carlson and Simpson (1996) reveals the turbidity in Crescent Lake can be explained by the presence of large flakes of algae. This was manifested by higher chlorophyll-a concentrations than those predicted by the Secchi depth, which can occur when chlorophyll is packaged in large filamentous or colonial algae that attenuate less light than an equal biomass of smaller algal particles (Carlson and Havens, 2005; Edmondson, 1980). In addition, Crescent Lake is less turbid, therefore exhibiting more photosynthetic light, compared with the main lake. This situation favours the growth of the algal species into large filamentous or colonial structures. 
The presence of small particles of suspended sediment and dissolved coloured matter lead to a situation where the TSI-SD over-predicts the TSICHL (Havens et al., 2000), which was mainly observed in the sampling sites in Lake Naivasha close to the input locations (Mouth of Malewa; north-east), which contain relatively more dissolved and suspended solids (Fig. 6). The Mouth of Malewa sampling site was largely influenced by the discharge of the River Malewa, which contains suspended clay particles, as well as dissolved coloured matter emanating from the catchment run-off and river channel erosion, thereby causing the TSI-SD to over-predict the TSI-CHL. However, the north-east sampling site is influenced by urban run-off, the municipal wastewater treatment plant effluents and small-scale farming activities in the riparian zone near the Kihoto informal settlements, which may be constituted by the relatively high dissolved and suspended solids concentrations.

Deviations of the TSI-CHL from the TSI-TP emphasized phosphorus limitation on phytoplankton biomass, as expected for tropical freshwater ecosystems (Kalff, 1983). The positive values observed for almost all the sampling sites signify the lake is phosphorus limited in regard to algal biomass. However, instances of negative values occurred coincident with storm events, wherein the phosphorus concentration was high because of catchment and urban runoff or internal mixing. Phosphorus is generally considered limiting when the nitrogen-to-phosphorus ratio is larger than 10 (Smith, 1984). The calculated TN/TP ratio of the collected samples revealed that $87 \%$ of the 139 samples had a ratio of $>10$, suggesting phosphorus is indeed the limiting nutrient in Lake Naiva sha. The samples with relatively high TP concentrations had TN/TP ratios lower than 10 , indicating TP may not be limiting during the storm events. Deviations of the TSI-SD and the TSI-TP from the TSI-CHL that lie at, or near, the 1:1 linear line passing through the origin denotes nonalgal turbidity. This can occur in a situation where the phosphorus concentration is linearly correlated with the Secchi depth, and when phosphorus is bound in sediments or other non-algal matter (Carlson and Havens, 2005). This situation occurs periodically at the Mouth of Malewa, Kamere and north-east sampling sites. Crescent Lake also falls on the 1:1 line, signifying phosphorus is not only bound in the large filamentous or colonial algae, but also in non-algal matter such as sediments and detritus. Coincidentally, the Crescent Lake and north-east sampling sites also appear to exhibit zooplankton grazing of phytoplankton. Other studies have confirmed the existence of zooplankton grazing in Lake Naivasha (Hubble and Harper, 2000; Mergeay, 2004).

Discriminant analysis of the trophic state variables suggested that there were three distinct regions in Lake Naivasha: the northern part of the lake, the mid and southern region, and the more or less isolated Crescent Lake which is less affected by the exogenous input into the lake. These regions are in line 
with earlier studies that found spatial differences between Mouth of Malewa site which is influenced by the input rivers, Crescent Lake due to partial hydrological separation and the main lake which is relatively well mixed (Hubble and Harper, 2001b).

\subsection{Conclusions}

The present study evaluated the spatio-temporal variability of three trophic state variables (total phosphorus, chlorophyll-a and Secchi depth) in Lake Naivasha in year 2011. The results indicate Lake Naivasha exhibits a trophic condition between eutrophic and hypereutrophic. The total phosphorus concentration often portrayed the lake as eutrophic, with concentrations ranging between 0.05 and $0.1 \mathrm{mg} \mathrm{L-1}$, corresponding to a TSI range of 6070 , but shifting to a hypereutrophic condition during the two peak periods corresponding to heavy rainfall events at the beginning of the rainy seasons that flushed the nutrients from the top soil into the river and towards Lake Naivasha. The chlorophyll-a and Secchi depth indicated a hypereutrophic state, with TSI values $>70$ at all the studied sites. The exception was Crescent Lake which exhibited a higher Secchi depth, resulting in a lower TSI (60-70), thereby being classified as eutrophic. The high chlorophyll-a concentration could be a result of nutrient availability and improved light penetration into the lake. The trophic state of Lake Naivasha generally decreases from the northern part towards the south, an indication of exogenous eutrophication emanating from nutrients from the catchment reaching the lake through the rivers.

Graphical representation of the deviation of the TSICHL and TSI-TP indicates the lake is predominantly phosphorus-limited (TSI-CHL > TSI-TP). Further scrutiny reveals that the turbidity constituents close to the Mouth of Malewa (river input), north-east (near the municipal water treatment plant effluent discharge point and Kihoto informal settlement) and Kamere Beach (near Kamere informal settlement) are dominated mainly by sediments or other organic matter, rather than chlorophyll-a (TSICHL < TSI-SD). The TSI-CHL appeared to exceed the TSI-SD (TSI-CHL > TSI-SD) in Crescent Lake, indicating the presence of algae species with a more filamentous or colonial structure than exhibited in the rest of the lake. Discriminant analysis resulted into three distinct regions, namely the northern part of the lake, the mid and southern region, and Crescent Lake, the latter being more or less isolated from the main body of the lake during low water levels. Compared with the results of previous water quality studies, the present study suggests Lake Naivasha has become more eutrophic, indicating a progressive deterioration of its quality. These findings provide good rationale for further investigation of the loading magnitude of both nutrients and sediments, to facilitate the restoration of the lake's community integrity and ecosystem functions. 


\section{Chapter 4}

\section{Evaluation of Spatio-temporal Variations of Chlorophyll-a in Lake Naivasha, Kenya: Remote sensing approach ${ }^{3}$}

\footnotetext{
${ }^{3}$ This chapter is based on: Ndungu, J.N., Monger, B.C., Augustijn, D.C.M., Hulscher, S.J.M.H., Kitaka, N. \& Mathooko, J.M. (2013). Evaluation of spatio-temporal variations in chlorophyll-a in Lake Naivasha, Kenya: remote-sensing approach. International journal of remote sensing, 34(22), 8142-8155.
} 


\begin{abstract}
Restoration of the ecosystem services and functions of lakes requires an understanding of the turbidity dynamics in order to arrive at informed environmental management decisions. The understanding of the spatiotemporal dynamics of turbidity requires frequent monitoring of the turbidity components such as chlorophyll-a concentration. In this study, we explored the use of Moderate Resolution Imaging Spectroradiometer Aqua (MODISAqua) satellite data in studying the spatio-temporal changes in chlorophyll-a concentration in Lake Naivasha, a turbid tropical system. The temporal trend of chlorophyll-a concentration over the study period in the lake was also evaluated. The temporal trend assessment was achieved through the removal of periodic seasonal interference using Seasonal-Trend decomposition based on the LOESS (Local Regression) procedure. The resultant chlorophyll-a concentration maps derived from MODIS-Aqua satellite data give an indication of the monthly spatial variation in chlorophyll-a concentration from 2002 to 2012. The results of regression analyses between satellite-derived chlorophyll-a and in situ measurements reveal a high level of precision, but with a measureable bias with the satellite underestimating actual in situ measurements $\left(R^{2}=0.65, P<0.001\right)$. Although the actual values of the chlorophyll-a concentrations are underestimated, the significant relationship between satellite-derived chlorophyll-a and in situ measurements provides reliable information for studying spatial variations and temporal trends. In 2009 and 2010, it was difficult to detect chlorophyll-a from the MODIS-Aqua imagery, and this coincided with a period of the lowest water levels in Lake Naivasha. An inverse relationship between de-seasoned water level and chlorophyll-a concentration was evident. This study shows that MODIS-Aqua satellite data provide useful information on the spatio-temporal variations in Lake Naivasha, which is useful in establishing general trends that are more difficult to determine through routine ground measurements.
\end{abstract}




\subsection{Introduction}

An increase in chlorophyll-a concentration indicates eutrophication in lakes, which is associated with low biodiversity and hence deprives the aquatic environment of sufficient ecosystem services. Chlorophyll-a is considered one of the main components that contribute to turbidity in aquatic ecosystems. Turbidity is one of the variables that define the water quality of aquatic ecosystems (Lloyd, 1987), and hence dictates the fate of the entire biodiversity, which includes fisheries, mammals, and birds. Increase in turbidity can result in a shift from a clear to turbid state, which adversely destabilizes the ecosystem services and functions (Scheffer, 1998). Turbidity is therefore detrimental to the local community livelihood that is largely dependent on income from the sale of fish and tourism-related revenue. Therefore, restoration of the ecosystem services and functions requires an understanding of the turbidity dynamics in order to arrive at informed management decisions. The understanding of the spatio-temporal dynamics of turbidity requires frequent monitoring of the turbidity characteristics such as chlorophyll-a concentration. However, it is difficult to acquire such data through routine ground measurements because of the high cost and time involved. Remote-sensing technology has the potential to present synoptic estimates of chlorophyll-a in turbid lakes.

A great deal of prior research has been done on remotely sensed retrieval of chlorophyll-a from satellite images in marine systems using the Sea-viewing Wide Field of view Sensor (SeaWiFS) (O'Reilly et al., 1998), Landsat TM (Ekstrand, 1992), Medium Resolution Imaging Spectrometer (MERIS) (Gordoa et al., 2008), and Moderate Resolution Imaging Spectroradiometer (MODIS) (Binding et al., 2012; Dall'Olmo et al., 2005; Gitelson et al., 2009). During the period of this study, Landsat 5 satellite data acquisition failed after having been in operation since 1972. Moreover, Landsat 7 has had a Scan Line Corrector (SLC) failure since 2003. In April 2012, the MERIS satellite also failed. These occurrences necessitate the exploration of operational satellites such as MODIS. Consequently, more research needs to be done to improve the accuracy of the actual values and maybe this could form the basis for the next phase in this work.

Lake Naivasha is a turbid tropical freshwater lake in the Kenyan rift valley where a shift from a clear to a turbid state has been observed over the past decade. In the 1930s, the lake was described as clear (Beadle, 1932) but currently it is turbid (Grey and Jackson, 2012; Harper, 2002; Ndungu et al., 2013a). Despite the increase in turbidity in the lake and sporadic studies by several researchers, there is still limited data collection because of the time involved and high cost of in situ field data acquisition coupled with limited availability of funds. 
In this study, we explore the use of MODIS-Aqua data in the retrieval of chlorophyll-a as a measure of the phytoplankton biomass in Lake Naivasha. This is because the imagery is readily available free of charge and has daily temporal resolution allowing frequent monitoring of water quality. This is useful especially for water quality studies in developing countries like Kenya, where continuous data collection is a challenge due to limited research and monitoring funds. Furthermore, successful retrieval of satellite data is fundamental because it allows retrospective analysis of the chlorophyll-a in aquatic systems and therefore provides data at times when ground measurements do not exist. The spatiotemporal dynamics of turbidity in Lake Naivasha were evaluated based on chlorophyll-a concentration retrieved from MODIS-Aqua $500 \mathrm{~m}$ resolution images from July 2002 to June 2012 using the Chlorophyll 2 (OC2) pigment algorithm. The OC2 pigment algorithm is a welldocumented standard algorithm in general use by the ocean colour community for chlorophyll-a retrieval in lakes (Chavula et al., 2009; Wang et al., 2011). It is implemented in the current SeaDAS processing software (developed by the National Aeronautics and Space Administration (NASA), Ocean Biology Processing Group in Goddard Space Flight Center, Greenbelt, MD, USA) and uses the two $500 \mathrm{~m}$ high-spatial resolution bands that were traditionally intended for land remote sensing.

The specific objectives of the study included: (1) estimation of chlorophyll-a concentration in Lake Naivasha using MODIS-Aqua satellite data; (2) assessment of monthly spatial variations in chlorophyll-a concentration in Lake Naivasha; (3) assessment of the temporal trend of chlorophyll-a concentration in Lake Naivasha using time series plot and STL (SeasonalTrend decomposition based on the LOESS (Local Regression)) procedure; and (4) exploration of possible causes of the spatio-temporal variations. The STL procedure has previously been applied in remotely sensed normalized difference vegetation index (NDVI) (Verbesselt et al., 2010) and leaf area index (LAI) time series studies (Jiang et al., 2010), but has not been applied in remotely sensed water quality data before this study.

\subsection{Study area}

Lake Naivasha lies at latitude $00^{\circ} 46^{\prime} \mathrm{S}$ and longitude $36^{\circ} 22^{\prime}$ E (Figure 4.1). It is an endorheic freshwater lake situated on the floor of the Eastern Rift Valley in Kenya at $1885 \mathrm{~m}$ above sea level. The annual surface water inflow into the lake is estimated to be $217 \times 10^{6} \mathrm{~m}^{3}$ (Becht and Harper, 2002). The main discharge into the lake is from rivers Malewa ( $80 \%$ of the discharge) and Gilgil (10\%) at the northern region of the lake, with catchment areas of $1700 \mathrm{~km}^{2}$ and $400 \mathrm{~km}^{2}$, respectively. The remainder of the discharge $(\sim 10 \%)$ comes from other minor rivers around the lake such as Karati. The entire lake's catchment area is $3416 \mathrm{~km}^{2}$ (Ndungu et al., 2012). The mean 
temperature around Lake Naivasha is approximately $25^{\circ} \mathrm{C}$. The area receives bimodal annual rainfall in March/April/May and October/November. The average rainfall around the lake is approximately $650 \mathrm{~mm}$ per year (Vincent et al., 1979) but is much higher in the upper catchment. A substantial area of the lake basin is currently under large-scale production of horticultural products for export markets. The agricultural production depends heavily on irrigation from the lake, the rivers and groundwater (boreholes). To sustain these intensive agricultural activities, farmers use large amounts of fertilizers and pesticides.

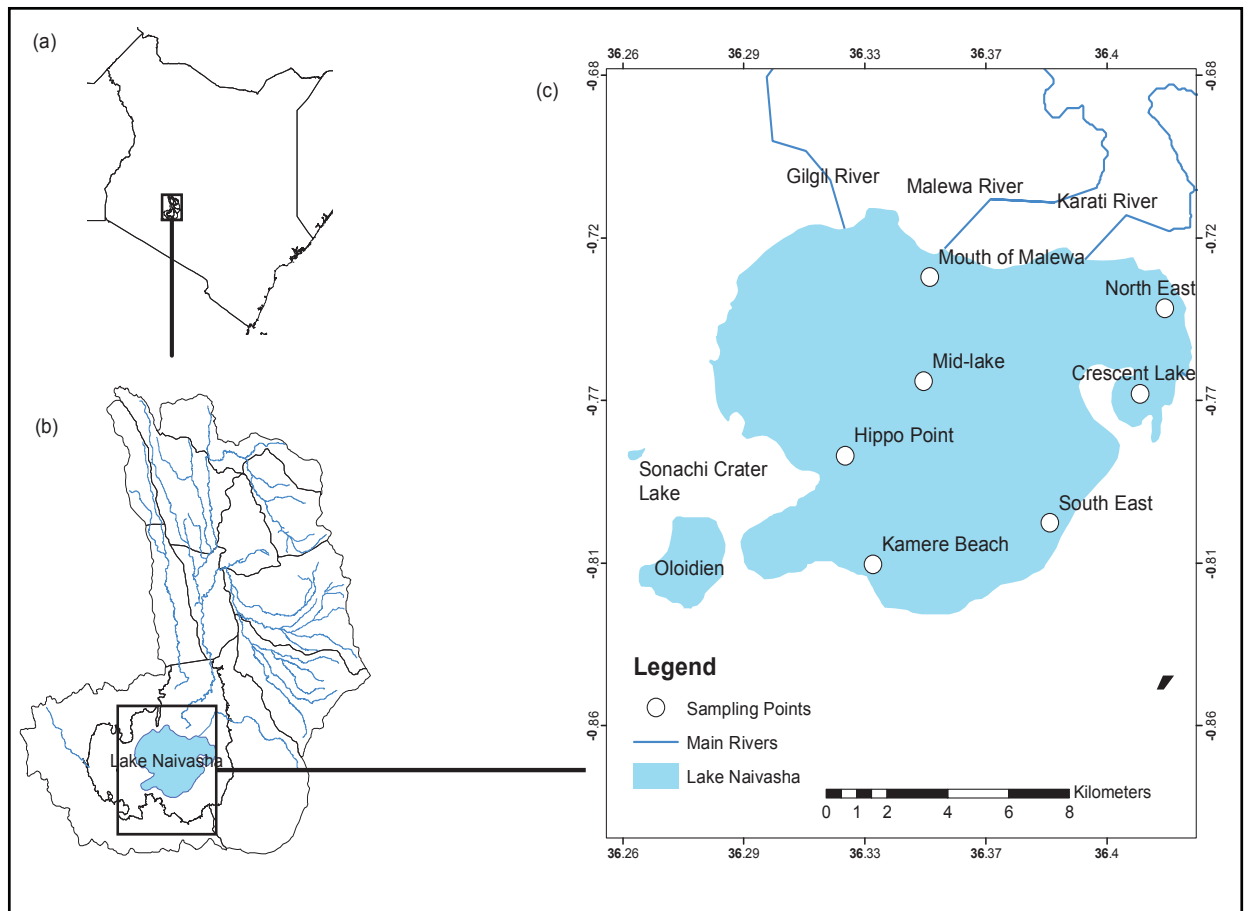

Figure 4.1 Study area of Lake Naivasha catchment in Kenya (a), the extent of the catchment together with the major rivers that drain into the Lake (b), and the lake area including sampling sites (c).

\subsection{Material and methods}

\subsubsection{Field data collection and analysis}

The chlorophyll-a field data used in this study were part of a larger field survey on water quality in Lake Naivasha from January to November 2011 (Ndungu et al., 2012). Chlorophyll-a concentrations were only analyzed between February and May 2011 from surface water samples collected at 0$0.5 \mathrm{~m}$ depth from the seven sampling sites shown in Figure 1c. The water samples were transported to the laboratory in a cooler box immediately after collection. $100 \mathrm{ml}$ of the samples was filtered using an electric filtration unit 
through prewashed Whatman GF/F $0.47 \mu \mathrm{m}$ diameter filters and extracted overnight using $10 \mathrm{ml}$ of $90 \%$ acetone. Chlorophyll-a absorption was then determined using Thermo Scientific GENESYSTM $10 \mathrm{~S}$ Bio UV/Visible Spectrophotometer by measuring the absorbencies at 663 and 750 nanometers wavelength after standardizing using acetone. The formulae by Talling \& Driver (1961) were used to calculate the Chlorophyll-a concentration.

\subsubsection{MODIS data processing}

MODIS radiance images (Level-1A) were downloaded from the National Aeronautics and Space Administration (NASA) Goddard Space Flight Center website (http://oceancolor.gsfc.nasa.gov/cgi/browse.pl?sen=am).

Data processing from Level-1A to reflectance images (Level-2) and chlorophyll-a concentration maps (Level-3) were done using SeaDAS 6.3 software (Fu et al., 1998). To improve estimates for chlorophyll-a concentration, the threshold value for high cloud albedo quality control flagging was set to 0.054 . This was done because in turbid lakes, the cloud albedo threshold is much higher than the default SeaDAS software value of 0.024 . The clouds were then masked in accordance to the Top of Atmosphere (TOA) reflectance at $859 \mathrm{~nm}$ band (Chen et al., 2007). Atmospheric correction was done using the short wave infrared bands (SWIR) ocean color procedure (Shi and Wang, 2009; Son and Wang, 2012; Wang et al., 2011) which is embedded in the SeaDAS 6.3 software. Proc_land routine was also applied to ensure that the processing was extended to land. The Chlorophyll 2 algorithm (OC2) was used to derive $500 \mathrm{~m}$ resolution chlorophyll-a maps. This process was automated using the Interactive Data Language (IDL) scripts. The processing steps are summarized in Figure 4.2. 


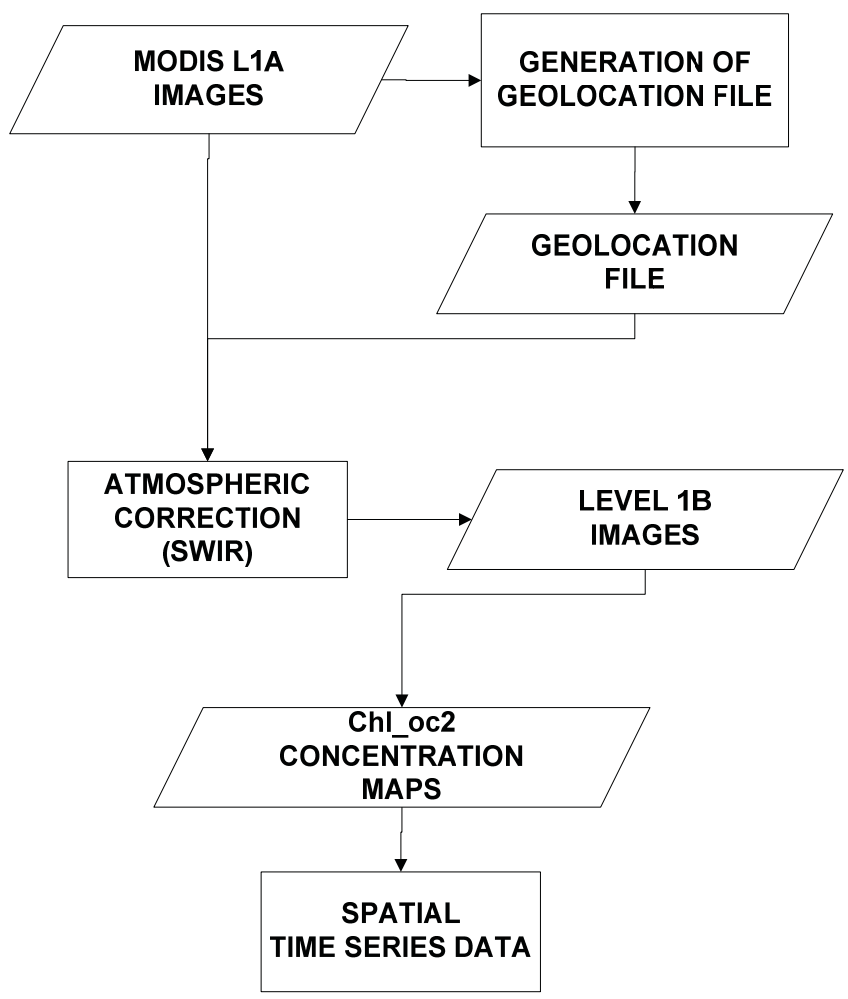

Figure 4.2 Flow diagram of the procedure to obtain chlorophyll-a concentrations maps.

\subsubsection{Data analysis}

After the processing of daily chlorophyll-a concentration maps, composite averaging was done to acquire monthly images from July 2002 to June 2012. This was done to improve the spatial coverage which includes gaps as a result of cloud cover and/or macrophytes. To assess the temporal changes in chlorophyll-a concentration over the years, a lake-wide spatial average was computed for each of the monthly-composite images. The 2002 and 2012 data was omitted in this computation because the data were partial and did not cover the whole year. The data were then plotted in a time series plot and due to gaps noted from May 2009 to August 2010; trend assessment was only done for the period between July 2002 and May 2009. Decomposition of the time series into seasonal, trend and residual components was done using STL procedure in $\mathrm{R}$ software ( $\mathrm{R}$ Development Core Team, 2008). The details of the procedure are stipulated in Cleveland (1990). The seasonal component was calculated for aperiodic seasonal window of 12 months. This method has the capability of smoothing out the 
seasonal effect which results in a more visible long-term time series trend of chlorophyll-a concentration. This basic analysis approach was similarly applied to monthly lake level data.

\subsubsection{Validation}

For validation purposes, in situ chlorophyll-a data from seven field sampling sites (Figure 4.1) were assessed for suitability as match-up dataset. Unfortunately, the in situ data did not match with the exact date and location in the MODIS data. Therefore, accuracy assessment between the in situ and retrieved chlorophyll-a was done within a weekly time span. If a direct match was found, the value was picked for validation purposes. If not, the search was extended gradually to a maximum of $5 \times 5$ pixels range. Regression analysis showed a significant variation in the concentrations of chlorophyll-a $\left(R^{2}=0.65, \quad P<0.001, N=25\right)$, however, the concentrations derived from MODIS systematically underestimated the field data. The $65 \%$ variation was considered sufficient for this study because it focuses on the overall spatiovariation and trend of the chlorophyll-a concentration and not absolute values. The MODIS data should, therefore, be interpreted as an index rather than actual chlorophyll-a concentration values.

\subsection{Results}

\subsubsection{Spatio-temporal variation in chlorophyll-a concentration}

Monthly climatological patterns of chlorophyll-a concentration in the lake, derived from composite average of respective monthly images between 2003 and 2011, are presented in Figure 4.3. In January, a major part of the lake showed medium chlorophyll-a concentrations (green color), except near the Mouth of Malewa River where low (blue color) concentrations were evident. In February the lower concentrations seemed to spread over a larger part of the lake whilst from March until July the chlorophyll-a concentrations were in the medium range. In August the concentrations in the south sector of the lake were lower than in the north, while in September the opposite occurred but with a much higher concentration (red colour) in the south. In October and November the concentrations seemed to diminish again with November showing the lowest concentrations among all months. In December the concentrations increased again. The black areas denoted pixels without data and occurred especially around the border of the lake, where the lake is too shallow or covered by macrophytes. This was not unusual since the pixels on the fringe (edge) of the lake are generally based on less data than the pixels in the center of the lake due to land adjacency effect and changes in lake levels. 

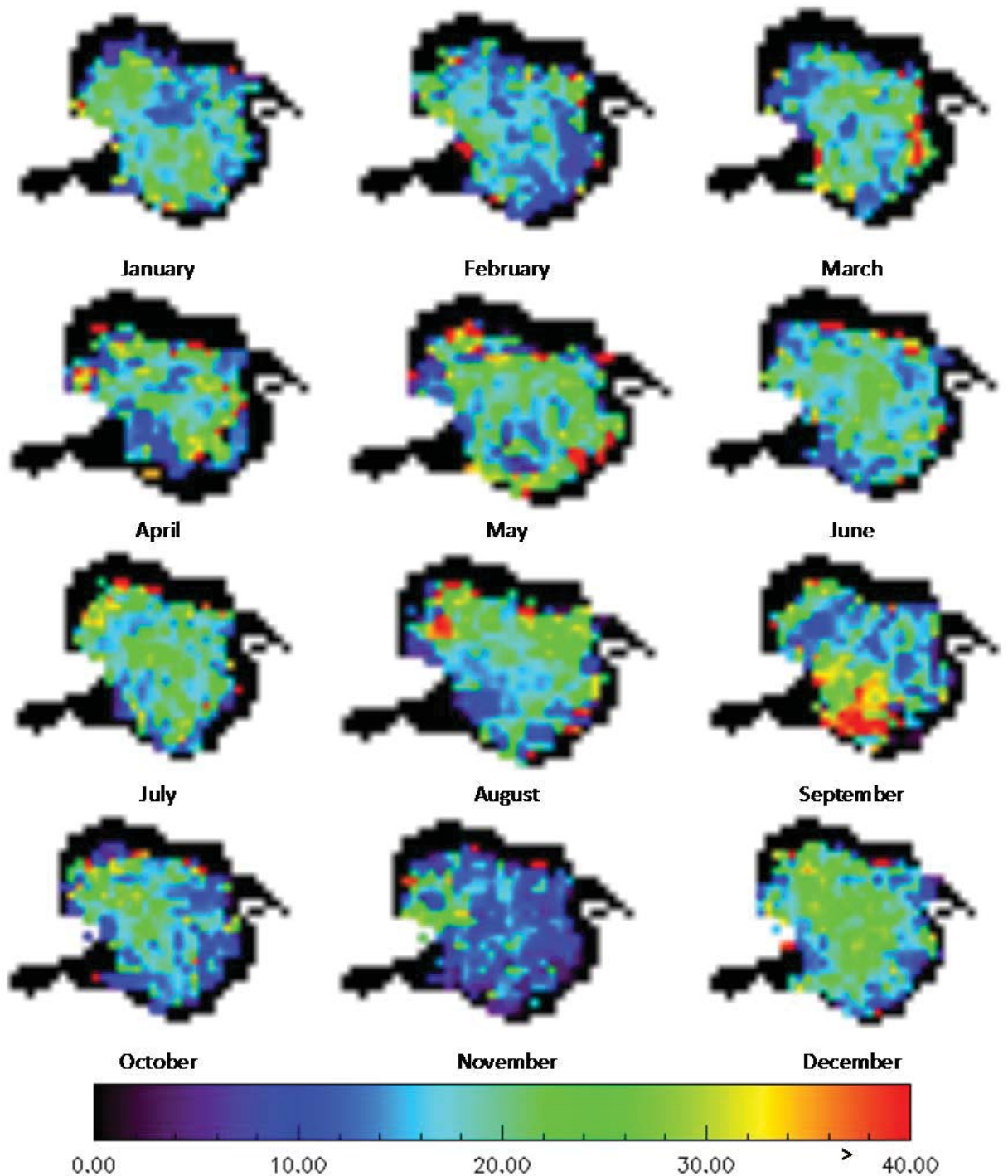

November

December

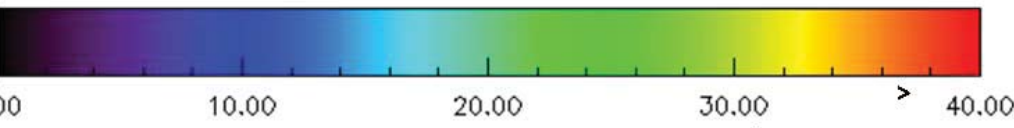

\section{Chorophyll-a concnetrations in $\mathbf{~ m g ~}^{-3}$}

Figure 4.3 Monthly average of chlorophyll-a concentration maps from 2003 to 2011

The time series of the spatially-averaged monthly chlorophyll-a concentration and lake levels are shown in Figure 4.4. After a decline in 2003, the chlorophyll-a concentration showed a general increase until the end of 2009. Throughout the study period, chlorophyll-a concentration were higher when lake levels were low and vice versa.

Between April 2009 and August 2010 the detection of chlorophyll-a concentration from the MODIS images was limited. This period coincided with the lowest lake water levels (1884 m.a.s.I) in the last century as a result of 
prolonged drought. In September 2010 the lake levels steadily increased and chlorophyll-a concentration became detectable again and exhibited an unpredictable and erratic behavior.

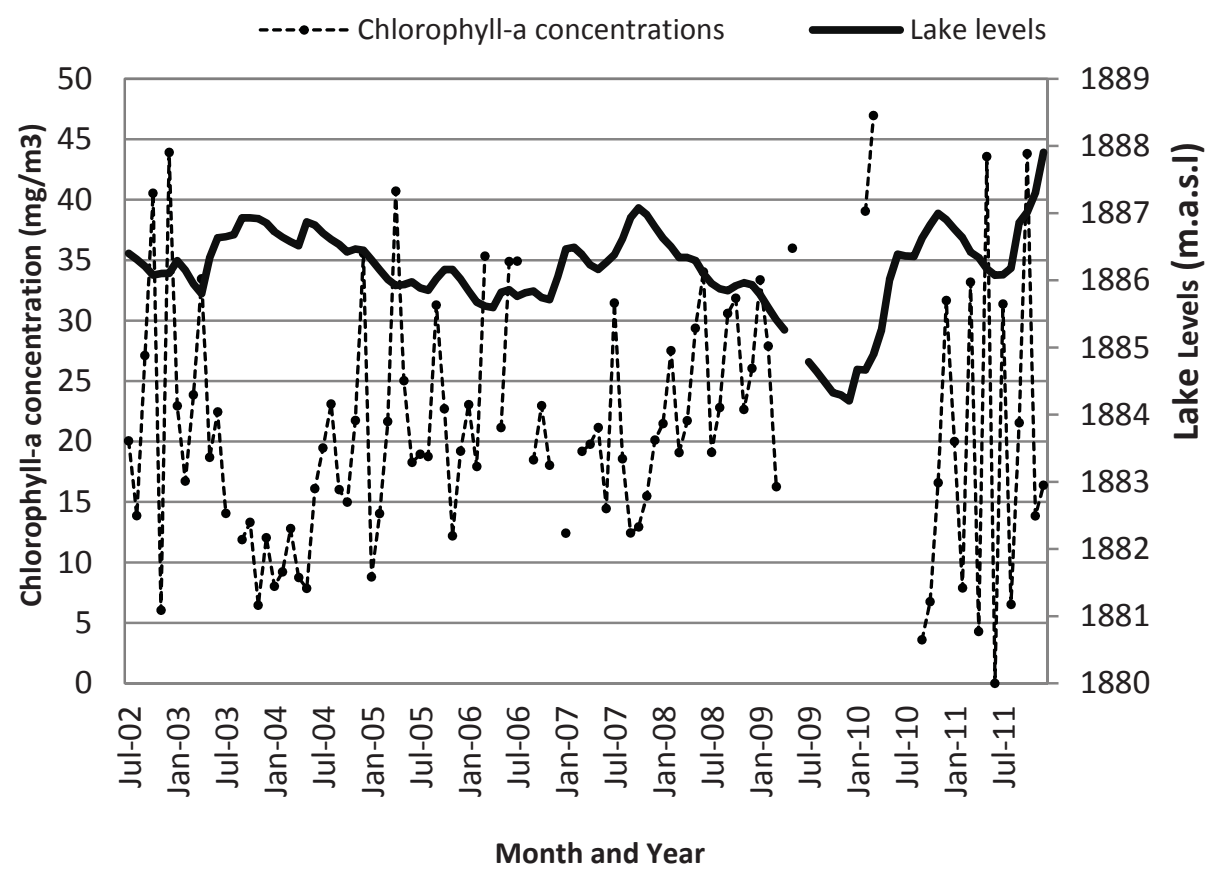

Figure 4.4 The time series of chlorophyll-a concentration based on MODIS data (dotted line) and lake water levels (line graph) in Lake Naivasha from July 2002 to May 2012.

The STL decomposition of the temporal trend of chlorophyll-a concentration is shown in Figure 4.5. The upper panel shows the time series of chlorophyll-a concentration from 2002 to 2009 (Figure 4.5). The decomposition of the data series into a seasonal and trend component is given in the second and the third panels of Figure 4.5 while the fourth panel shows the residuals. The grey bar on the right shows the data range for scale comparison. The seasonal component shows similarities with the monthly patterns (see Figure 4.3), with relatively low concentrations in February and November compared to the other months. The data exhibit a trend where a decline in chlorophyll-a concentration was observed from 2002 to 2003 followed by a general increase until 2009 with a slight decline in 2007. 


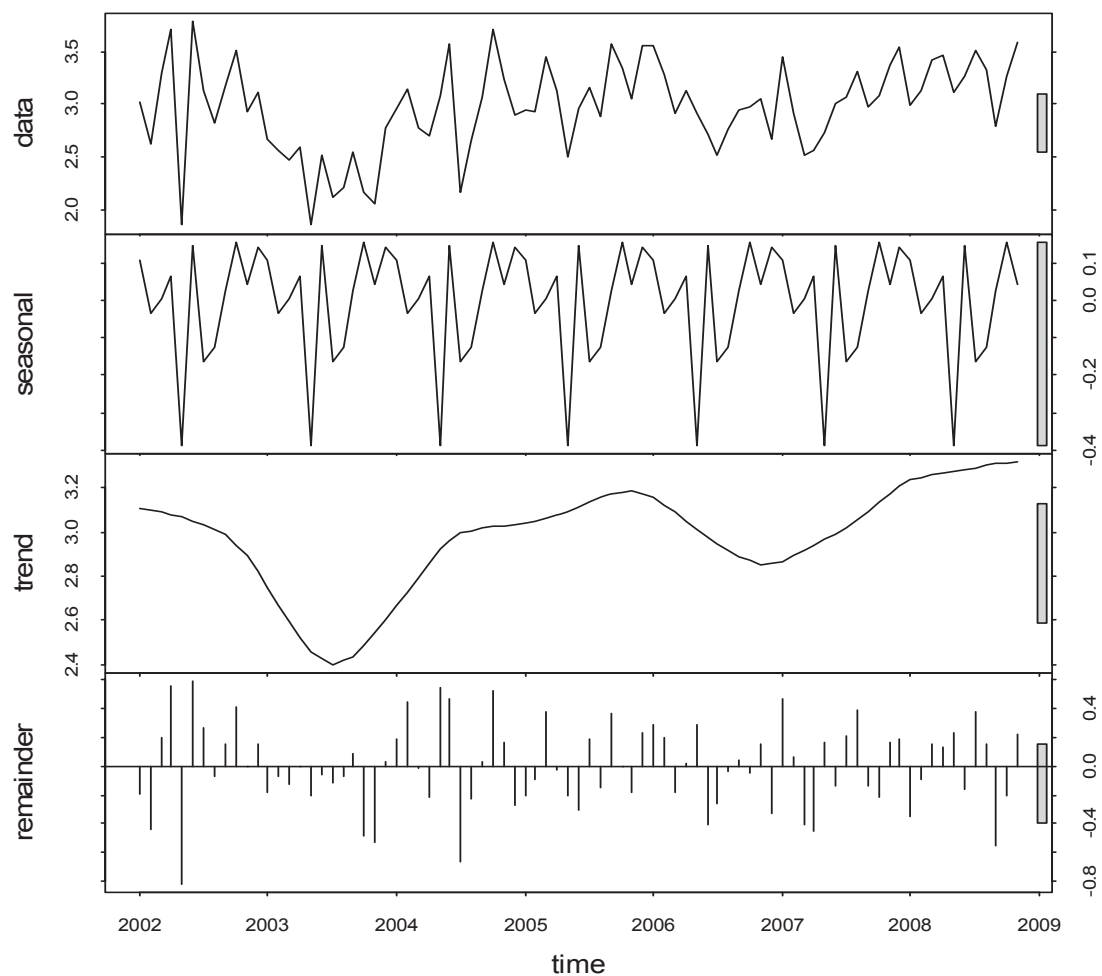

Figure 4.5 Decomposition of chlorophyll-a data into seasonal, trend and residual component

To investigate the apparent relationship between chlorophyll-a concentration and lake levels, STL decomposition was also applied to the time series of the lake level data over the same period. The resultant lake level trend is plotted together with the chlorophyll-a concentration trend in Figure 4.6, which shows an inverse relationship between chlorophyll-a and lake levels. 


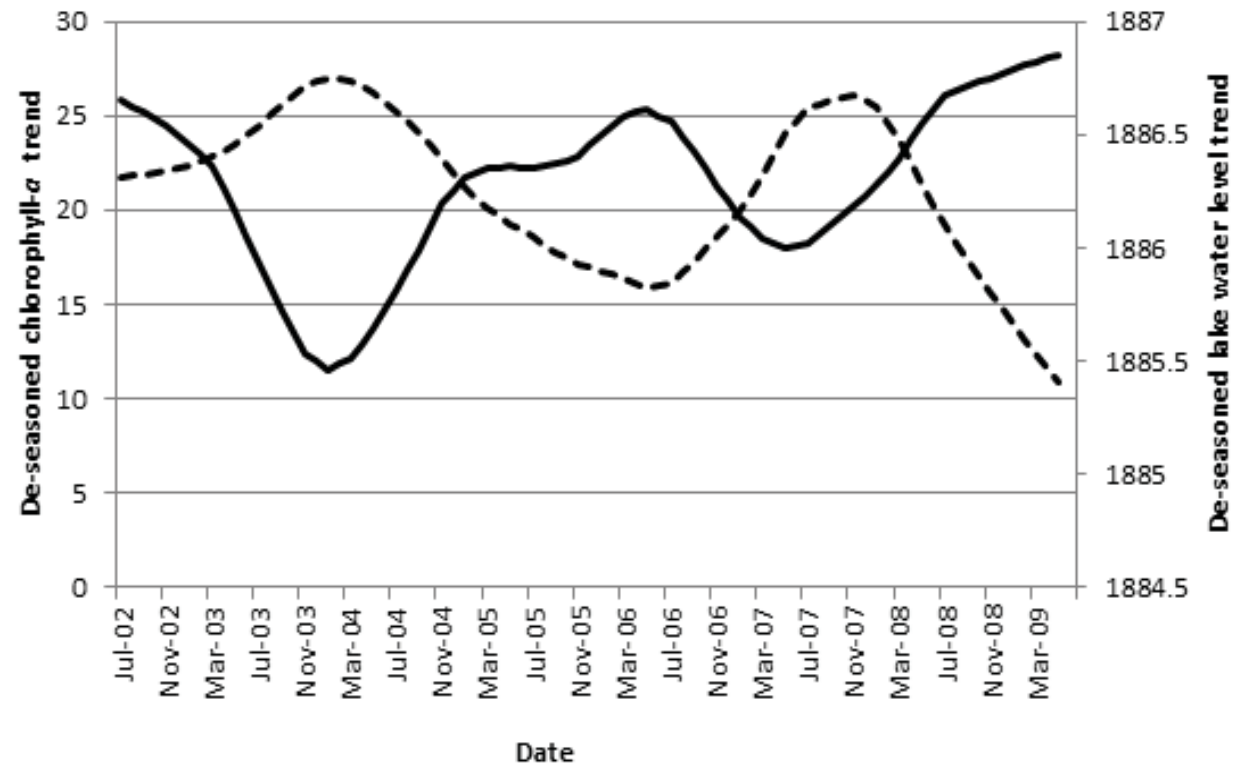

Figure 4.6 Comparison between the trends of de-seasoned chlorophyll-a (dashed line) concentration and de-seasoned lake water levels (solid line) from July 2002 to May 2009

\subsection{Discussion}

\subsubsection{MODIS data}

This study demonstrates the possibility of utilizing MODIS-Aqua $500 \mathrm{~m}$ resolution images in the analysis of spatio-temporal variation of chlorophyll-a concentration in tropical lakes. The success in the retrieval of the chlorophylla concentration is likely to be attributed to the choice of the atmospheric correction method and the algorithm applied in the retrieval of the chlorophyll-a concentration. Shortwave infrared (SWIR) atmospheric correction procedure was preferred in this study because of its robustness in turbid water environments (Shi and Wang, 2009). OC2 algorithm yielded relatively good estimates of chlorophyll-a concentration. Although the OC2 algorithm was first developed for SeaWiFSdata (Darecki and Stramski, 2004; O'Reilly et al., 1998; O'Reilly et al., 2000), it has proven to work in MODIS high resolution bands $(500 \mathrm{~m}$ ) in turbid waters (Hudson et al., 2000; Wang and Shi, 2008; Wang et al., 2007). OC2 algorithm has also been tested in turbid lake environments (Chang et al., 2012; Weghorst, 2008). Other studies have found the MODIS medium-resolution bands ( 250 and $500 \mathrm{~m}$ ) to be 4 to 5 times more sensitive than the Landsat 7 bands (Hu et al., 2004). Moreover, the daily temporal resolution of MODIS-Aqua data is high compared to the 16 day revisit time of the Landsat images. 


\subsubsection{Spatio-temporal variations in chlorophyll-a}

The annual variations in chlorophyll-a concentration depict seasonal and environmental influences. One of the main seasonal factors could be agricultural activities in the catchment which may be linked to climatic factors such as rainfall (Mageria et al., 2006). In January, lower concentrations of chlorophyll-a were observed at the northern part of the lake near the mouth of the Malewa river which suggests that the chlorophyll-a concentration near the river mouth was diluted by the river water and/or the river water conditions (e.g. velocity, sediment load) that favours only opportunistic phytoplankton species growth. The dilution effect spread over the lake in February resulting in an overall decline in chlorophyll-a concentration in the lake. However, February is usually the planting season and farmers use fertilizers on their farms (Ngugi et al., 2005). In the event of a first heavy rainfall storm around this period, peaks in nutrients are highly likely. This may translate into higher nutrients concentration in the lake which is evidenced by increased chlorophyll-a concentration (Hansson, 1990) from March to May. Chlorophyll-a concentration is expected to rise within a window of 3-7 days following an increase in nutrients (Wilkerson et al., 2006).

In addition, the river water flows much farther into the lake during the rainy season, with consequent additional nutrients which provide favourable environment for phytoplankton development (Kitaka et al., 2002). Around August, top dressing of the agricultural plants with fertilizers takes place (Schmidt et al., 1979). Again, if a heavy storm occurs thereafter, nutrients may be washed down into the lake and consequently lead to flourishing of phytoplankton and hence chlorophyll-a concentration increases. The rains in October and November have a diluting effect on the chlorophyll-a concentration. High nutrient concentrations may also promote the growth of macrophytes such as water hyacinth (Eichhornia crassipes) (Kampeshi and Shantima, 1999), which resulted in data gaps in the MODIS-Aqua images of Lake Naivasha. Cloud cover also affects the spatial coverage of the satellite data especially during the wet months (March/April/May and October/November).

The general increase in chlorophyll-a concentration may be attributed to an increase in the agricultural activities within the catchment (Harper et al., 2011b; Mergeay, 2004; Stoof-Leichsenring et al., 2011; Verschuren et al., 2000b). In addition, common carp (Cyprinus carpio), which is a benthic feeder, was accidentally introduced in the lake in 1998 and started being caught by commercial fishermen in 2002 (Britton et al., 2007). The carp's burrowing activities causes resuspension of sediments thus redistributing and making the nutrients available in the water column of the lake. 
In 2009 and 2010, chlorophyll-a concentration was barely detectable from the MODIS satellite images which was attributed either to the shallowness of the lake due to low lake levels or high reflectance of turbidity constituents such as suspended solids. Around this period, some researchers described the lake as a muddy fish pond because of the reduced size and dissolved and suspended particulate matter which turned the colour of the water to brown (Njogu et al., 2011). In February 2010, a large fish kill occurred apparently due to high organic matter concentrations in the water column (including dead phytoplankton) that cause high oxygen demands and may, in severe cases, lead to anoxic conditions that cause fish kills (Carrick et al., 2005). The muddy condition began to improve in 2011 following a considerable increase in rainfall which resulted in higher lake water levels compared to the previous two years. In 2012, the lake level started to decline again with a possibility of increased turbidity in the lake.

\subsubsection{Lake levels and chlorophyll-a concentration}

The concentration of chlorophyll-a depends on the availability of solar radiation (light and temperature) and nutrients which are fundamental in photosynthesis and phytoplankton growth, respectively (Schlüter et al., 2000). Near the equator daylight is constant, making variations in temperature around Lake Naivasha minimal. This prompts us to plausibly postulate that the main cause of the observed inverse relationship between the chloropyhll-a concentration and water levels may be due to nutrient supply. Nutrient availability in lakes is regulated by, inter alia, additional input from the inflowing rivers, release from decay of dead organic matter (e.g. macrophytes and phytoplanktons), deposition of atmospheric dust particles, and resuspension of the bottom sediments by wind waves, boats, hippos and burrowing fish (Asaeda et al., 2000; Breukelaar et al., 2006; Kilham and Kilham, 2006; Kronvang et al., 2005; Likens, 1972; Sickman et al., 2003).

The relationship between lake level and chlorophyll-a concentration in Lake Naivasha is associated with complex processes that affect nutrient availability and phytoplankton growth (Scheffer, 1998; Scheffer, 2009; Scheffer and Jeppesen, 2007). The relationship suggests that the nutrient availability, and hence phytoplankton growth, decrease with increasing water level in lake Naivasha. Apparently, it appears that the rainfall and river discharge which are responsible for the lake level rise exhibit lower nutrient concentrations than the lake and could likely lead to dilution of the nutrients and chlorophylla concentrations. Furthermore, a combination of low water levels and uniform temperatures allows lakes to mix completely leading to a recharge of the bottom water with oxygen and bringing up nutrients to the surface (Michaud, 1991). This condition favours phytoplankton growth thus explaining the rise 
of chlorophyll-a concentration in Lake Naivasha during low water levels and in agreement with the findings(Zinabu, 2002). Moreover, nutrient input depends on the combination of fertilizer application and rainfall patterns. Other studies have shown the dependence of shallow lakes in internal as well as external environmental changes which influence the prevailing processes and mechanisms (Scheffer, 1998; Scheffer, 2009; Scheffer and Jeppesen, 2007). Wang et al (2012) found a non-linear relationship between water level and chlorophyll-a through wavelet modelling. Contrary to this finding, the inverse relationship of de-seasoned chlorophyll-a and lake water levels observed in this study is a significant contribution to aquatic science because to the best of our knowledge, it has not been observed or reported before. This finding re-emphasizes and enhances our understanding of the hydrological influence on the ecology of the lake and could therefore assist in controlling and management of chlorophyll-a concentration and subsequently improve the trophic state of lake Naivasha.

\subsection{Conclusions and recommendations}

The findings in this paper affirm the possibility of estimating chlorophyll-a concentration using data from MODIS-Aqua satellite to enhance the understanding of the turbidity dynamics in Lake Naivasha. Although the chlorophyll-a concentrations are underestimated by MODIS compared to field data, the significant relationship provides reliable information for studying spatial variations and temporal trends. The results reveal the possibility of capturing a synoptic view of spatio-temporal variation of the chlorophyll-a concentration in Lake Naivasha, a high turbid tropical lake in Kenya. Indeed, the satellite data allows retrospective analysis of the chlorophyll-a in aquatic systems and therefore provide data at times when routine ground measurements do not exist.

This study demonstrates the existence of a large inter-annual spatial variation in chlorophyll-a concentrations over the lake which is evident in the monthly composite maps. The results portray a large temporal variability which is partly caused by seasonal influences such as climate (rainfall) and seasonal agricultural practices. The decomposition of the time series from 2002 until 2009 reveals seasonal variations that correspond to the monthly averaged maps. This is also evident in the long-term trend variations that correlate to the lake level, which plausibly could be explained by dilution and concentration effects. The significant relationship between chlorophyll-a and lake level trends provides the much needed information to managers and decision makers in controlling and managing chlorophyll-a concentration, which subsequently leads to the improvement of the trophic state of Lake Naivasha. 
Chapter 5

Hydrodynamics and water quality analysis in Lake Naivasha 


\begin{abstract}
The hydrodynamics and water quality in Lake Naivasha, an andorheic lake, are simulated and analysed in this chapter. The understanding of hydrodynamics and the processes governing the quality of water in Lake Naivasha would provide information on the driving forces of the turbidity dynamics. The objectives of the study were to assess the major driving forces in hydrodynamics and the subsequent water quality and the associated substances dynamics. The objectives were achieved using Delft3D Flow Module and a stirred-tank reactor model. Investigation on the driving forces showed wind as the major forcing function of the hydrodynamics. The study also revealed an immediate response of the pollutant concentration when the changes in lake volume emanate from rainfall, river discharges, or ET, while seepage and water abstraction lead to gradual pollutant concentration changes. Moreover, that pollutant reduction would improve the water quality gradually and it would take more than 40 years before a new equilibrium is reached. The study also showed that ground water seepage could be responsible of maintaining the fresh water characteristic in Lake Naivasha.
\end{abstract}




\subsection{Introduction}

Hydrodynamics and water quality modelling are useful tools in provision of information that is useful in management of lake ecosystems. Hydrodynamics in particular play a role in sediments redistribution and the associated transport of the contaminants in shallow lakes. Upwelling and vertical mixing in lakes could lead to sediment nutrient resuspension from sediment layer through and therefore accelerating eutrophication which results to high turbidity. The information on the hydrodynamics can provide the circulation and mixing patterns and therefore help in implementation of eutrophication mitigation measures such as dredging, nutrient reduction, or biological control management options. Investigation on the effect of changes in pollutant concentration as a function of water volume in lakes could help in understanding the response time after implementation of some of the mitigation measures such as reduction in nutrient loads.

Research has portrayed numerical models as powerful tools for simulation of hydrodynamics of and water quality in shallow lakes. Zhu et al. (2009) not only simulated the currents from three dimensional hydrodynamic characteristics but also employed two dimensional water quality numerical models to simulate diffusion and transport of pollutants in Lake Yangchenghu. You et al. (2007) investigated eutrophication in Lake Taihu by simulating the effects of hydrodynamics on phosphorus fluxes. Other researchers have modelled sediment resuspension and transport ( $\mathrm{Jin}$ and $\mathrm{Ji}$, 2004, 2005; Lee et al., 2007; Lou et al., 2000). Although hydrodynamics have been applied in other lakes in the world, there has not been any other similar study in Lake Naivasha.

Lake Naivasha is one of the lakes that have transformed from a clear lake to a turbid lake in the recent decades. The understanding of hydrodynamics and other process governing the water quality in Lake Naivasha would provide information on the driving forces of the turbidity dynamics.

The main aim of the study was to assess the major driving forces in hydrodynamics. Subsequent dynamics in water quality and associated substances were also assessed to study the response of the lake to mitigation measures such as nutrient reduction. The hydrodynamics were simulated using the Delft3D flow module while water quality was simulated in respect to the lake changes as a function of inflow, outflow, and volume were modelled using a simple stirred-tank reactor model. This chapter describes how the Lake Naivasha models were set up. The information on the major forces function of the currents is provided. Equilibrium rate, residence time and the dynamic conditions of the pollutant concentration information is also provided. 


\subsection{Study area}

This study was conducted in Lake Naivasha, a shallow endorheic lake situated on the floor of the Eastern Rift Valley in Kenya at $1885 \mathrm{~m}$ above sea level. It lies at latitude $00^{\circ} 46^{\prime} \mathrm{S}$ and longitude $36^{\circ} 22^{\prime}$ (Figure 5.1). The mean air temperature around Lake Naivasha is approximately $25^{\circ} \mathrm{C}$. The main inputs into the lake are mainly from Malewa and Gilgil rivers that accounts for $80 \%$ and $10 \%$ of the lakes discharge, respectively (Table 5.1 ). The remaining inflow comes from other less significant rivers around the lake such as Karati. On the eastern side lies the Crescent Crater Lake which is much deeper (approximate maximum depth of $17 \mathrm{~m}$ in October 2011) than the main lake which is somewhat separated from the main lake especially at low water levels. The west and the southern lake shores are surrounded by high hills while the North East is relatively flat. More details on the study area are discussed in Ndungu et al. 2013 (a, b).

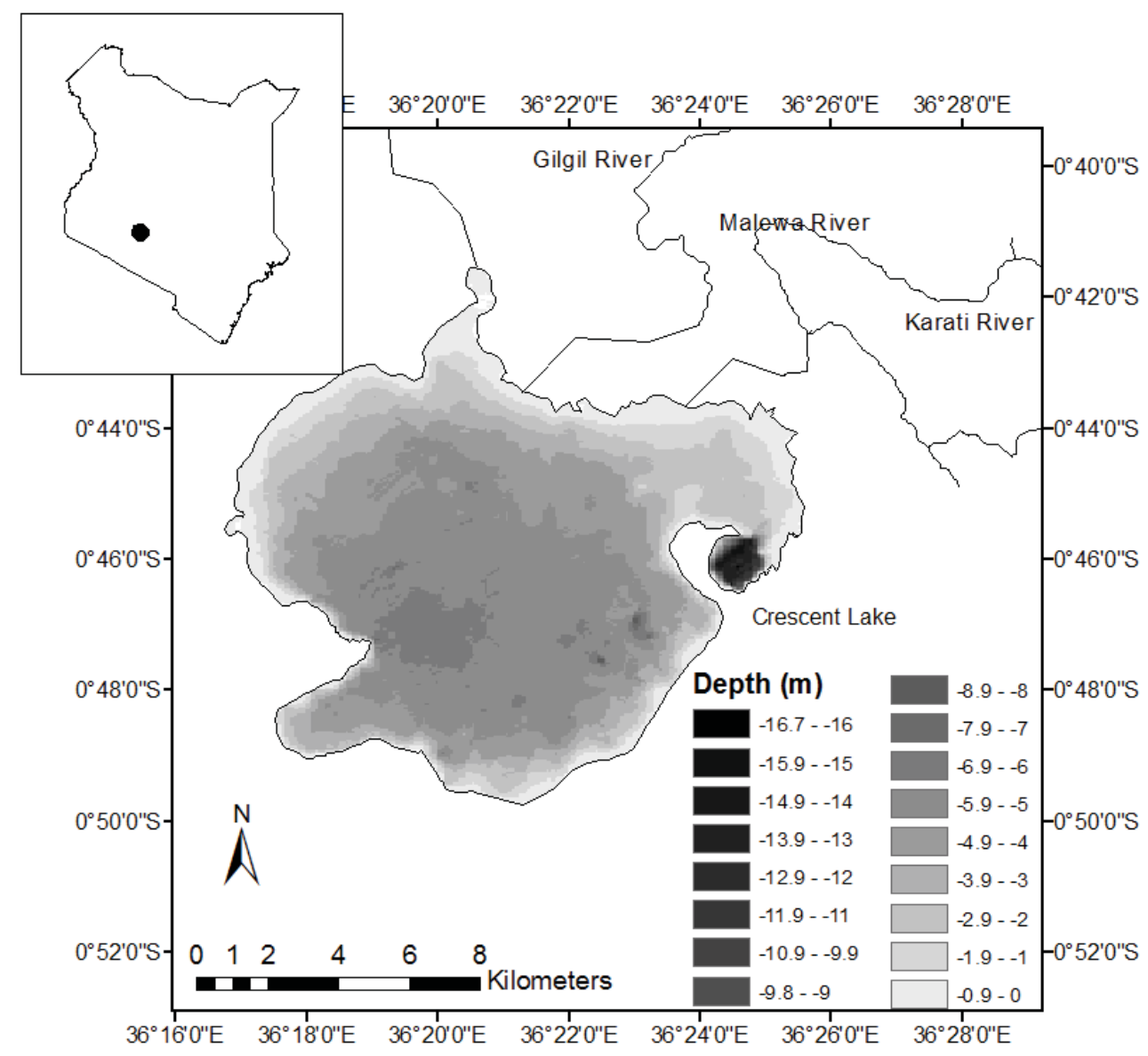

Figure 5.1 Map showing the location of Lake Naivasha in Kenya, the bathymetry and the Crescent Lake 


\subsection{Lake naivasha hydrodynamic model}

Several computational hydrodynamic models have been developed (Fan, 1988; Razmi et al., 2013; Rodi, 2006; Teeter et al., 2001; Wolfgang, 2006). Reviews of the existing hydrodynamic models can be found in (Elfrink and Baldock, 2002; Nakato, 1990; Onishi, 1994; Papanicolaou et al., 2008; Przedwojski et al., 1995; Spasojevic and Holly, 2000). The models are classified according to their formulation in space and time (such as one dimensional, two dimensional or three dimensional, and steady or transient models); and application (such as suspended load or bed-load, chemical or physical transport). The choice of the model to use depends on the nature of the associated problem, data availability, the available time to solve the problem and the ability of the model to simulate the ecosystem adequately. Delft3D has been preferred in this study because of its robust modelling capabilities. This enabled us to model the lake in respect to the bathymetry rather than having a uniform depth. The lake was modelled as one layer because it is a shallow lake and therefore considered well mixed and devoid of stratification most of the time. However, three dimensional circulation studies can be considered in the future.

A grid of $40 \mathrm{~m}$ by $40 \mathrm{~m}$ was developed within the lake boundary. Depth measurements collected in October 2011 were interpolated using QUICKIN Module of Delft3D to generate the depth file (bathymetry). Water inflow and air temperatures as well as wind play a role in water movements and therefore taken into account in this study. A constant value of 23 degrees Celsius was adopted based on October 2011 water temperature field data. Manning roughness option was chosen at a fixed value of $0.02 \mathrm{~m}^{\wedge} 1 / 2 \mathrm{~s}^{-1}$ (Podsetchine and Schernewski, 1999). Viscosity and diffusivity values were 1 and $10 \mathrm{~m}^{2} \mathrm{~s}^{-1}$ respectively. Absolute flux, total solar radiation option was used because it takes into account the relative humidity, air temperature and heat losses due to evaporation and convection. Air temperature, relative humidity, total radiation, wind speed and direction data were acquired from weather analytics station ${ }^{\mathrm{TM}}$ sensor number 427286 close to Moi South Lake Road in Naivasha. Weather analytics stations are composed of $35 \times 35 \mathrm{~km}$ grid squares and therefore are area based weather stations. In March of 2011 NOAA/NCEP (National Center for Environmental Prediction) released a new, high resolution Climate Forecast System Reanalysis (CFSR) data set containing the complete hour-by-hour condition of the earth's atmosphere from January 1979 with a $1 / 3^{\circ}$ resolution. This CFSR data set is an upgraded version of the Global Reanalysis System, $1^{\circ}$ data set and is maintained as a statistically stable record of the earth's atmosphere to serve as the base for long range forecasts by NOAA. It is kept current with updates every 6 hours and contains over 580 weather condition variables from the earth's surface to 
the top of the atmosphere. More information on the dataset can be obtained from: http://www.weatheranalytics.com/weather-products/.

The main discharge into the lake is from the Malewa River which accounts for $80 \%$ of the discharge. Discharge data from WRMA gauging station 2GB1 was used as input. Although the Gilgil and Karati rivers discharges are less significant, the values were estimated from field data.

To assess the main driving forces of water movement in Lake Naivasha, the scenarios in Table 5.1 were simulated. Wind direction varies over the year as illustrated by the wind rose diagram (Figure 5.2). The plot was generated from daily average wind speed and direction data in 2011. The major wind directions were found to be $45^{\circ}$ and $90^{\circ}$. However, rare and stronger winds originated from south east $135^{\circ}$. Therefore, the simulations were performed on the three wind directions. There were no winds from the west and south west because the area consists of hills may block the wind.

Table 5.1: Table showing the scenario simulated with against the respective values

\begin{tabular}{|c|c|c|c|}
\hline Scenario & $\begin{array}{l}\text { Wind } \\
\text { direction } \\
\text { (degrees) }\end{array}$ & Wind speed $(\mathrm{m} / \mathrm{s})$ & Discharge $\left(\mathrm{m}^{3} / \mathrm{s}\right)$ \\
\hline 1. & - & 0 & $\begin{array}{ll}1 . & 1.6 \text { (Gilgil) } \\
2 . & 19.7 \text { (Malewa) } \\
3 . & 0.4 \text { (Karati) }\end{array}$ \\
\hline 2. & 45 & 3.6 & 0 \\
\hline 3. & 45 & 3.6 & $\begin{array}{ll}\text { 1. } & 1.6 \text { (Gilgil) } \\
2 . & 19.7 \text { (Malewa) } \\
\text { 3. } & 0.4 \text { (Karati) }\end{array}$ \\
\hline 4. & 90 & 3.6 & 0 \\
\hline 5. & 90 & 3.6 & $\begin{array}{ll}\text { 1. } & 1.6 \text { (Gilgil) } \\
2 . & 19.7 \text { (Malewa) } \\
\text { 3. } & 0.4 \text { (Karati) }\end{array}$ \\
\hline 6. & 135 & 3.6 & $\begin{array}{ll}\text { 1. } & 1.6 \text { (Gilgil) } \\
2 . & 19.7 \text { (Malewa) } \\
\text { 3. } & 0.4 \text { (Karati) }\end{array}$ \\
\hline
\end{tabular}




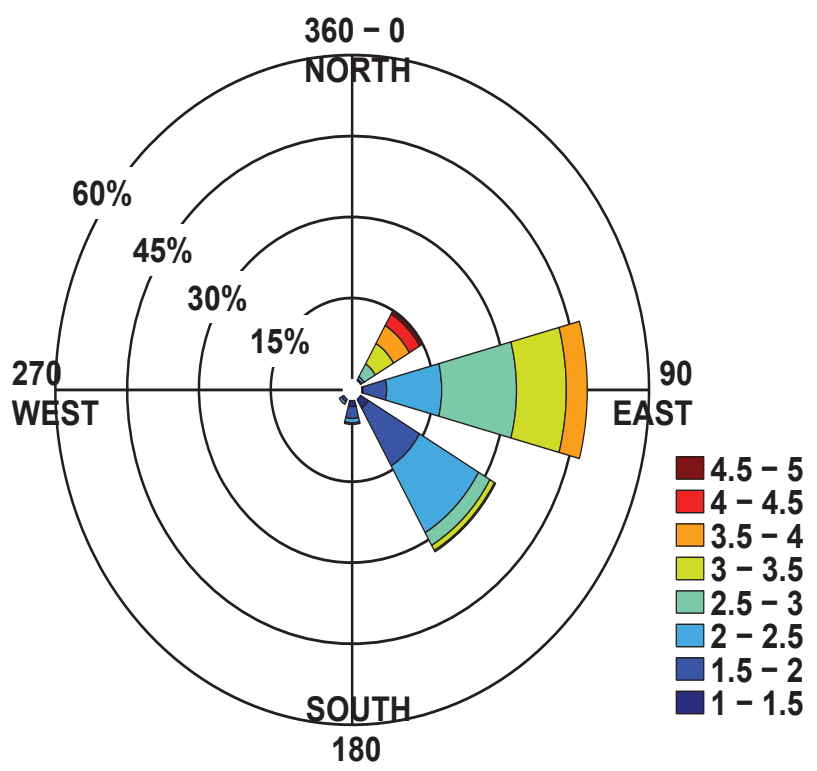

Figure 5.2 Wind rose plotted from the daily average wind speed $\left(\mathrm{ms}^{-1}\right)$ data in year 2011

The highest wind speed for this study was determined by selecting the speed at about $90 \%$ of the year 2011 to avoid working with extreme outliers. The value was found to be $3.6 \mathrm{~m} \mathrm{~s}^{-1}$ (Figure $5.3(\mathrm{~d})$ ). The highest discharge was determined in a similar way by plotting the cumulative frequency distribution of Gilgil, Malewa and Karati rivers discharge, respectively (Figure 5.3). The selected discharge values were 1.6, 19.7 and $0.4 \mathrm{~m}^{3} / \mathrm{s}$ in Gilgil, Malewa and Karati rivers, respectively. 
(a)

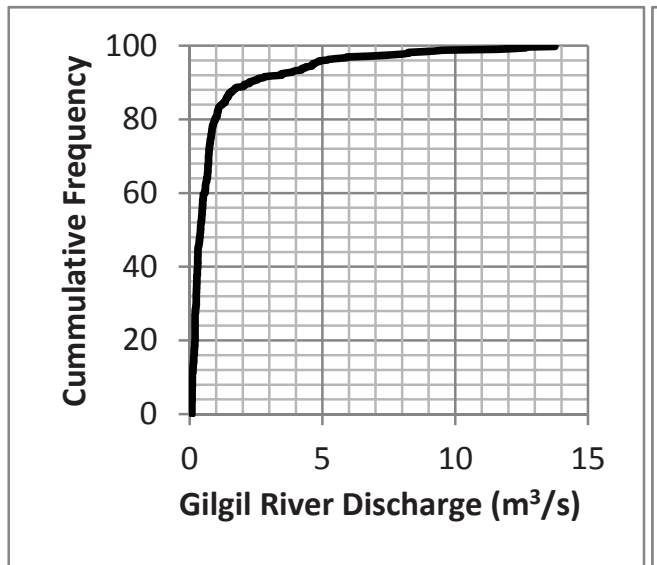

(b)

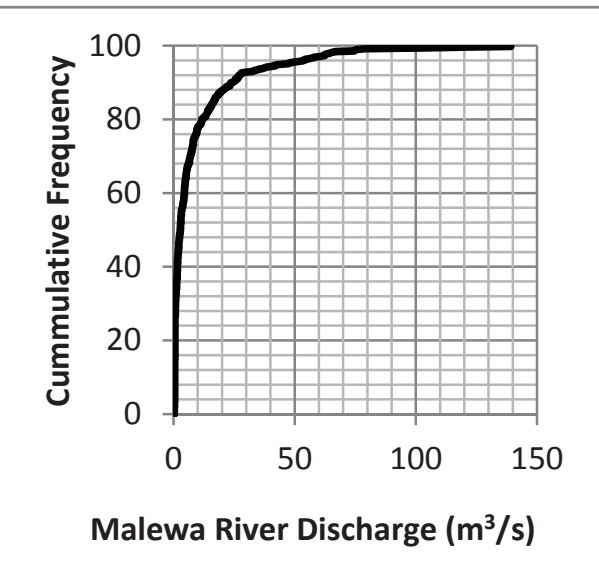

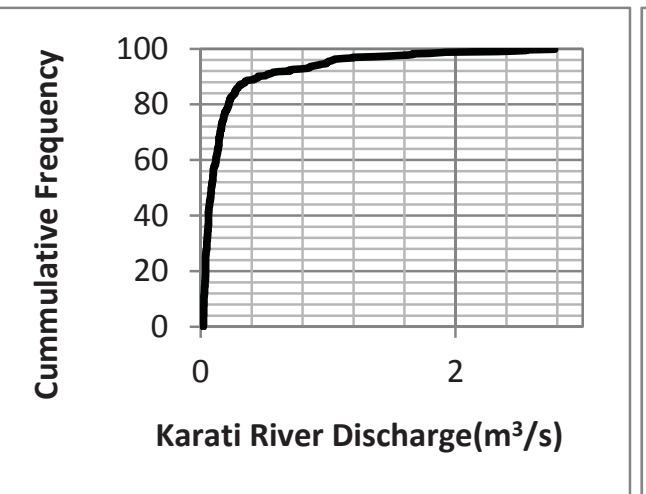

(c)

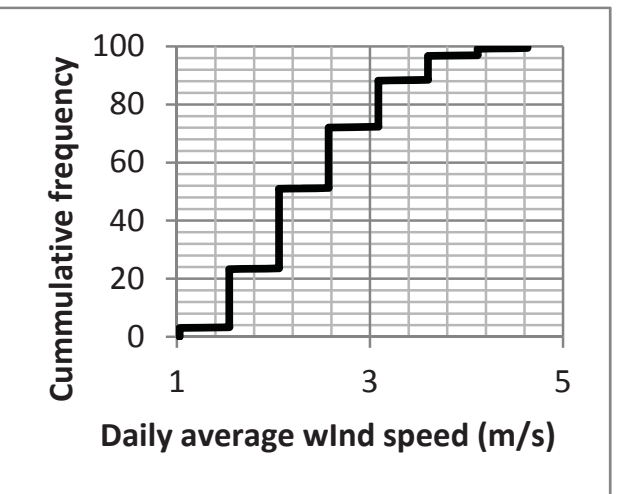

(d)

Figure 5.3 Cumulative frequencies of wind speed and discharge from Gilgil, Malewa and Karati rivers for 2011.

\subsection{Results of hydrodynamics model}

The results of the hydrodynamic model for each scenario are shown in maps. The simulation from zero wind speed and high discharge showed northwest water circulation concentrated only around the discharge locations Figure 5.4 (A)). The rest of the lake was virtually calm. However, the simulation with the zero discharge and 'high' $\left(3.6 \mathrm{~ms}^{-1}\right)$ wind speed from north east and eastern direction (in both $45^{\circ}$ and $90^{\circ}$ ) showed two circular motions at the north and southern regions of the lake(Figure 5.4 (B) and (C); Figure 5.5). The velocities were relatively higher in the shallow areas as compared to the deep zones. In the northern part, the currents curve and move against the wind direction around the deep zone (middle of the lake) in an anticlockwise direction. The southern part also curves towards the middle of the lake but in 
a clockwise direction. This behaviour has been observed in other parts of the world where the wind-driven currents move against the wind direction in the deep zone of a trough shaped water body (Mathieu et al., 2002). High wind speed and high discharge showed a similar pattern as that of zero discharge and high wind speed scenario indicating that wind is the dominant driving force for the currents in the lake. The south east $\left(135^{\circ}\right)$ also showed currents motion against the wind direction in the deep zones (Figure 5.6).

Wind direction $=45^{\circ}$

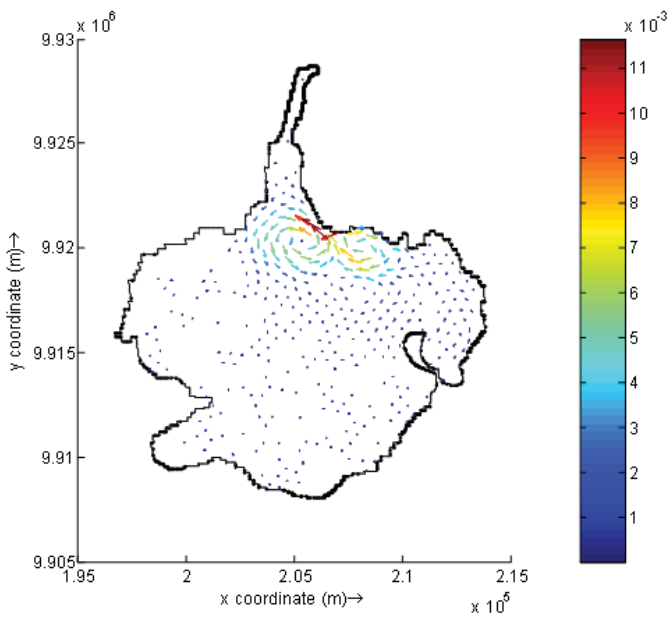

(A) Wind speed $=0$, Discharge $=19.74,0.4,1.6$

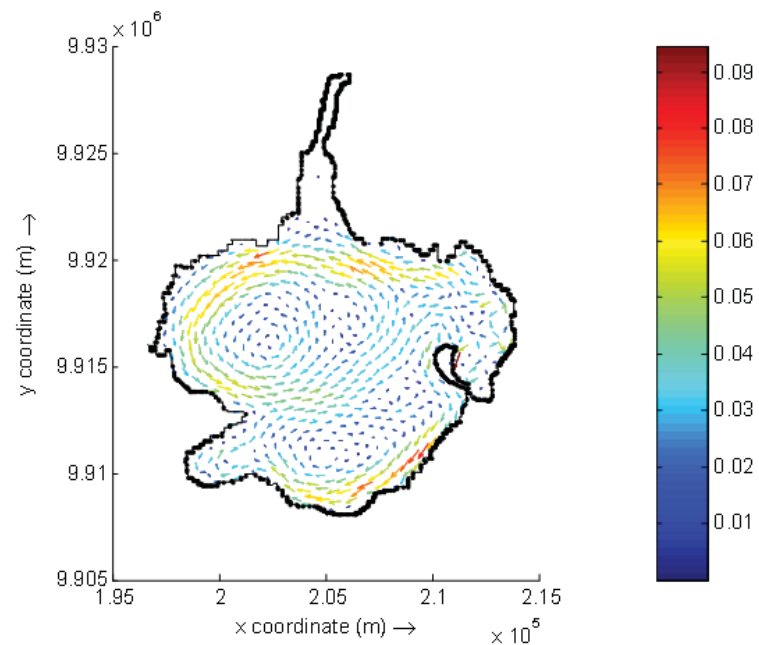

(B) Wind speed $=3.6 \mathrm{~ms}^{-1}$, Discharge $=0$ 


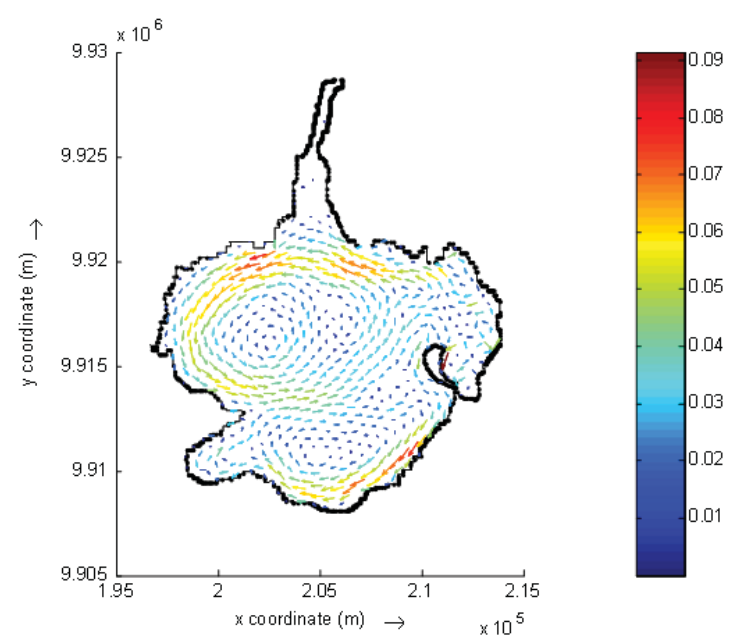

(C) wind speed $=3.6 \mathrm{~ms}^{-1}$, Discharge $=19.74,0.4,1.6$

Figure 5.4 Map showing the spatial current movement pattern with; a) zero wind velocity and high discharge, b) high wind velocity, zero discharge, c) high wind velocity and high discharge, all at 45 degrees wind direction (actual values are shown in table 1) 


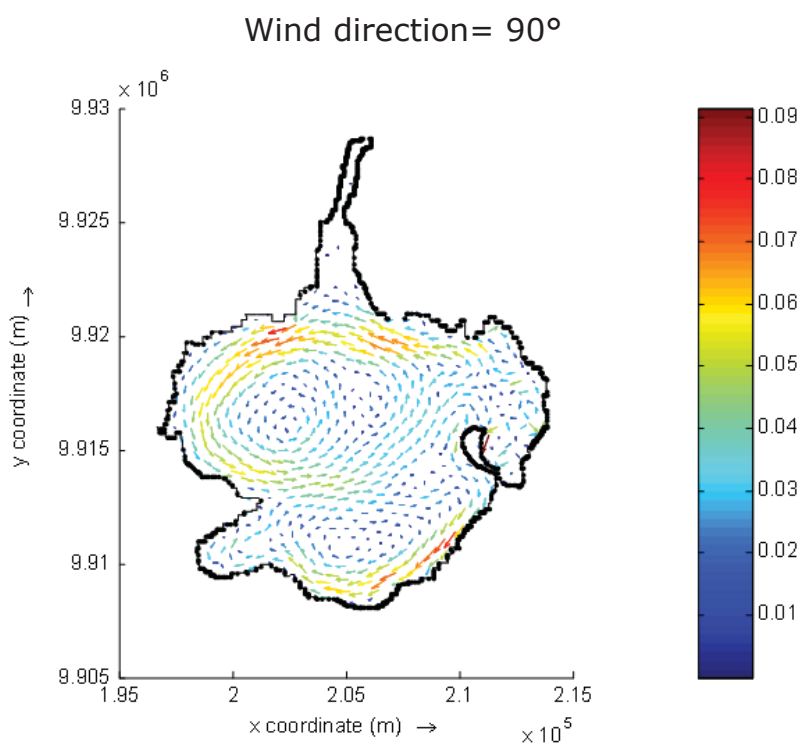

(A) Wind speed $=3.6 \mathrm{~ms}^{-1}$, Discharge $=0$

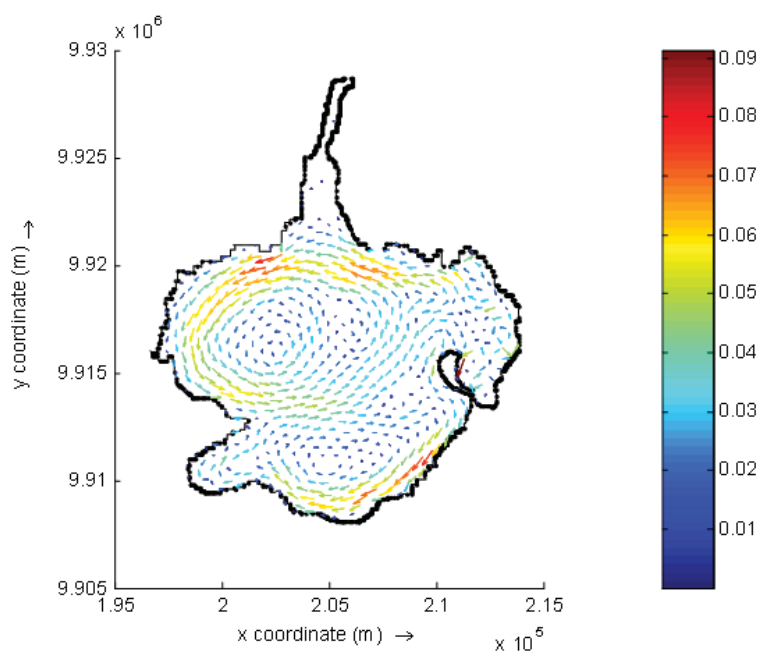

(B) wind speed $=3.6 \mathrm{~ms}-1$, Discharge $=19.74,0.4,1.6$

Figure 5.5 Map showing the spatial water movement pattern with; a) zero wind velocity and high discharge, b) high wind velocity, zero discharge, c) high wind velocity and high discharge, all at 90 degrees wind direction (actual values are shown in table 1) 


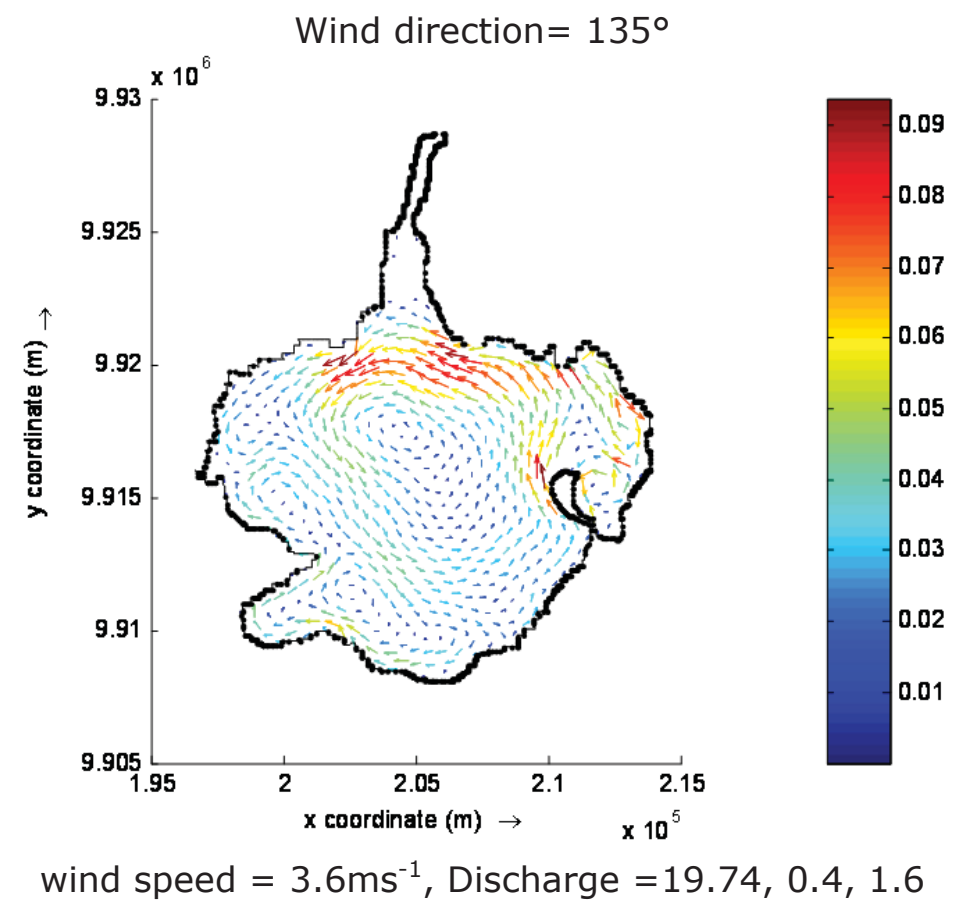

Figure 5.6 Map showing the spatial water movement pattern with; a) zero wind velocity and high discharge, b) high wind velocity, zero discharge, c) high wind velocity and high discharge, all at 135 degrees wind direction (actual values are shown in table 1)

\subsection{Idealised hydrodynamics model}

To verify the Delt3D output, an idealized model was developed as described in Mathieu et al (2002).

A rectangular basin of length $2 \mathrm{~L}$, width $2 \mathrm{~B}$ was considered (Figure 5.7). $\mathrm{x}$ and $y$ were taken to be the along- basin and cross-basin coordinates, such that the basin boundaries position was at $x=-L, L$ and $y=-B, B$. The vertical coordinate $z$ points upward, and $z=\eta$ denote the free surface elevation with respect to the undisturbed water level $z=0$ and the bed level at $z=-h$. In general, $\mathrm{h}$ is a function of $\mathrm{x}, \mathrm{y}$ but for simplicity $\mathrm{h}$ is taken to be equivalent to $h(y)(h=h(y))$. 


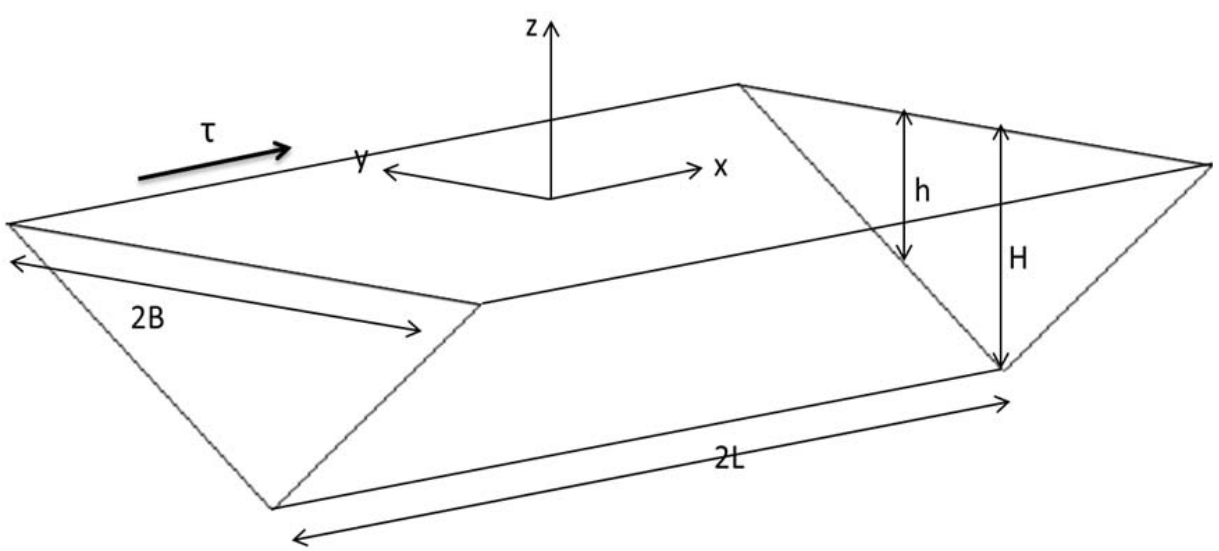

Figure 5.7 Schematic diagram of the idealized model

A steady flow $(\partial / \partial t=0)$ was considered and the linearized mass and momentum equations were solved assuming the pressure to be hydrostatic. The non-dimensional terms were introduced to account for the boundary condition. The horizontal velocity and transport were then modelled together with the stream function. The step by step explanation of the idealized model is show in appendix 1.

The results give similar results as those of the Delft3D model. The shallow part of the lake show current moving in the direction where the wind is blowing to while the deeper region shows the currents moving against the wind direction. Figure 5.9 illustrate the magnitude of the currents in the idealized model. 


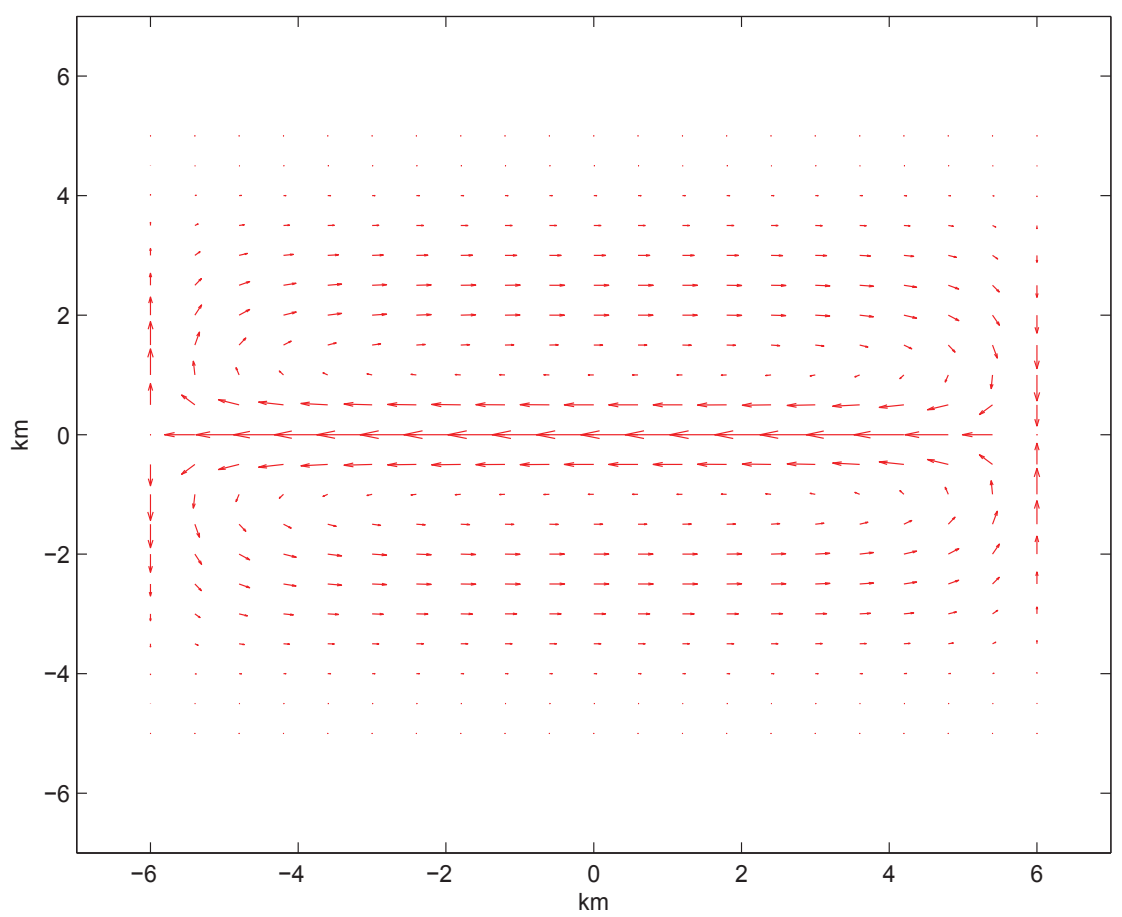

Figure 5.8 Current direction simulated with a wind blowing from the west.
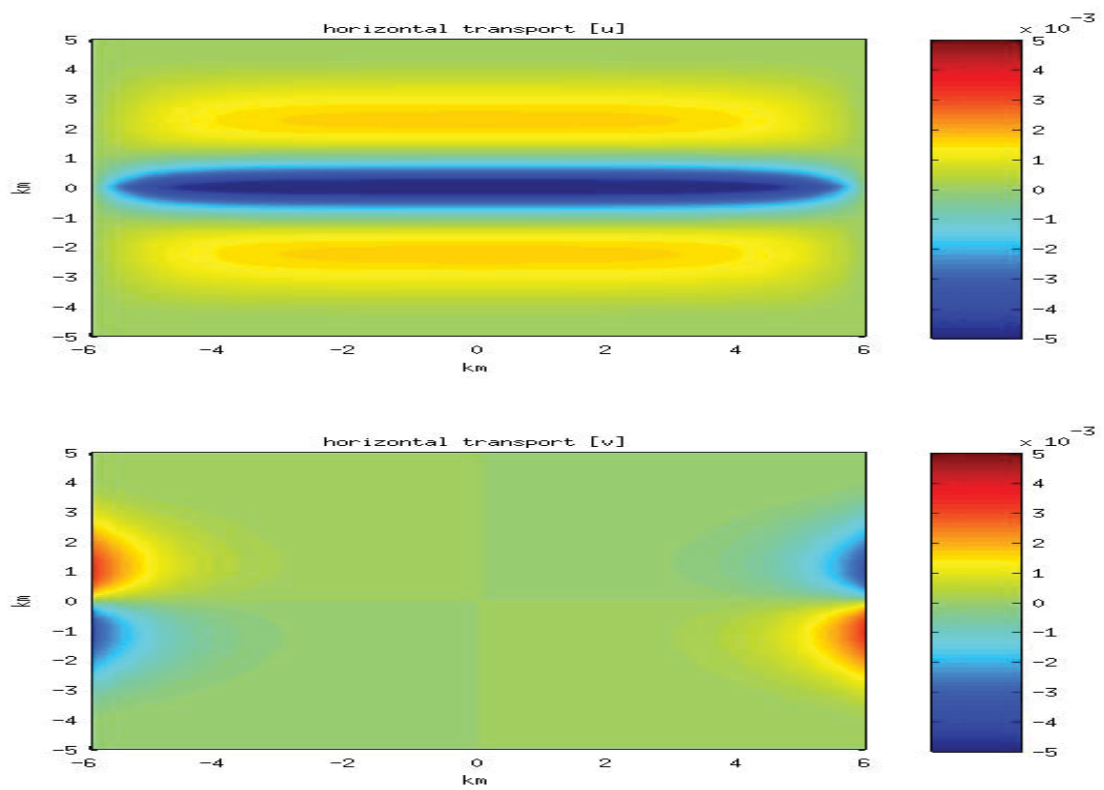

Figure 5.9 Illustration of the horizontal transport current magnitude 
In both the idealized and the Delft3D models, the currents movements are against the wind direction in the deep area because in a wind driven current system, the current magnitude and direction is proportional to the sum of the initial current velocity and surface wind velocity. With the assumption of a steady state (no acceleration) then the depth averaged momentum equation would be expressed as:

$\frac{\partial u}{\partial t}+u \frac{\partial u}{\partial x}+u \frac{\partial v}{\partial y}=g \frac{\partial \xi}{\partial x}-\frac{r u+\tau w}{H}$

Where $u$ represents flow velocity vector, $x$ and $y$ are the directions, $\tau w$ is the wind shear stress, $H$ is the depth while $r$ is the bottom frictional coefficient. In a steady situation $\frac{\partial u}{\partial t}, u \frac{\partial u}{\partial x}$ and $u \frac{\partial v}{\partial y}$ are assumed to be equivalent to zero, when the pressure is assumed to be hydrostatic. Therefore, equation 5.1 can be rewritten as:

$g \frac{\partial \xi}{\partial x}-\frac{r u+\tau w}{H}=0$

In Lake Naivasha we have deep area around the middle $\left(\mathrm{H}_{2}\right)$ and shallow areas at the edges of the lake $\left(H_{1}\right)$. Because acceleration $\left(g \frac{\partial \xi}{\partial x}\right)$ is assumed to be zero, therefore, equation 5.2 can be re-written as:

$-\frac{r_{1} u+\tau w}{H_{1}}=-\frac{r_{2} u+\tau w}{H_{2}}$

which can be simplified as:

$\left(r u_{1}+\tau w\right) H_{2}=\left(r u_{2}+\tau w\right) H_{1}$

In the continuity terms, $u_{1} H_{1}=-u_{2} H_{2}$ and therefore:

$u_{1}=-u_{2} \frac{H_{2}}{H_{1}}$

Substituting equation 5.5 into equation 5.4 would result in the following equation as a solution for $u_{2}$ :

$u_{2}=\frac{\tau w}{r}\left(\frac{\left(H_{1}-H_{2}\right) H_{1}}{H_{1}^{2}+H_{2}^{2}}\right)$

Therefore, if $H_{2}>H_{1}$, currents move against the wind direction and when $H_{2}<H_{1}$ the currents motion would be in the direction of the wind. This is the reason why the currents in the Delft3D model of Lake Naivasha are against the wind direction in the deep region. 


\subsection{Lake Naivasha water quality model}

Water quality in Lake Naivasha can be modelled with various models such as Delft3D (Postma et al., 1999), PClake (Janse, 1997), WASP (Ambrose et al., 1988) among others as reviewed in Wang et al. (2013). However, these models are rather complex and require much data which is not available for this lake. The results from the Lake Naivasha hydrodynamic study showed that the main lake can be considered as reasonably well mixed. This allows us to treat the lake as non-dimensional stirred-tank reactor and build a simple model to evaluate the response time of the lake to various environmental perturbations.

\subsubsection{Water and mass balance}

Figure 5.10 shows a schematic diagram of the processes affecting water quality in Lake Naivasha. The inflow into Lake Naivasha is determined by the inflow from rivers ( $Q_{\text {rivers }}$ ) consisting of the Malewa (about $80 \%$ ), the Gilgil $(10 \%)$ and other less significant streams such as the Karati river $(10 \%)$ and inflow from the waste water treatment plant (WWTP) and return flow from irrigated greenhouses or agricultural farms. This return could be discharged directly into the lake or reach the lake via the rivers. These two sources of waste water $\left(Q_{w w}\right)$ are relatively low in volume but may have high concentrations. Besides inflow via river discharges and waste water discharges, water enters the lake also through direct rainfall on the lake. This is a substantial amount of the total input of water (see Table 5.2). This amount depends on the area of the lake. It is unknown whether the lake is fed by groundwater and is therefore not taken into account here. 


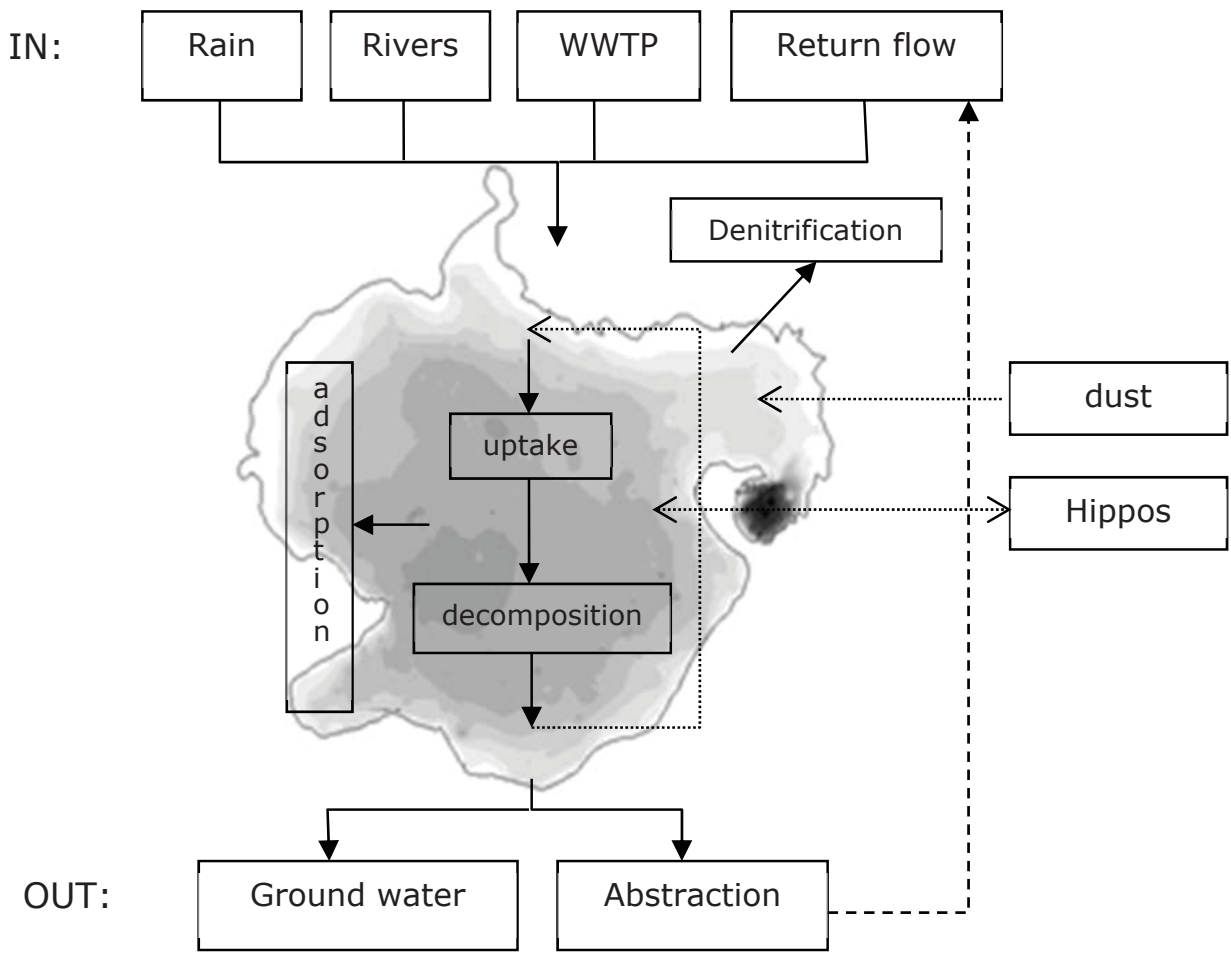

Figure 5.10 Schematic overview of the processes affecting water quality in Lake Naivasha

Hence, the total inflow $\left(\mathrm{m}^{3} / \mathrm{s}\right)$ in Lake Naivasha can defined by:

$Q_{\text {in }}=Q_{\text {rain }}+Q_{\text {rivers }}+Q_{w w}$

Water leaves the lake via evapotranspiration $\left(Q_{E T}\right)$, groundwater and abstraction (Equation 5.8). Both seepage to groundwater and abstraction are taken together in one term ( $Q_{\text {outflow }}$ ) as they are considered to have the same effect on the pollutant mass balance. Evapotranspiration depends on the surface area of the lake (evaporation) and the amount of macrophytes (transpiration).

$Q_{\text {out }}=Q_{E T}+Q_{\text {outflow }}$

The change in volume of the lake is therefore expressed as:

$\frac{\partial V}{\partial t}=Q_{\text {rain }}+Q_{\text {rivers }}+Q_{w w}-Q_{E T}-Q_{\text {outflow }}$ 
The total mass load $(\mathrm{g} / \mathrm{s})$ of a pollutant into the lake is the sum of the loads contributed by each inflow term $\left(Q\right.$ in $\left.\mathrm{m}^{3} \mathrm{~s}^{-1}\right)$ multiplied by the concentration of the pollutants $\left(C\right.$ in $\mathrm{g} / \mathrm{m}^{3}$ ) which is expressed as:

$$
Q_{\text {in }} C_{\text {in }}=Q_{\text {rain }} C_{\text {rain }}+Q_{\text {rivers }} C_{\text {rivers }}+Q_{w w} C_{w w}
$$

$C_{\text {in }}$ is the inflow-weighted average of all the concentrations entering the lake. If the concentration in one of the terms increases, $C_{\text {in }}$ will also increase proportionally, relative to the contribution of that term. The concentration in the rain is for most pollutants negligible, except maybe for nitrogen (as $\mathrm{NO}_{\mathrm{x}}$ ), so most pollutant mass reaches the lake via the rivers and waste water. Dust is also a source of pollutants. This term is not included in the model separately because the load via dust is unknown, but could be compensated for in the concentration $C_{i n}$.

Mass flow out of the lake is mainly through groundwater and abstraction. The mass flow through evapotranspiration is zero

$\left(C_{E T}=0\right)$. For a well-mixed system, the water leaving the lake through seepage to groundwater or water abstraction from the lake has the same concentration as that of the water in the lake $(C)$. Therefore, the total mass/load flow out of the lake could be represented by Equation 5.11.

$$
Q_{\text {out }} C_{\text {out }}=Q_{E T} \cdot 0+Q_{\text {outflow }} C=Q_{\text {outflow }} C=\left(\left(Q_{\text {out }}-Q_{E T}\right) C\right.
$$

In the lake, pollutants (in this case pollutants refer to excess nutrients and other ions) can be taken up by plants or other organisms thereby reducing the concentration. Living organisms may die and eventually decompose releasing the pollutants again into to the lake leading to an increase in the concentration. This cycle mainly applies to nutrients. This means that nutrients are temporarily stored in the biomass. This amount may increase and decrease over time, the net storage over a long period of time is considered as zero in this study. In general, it is expected that the fixation is larger than the release since not all organic matter may be decomposed and some pollutants may remain fixed in organic matter. Hippos consume the nutrients by foraging on macrophytes but excrete them again as well. They may relocate nutrients by foraging on land and dropping them as faeces in the water or vice versa. Since the net effect of this process is unknown it is assumed that this process may be neglected. Fish also store part of the nutrients. Fish catches by fishermen remove these nutrients from the lake. Some pollutants (e.g. phosphorus, metals) may also be adsorbed to the sediment. Some of these adsorbed pollutants may be released when the sediment is suspended by waves or fish barrowing into the sediments, but 
most of the adsorbed pollutants are not biologically available. Nitrate can be converted to nitrogen gas under anaerobic conditions and be lost to the atmosphere (denitrification). This loss can be substantial (Burgin and Hamilton, 2007). In general, the loss of pollutants in this study is expected to be somewhat higher than the release. Therefore, if the net effect of these processes is ignored the concentration in the lake is likely to be overestimated. To incorporate these processes a first-order loss term is included in the mass balance, because it is assumed that losses increase with an increase in the concentration. For nitrogen this term may not be negligible, but for other pollutants this term could be taken as zero as an initial estimate. Of course all terms can be strongly variable in time.

The change of mass in the lake can be written as:

$\frac{\partial M}{\partial t}=\frac{\partial V C}{\partial t}=Q_{\text {in }} C_{\text {in }}-Q_{\text {outflow }} C-k V C$

Where $M$ is the mass of a pollutant in the lake, $V$ is the volume of the lake and $k$ is the first-order rate constant for the first-order loss rate.

\subsubsection{Dimensionless parameters}

For scaling purposes it can be useful to use dimensionless parameters. The following dimensionless parameters are introduced:

$F$ is the fraction of seepage to groundwater and abstraction ( $Q_{\text {outflow }}$ ) of the total outflow (Qoufflow):

$F=\frac{Q_{\text {outflow }}}{Q_{\text {out }}}=\frac{Q_{\text {out }}-Q_{E T}}{Q_{\text {out }}}$

$D$ is the Damkohler number which is the ratio between the residence time of water in the lake $\left(T=V / Q_{\text {in }}\right)$ and the characteristic time for the loss rate $\left(k^{-1}\right)$ :

$D=\frac{k V}{Q_{\text {in }}}=k T$

\subsubsection{Equilibrium concentration}

When the inflow and outflow (i.e. volume and lake level) are constant and the concentration of the inflow $\left(C_{\text {in }}\right)$ is constant, eventually the concentration in the lake will also become constant. This steady state or equilibrium concentration can be derived as: 
$C_{\text {eq }}=\frac{Q_{\text {in }} C_{\text {in }}}{Q_{\text {outflow }}+k V}$

Or in dimensionless parameters:

$C_{e q}^{*}=\frac{1}{F+D}$

With

$C_{e q}^{*}=\frac{C_{e q}}{C_{i n}}$

Equation 5.17 shows that the equilibrium or steady state concentration will increase when:

- There is an increasing load to the lake $\left(Q_{i n} C_{i n}\right)$;

- less water is lost from the lake via seepage and abstraction relative to the input;

- and when pollutants are not lost by other processes.

\subsubsection{Rate to equilibrium}

The pollutant concentration $(C)$ can therefore be solved as:

$C=\left(C_{0}-\frac{Q_{\text {in }} C_{\text {in }}}{Q_{\text {oufflow }}+k V}\right) e^{-\left(Q_{\text {ouffow }}+k V\right) t / V}+\frac{Q_{\text {in }} C_{\text {in }}}{Q_{\text {outflow }}+k V}$

Where $\mathrm{C}_{0}$ is the initial concentration at $\mathrm{t}=0$. Or in non-dimensionless parameters $(*)$ :

$C^{*}=\left(C_{0}^{*}-\frac{1}{F+D}\right) e^{-(F+D) t / T}+\frac{1}{F+D}$

With

$C^{*}=\frac{C}{C_{\text {in }}}$ and $C_{0}^{*}=\frac{C_{0}}{C_{\text {in }}}$

The rate $\left(R, s^{-1}\right)$, or relaxation time, at which the concentration approaches equilibrium is:

$R=\frac{F+D}{T}$

The equilibrium concentration will be reached faster when the fraction of water loss to groundwater and by abstraction is larger, and the residence time will be smaller.

\subsubsection{Dynamic conditions}

For dynamic conditions the water balance (equation 5.9) can be solved numerically by: 
$V_{t+\Delta t}=V_{t}+\left(Q_{\text {rain, }}+Q_{\text {river,t }}+Q_{w w, t}-Q_{\text {outflowt }}-Q_{E T, t}\right) \Delta t$

With $\Delta t$ the time step.

The volume in the lake can increase when:

- rainfall increases (same effect as increase of groundwater inflow)

- the discharge from rivers increases

- the outflow decrease

- evapotranspiration decreases

Similarly the mass balance (equation 5.10) can be solved by:

$C_{t+\Delta t}=\frac{\left(Q_{\text {rain }, t} C_{\text {rain }}+Q_{\text {river }, t} C_{\text {river }}+Q_{w w, t} C_{w w}\right) \Delta t-\left(Q_{\text {outflow }, t} \Delta t-V_{t}+\frac{1}{2} k V_{t} \Delta t\right) C_{t}}{V_{t+\Delta t}\left(1+\frac{1}{2} k \Delta t\right)}$

\subsection{Water quality model results}

\subsubsection{Water and mass balance}

The water balance in Lake Naivasha, taken from different sources, is shown in Table 5.2 below. The values used for this study are shown in table 5.3.

Table 5.2 Lake balance in pre-abstraction era. Based on Van Oel et al. (2013)

\begin{tabular}{|c|c|c|c|c|c|c|c|}
\hline \multirow{2}{*}{$\begin{array}{l} \\
\text { Hydrologic } \\
\text { budget }^{1}\end{array}$} & \multirow{2}{*}{$\begin{array}{c}\begin{array}{c}\text { McCann } \\
(1974)\end{array} \\
\begin{array}{c}\text { Various } \\
\text { years }\end{array}\end{array}$} & \multirow{2}{*}{$\begin{array}{c}\begin{array}{c}\text { Gaudet and } \\
\text { Melack } \\
(1981)\end{array} \\
1973-1975\end{array}$} & \multicolumn{2}{|c|}{ Åse et al. (1986) } & \multirow{2}{*}{$\begin{array}{c}\begin{array}{c}\text { Becht and } \\
\text { Harper } \\
(2002)\end{array} \\
1932- \\
1981\end{array}$} & \multirow{2}{*}{$\begin{array}{c}\begin{array}{c}\text { Van Oel } \\
\text { et al. } \\
\text { (2013) }\end{array} \\
1965- \\
1979 \\
\end{array}$} & \multirow[t]{2}{*}{ Range } \\
\hline & & & $\begin{array}{l}1972- \\
1974\end{array}$ & $\begin{array}{l}1978- \\
1980\end{array}$ & & & \\
\hline Total inflow & 380 & 337 & 279 & 375 & 311 & 353 & $\begin{array}{r}340 \pm \\
70\end{array}$ \\
\hline Precipitation & 132 & 103 & 106 & 135 & 94 & 123 & $\begin{array}{r}116 \pm \\
20\end{array}$ \\
\hline River discharge & 248 & 234 & 148 & 215 & 217 & 230 & $\begin{array}{r}215 \pm \\
50\end{array}$ \\
\hline Total outflow & 380 & 368 & 351 & 341 & 312 & 362 & $\begin{array}{r}352 \pm \\
80 \\
\end{array}$ \\
\hline $\begin{array}{l}\text { Evapotranspirat } \\
\text { ion } \\
\text { incl. swamp }\end{array}$ & 188 & 312 & 284 & 288 & 256 & 328 & $\begin{array}{r}276 \pm \\
90\end{array}$ \\
\hline $\begin{array}{l}\text { Groundwater } \\
\text { seepage }\end{array}$ & 34 & 56 & 67 & 53 & 56 & 34 & $50 \pm 20$ \\
\hline \multicolumn{8}{|l|}{ Assumptions ${ }^{2}$} \\
\hline Precipitation & $6393^{3}$ & 683 & 575 & 709 & 648 & 695 & $\begin{array}{r}658 \pm \\
70\end{array}$ \\
\hline $\begin{array}{l}\text { Evapotranspirat } \\
\text { ion }\end{array}$ & $17914^{4}$ & 1989 & 1542 & 1504 & 1788 & 1788 & $\begin{array}{r}1734 \pm \\
250\end{array}$ \\
\hline
\end{tabular}


Table 5.3 Water balance data used in model (Excel).

\begin{tabular}{|c|c|c|c|c|c|c|}
\hline 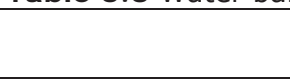 & $\mathrm{Mm}^{3} / \mathrm{yr}$ & $\mathrm{mm}_{1} / \mathrm{yr}$ & $\mathrm{m}^{3} / \mathrm{s}$ & $\mathrm{m}^{3} / \mathrm{d}$ & $\%$ & $\begin{array}{c}\begin{array}{c}\% \text { of } \\
\text { volume }\end{array} \\
\end{array}$ \\
\hline Total inflow $\left(Q_{\text {in }}\right)$ & 350 & 2333 & 11.1 & $95.9 \times 10$ & 100 & 39 \\
\hline Precipitation $\left(Q_{\text {rain }}\right)$ & 120 & 800 & 3.8 & $32.9 \times 10$ & 34 & 13 \\
\hline River discharge $\left(Q_{\text {river }}\right)$ & 225 & 1500 & 7.1 & $61.6 \times 10$ & 64 & 25 \\
\hline Waste water $\left(Q_{w w}\right)$ & 5 & 33 & 0.2 & $1.4 \times 10^{4}$ & 1 & 1 \\
\hline Total outflow $\left(Q_{\text {out }}\right)$ & 350 & 2333 & 11.1 & $95.9 \times 10$ & 100 & 39 \\
\hline Evapotranspiration $\left(\mathrm{Q}_{\mathrm{ET}}\right)$ & 300 & 2000 & 9.5 & $82.2 \times 10_{4}$ & 86 & 33 \\
\hline $\begin{array}{l}\text { Groundwater seepage + } \\
\text { abstraction }\left(Q_{\text {outflow }}\right)\end{array}$ & 50 & 333 & 1.6 & $13.7 \times 10$ & 14 & 6 \\
\hline
\end{tabular}

\subsubsection{Equilibrium concentration of pollutants}

Figure 5.11 shows the relationship between the fraction of water loss from the lake through seepage to groundwater and abstraction $(F)$ versus the relative concentration at equilibrium $\left(C_{e q}{ }^{*}\right)$ as described by equation 5.8 and assuming only loss of pollutant mass by outflow of water $(D=0)$. The red marker indicates the estimated pollutant concentration at equilibrium in lake Naivasha, being 7 times higher than $C_{i n}$. The higher the water loss through groundwater and/or abstraction, the lower the equilibrium concentration. This means that the risk of salinisation of the lake increases when more water is lost by ET compared to the water loss through seepage and abstraction. The fresh water in Lake Naivasha is an indication that a substantial amount of water out of the lake is lost to groundwater and abstraction. When mass is lost through other process $(D>0)$, e.g. denitrification for nitrogen, the concentration in the lake would be lower than the blue line in Figure 5.11. 


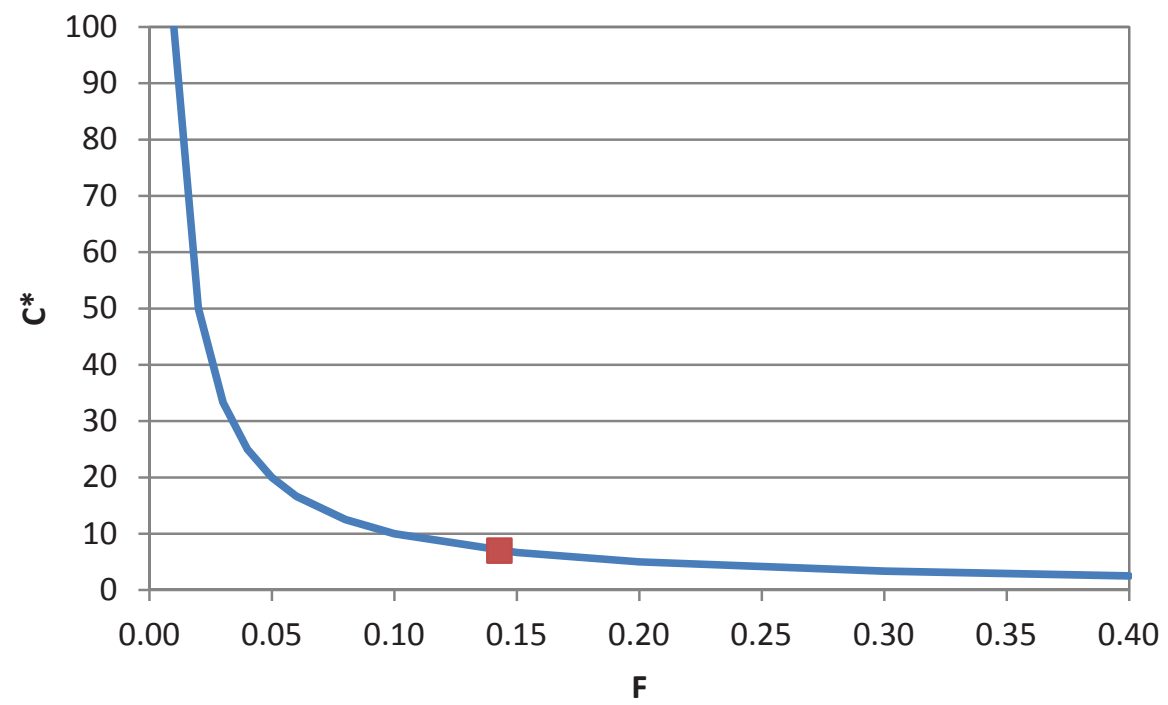

Figure 5.11 Relationship between the relative equilibrium concentration $\left(C^{*}=C / C_{\text {in }}\right)$ and the fraction of water lost to groundwater or by abstraction (F) given a constant volume in the lake. The red marker indicates the estimated equilibrium level for Lake Naivasha.

\subsubsection{Equilibrium rate}

Based on the values in Table 5.3 the residence time of the water in the lake is 2.6 years. The rate $(R$, equation 5.13 and $D=0)$ at which the lake approaches equilibrium was found to be $0.054 \mathrm{yr}^{-1}$. The characteristic time or relaxation time $(1 / \mathrm{R})$ was $18.4 \mathrm{yrs}$. The time to approach $90 \%$ of the equilibrium concentration takes over 40 years as illustrated in Figure 5.13 assuming $\mathrm{C}_{0}=0$. 


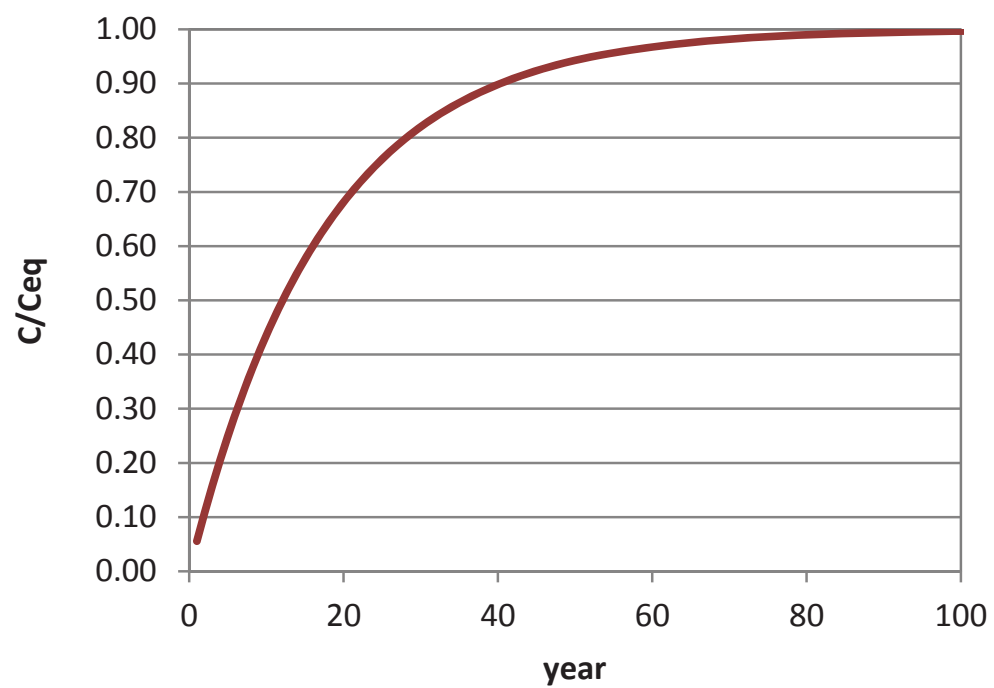

Figure 5.12 Approach to equilibrium concentration in Lake Naivasha.

\subsubsection{Dynamic conditions}

Various inflow and outflow terms were simulated to evaluate the effect of the inflow and outflow on pollutant concentration. Table 5.4 shows how the variables were varied. The main terms in the water balance are increased or decreased by $20 \times 10^{6} \mathrm{~m}^{3} /$ year for 20 years.

Other values used are $C_{\text {rain }}=0, C_{\text {rivers }}=0.5 \mathrm{mg} / \mathrm{l}, C_{w w}=1 \mathrm{mg} / \mathrm{l}, k=0$, and $\Delta t=$ 1 day. For these values the equilibrium concentration is $2.35 \mathrm{mg} / \mathrm{l}$ and $C_{\text {in }}=$ $0.34 \mathrm{mg} / \mathrm{l}$. 
Table 5.4 Changes in water balance for the dynamic calculations. Orange box indicates that the loss is larger than input (lowering water table) while green box indicates that the inflow is larger than loss (increasing water tables).

\begin{tabular}{|c|c|c|c|c|c|c|c|c|c|}
\hline & $\mathrm{Mm}^{3} / \mathrm{yr}$ & $\mathbf{Q}_{\text {in }}$ & $Q_{\text {rain }}$ & $Q_{\text {river }}$ & Qww & Qout & $\mathrm{Q}_{\mathrm{ET}}$ & Qoutflow & Net \\
\hline & Balanced & 350 & 120 & 225 & 5 & 350 & 300 & 50 & 0 \\
\hline \multirow[t]{2}{*}{ Rain } & year 0-20 & 330 & 100 & 225 & 5 & 350 & 300 & 50 & -20 \\
\hline & $\begin{array}{l}\text { year 20- } \\
40\end{array}$ & 370 & 140 & 225 & 5 & 350 & 300 & 50 & 20 \\
\hline \multirow[t]{2}{*}{ River } & $\begin{array}{l}\text { year } 40- \\
60\end{array}$ & 330 & 120 & 205 & 5 & 350 & 300 & 50 & -20 \\
\hline & $\begin{array}{l}\text { year 60- } \\
80\end{array}$ & 370 & 120 & 245 & 5 & 350 & 300 & 50 & 20 \\
\hline \multirow[t]{2}{*}{ Seepage } & $\begin{array}{l}\text { Year 80- } \\
100\end{array}$ & 350 & 120 & 225 & 5 & 370 & 300 & 70 & -20 \\
\hline & $\begin{array}{l}\text { Year 100- } \\
120\end{array}$ & 350 & 120 & 225 & 5 & 330 & 300 & 30 & 20 \\
\hline \multirow[t]{3}{*}{ ET } & $\begin{array}{l}\text { Year 120- } \\
140\end{array}$ & 350 & 120 & 225 & 5 & 330 & 320 & 50 & -20 \\
\hline & $\begin{array}{l}\text { Year 140- } \\
160\end{array}$ & 350 & 120 & 225 & 5 & 370 & 280 & 50 & 20 \\
\hline & $\begin{array}{l}\text { Year } \\
160+\end{array}$ & 350 & 120 & 225 & 5 & 350 & 300 & 50 & 0 \\
\hline
\end{tabular}

Figure 5.13 shows the change in concentration when the initial concentration is at equilibrium ( $C=2.35 \mathrm{mgL}^{-1}$ dashed line). In these results, the effect of a smaller surface area of the lake (less direct rainfall on the lake and less loss by ET) is ignored. When the precipitation becomes less and all other variables remain constant, the volume decreases, and subsequently the lake level will drop. When the volume decreases, the solutes become more concentrated and therefore the concentration increases. The increase in concentration is almost inversely proportional to the decrease in volume; the increase in concentration is slightly less than would be expected based on the decrease in volume because some mass is also lost to groundwater. When rainfall increases again the volume increases and the lake is diluted (concentration decreases). The concentration drops even below the equilibrium concentration for constant volume because over the 40 years more mass is lost by seepage and abstraction than the mass that entered via rivers and waste water $\left(0.34 \mathrm{~g} / \mathrm{m}^{3} \cdot 225 \times 10^{6} \mathrm{~m}^{3} / \mathrm{yr} \cdot 40 \mathrm{yr}=3060\right.$ tonnes [inflow] vs. ca. $2.5 \mathrm{~g} / \mathrm{m}^{3} \cdot 50 \times 10^{6} \mathrm{~m}^{3} / \mathrm{yr} \cdot 40 \mathrm{yr}=5000$ tonnes [outflow]). After 40 years the inflow by rivers reduces by $20 \mathrm{Mm}^{3}$ per year. The volume decreases and subsequently the solutes become more concentrated. But because the pollutant loading via the rivers also decreases, the gradient of the concentration increase is less steep than the case of a reduction in rainfall with the same amount. Also because the initial concentration ( $C$ at $t=40 \mathrm{yr}$ ) is lower, the concentration does not reach the same value as after the first 20 years with reduced rainfall. When the river discharge increases again at $t$ $=60 \mathrm{yr}$, the volume increases and the concentration drops. However, the decrease in concentration is slower because the pollutant loading $\left(Q_{i n} C_{i n}\right)$ also increases. An increase in seepage lowers the volume; however, the solutes 
do not become more concentrated because the mass dissolved in the water is also lost. When the ET increases, the volume decreases, and the lake becomes more concentrated similar to a reduction in rainfall. When the water balance is constant again (inflow = outflow) the concentration goes back to the equilibrium concentration. This takes more than 40 year as shown before.

In conclusion, concentrations in the lake respond directly to a change in volume of the lake (higher concentrations with decreasing lake levels and lower concentrations with increasing lake levels) when the volume changes due to changes in rainfall or evapotranspiration and to a lesser degree due to changes in river discharges. When the volume in the lake changes due to changes in seepage or abstraction, there is no direct effect on concentrations in the lake. Besides this the lake is trying to reach the equilibrium concentration which takes place over a much longer time scale of more than 40 years. This equilibrium concentration depends on the input concentration $\left(C_{i n}\right)$, the fraction of outflow by seepage and abstraction $(F)$ and possible other sources of mass loss $(D)$.

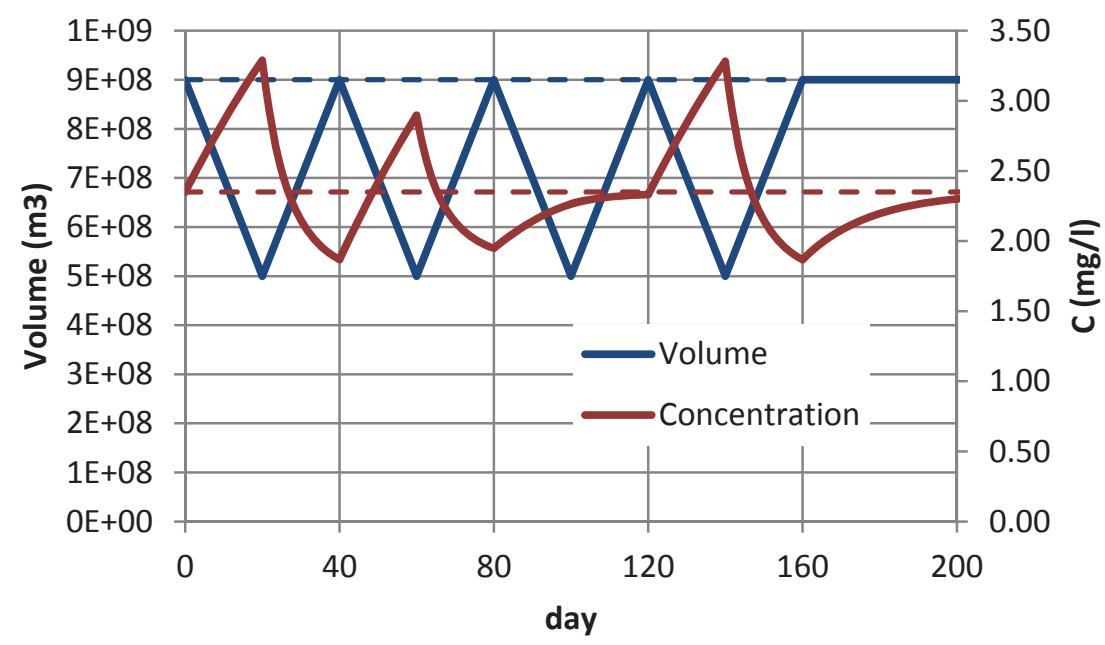

Figure 5.13 Concentration as function of a dynamic lake level, starting with the equilibrium concentration of a closed water balance $\left(C_{\text {eq }}=2.35 \mathrm{mg} / \mathrm{l}\right)$.

\subsection{Discussion}

The Delft3D model results potrayed circular motions in the main-lake which suggests some mixing in the main lake. The mid-lake and the southern region of the lake were similar in terms of water quality parameters (Hubble and Harper, 2002; Ndungu et al., 2013a) which could be explained by the hydrodynamics. The northern region showed high velocities which could be attributed to the shallow depth. Chapter 3 of this study showed dominance of the colored dissolved particles in the northern region which could be as a 
result of the high velocities which keep small particles in suspension (Ndungu et al., 2013a). Crescent Lake showed limited exchange with the main lake especially at $45^{\circ}$ wind direction. Previous studies have shown that the Crescent Lake is distinct from the main-lake (Hubble and Harper, 2002).

Zero and maximum discharge in combination with highest wind speed simulation outcomes were similar indicating the influence of the rivers' discharge on currents was limited. Therefore, wind is the major forcing factor in current direction and magnitude rather than the discharge in Lake Naivasha. Kranenburg (1992) has shown the effect of wind driven chaotic advection on transport of a passive tracer in shallow lakes with a conclusion that time dependent velocity fields can produce complex advection patterns. The circulation of other Rift valley lakes such as Lake Victoria in Kenya are known to be wind driven (Abuodha et al., 2005; Stager et al., 1997). Ssebuggwawo et al. (2005) simulated the hydrodynamics of Lake Victoria using Delft3D were found to be in agreement with currents field data. Although other researchers have mentioned wind-driven turbulence in Sonachi Crater Lake which is part of the lake Naivasha system, no other the study has been undertaken in hydrodynamic simulation for Lake Naivasha main lake.

The fresh water in Lake Naivasha is an indication that water is lost through seepage to groundwater. When the volume of the lake changes due to changes in rainfall, river discharges, or ET, the concentration responds immediately; by either an increase in concentration with a decrease in the volume of water, or a decrease in concentration (dilution effect) with an increase in the volume of water. When the volume of the water in the lake changes as a result of water loss through seepage into the groundwater or by abstraction, the pollutant concentrations changes is minimal. Other studies have linked high concentration of solutes to evaporation in shallow lakes (Noges et al., 2007).

When the pollutant loading $\left(C_{\text {in }}\right)$ into the lake changes, it takes more than 40 years to reach the equilibrium concentration. When pollutants are adsorbed they may be released later and this may also increase the time required to reach a new equilibrium. This also means that if all sources are reduced now the water quality in the lake will improve gradually and it will take more than 40 years before a new equilibrium is reached. Considering that the pollution of the lake started in the 70 s or 80 s with the introduction of horticultural farms, the lake would be approaching equilibrium state in 10 years from now. This would be expected if the pollutant loading would remain constant over the 40 years. However, if the pollutant loading is dynamic, then reaching the equilibrium state would take much longer time and therefore the effect of pollutants will be felt for a longer period of time. Considering hysteresis to be 
a major cause of delayed response of shallow lakes to reduction of nutrient loading (Janse et al., 2008; Scheffer, 1990), then a reduction to the However, this study could only link the delayed response to the initial concentration in respect to the changes in the lake water volume. The residence time value (2.6 years) from this study falls in the range recorded in Verschuren et al. (2000a).

\subsection{Conclusions}

From the hydrodynamic model, we conclude that currents are mainly winddriven in Lake Naivasha. The currents could be responsible for the mass transport from the input rivers which impacts on the spatial temporal variability in water quality in Lake Naivasha. This is because the current seem to propel fast in the shallow northern region and assumes circular motions in the deep central part of the lake. There exists mixing (denoted by circular motions) in the main lake which can enhance nutrient redistribution and eventually impact on the algal biomass growth and hence the turbidity levels. The mixing indicates that the main lake could be well mixed. The study also limited exchange between the crescent lake and the main lake. This explains the reason behind the spatial variability described in chapter 2 and 3 .

This study showed that it takes more than 40 years to achieve a new equilibrium with a constant change in the pollutant loading. Therefore, the local processes such as redistribution of substances by currents, concentration or dilution effects due to changes in volume, caused by temporal effects such as rainfall and high evaporation could be responsible for the observed differences in concentrations in the year of field experiments in Chapter 3 of this study. The effluent from the WWTP and direct return flow from greenhouses or agricultural plots have limited effect on the average concentration of the whole lake; since they account only a small portion of $\mathrm{C}_{\text {in }}$. This study also revealed that abstraction and ground water seepage keeps the lake water fresh. Abstraction and ground water seepage affects the volume which is inclusive of the pollutant concentration within the water. Hence, abstraction of water from the lake is not necessarily negative for the sustainability of the lake ecosystem but could even be positive (in reduction of pollutant concentration) as long as it does not affect the volume of the lake significantly, and the return flows are treated such that the load to the lake $\left(C_{i n}\right)$ does not increase.

The best measure to improve the water quality of the lake is to reduce the inflow of pollutants. This can be done by restoring the swamp in the north of the lake such that most of the pollutants and sediments are retained in this area. However, even if the water quality of the lake is improved, it may not automatically return to a clear state because of the mechanisms (such as 
changes in the loading) that push the equilibrium level to a much longer period. More so, macrophytes and fish community change with a change in the stable states which makes it even harder for lake ecosystem to shift to an alternative stable state (Scheffer, 1990). 


\section{Chapter 6}

\section{Relationship between fish community succession, water quality and livelihood: case study in Lake Naivasha, Kenya4}

\footnotetext{
${ }^{4}$ This chapter is based on: Ndungu, J.N., Augustijn, D.C.M., Hulscher, S.J.M.H., Kitaka, N. \& Mathooko, J.M., Relationship between fish community succession, water quality and livelihood: case study in Lake Naivasha, Kenya (submitted).
} 


\begin{abstract}
The fish community in an aquatic system determines the quality of the water as well as the biodiversity. Presence of benthic feeders can transform a clear lake to a turbid lake which is detrimental to the ecosystem's functions and services. This study evaluates the changes of fish communities from 2003 to 2010 and its relationship with the water quality in Lake Naivasha through time series plots and correlation techniques. In addition, the study assesses the progressive annual income generated from fish catches by each fishermen, and the percentage revenue generated per species to assess the contribution of the fish catches to the community livelihood. The results of the study revealed that the catches of Cyprinus carpio (which is a benthic feeder) increased tremendously over the study period and led to gradual elimination of other commercial fish species such as Tilapia zillii in Lake Naivasha. Correlation results revealed significant positive relationship between the Cyprinus carpio and chlorophyll-a, as a water quality indicator and hence Tilapia zillii catches were found to decrease with a increase in chlorophyll-a probably due to impairment in visibility. Micropterus salmoides showed tolerance to turbid conditions the correlation with chlorophyll-a concentration was insignificant.
\end{abstract}




\subsection{Introduction}

Aquatic fishery resources contribute to communities' livelihood and nutritional security. However, the exploitation of the resources could be achieved at the expense of the environmental integrity. Introduction of benthivores fish communities can transform a clear lake endowed with diversity richness to a turbid lake which is associated with low biodiversity, low aesthetic value and therefore less tourism related revenue (Meijer et al., 1990; Scheffer, 1990). These have implications on decision makers' choices in management of the aquatic systems: in every management option chosen, it is important to consider the environmental status, preferred fish communities and revenue generation. The emphasis is on preferred fish species because the success of each species may be dependent on the status of the water quality. However, some fish species such as the benthic feeders contribute to the deterioration of the water quality. The benthic feeders' barrowing activity leads to resuspension of sediments which results in the release of nutrients into the water column that enhances phytoplankton/algae growth and could translate to high chlorophyll-a concentrations (Figure 6.1). The re-suspended sediment and algae lead to increase in turbidity which reduces the ability to spot the prey and therefore hinders the growth of the pelagic predator fish species. 


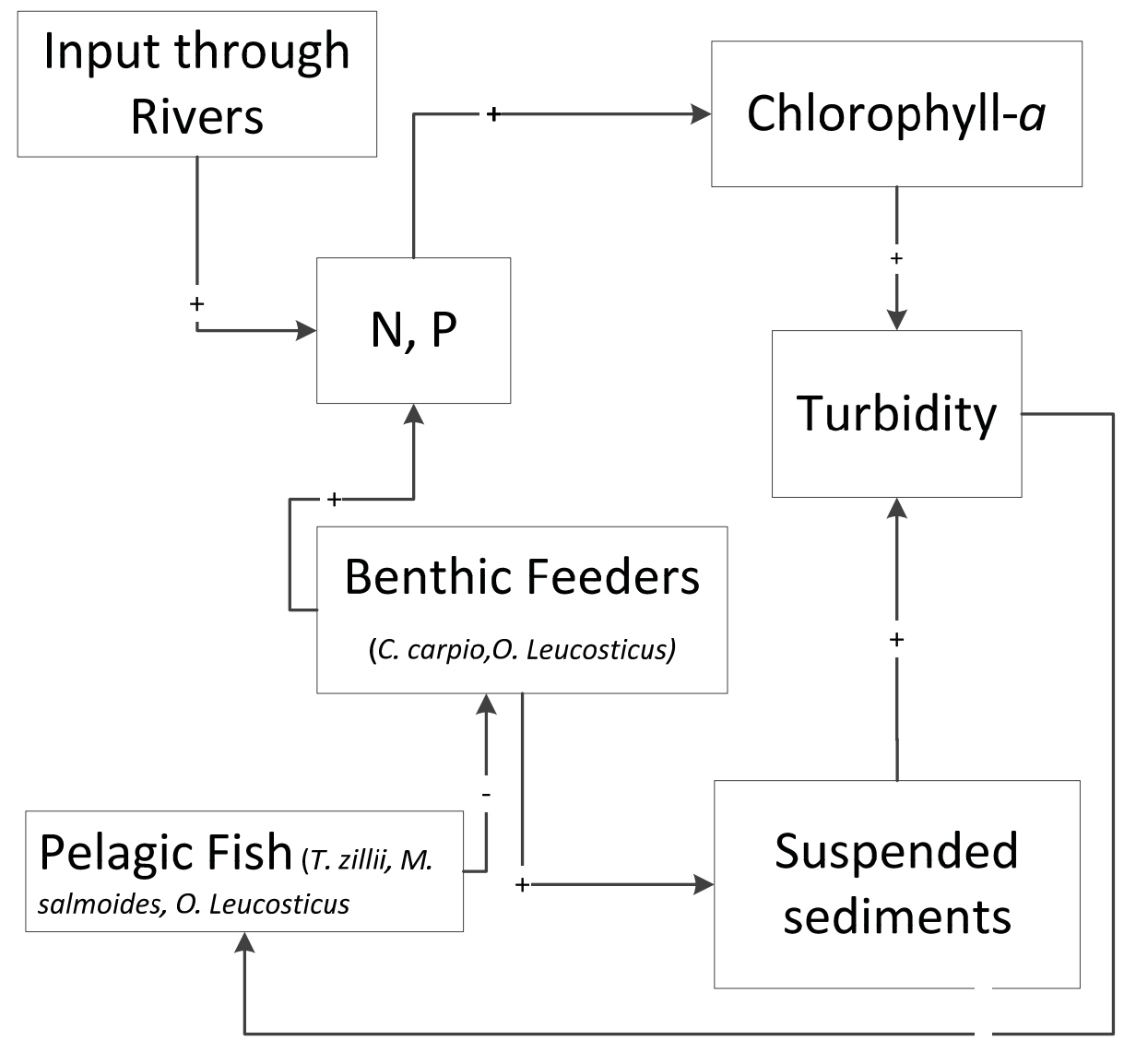

Figure 6.1 Illustration of the relationship between fish and water quality

Previous research has shown significant effect of Cyprinus carpio on turbidity and habitat structure of aquatic ecosystems (Roberts et al., 1995). Jackson et al. (2010) established that the presence of benthivores fish assemblages results in tremendous decline in sight reliant feeders in aquatic ecosystems. Although the benthic feeders have negative effect on other fish and aquatic communities, the economic gains outweigh the associated economic losses (Miller and Crowl, 2006; Pimentel et al., 2000). In Lake Naivasha, the fishing industry currently employs more than 1000 Kenyan citizens, and provides a source of protein for area residents as well as others in nearby towns (Kundu et al., 2010). However, the commercial fish catches keep changing with introduction of alien species. The last endemic fish species Aplocheilichthys antinorii (Vinciguerra) was last recorded in 1962 (Elder et al., 1971). Sarotherodon spirulus niger currently referred to Oreochromis spirulus niger (Gunther) appeared in the lake in the 1950s and 1960s but disappeared since 1971 (Siddiqui, 1979). Other fish species that disappeared include the hybrid 
of Sarotherodon/Oreochromis leucosticus (Trewavas) and Sarotherodon spirulus niger which used to be abundant in the 1960s and disappeared in 1972. In the late 70s, the fish population in the lake consisted of six introduced species: Sarotherodon/Oreochromis leucosticus, Tillapia zillii (Gervais), Micropterus salmoides (La Cepède) Gambusia spicies. Poecilia reticulate and Onchorhynchus mykiss (Elder et al., 1971; Hickley et al., 2008; Ojuok et al., 2013). Notably, Oreochromis niloticus (Nile Tilapia) was introduced in the lake in 1967 and disappeared in 1971. However, it was reintroduced in the lake by the government in 2011 through the Economic Stimulus Programme.

Lake Naivasha's water quality deteriorated significantly especially in the last decades: Ndungu et al. (2013b) reported that the chlorophyll-a concentration as a turbidity indicator increased from 2002 to 2012. In the same period, the commercial fisheries in the lake experienced Cyprinus carpio dominance at the expense of Tilapia zillii, Oreochromis leucosticus (Trewavas), and Micropterous salmoides species (Oyugi et al., 2011). Oyugi (2011) associated the decline in the water transparency to Cyprinus carpio based on Secchi depth readings of 2002 and 2009. However, no other study has gone to the extent of establishing the relationship between Cyprinus carpio as well as other commercial fisheries and the chlorophyll-a concentration as a turbidity indicator in Lake Naivasha. Water levels were found to have an inverse relationship with chlorophyll-a concentration (Ndungu et al., 2013b) and were therefore also used as one of the factors that influence the water quality. The specific objectives of this study were to: 1) study the commercial fish community succession in the last decade (succession in the context of this study refers to the observed changes in fish community following an environmental perturbation (Connell and Slatyer, 1977); 2), establish the relationship between the fish community succession and water quality; and 3) assess the impact of fish community succession on the livelihood of the people around the lake. These objectives were achieved based on time series plots of the different fish species and correlation statistical techniques. This chapter provides information on the main fish species in the commercial fisheries, shows the progressive trend in the fish catches per species and explains the relationship between the total catches (in weight) and environmental variables (Chlorophyll-a and water levels).

\subsection{Study area}

This study was conducted in Lake Naivasha, a shallow equatorial lake situated on the floor of the Eastern Rift Valley in Kenya at $1885 \mathrm{~m}$ above sea level; and lies between latitude $00^{\circ} 46^{\prime} \mathrm{S}$ and longitude $36^{\circ} 22^{\prime} \mathrm{E}$ (Figure 6.2). Apart from the main lake which is of tectonic origin, there lies the Crescent Lake which was formed through volcanic activity and remains 
connected to the main lake except during extreme decline in lake levels. The mean temperature around the lake is $25^{\circ} \mathrm{C}$ and the annual rainfall is bimodal which occur in March/April/May and October/November, respectively.

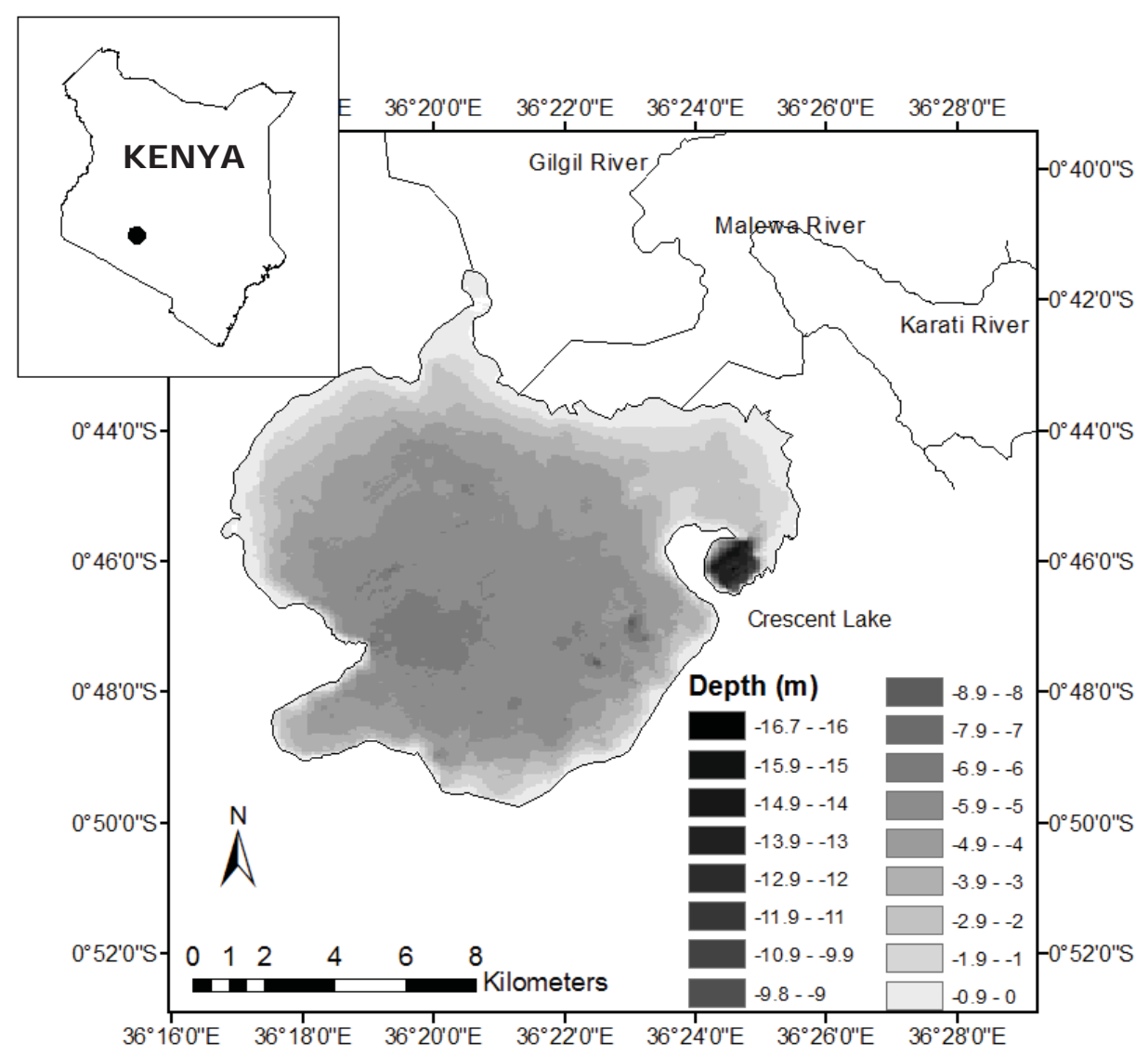

Figure 6.2 Map showing Lake Naivasha, and the input rivers

\subsection{Materials and methods}

\subsubsection{Data collection}

Monthly commercial fisheries catch data (from 2005 to 2010) were sourced from the Fisheries Department's station in Naivasha, Kenya. The data were cumulative figures of the daily amount of commercial fish caught from Lake Naivasha per day for each species in all the landing beaches. The Fisheries Department sums them up and comes up with a monthly value for each species which is documented in the annual reports. The chlorophyll-a concentration and lake level trend data were acquired from Moderate Resolution Imaging Spectroradiometer Aqua (MODIS-Aqua) satellite data and 
the national water level gauge (2GB6) station located close to Crescent Lake, respectively, as published in Ndungu et al. (2013b).

\subsubsection{Data analysis}

To assess the commercial fish succession, monthly time series plots of all the commercial fish species were made. However, June, July, and August months were excluded in the analysis because the fishermen were not allowed to fish during that period (a closed season). Pearson correlation between the fish catches and chlorophyll-a concentration as well as the lake level trends were performed to investigate the relationship between the fish community and the water quality of Lake Naivasha. To assess the contribution of fish to the livelihood of the people around the lake, total annual revenue per fisherman, price per unit of each fish species, and percentage contribution of the revenue generation were calculated and presented in bar graphs. Each boat was allowed by the authorities to have 10 fishing nets and three fishermen on board. To get the number of fishermen, the number of boats was multiplied by three. The results were used to calculate the annual income per fisherman.

\subsubsection{Characteristics of the commercial fisheries in Lake Naivasha}

The information on the characteristic of the fish species is important in this study. Knowledge on reproduction rate and the age can help in the understanding of the response of the fish species to environmental perturbations. The information on the weight/size can help in visualizing the number of fish given a certain number of kilograms. The knowledge on foraging behaviour can help in the understanding of the habitat requirements.

The commercial fish species in Lake Naivasha during the time of this study included: Common carp (Cyprinus carpio), Tilapia zillii, Oreochromis leucosticus, and Micropterous salmoides (Figure 6.3). The common carp is tolerant to low oxygen levels and prefers burrowing benthic insects, worms and other crustaceans although it is known to be omnivorous. A single common carp can lay over a million eggs a year, a typical female can lay 300,000 eggs in a single spawn (Smith and Walker, 2004). In the tropics, the spawning can take place more than once in a season. The Carp can reproduce throughout its lifetime (Sivakumaran et al., 2003). The egg production increases with the age of the carp (Brown, 2003). In Lake Victoria, a female carp of 32 years was observed (Brown, 2003). The growth of eggs depends on the environmental conditions such as water temperature, food, and daylight length. The carp in temperate zones matures after two years and spawn in spring. Male common carp can live for up to the age of 8 
years (Tempero et al., 2006). The average size of the common carp can be $40-80 \mathrm{~cm}$ and $2-14 \mathrm{~kg}$.

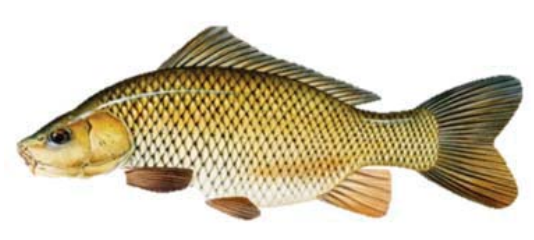

Cyprinus carpio

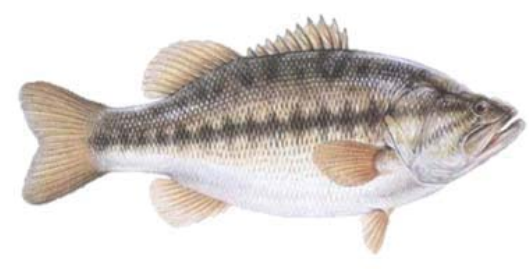

Micropterus salmoides

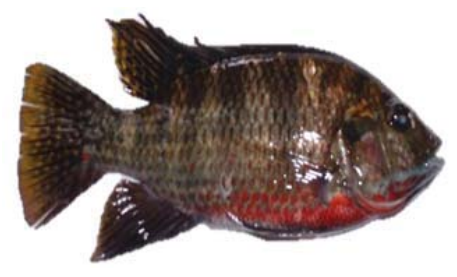

Tilapia zillii

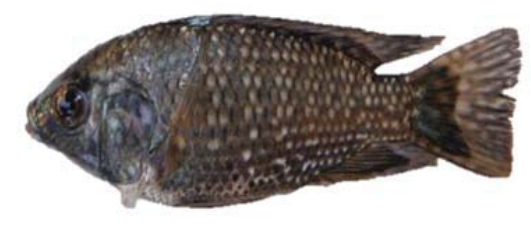

Oreochromis leucosticus

Figure 6.3 Pictures of the commercial fish species in Lake Naivasha

Tilapia zillii takes 6 to 7 months to mature to harvest size. Spawning size is $13-14 \mathrm{~cm}$ which is reached in 2 years. It has a maximum length of $40 \mathrm{~cm}$ and the maximum weight is 300 grams. Tilapia zillii is omnivores and often decrease the plant density leading to a change in the composition of native plants which can threaten many the aquatic organisms that depend on such plants for food, camouflage, or breeding (Spataru, 1978). The juvenilles are more carnivorous predating on zoobenthos and prefers shallow vegetated habitats in tropical aquatic environment with a pH level range of 6 to 9.

Micropterus salmoides is predator of the Tilapia zillii. It also feeds on crayfish and frogs while the young feed on crustaceans, insects and small fishes. It prefers clear vegetated lakes but highly is adaptable to all warm water habitats. It's known to be benthopelagic. Its reproduction can be inhibited by temperatures below $10^{\circ} \mathrm{C}$ or $\mathrm{pH}$ below 6 . Spawning takes place when tempretature are above $15^{\circ} \mathrm{C}$. Adults mate at the age of 5-12 years and the maximum published weight is 10.1 Kilograms.

Oreochromis leucosticus is a benthopelagic tropical fresh water fish. It does well in $\mathrm{pH}$ range of 7.0 to 9.0 and temperatures between $26-28^{\circ} \mathrm{C}$. Maximum length is $36 \mathrm{~cm}$ (Welcomme, 1967). At maturity the length of the Oreochromis leucosticus ranges between $6-22 \mathrm{~cm}$. 
Table 6.1 Summary of the characteristic of the commercial fish species in Lake Naivasha

\begin{tabular}{llllll}
\hline Fish species & $\begin{array}{l}\text { Max. } \\
\text { Size }\end{array}$ & $\begin{array}{l}\text { Max. } \\
\text { Weight }\end{array}$ & Habitat & Feeding & Lifespan \\
\hline C. carpio & $80 \mathrm{~cm}$ & $14 \mathrm{~kg}$ & Benthic & Benthivores & $>40 \mathrm{yrs}$ \\
T. zillii & $40 \mathrm{~cm}$ & $300 \mathrm{~g}$ & Pelagic & Omnivores & $6 \mathrm{yrs}$. \\
M. salmoides & $75 \mathrm{~cm}$ & 10.1 & Benthopelagic & Carnivores & $16 \mathrm{yrs}$. \\
O. leucostica & $36 \mathrm{~cm}$ & - & Benthopelagic & $\begin{array}{l}\text { Plankton and } \\
\text { detritus }\end{array}$ & \\
& & & & &
\end{tabular}

\subsection{Results}

\subsubsection{Commercial fisheries succession}

A tremendous increase in the Cyprinus carpio catches is eminent all the way from 2005 to 2009 but dropped in 2010. Since 2005, other fish species catches diminished (Figure 6.4). The Tilapia zillii experienced a significant decline until it was completely phased out in the commercial fisheries from 2009. The Oreochromis leucosticus catches were almost zero but re-emerged for one year in 2008. Micropterus salmoides decline was gradual with still some catches in 2010. 


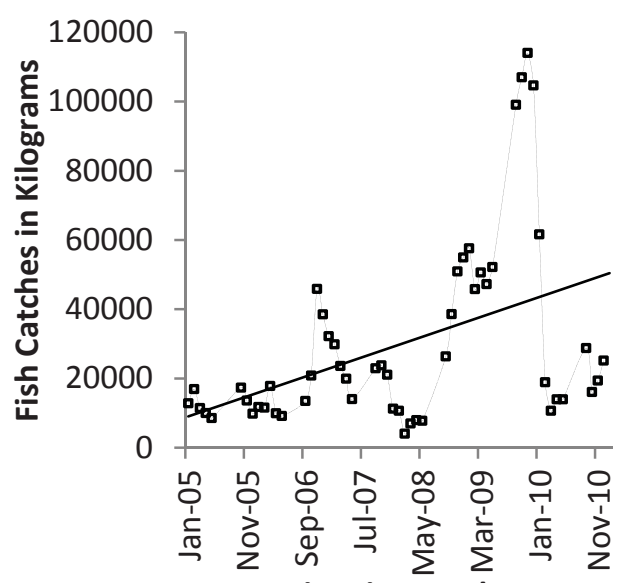

Time in months

Cyprinus carpio

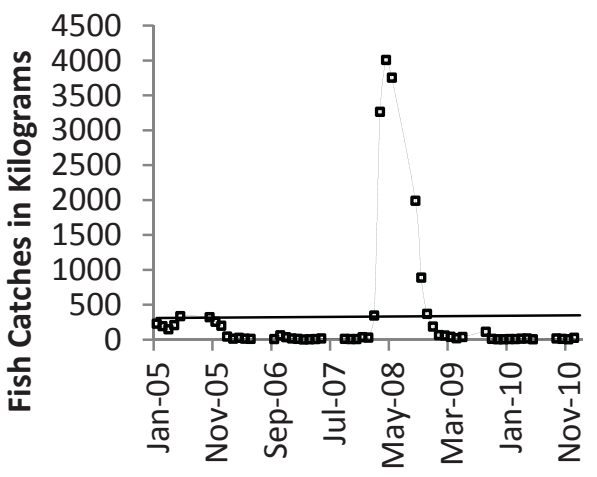

Time in months

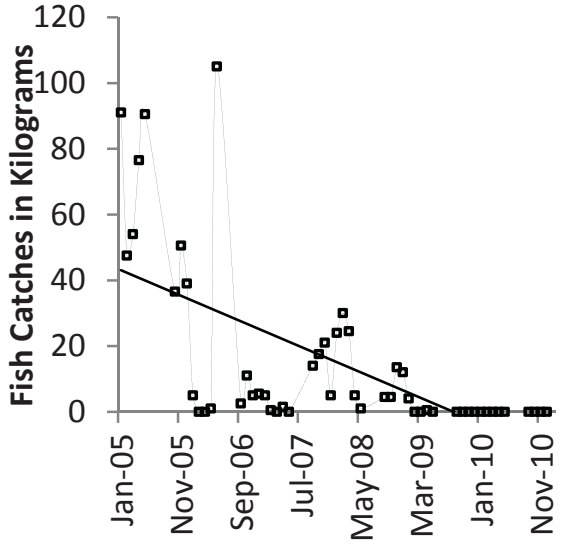

Time in months

Tilapia zillii

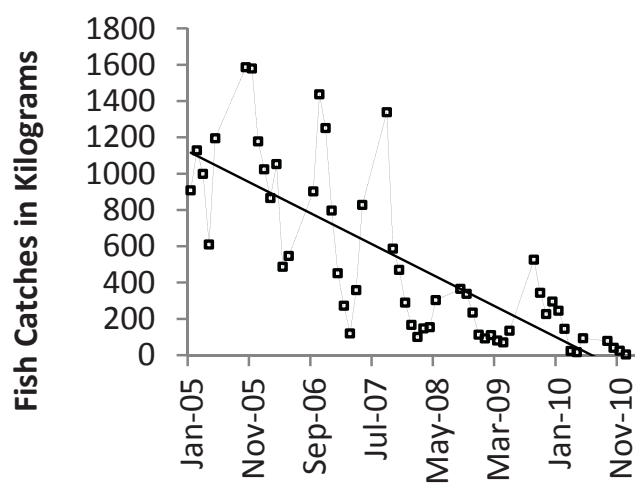

Time in months

Micropterous salmoides

Oreochromis leucosticus

Figure 6.4 Commercial fish monthly catches from 2003 to 2010 in Lake Naivasha. The solid line is the trend line. NB. June, July, and August months were excluded in the analysis because it is a closed season 


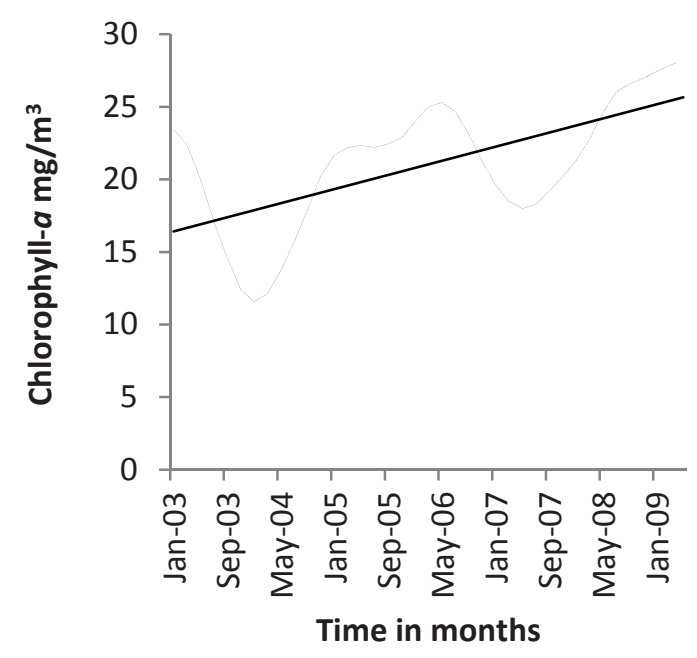

Chlorophyll-a

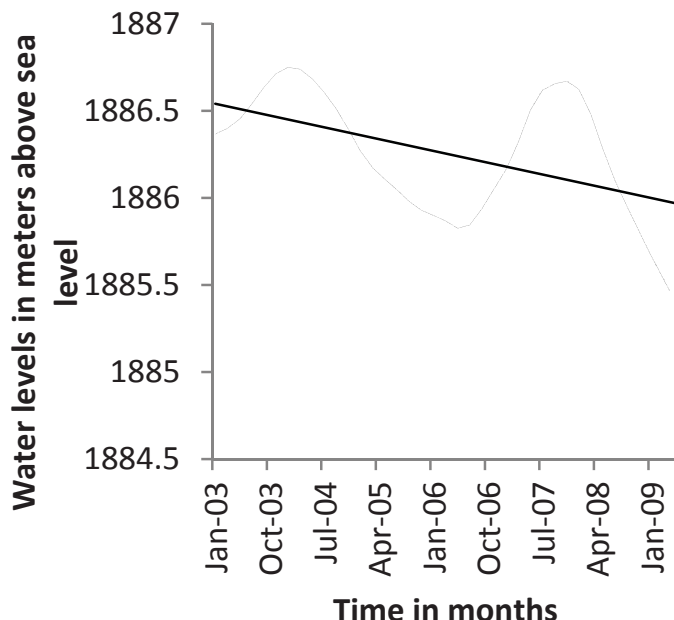

Lake Water Level

Figure 6.5 Time series plot of the chlorophyll-a concentration and Lake water levels trends from January 2003 to April 2009

\subsubsection{Relationship between chlorophyll-a and commercial fisheries succession in Lake Naivasha}

The chlorophyll-a and water levels are shown in Figure 6.5. From the figure, we observe an increasing trend in chlorophyll-a and a decrease trend in water levels. Correlation ( $r$ ) analysis between the commercial fish species 
showed that Cyprinus carpio and Tilapia zillii were more strongly correlated to Chlorophyll-a than the rest of the fish species (Table 6.2). It was evident that an increase in Cyprinus carpio catches corresponded to an increase in Chlorophyll-a. The water level showed negative correlation with chlorophyll-a and therefore expected to also correlate negatively with the Cyprinus carpio catches. The Tilapia zillii had an inverse relationship to the chlorophyll-a concentration and positive relationship with lake levels. Micropterus salmoides and Oreuchromis leucosticus showed a weak negative relationship with chlorophyll-a despite the clear decline in M. salmoides (Figure 6.4). Oreuchromis leucosticus had a stronger relationship with water levels than the Micropterus salmoides.

Table 6.2 Table showing the correlation coefficient between the commercial fish species and chlorophyll-a

\begin{tabular}{lccc}
\hline \multicolumn{1}{c}{ Variables } & $\begin{array}{c}\text { Correlation } \\
\text { coefficient }(r)\end{array}$ & p-values & $\begin{array}{c}\text { Coefficients of } \\
\text { determination }\left(R^{2}\right):\end{array}$ \\
\hline C. Cyprinus & $\mathbf{0 . 5 2 2}$ & $<\mathbf{0 . 0 0 1}$ & 0.272 \\
T.zilli & $\mathbf{- 0 . 5 4 4}$ & $<\mathbf{0 . 0 0 0 1}$ & 0.296 \\
M. salmoides & $\mathbf{- 0 . 3 2 0}$ & $\mathbf{0 . 0 1 7}$ & 0.102 \\
O. leucostictus & $\mathbf{- 0 . 3 0 7}$ & $\mathbf{0 . 0 2 3}$ & 0.094 \\
Lake Water level & $\mathbf{- 0 . 8 3 9}$ & $<\mathbf{0 . 0 0 1}$ & 0.704 \\
\hline
\end{tabular}

Values in bold are significant (significance level alpha=0.05) for the $(r)$.

\subsubsection{Revenue generation from fish catches}

The annual total income generated from the total catches per fisherman in lake Naivasha increased tremendously up to 2009 followed by a sharp decrease in 2010 (Figure 6.6 (a)). Micropterus salmoides had a higher unit cost than the other the fish species (Figure 6.6 (b)). Cyprinus carpio species had the lowest average value per kilogram although it constitutes over $90 \%$ of the total annual income generated from the lake in 2005 to 2010 (Figure 6.6(c)). 

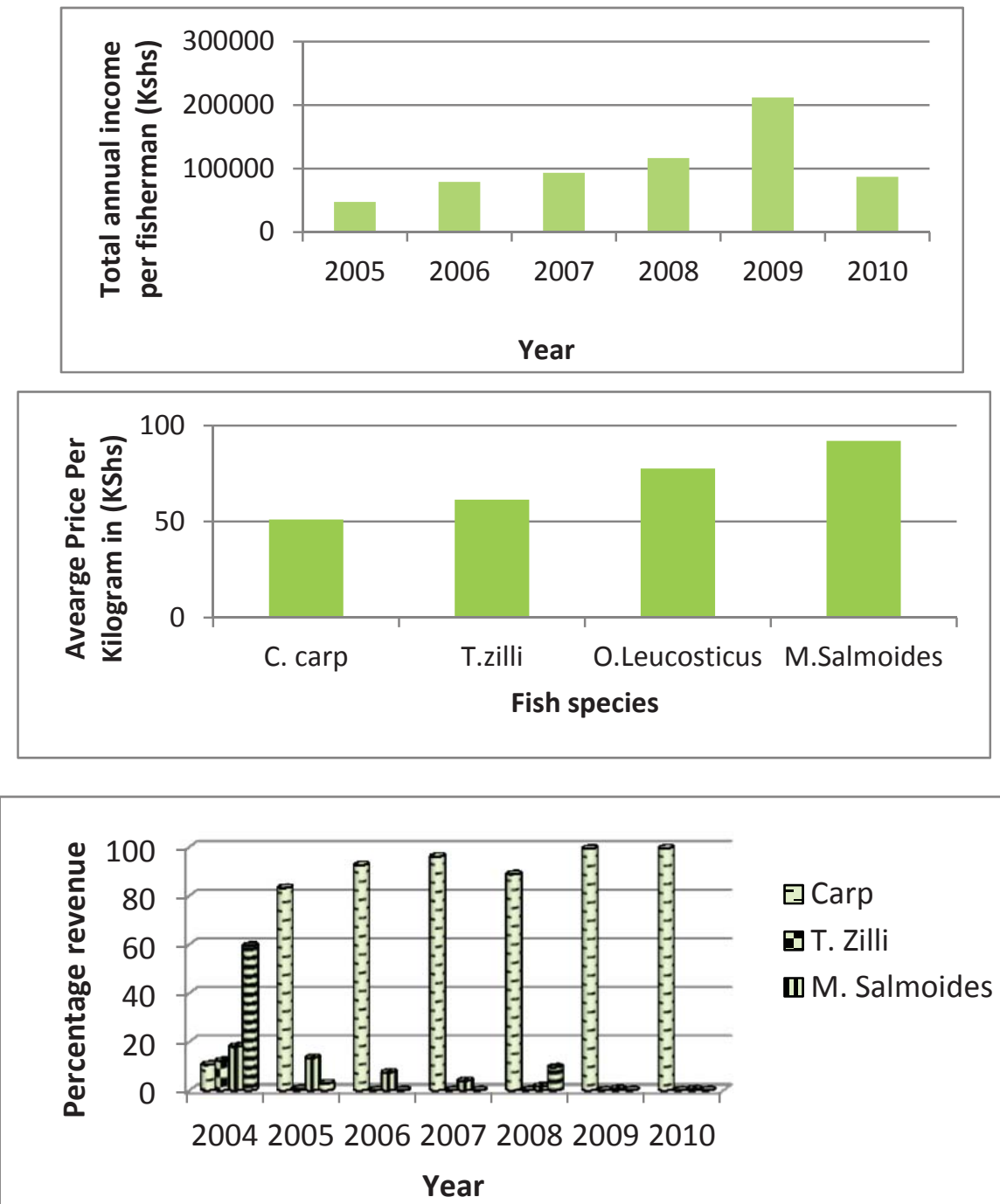

ECarp

T. Zilli

m. Salmoides

Figure 6.6 Figure illustrating the total annual income generated by each fisherman (a), average price per kilogram of each fish species (b), and the percentage income generated by each fish species (1 Euro 100 Kenya shillings)

\subsection{Discussion}

The results of this study show that chlorophyll-a concentration had a positive correlation with Cyprinus carpio catches which could be attributed to sediments re-suspension leading to release of nutrients to the water column as the Cyprinus carpio barrows into the sediments during feeding. The availability of nutrients in the water column enhances the growth of algae, whose biomass is estimated through chlorophyll-a concentration, which 
contribute to high turbidity in Lake Naivasha. Other researchers have reported that turbid lakes are dominated by benthivores fish assemblages and contains very few sight reliant feeders (Jackson et al., 2010; Jeppesen et al., 1997). Lakes with high Cyprinus carpio catches are known to have high nutrient levels, high chlorophyll-a concentration and low transparency (Jackson et al., 2010). The Cyprinus carpio was introduced accidentally in 1997-98 period and started being seen in the Lake Naivasha commercial fisheries in 2002 (Oyugi 2012). Ferincz et al. (2012) did a long-term analysis and found that invasive fish species can eliminate the native species in four years without fishing activities. Other studies have also found positive relationships between chlorophyll-a and Cyprinus carpio (Egertson and Downing, 2004).

Being omnivorous, Tilapia zillii relies on vision to spot its prey (Agbabiaka, 2012) and therefore an increase in turbidity level would lead to a decline in Tilapia zillii. In this study, an inverse correlation was observed between chlorophyll-a and Tilapia zillii. These findings imply that in less turbid water, the Tilapia zillii is able to feed and therefore grows to a larger size that can be caught using the large mesh size nets used by the commercial fishermen. This interpretation is based on the total weight of the catches which means that the existing population increase in weight and therefore become big enough to be caught and does not necessarily mean that the entire population of the Tilapia zillii increases at the same rate. In 2009 and 2010, the Tilapia zillii catches dropped to zero signifying a non-torelance to high turbid conditions which were enhanced by low water levels at the time. These findings are in agreement with Egerton and Downing (2004) who found a decline in the catch per unit effort of spot fisheries with an increase in chlorophyll-a. However, no other study at our disposal that has related chlorophyll-a and Tilapia zillii species specifically. Water levels are inversely related to the turbidity due to dilution effect and therefore correlate positively with the Tilapia zillii catches as revealed in this study.

Oreochromis leucosticus feeds on both phytoplankton and detritus. This would imply that high turbid waters would lead to an increase in Oreochromis leucosticus. However, the trend of Oreochromis leucosticus catches was found to be almost constant with a sudden peak in 2008 and 2009. The peak period corresponded with the lowest Cyprinus carpio catches. Both Oreochromis leucosticus and Cyprinus carpio feed on detritus and therefore compete for the same type of food leading to an increase in Oreochromis leucosticus when the Cyprinus carpio catches decline to approximately below $10,000 \mathrm{~kg}$ per month (Figure 6.4). There are no other studies for comparison which have portrayed food competition between Oreochromis leucosticus and Cyprinus carpio. 
Micropterus salmoides showed a weak relationship with both Chlorophyll-a and water levels. This is mainly because Micropterus salmoides species is a carnivore which feeds on a wide range of small animals (such as small fish, frogs, snails, small birds, snakes, salamanders, among others) which are much larger and easier to spot even in turbid water compared to insects (partial diet for the Tilapia zillii). This would imply that feeding effort of Micropterus salmoides is not affected by water turbidity. However, the overall succession indicated a decline of the species which may be attributed to availability of its prey as they decline in response to turbid conditions.

It would be ideal to perform cross correlation between the chlorophyll-a or water level and the monthly commercial fish catches to give an insight on the lag time taken for the species to respond to water quality changes in terms of growth and replication. However, the results would be biased considered the June, July and August closed season.

In as much as the community diversity has declined in the last decade, the economic status of the fishermen seems to have improved because though the Cyprinus carpio eradicated some species, its catches multiplied several times more than the total catches of the rest of the fish species. Being, a benthic feeder, the Cyprinus carpio has taken over the commercial fisheries since its appearance with over $99 \%$ dominance in annual revenue generation in 2009 and 2010. However, Micropterus salmoides is the most expensive fish species in Lake Naivasha and therefore likely to be more lucrative if its population would increase. Oreochromis leucosticus has the second highest price per unit cost.

\subsection{Conclusions}

This study investigated the succession in fish community following the introduction of the Cyprinus carpio; the effects of the fish succession on water quality; and the relationship of the succession in fish community on livelihoods of the people around the lake. Monthly fish catches data from 2005 to 2010 acquired from the fisheries department and were used for the analysis. The evaluation of the fish community succession revealed that the Cyprinus carpio has not only led to elimination of sight dependent feeders such as Tilapia zillii but may also contribute to an increase in chlorophyll-a concentration through nutrient enrichment from the lake sediment layer. This was shown through the correlation analysis which indicated positive relationship between chlorophyll-a concentration and Cyprinus carpio. This was attributed to the burrowing activity of the Cyprinus carpio that causes re-suspension of sediment which results in release of adsorbed nutrients into the water column. The presence of nutrients in the water column enhanced algae growth whose biomass is estimated through chlorophyll-a 
concentration. The increase in turbidity led to a decline in visibility and therefore difficult for some fish species to survive due to the limitation in spotting their prey. These effects could have led to the elimination of Tilapia zillii and decline of other fish species like the Micropterus samoides. However, Micropterus salmoides was found to be more tolerant to turbid conditions because the decline of the catches was more gradual and steady as compared to other species. In terms of fishermen revenue, Cyprinus carpio was more lucrative because of the large quantities even though it had the least unit cost (Figure 6.6). The revenue generated from fish since 2006 to 2010 was found to contain more than 90\% Cyprinus carpio dominance. 
Chapter 7

Conclusions and Recommendations 


\section{Conclusions and Recommendations}

This study aimed at assessing the water quality in Lake Naivasha. The study provided information on the distribution of the physiochemical characteristics, nutrients, and main ions. The trophic state at the time of the study was evaluated. The chlorophyll-a concentration in the last decade was investigated to provide information on the spatio-temporal dynamics of water quality in the previous years in Lake Naivasha. The main driving factors of water quality have been investigated through hydrodynamics and water quality modelling. Further, the relationship between fish community succession and the water quality are assessed. This study demonstrates the integration of ground measurements, remote sensing technology and modelling approaches to enhance the understanding of water quality status, retrogressive water quality conditions and hydrodynamics in the lake, respectively.

\subsection{Conclusions}

\subsubsection{What is the status of water quality in Lake Naivasha?}

The first objective in this research was to investigate the status of water quality in Lake Naivasha (Chapter 2). To achieve this objective, Principal Component Analysis (PCA) and Cluster Analysis (CA) multivariate techniques were used to analyse 19 water quality parameters collected from seven sampling stations from January to November 2011. The parameters used include physicochemical parameters (temperature, $\mathrm{pH}$, conductivity, turbidity, total dissolved solids, total suspended solids, total hardness, and total alkalinity); nutrients such as nitrogen (as $\mathrm{NH}_{4}-\mathrm{N}, \mathrm{NO}_{3}-\mathrm{N}$ and $\mathrm{NO}_{2}-\mathrm{N}$ ), and phosphorus (as $\mathrm{PO}_{4}{ }^{3-}-\mathrm{P}$ and TP); and main ions (calcium, magnesium, iron, manganese, chlorides, and sulphates). The inferences made from this study are based on joint relationships of the parameters which provide an opportunity for succinct summaries of large datasets especially in exploratory stages of investigations.

Spatial variation in the status of chemical, physical and main ions is evident in Lake Naivasha. The northern region which is close to the river inputs (Mouth of Malewa, North East), Crescent Lake and the main lake (Kamere Beach, Hippo point, South East and Midlake) regions were observably distinct. The North East region of the Lake was dominated by domestic waste water with relatively high NH4-N and the interaction with Crescent Lake (high $\mathrm{Mg}^{2+}$ ) whose natural mineral composition, associated with its volcanic origin play a major role. The water quality around the river inputs (Mouth of Malewa) is influenced by agricultural activities associated with high amounts 
of nutrients and high turbidity. This implies that the management interventions do not only require the information on the status of water quality but also the probable causes of the water quality variability, which is provided in this study, to help in identification of the appropriate mitigation measures.

\subsubsection{What is the status of the trophic state of Lake Naivasha?}

The second objective was to investigate the trophic state of Lake Naivasha. This was done by determining the trophic state in the lake which gives information on the biological productivity in aquatic systems (Chapter 3). Apart from establishing the trophic state, this study investigated the constituents of turbidity based on the trophic state indices (TSI) which were derived from chlorophyll-a concentration, secchi depth, and total phosphorus concentration. The TSI were calculated using Carlson's (1977) formulae which are based on the assumption that there is a close relationship between chlorophyll-a, secchi depth, and total phosphorus.

In comparison to previous water quality studies, this study shows that the lake has become more eutrophic indicating a progressive deterioration of the quality of the lake. The turbidity around the river mouth is mainly due to dissolved sediments and other organic matter rather than chlorophyll-a (Figure 3.6) which is also evident in Figure 2.3 which shows turbidity (in NTU) as more influencing in the distinction of Mouth of Malewa than the rest of the studied sites unlike the Total Suspended Solids (TSS). Dissolved and small particles passes through the filter during the TSS determination which makes the Mouth of Malewa site to show higher turbidity (in NTU) influence than TSS. Three distinct trophic state regions are evident: the northern part of the lake, the mid and southern region, and the Crescent Lake which is more or less isolated during low water levels in the lake. These regions coincide with the overall water quality findings in chapter2 in Figure 2.3. However, North East sampling site has unique $\mathrm{Mg}^{2+}$ influence which skews the site towards Crescent Lake. Apart from identification of turbidity constituents, the graphical representation of the deviation of TSI-CHL and TSI-TP indicate that the lake is predominantly phosphorus limited.

\subsubsection{Does the current status of water quality of Lake Naivasha differ from the water quality of the past decades?}

Objective three was to investigate the retrospective water quality from satellite data (Chapter 4). To achieve this objective, MODIS-Aqua satellite images were used to estimate chlorophyll-a concentration as one of the water 
quality parameters from June 2002 to June 2012. Spatio- temporal variations of the chlorophyll-a concentration were investigated. The resultant chlorophyll-a concentration maps derived from MODIS-Aqua satellite data, gave an indication of the monthly spatial variation in chlorophyll-a concentration. Regression analyses between satellite-derived chlorophyll-a concentration and in situ measurements revealed a high level of precision $\left(R^{2}=0.65, P<0.001\right)$, but with a measureable bias with the satellite under estimating actual in situ measurements. Although the actual values of the chlorophyll-a concentrations are underestimated, the significant relationship between satellite-derived chlorophyll-a and in situ measurements provides reliable information for studying spatial variations and temporal trends.

The retrospective water quality condition assessed using MODIS-Aqua images from 2002 to 2009 showed an increasing trend in chlorophyll-a concentration which is an indication of deteriorating ecological quality of Lake Naivasha (Figure 4.5). The findings coincide with Chapter 3 of this study which indicates the deterioration of the trophic status as compared to previous studies. Chlorophyll-a is one of the water quality parameters used in the determination of the trophic status of the aquatic ecosystem. Therefore, the retrogressive information on spatial variations and temporal trends provided in this study can also give an indication of the trophic state trends especially at times when routine ground measurements do not exist.

The study also showed an inverse relationship between chlorophyll-a concentration and lake water levels which suggest that an intervention on water quantity in the lake could be one of the strategies that could help in improvement of the deteriorating water quality in Lake Naivasha.

\subsubsection{What are the mechanisms that cause the spatio- temporal variability in Lake Naivasha's water quality?}

Objective five of this study was to investigate hydrodynamics as one of the mechanisms that result in spatio-temporal variability in Lake Naivasha's water quality. The main hydrodynamic forcing functions in the model are discharge and wind. Six scenarios were simulated. The first one was simulated with high discharge (at 19.74, 1.55, and $0.35 \mathrm{~m}^{3} \mathrm{~s}^{-1}$, in Malewa, Gilgil, and Karati rivers, respectively) and zero wind speed. This scenario resulted in low currents concentrated only around discharge locations. The low velocity localised at the river mouth implies that currents are mainly wind-driven in Lake Naivasha. The second scenario was simulated with maximum wind speed $\left(3.6 \mathrm{~m} \mathrm{~s}^{-1}\right)$ and zero discharge at $45^{\circ}$ wind direction which resulted in widespread movement all over the lake. The third scenario was simulated with high discharge and high wind speed which resulted in 
similar results as scenario two. Scenario two and three were repeated at $90^{\circ}$ and $135^{\circ}$ wind direction. The resultant current direction in $90^{\circ}$ and $45^{\circ}$ scenarios were similar which shows circular motions in the northern and southern regions of the lake. The circular horizontal motions observed in the main lake could be interpreted as existence mixing. The currents could contribute to vertical transport/upwelling of sediments which results in release of adsorbed nutrients into the water column. The availability of the nutrients in the water column could enhance proliferation of algal biomass leading to high turbidity levels.

Water quality modelling revealed that response of the lake ecosystem to reduction of pollutants is gradual and it would take 40 years to reach the equilibrium state if the loading remained constant. Ground water seepage could be the main reason behind the freshness of Lake Naivasha despite nonexistence of a visible outlet.

\subsubsection{What is the relationship between the fish community succession, livelihoods and the water quality of Lake Naivasha?}

Succession in the context of this study refers to the observed changes in fish community following an environmental perturbation (Connell and Slatyer, 1977). In objective four (Chapter 6), this study investigated the succession in fish community; the implication of the succession in fish community on livelihoods of the people around the lake; and the relationship between the fish community and water quality. Monthly fish catches data from 2005 to 2010 were acquired from the fisheries department. Chapter 6 showed the impact of changes in fish species on the quality of water in Lake Naivasha. From the study, replacement of previous fish species such as Tilapia zilli by an increasing population of Cyprinus carpio is evident. This is an indication of non-tolerance of Tilapia zilli and other fish species to turbid conditions which is correlated to the increase in Cyprinus carpio. Micropterus salmoides seemed to be more torrelant but still showed a gradual decline.

Recently, Orechromis nilotica was introduced in the lake to improve the current fishery status in Lake Naivasha. However, it forages on similar food as the Tilapia zillii which was already not doing very well during the time of this study and therefore likely to compete in an environment which is more or less disturbed by the Cyprinus carpio that burrows on the bottom sediments destroying the much needed vegetative material as well as the insects and crustaceans habitats. Although there is elimination of species within the study with the introduction of Cyprinus carpio, the total annual income generated per fisherman increased (Figure 6.6). This implies that the livelihood of the people around the lake improved over the study period. The revenue 
generated from fish since 2005 to 2010 was found to contain more than $90 \%$ Cyprinus carpio implying that the revenue generation from fish catches is almost exclusively Cyprinus carpio. Chlorophyll-a, which is one of the turbidity constituents, was found to increase with an increase in the Cyprinus carpio. This is attributed to the burrowing activity of the Cyprinus carpio that causes re-suspension of sediment which results in release of nutrients into the water column. The presence of nutrients in the water column enhances algae growth (Figure 1.2) whose biomass is estimated through chlorophyll-a concentration. The increase in turbidity leads to a decline in visibility and it is therefore difficult for some fish species to tolerate due to the limitation in spotting their prey. High turbidity can also limit growth of vegetation in the water and therefore reduce food for some species. These effects could have led to the elimination of Tilapia zilli and decline of other fish species like the Micropterus salmoides.

\subsection{Recommendations}

\subsubsection{Scientific recommendations}

The findings of the water quality status in Lake Naivasha are based on field measurements taken year 2011. Long term monitoring is useful in providing information on the trends and could therefore facilitate immediate interventions. We therefore recommend an intensive monitoring program which would take into account more water quality elements such as heavy metals and other pollutants which can reach the lake through pesticides application in the agricultural farms. More studies on the nutrients critical loading levels would be beneficial in setting management guidelines because they could provide information on the tipping points at which the ecosystem equilibrium collapses. Studies have shown that perturbation of the ecosystem results in a regime shift to an alternative stable state depending on the resilience of the ecosystem which is driven by ecological feed backs (Holling, 1973). In most lake ecosystems, the drivers of equilibrium state include nutrient load and predation pressure (Janse et al., 2008). Exceedance of phosphorus levels beyond the critical level (thresholds) may lead to a shift from clear state dominated by macrophytes to turbid state dominated by phytoplankton in a lake ecosystem. Once the ecosystem shifts from clear to turbid state, it is very difficult to restore the ecosystem due to hysteresis phenomenon (Janse et al., 2010; Scheffer, 1990). The tipping point information would therefore help in understanding the stable equilibrium level of nutrients and give an insight regarding the magnitude of the nutrient reduction for the lake restoration.

This study tried to apply remote sensing in retrospective water quality studies in Lake Naivasha with significant precision between the MODIS chlorophyll-a 
concentration and field measurement but with a bias in the actual concentration values. We therefore recommend improvement in the accuracy of the chlorophyll-a retrieval from MODIS-Aqua satellite images. This can be achieved through long-term collection of simultaneous radiometric measurements (to improve atmospheric corrections) and chlorophyll-a concentration in correspondence to MODIS-Aqua satellite data acquisition time. The study could go further and incorporate the coloured dissolved matter and the suspended solids. Other satellites such as Landsat have been in existence for a longer period than MODIS and could therefore help in provision retrospective studies of a longer period. The overlapping images from Landsat could be used as validation for the MODIS data.

The assessment of the fish succession finding of this study calls for more studies on the maximum sustainable yields of the different fish species to establish the carrying capacity of the lake within the prevailing environmental conditions. Studies on the coexistence in terms of intra-specific and interspecific competition between the fish species could be of immense benefit especially in selecting restocking fish species.

More exploration of the mechanisms which lead to spatial-temporal variability in water quality would be beneficial particularly in sedimentation processes which include transport and dissipation of particles. Internal wave motion and the subsequent re-suspension of sediments to the water column could provide immense information especially if dredging is considered as a management option. These studies could be coupled with eutrophication processes which could result from the release of the nutrients in the resuspended sediment. Sedimentation has a relationship with the oxygen demand which was reported as the main cause of fish kills in Lake Naivasha. Therefore, coupling of the sedimentation studies with oxygen demand could provide valuable information on fish kills. All these processes are embedded in the Delft3D model and therefore the present study could be a good baseline which can be built on to arrive at the suggested processes investigation. A three dimensional study would be useful in revealing the wave action and its contribution in turbidity dynamics. It would be useful to try to validate the models with the help of field measurements rather than the idealised model used in this study.

\subsubsection{Management recommendations}

Much of the research done in Lake Naivasha ends up in the scientific realm. However, sustainable utilization of Lake Naivasha requires research and stakeholder integration in the decision making process. This would ensure implementation of decisions that are founded on scientific findings and takes into account all the interest of the beneficiaries. Improved agricultural 
farming methods with specific emphasis on reduction of sedimentation could be of immense contribution in the improvement of water quality. The control of sedimentation would reduce the amount of sediments in the lake. Reduction in the nutrient loading was found to be able to control water quality (chapter 6) and is therefore recommended. Controlled water abstractions both on the lake surface water and the streams would help in the reduction of turbidity since this study have shown a reduction in chlorophyll-a with an increase in water levels. Replacement of the carp with a competitive fish species with less environmental consequences could minimise re-suspension and consequent release of adsorbed nutrients to the water column (biological control of the carp). In 2011, Nile Tilapia was introduced in Lake Naivasha. However, its success may be dependent on the extent of the Cyprinus carpio effect or increase in water level which could reduce the water turbidity leading to more plant growth and larger habitats for the insects and crustaceans. This could minimize competition with the Tilapia zillii.

Empowerment of the local communities especially in monitoring and implementation of the water quality mitigation measures could minimise the cost of maintenance of lake. This could be achieved through environmental and management skills education. Above all, commitment to the rule of law, enforcement and compliance in management is the key to sustainable utilization of ecosystem services and functions.

Existing management options include: nutrient reduction, biological control (introduction of species that could feed on other or out-compete) and dredging especially in the control of eutrophication in aquatic systems. However, Lake Naivasha is a natural and vast ecosystem (lake area range = 100 to $140 \mathrm{Km}^{2}$ ) and therefore dredging costs would be very high and destructive in terms of biodiversity. Nutrient reduction especially through controlled agricultural systems in the catchment and enforcement of the regulatory measures in waste water treatment from the escalating urbanization would to the control eutrophication. The choice of the management options depends on the nature of the ecosystem, level of deterioration and costs. Restoration of the north-swamp (close to mouth of Malewa river) to help in retention of sediments and nutrients could be a feasible management option. 


\section{Bibliography}

Abuodha, J., Muyodi, F., Hecky, R., and Mwanuzi, F. L. (2005). Lake Victoria Environment Management Project (LVEMP) Water Quality and Ecosystem Status: Lake Victoria Regional Water Quality Synthesis Report.

Agbabiaka, L. (2012). Food and Feeding Habits of Tilapia Zilli (Pisces: Cichlidae) in River Otamiri South-Eastern Nigeria. Algae 71, 8.82.

Alberto, W. D., María del Pilar, D. a., María Valeria, A., Fabiana, P. S., Cecilia, H. A., and María de los Ángeles, B. (2001). Pattern Recognition Techniques for the Evaluation of Spatial and Temporal Variations in Water Quality. A Case Study:: Suquía River Basin (CórdobaArgentina). Water Research 35, 2881-2894.

Ambrose, R. B., Wood, T. A., Connolly, J. P., and Schanz, R. W. (1988). WASP4, a hydrodynamic and water quality model: model theory, user's manual and programmer's guide. EPA.

APHA (2005). "Standard methods, 21st Edition.," 19th Edition/Ed. American Public Health Association. Washington DC.

Asaeda, T., Trung, V. K., and Manatunge, J. (2000). Modeling the effects of macrophyte growth and decomposition on the nutrient budget in shallow lakes. Aquatic Botany 68, 217-237.

Åse, L.-E. (1987). A Note on the Water Budget of Lake Naivasha, Kenya. Especially the Role of Salvinia Molesta Mitch and Cyperus papyrus L. Geografiska Annaler. Series A. Physical Geography, 415-429.

Ayenew, T. (2005). Major ions composition of the groundwater and surface water systems and their geological and geochemical controls in the Ethiopian volcanic terrain. SINET: Ethiopian Journal of Science 28, 171-188.

Ballot, A., Kotut, K., Novelo, E., and Krienitz, L. (2009). Changes of phytoplankton communities in Lakes Naivasha and Oloidien, examples of degradation and salinization of lakes in the Kenyan Rift Valley. Hydrobiologia 632, 359-363.

Beadle, L. C. (1932). The Water of Some East Africa Lakes. Journal of the Linnean Society of London, Zoology 38, 157-211.

Becht, R., and Harper, D. M. (2002). Towards an understanding of human impact upon the hydrology of Lake Naivasha, Kenya. Hydrobiologia 488, 1-11.

Becht, R., Odada, E. O., and Higgins, S. (2005). Lake Naivasha: experience and lessons learned brief. In "Lake basin management initiative: experience and lessons learned briefs. Including the final report: managing lakes and basins for sustainable use, a report for lake basin managers and stakeholders. ", pp. 277-298. International Lake Environment Foundation Committee (ILEC), Kusatsu. 
Binding, C. E., Greenberg, T. A., and Bukata, R. P. (2012). An analysis of MODIS-derived algal and mineral turbidity in Lake Erie. Journal of Great Lakes Research 38, 107-116.

Breukelaar, A. W., Lammens, E. H., Breteler, J. G. K., and Tatrai, I. (2006). Effects of benthivorous bream (Abramis brama) and carp (Cyprinus carpio) on sediment resuspension and concentrations of nutrients and chlorophyll a. Freshwater Biology 32, 113-121.

Brezonik, P. L., and Shannon, E. E. (1971). "Trophic state of lakes in north central Florida," Florida Water Resources Research Center.

Britton, J., Harper, D., Oyugi, D., and Grey, J. (2010). The introduced Micropterus salmoides in an equatorial lake: a paradoxical loser in an invasion meltdown scenario? Biological Invasions, 1-10.

Britton, J. R., Boar, R. R., Grey, J., Foster, J., Lugonzo, J., and Harper, D. M. (2007). From introduction to fishery dominance: the initial impacts of the invasive carp Cyprinus carpio in Lake Naivasha, Kenya, 1999 to 2006. J ournal of Fish Biology 71, 239-257.

Brown, P. (2003). "Carp population biology in Victoria," Marine and Freshwater Resources Institute, Department of Primary Industry.

Burgin, A. J., and Hamilton, S. K. (2007). Have we overemphasized the role of denitrification in aquatic ecosystems? A review of nitrate removal pathways. Front Ecol Environ 5, 89-96.

Carlson, R. E. (1977). "A trophic state index for lakes," American Society of Limnology and Oceanography., Lawrence, Kan.

Carlson, R. E., and Havens, K. E. (2005). Simple Graphical Methods for the Interpretation of Relationships Between Trophic State Variables. Lake and Reservoir Management 21, 107-118.

Carlson, R. E., and Simpson, J. (1996). A Coordinator's Guide to Volunteer Lake Monitoring Methods. North American Lake Management Society., $96 \mathrm{pp}$.

Carrick, H. J., Moon, J. B., and Gaylord, B. F. (2005). Phytoplankton dynamics and hypoxia in Lake Erie: A hypothesis concerning benthicpelagic coupling in the Central Basin. Journal of Great Lakes Research 31, 111-124.

Carter, R. (1993). The morphology, hydrodynamics and sedimentation processes of Lough Neagh. In "Lough Neagh", pp. 35-57. Springer.

Chang, N. B., Yang, Y. J., Daranpob, A., Jin, K. R., and James, T. (2012). Spatiotemporal pattern validation of chlorophyll-a concentrations in Lake Okeechobee, Florida, using a comparative MODIS image mining approach. International J ournal of Remote Sensing 33, 2233-2260.

Chavula, G., Brezonik, P., Thenkabail, P., Johnson, T., and Bauer, M. (2009). Estimating chlorophyll concentration in Lake Malawi from MODIS satellite imagery. Physics and Chemistry of the Earth, Parts A/B/C 34, 755-760. 
Chen, Y., Fan, C., Teubner, K., and Dokulil, M. (2003). Changes of nutrients and phytoplankton chlorophyll-a in a large shallow lake, Taihu, China: an 8-year investigation. Hydrobiologia 506, 273-279.

Chen, Z., Hu, C., and Muller-Karger, F. (2007). Monitoring turbidity in Tampa Bay using MODIS/Aqua 250-m imagery. Remote Sensing of Environment 109, 207-220.

Chernet, T., Travi, Y., and Valles, V. (2001). Mechanism of degradation of the quality of natural water in the lakes region of the Ethiopian rift valley. Water Research 35, 2819-2832.

Childress, R. B., Bennun, L. A., and Harper, D. M. (2002). Population changes in sympatric Great and Long-tailed Cormorants (\&lt;i\&gt; Phalacrocorax carbo\&lt;/i\&gt; and \&lt;i\&gt;P. africanus\&lt;/i\&gt; ): the effects of niche overlap or environmental change? Hydrobiologia 488, 163-170.

Cleveland, R. B., Cleveland, W. S., McRae, J. E., and Terpenning, I. (1990). STL: A seasonal-trend decomposition procedure based on loess. J ournal of Official Statistics 6, 3-73.

Connell, J. H., and Slatyer, R. O. (1977). Mechanisms of succession in natural communities and their role in community stability and organization. American naturalist, 1119-1144.

Costantini, M. L., Rossi, L., Scialanca, F., Nascetti, G., Rossi, D., and Sabetta, L. (2007). Association of riparian features and water chemistry with reed litter breakdown in a volcanic lake (Lake Vico, Italy). Aquatic Sciences 69, 503-510.

Cui, L., Wu, G., and Liu, Y. (2009). Monitoring the impact of backflow and dredging on water clarity using MODIS images of Poyang Lake, China. Hydrological Processes 23, 342-350.

Dall'Olmo, G., Gitelson, A. A., Rundquist, D. C., Leavitt, B., Barrow, T., and Holz, J. C. (2005). Assessing the potential of SeaWiFS and MODIS for estimating chlorophyll concentration in turbid productive waters using red and near-infrared bands. Remote Sensing of Environment 96, 176187.

Darecki, M., and Stramski, D. (2004). An evaluation of MODIS and SeaWiFS bio-optical algorithms in the Baltic Sea. Remote Sensing of Environment 89, 326-350.

De-Jong, T. (2011). Review on river water resource monitoring and allocation planning in the Lake Naivasha Basin, Kenya., Wageningen University.

Dekker, A. G., Vos, R. J., and Peters, S. W. M. (2002). Analytical algorithms for lake water TSM estimation for retrospective analyses of TM and SPOT sensor data. International Journal of Remote Sensing 23, 15 35.

Delgado, J., Nieto, J., and Boski, T. (2010). Analysis of the spatial variation of heavy metals in the Guadiana Estuary sediments (SW Iberian Peninsula) based on GIS-mapping techniques. Estuarine, Coastal and Shelf Science 88, 71-83. 
Edmondson, W. (1980). Secchi disk and chlorophyll [content of plankton]. Limnology and Oceanography.

Egertson, C. J., and Downing, J. A. (2004). Relationship of fish catch and composition to water quality in a suite of agriculturally eutrophic lakes. Canadian J ournal of Fisheries and Aquatic Sciences 61, 1784-1796.

Ekstrand, S. (1992). Landsat TM based quantification of chlorophyll-a during algae blooms in coastal waters. International Journal of Remote Sensing 13, 1913-1926.

Elder, H. Y., Garrod, D. J., and Whitehead, P. J. P. (1971). Natural hybrids of the African cichlid fishes Tilapia spilurus nigra and T. leucosticta: a case of hybrid introgression. Biological Journal of the Linnean Society $\mathbf{3}$, 103-146.

Elfrink, B., and Baldock, T. (2002). Hydrodynamics and sediment transport in the swash zone: a review and perspectives. Coastal Engineering 45, 149-167.

Fan, S.-S. (1988). Twelve selected computer stream sedimentation models developed in the United States.

Ferincz, A., Staszny, A., Acs, A., Weiperth, A., Tatrai, I., and Pantovits, G. (2012). Long-term development offish assemblage in Lake Feneki(KisBalaton Water Protection System, Hungary): succession, invasion and stabilization. Acta Zoologica Academiae Scientiarum Hungaricae 58, 318.

Fu, G., Baith, K. S., and McClain, C. R. (1998). SeaDAS: The SeaWiFS data analysis system. In "Proceedings of the 4th Pacific Ocean Remote Sensing Conference, Qingdao, China", pp. 28-31.

Galvez-Cloutier, R., and Sanchez, M. G. (2007). Trophic Status Evaluation for 154 Lakes in Quebec, Canada : Monitoring and Recommendations. Vol. 42, pp. 17. National Water Research Institute, Burlington, ON, CANADA.

Gaudet, J. J. (1979). Seasonal changes in nutrients in a tropical swamp: North Swamp, Lake Naivasha, Kenya. The J ournal of Ecology, 953-981.

Gaudet, J. J., and Melack, J. M. (1981). Major ion chemistry in a tropical African lake basin. Freshwater Biology 11, 309-333.

Gelda, R. K., and Effler, S. W. (2007). Modeling Turbidity in a Water Supply Reservoir: Advancements and Issues. Journal of Environmental Engineering 133, 139-148.

Gitelson, A. A., Gurlin, D., Moses, W. J., and Barrow, T. (2009). A bio-optical algorithm for the remote estimation of the chlorophyll-a concentration in case 2 waters. Environmental Research Letters 4, 045003.

Gitonga, M. S. (1999). Study of long term waterbalance of lake Naivasha, Kenya, ITC, Enschede.

Gordoa, A., Illas, X., Cruzado, A., and Velásques, Z. (2008). Spatio-temporal patterns in the north-western Mediterranean from MERIS derived chlorophyll a concentration. Scientia Marina 72, 757-767. 
Grey, J., and Jackson, M. C. (2012). 'Leaves and Eats Shoots': Direct Terrestrial Feeding Can Supplement Invasive Red Swamp Crayfish in Times of Need. PLoS ONE 7, e42575.

Grochowska, J., and Tandyrak, R. (2009). The influence of the use of land on the content of calcium. magnesium. iron and manganese in water, exemplified in three lakes in the Olsztyn vicinity. Limnol. Rev 9, 9-16.

HACH (2005). " DR 2800 User Manual," 1st Edition/Ed. HACH Chemical Company, Loveland, Colorado.

Håkanson, L. (1977). The influence of wind, fetch, and water depth on the distribution of sediments in Lake Vänern, Sweden. Canadian J ournal of Earth Sciences 14, 397-412.

Hamilton, D. P., and Schladow, S. G. (1997). Prediction of water quality in lakes and reservoirs. Part I-Model description. Ecological Modelling 96, 91-110.

Hansson, L.-A. (1990). Quantifying the impact of periphytic algae on nutrient availability for phytoplankton. Freshwater Biology 24, 265-273.

Harper, D. (1992). The ecological relationships of aquatic plants at Lake Naivasha, Kenya. Hydrobiologia 232, 65-71.

Harper, D. M., Morrison, E. H., Macharia, M. M., Mavuti, K. M., and Upton, C. (2011a). Lake Naivasha, Kenya: ecology, society and future. Freshwater Reviews 4, 89-114.

Harper, D. M., Morrison, E. H. J., Macharia, M. M., Mavuti, K. M., and Upton, C. (2011b). Lake Naivasha, Kenya: Ecology, Society and Future. Freshwater Reviews 4, 89-114.

Harper, D. M., Smart, Andrew C., Coley, Stephanie, Schmitz, Sophie, Gouder de Beauregard, Anne-Christine, North, Rick, Adams, Chris, Obade, Paul, Kamau Mbogo (2002). Distribution and abundance of the Louisiana red swamp crayfish Procambarus clarkii Girard at Lake Naivasha, Kenya between 1987 and 1999. Hydrobiologia 488, 143151.

Havens, K. E., East, T. L., Marcus, J., Essex, P., Bolan, B., Raymond, S., and Beaver, J. R. (2000). Dynamics of the exotic Daphnia lumholtzii and native macro-zooplankton in a subtropical chain-of-lakes in Florida, USA. Freshwater Biology 45, 21-32.

Hickley, P., and Harper, D. (2007). "Fish Community and Habitat Changes in the Artificially Stocked Fishery of Lake Naivasha, Kenya," Blackwell Publishing Ltd.

Hickley, P., and Harper, D. M. (2002). "Fish population and habitat changes in the artificially stocked fishery of Lake Naivasha, Kenya," In Cowx, I.(eds) Management and Ecology of Lake and Reservoir Fisheries, /Ed. Blackwell, Oxford.

Hickley, P., Muchiri, M., Britton, J., and Boar, R. (2008). Economic gain versus ecological damage from the introduction of non-native freshwater fish: case studies from Kenya. 
Hickley, P., Muchiri, S. M., Britton, J. R., and Boar, R. R. (2004). Discovery of carp, Cyprinus carpio, in the already stressed fishery of Lake Naivasha, Kenya. Fisheries Management and Ecology 11, 139-142.

Holling, C. S. (1973). Resilience and Stability of Ecological Systems. Annual Review of Ecology and Systematics 4, 1-23.

Hu, C., Chen, Z., Clayton, T. D., Swarzenski, P., Brock, J. C., and MullerKarger, F. E. (2004). Assessment of estuarine water-quality indicators using MODIS medium-resolution bands: Initial results from Tampa Bay, FL. Remote Sensing of Environment 93, 423-441.

Hubble, D. S., and Harper, D. M. (2000). Top-down biological controls on tropical lake productivity. Lakes \& Reservoirs: Research \& Management 5, 187-194.

Hubble, D. S., and Harper, D. M. (2001a). Impact of light regimen and selfshading by algal cells on primary productivity in the water column of a shallow tropical lake (Lake Naivasha, Kenya). Lakes \& Reservoirs: Research \& Management 6, 143-150.

Hubble, D. S., and Harper, D. M. (2001b). What defines a 'healthy' lake? Evidence from Lake Naivasha, Kenya. Aquatic Ecosystem Health \& Management 4, 243-250.

Hubble, D. S., and Harper, D. M. (2002). Nutrient control of phytoplankton production in Lake Naivasha, Kenya. Hydrobiologia 488, 99-105.

Hudson, J. J., Taylor, W. D., and Schindler, D. W. (2000). Phosphate concentrations in lakes. Nature 406, 54-56.

Jackson, M. C., Donohue, I., Jackson, A. L., Britton, J. R., Harper, D. M., and Grey, J. (2012). Population-Level Metrics of Trophic Structure Based on Stable Isotopes and Their Application to Invasion Ecology. PLoS ONE 7 , e31757.

Jackson, Z. J., Quist, M. C., Downing, J. A., and Larscheid, J. G. (2010). Common carp (Cyprinus carpio), sport fishes, and water quality: Ecological thresholds in agriculturally eutrophic lakes. Lake and Reservoir Management 26, 14-22.

James, R., Havens, K., Zhu, G., and Qin, B. (2009). Comparative analysis of nutrients, chlorophyll and transparency in two large shallow lakes (Lake Taihu, P.R. China and Lake Okeechobee, USA). Hydrobiologia 627, 211-231.

Janse, J. H. (1997). A model of nutrient dynamics in shallow lakes in relation to multiple stable states. Hydrobiologia 342, 1-8.

Janse, J. H., Domis, L., Scheffer, M., Lijklema, L., Van Liere, L., Klinge, M., and Mooij, W. M. (2008). Critical phosphorus loading of different types of shallow lakes and the consequences for management estimated with the ecosystem model PCLake. Limnologica 38, 203-219.

Janse, J. H., Scheffer, M., Lijklema, L., Van Liere, L., Sloot, J. S., and Mooij, W. M. (2010). Estimating the critical phosphorus loading of shallow 
lakes with the ecosystem model PCLake: Sensitivity, calibration and uncertainty. Ecological Modelling 221, 654-665.

Jeppesen, E., Jensen, J. P., Søndergaard, M., Lauridsen, T., Pedersen, L. J., and Jensen, L. (1997). Top-down control in freshwater lakes: the role of nutrient state, submerged macrophytes and water depth. In "Shallow Lakes' 95", pp. 151-164. Springer.

Jiang, B., Liang, S., Wang, J., and Xiao, Z. (2010). Modeling MODIS LAI time series using three statistical methods. Remote Sensing of Environment 114, 1432-1444.

Jin, K.-R., Hamrick, J. H., and Tisdale, T. (2000). Application of threedimensional hydrodynamic model for Lake Okeechobee. Journal of Hydraulic Engineering 126, 758-771.

Jin, K.-R., and Ji, Z.-G. (2004). Case study: modeling of sediment transport and wind-wave impact in Lake Okeechobee. Journal of hydraulic engineering 130, 1055-1067.

Jin, K.-R., and Ji, Z.-G. (2005). Application and validation of threedimensional model in a shallow lake. Journal of waterway, port, coastal, and ocean engineering 131, 213-225.

Johnson, D. L., Ambrose, S. H., Bassett, T. J., Bowen, M. L., Crummey, D. E., Isaacson, J. S., Johnson, D. N., Lamb, P., Saul, M., and Winter-Nelson, A. E. (1997). Meanings of Environmental Terms. J. Environ. Qual. 26, 581-589.

Kalff, J. (1983). Phosphorus limitation in some tropical African lakes. Hydrobiologia 100, 101-112.

Kampeshi, C., and Shantima, M. (1999). Nutrient loading and water hyacinth infestation in the Lower Kafue River. In "Proceedings of the first IOBC global working group meeting for the biological and integrated control of water hyacinth".

Kannel, P., Kanel, S., Lee, S., and Lee, Y. S. (2011). Chemometrics in assessment of seasonal variation of water quality in fresh water systems. Environmental Monitoring and Assessment 174, 529-545.

Kazi, T., Arain, M., Jamali, M., Jalbani, N., Afridi, H., Sarfraz, R., Baig, J., and Shah, A. Q. (2009). Assessment of water quality of polluted lake using multivariate statistical techniques: A case study. Ecotoxicology and Environmental Safety 72, 301-309.

Kilham, P. (1990). Mechanisms controlling the chemical composition of lakes and rivers: Data from Africa. Limnol. Oceanogr 35, 80-83.

Kilham, P., and Kilham, S. S. (2006). OPINION Endless summer: internal loading processes dominate nutrient cycling in tropical lakes. Freshwater Biology 23, 379-389.

Kitaka, N., Harper, D. M., and Mavuti, K. M. (2002). Phosphorus inputs to Lake Naivasha, Kenya, from its catchment and the trophic state of the lake. Hydrobiologia 488, 73-80. 
Kranenburg, C. (1992). Wind-driven chaotic advection in a shallow model lake. J ournal of hydraulic research 30, 29-46.

Kratzer, C. R., and Brezonik, P. L. (1981). A CARLSON-TYPE TROPHIC STATE INDEX FOR NITROGEN IN FLORIDA LAKES1. JAWRA Journal of the American Water Resources Association 17, 713-715.

Kronvang, B., Jeppesen, E., Conley, D. J., Søndergaard, M., Larsen, S. E., Ovesen, N. B., and Carstensen, J. (2005). Nutrient pressures and ecological responses to nutrient loading reductions in Danish streams, lakes and coastal waters. Journal of Hydrology 304, 274-288.

Kundu, R., Aura, C. M., Muchiri, M., Njiru, J. M., and Ojuok, J. E. (2010). Difficulties of fishing at Lake Naivasha, Kenya: is community participation in management the solution? Lakes \& Reservoirs: Research \& Management 15, 15-23.

Larson, G., Hoffman, R., Hargreaves, B., and Collier, R. (2007). Predicting Secchi disk depth from average beam attenuation in a deep, ultra-clear lake. Hydrobiologia 574, 141-148.

Lee, C., Schwab, D. J., Beletsky, D., Stroud, J., and Lesht, B. (2007). Numerical modeling of mixed sediment resuspension, transport, and deposition during the March 1998 episodic events in southern Lake Michigan. J ournal of geophysical research 112, C02018.

Lee, C. S.-I., Li, X., Shi, W., Cheung, S. C.-n., and Thornton, I. (2006). Metal contamination in urban, suburban, and country park soils of Hong Kong: A study based on GIS and multivariate statistics. Science of the Total Environment 356, 45-61.

Lepistö, A., Huttula, T., Koponen, S., Kallio, K., Lindfors, A., Tarvainen, M., and Sarvala, J. (2010). Monitoring of spatial water quality in lakes by remote sensing and transect measurements. Aquatic Ecosystem Health \& Management 13, $176-184$.

Lidia, N., and Kobos, J. (2011). The trophic state of the Vistula Lagoon: an assessment based on selected biotic and abiotic parameters according to the Water Framework Directive. Oceanologia 53, 881-894.

Likens, G. E. (1972). Chemistry of precipitation in the Central Finger Lakes Region.

Liu, Y., and Li, G. (2009). Study of attenuation depths for MODIS bands in the Bohai Sea in China. Acta Oceanologica Sinica Vol. 28, 39-48.

Lloyd, D. S. (1987). Turbidity as a water quality standard for salmonid habitats in Alaska. North American journal of fisheries management $\mathbf{7}$, 34-45.

LNRA (1999). "Lake Naivasha Management Plan."

Lou, J., Schwab, D. J., Beletsky, D., and Hawley, N. (2000). A model of sediment resuspension and transport dynamics in southern Lake Michigan. J ournal of Geophysical Research: Oceans 105, 6591-6610. 
Lung'Ayia, H., M'harzi, A., Tackx, M., Gichuki, J., and Symoens, J. (2000). Phytoplankton community structure and environment in the Kenyan waters of Lake Victoria. Freshwater Biology 43, 529-543.

Mageria, C., Bosma, R., and Roem, A. (2006). Aquaculture Development Potential in and around Lake Naivasha, Kenya. Aquaculture.

Magyar, N., Hatvani, I. G., Székely, I. K., Herzig, A., Dinka, M., and Kovács, J. (2013). Application of multivariate statistical methods in determining spatial changes in water quality in the Austrian part of Neusiedler See. Ecological Engineering 55, 82-92.

Mathieu, P.-P., Deleersnijder, E., Cushman-Roisin, B. t., Beckers, J.-M., and Bolding, K. (2002). The role of topography in small well-mixed bays, with application to the lagoon of Mururoa. Continental Shelf Research 22, 1379-1395.

Matias, N.-G., and Boavida, M.-J. (2005). Effects of catchment development on the trophic status of a deep and a shallow reservoir in Portugal. Lake and Reservoir Management 21, 350-360.

Matthews, R., Hilles, M., and Pelletier, G. (2002). Determining trophic state in Lake Whatcom, Washington (USA), a soft water lake exhibiting seasonal nitrogen limitation. Hydrobiologia 468, 107-121.

Mazumder, A., and Havens, K. E. (1998). Nutrient-chlorophyll-Secchi relationships under contrasting grazer communities of temperate versus subtropical lakes. Canadian Journal of Fisheries and Aquatic Sciences 55, 1652-1662.

Meglen, R. R. (1992). Examining large databases: a chemometric approach using principal component analysis. Marine Chemistry 39, 217-237.

Meijer, M.-L., De Haan, M., Breukelaar, A., and Buiteveld, H. (1990). Is reduction of the benthivorous fish an important cause of high transparency following biomanipulation in shallow lakes? In "Biomanipulation Tool for Water Management", pp. 303-315. Springer.

Mellinger, M. (1987). Multivariate data analysis: its methods. Chemometrics and Intelligent Laboratory Systems 2, 29-36.

Mergeay, J. (2004). Two hundred years of a diverse Daphnia community in Lake Naivasha (Kenya): effects of natural and human-induced environmental changes. Freshwater biology 49, 998.

Michaud, J. P. (1991). "A citizen's guide to understanding and monitoring lakes and streams," Puget Sound Water Quality Authority, Washington State, United States.

Miller, S. A., and Crowl, T. A. (2006). Effects of common carp (Cyprinus carpio) on macrophytes and invertebrate communities in a shallow lake. Freshwater Biology 51, 85-94.

Mobley, C. D. (2004). Light and Water: Radiative Transfer in Natural Waters.

Morara, G. (2010). Oxygen depletion lead to death of fish in Lake Naivasha. (J. Ndungu, ed.). Personal communication, Naivasha. 
Mugidde, R., Gichuki, J., Rutagemwa, D., Ndawula, L., and Matovu, X. (2005). Status of water quality an its implication on the fishery production. In "The State of the Fisheries Resources of Lake Victoria and Their Management. Proceedings of the Regional Stakeholders' Conference" (L. V. F. O. Secretariat, ed.), pp. 106-12, Jinja, Uganda.

Nakato, T. (1990). Tests of selected sediment-transport formulas. J ournal of Hydraulic Engineering 116, 362-379.

NASA Land Processe Distributed Active Archive Center (LP DAAC) (2011). The ASTER Global Digital Elevation Model (ASTER GDEM). Ministry of Economy, Trade, and Industry (METI) of Japan and the United States National Aeronautics and Space Administration (NASA), USGS/Earth Resources Observation and Science (EROS) Center, Sioux Falls, South Dakota.

Ndungu, J., Augustijn, D. C. M., Hulscher, S. J. M. H., Kitaka, N., and Mathooko, J. (2013a). Spatio-temporal variations in the trophic status of Lake Naivasha, Kenya. Lakes \& Reservoirs: Research \& Management 18, 317-328.

Ndungu, J., Monger, B. C., Augustijn, D. C. M., Hulscher, S. J. M. H., Kitaka, N., and Mathooko, J. M. (2013b). Evaluation of spatio-temporal variations in chlorophyll-a in Lake Naivasha, Kenya: remote-sensing approach. International J ournal of Remote Sensing 34, 8142-8155.

Ngugi, D. N., Karau, P. K., and Nguyo, W. (2005). "East African Agriculture," Macmillan Education, Limited, Oxford, UK.

Njogu, P., Keriko, J., Wanjau, R., and Kitetu, J. (2011). Distribution of Heavy Metals in Various Lake Matrices; Water, Soil, Fish and Sediments: A Case Study of the Lake Naivasha Basin, Kenya. Journal of Agriculture, Science and Technology 13.

Noges, P., Kägu, M., and Noges, T. (2007). Role of climate and agricultural practice in determining matter discharge into large, shallow Lake Võrtsjärv, Estonia. In "Eutrophication of Shallow Lakes with Special Reference to Lake Taihu, China", pp. 125-134. Springer.

O'Reilly, J. E., Maritorena, S., Mitchell, B. G., Siegel, D. A., Carder, K. L., Garver, S. A., Kahru, M., and McClain, C. (1998). Ocean color chlorophyll algorithms for SeaWiFS. Journal of Geophysical Research: Oceans (1978-2012) 103, 24937-24953.

O’Reilly, J. E., Maritorena, S., Siegel, D. A., O’Brien, M. C., Toole, D., Mitchell, B. G., Kahru, M., Chavez, F. P., Strutton, P., and Cota, G. F. (2000). Ocean color chlorophyll a algorithms for SeaWiFS, OC2, and OC4: Version 4. SeaWiFS postlaunch calibration and validation analyses, Part 3, 9-23.

Ochieng, E., Lalah, J., and Wandiga, S. (2007). Analysis of heavy metals in water and surface sediment in five rift valley lakes in Kenya for assessment of recent increase in anthropogenic activities. Bulletin of environmental contamination and toxicology 79, 570-576. 
Ojuok, J., Morara, G., Ojwang, W., Maasai, D., Yongo, E., Wasike, C., and Nyamweya, C. (2013). Socio-economic Aspects of Fisheries Management in Lake Naivasha.

Onishi, Y. (1994). Sediment Transport Models and their Testing. In "Computer Modeling of Free-Surface and Pressurized Flows" (M. H. Chaudhry and L. Mays, eds.), Vol. 274, pp. 281-312. Springer Netherlands.

Oyugi, D. O., Cucherousset, J., Ntiba, M. J., Kisia, S. M., Harper, D. M., and Britton, J. R. (2011). Life history traits of an equatorial common carp, Cyprinus carpio, population in relation to thermal influences on invasive populations. Fisheries Research 110, 92-97.

Papanicolaou, A., Elhakeem, M., Krallis, G., Prakash, S., and Edinger, J. (2008). Sediment Transport Modeling Review-Current and Future Developments. Journal of Hydraulic Engineering 134, 1-14.

Payne, I. (1984). Tropical Lakes and Rivers. In "Butterworths", London.

Peeters, E. T. H. M., Franken, R. J. M., Jeppesen, E., Moss, B., Bécares, E., Hansson, L.-A., Romo, S., Kairesalo, T., Gross, E. M., Donk, E. v., Nõges, T., Irvine, K., Kornijów, R., and Scheffer, M. (2009). Assessing ecological quality of shallow lakes: Does knowledge of transparency suffice? Basic and Applied Ecology 10, 89-96.

Pharo, C., and Carmack, E. C. (1979). Sedimentation processes in a short residence-time intermontane lake, Kamloops Lake, British Columbia. Sedimentology 26, 523-541.

Pimentel, D., Lach, L., Zuniga, R., and Morrison, D. (2000). Environmental and economic costs of nonindigenous species in the United States. BioScience 50, 53-65.

Podsetchine, V., and Schernewski, G. (1999). The influence of spatial wind inhomogeneity on flow patterns in a small lake. Water Research 33, 3348-3356.

Postma, L., Stelling, G., and Boon, J. (1999). 3-dimensional water quality and hydrodynamic modelling in Hong Kong $ш$. Stratification and water quality.

Prepas, E. E., Planas, D., Gibson, J., Vitt, D., Prowse, T., Dinsmore, W., Halsey, L., McEachern, P., Paquet, S., and Scrimgeour, G. (2001). Landscape variables influencing nutrients and phytoplankton communities in Boreal Plain lakes of northern Alberta: a comparison of wetland-and upland-dominated catchments. Canadian Journal of Fisheries and Aquatic Sciences 58, 1286-1299.

Przedwojski, B., Błazejewski, R., and Pilarczyk, K. W. (1995). "River training techniques: fundamentals, design and applications," AA Balkema.

Ramsar (1996). The Ramsar 25th Anniversary Statement. In "Resolution VI.14, 6th Meeting of the Conference of the Contracting Parties", Brisbane. 
Razmi, A. M., Barry, D. A., Lemmin, U., Bonvin, F., Kohn, T., and Bakhtyar, R. (2013). Direct effects of dominant winds on residence and travel times in the wide and open lacustrine embayment: Vidy Bay (Lake Geneva, Switzerland). Aquatic Sciences, 1-13.

Reghunath, R., Murthy, T. R. S., and Raghavan, B. R. (2002). The utility of multivariate statistical techniques in hydrogeochemical studies: an example from Karnataka, India. Water Research 36, 2437-2442.

Riley, E., and Prepas, E. (1984). Role of internal phosphorus loading in two shallow, productive lakes in Alberta, Canada. Canadian Journal of Fisheries and Aquatic Sciences 41, 845-855.

Roberts, J., Chick, A., Oswald, L., and Thompson, P. (1995). Effect of carp, Cyprinus carpio, an exotic benthivorous fish, on aquatic plants and water quality in experimental ponds. Marine and Freshwater Research 46, 1171-1180.

Rodi, W. (2006). DNS and LES of some engineering flows. Fluid Dynamics Research 38, 145-173.

Scheffer, M. (1990). Multiplicity of Stable States in Fresh-Water Systems. Hydrobiologia 200, 475-486.

Scheffer, M. (1998). "Ecology of shallow lakes," London [etc.] : Chapman \& Hall.

Scheffer, M. (2009). "Critical transitions in nature and society," Princeton University Press.

Scheffer, M., Hosper, S. H., Meijer, M. L., Moss, B., and Jeppesen, E. (1993). Alternative Equilibria in Shallow Lakes. Trends in Ecology \& Evolution 8, 275-279.

Scheffer, M., and Jeppesen, E. (2007). Regime shifts in shallow lakes. Ecosystems 10, 1-3.

Schlüter, L., Møhlenberg, F., Havskum, H., and Larsen, S. (2000). The use of phytoplankton pigments for identifying and quantifying phytoplankton groups in coastal areas: testing the influence of light and nutrients on pigment/chlorophyll a ratios. Marine Ecology Progress Series 192, 4963.

Schmidt, H., Swoboda, R., and Jätzold, R. (1979). "Farm management handbook of Kenya," Ministry of Agriculture, Farm Management Section.

Sheela, A. M., Letha, J., Joseph, S., Chacko, M., Sanal kumar, S. P., and Thomas, J. (2012). Water quality assessment of a tropical coastal lake system using multivariate cluster, principal component and factor analysis. Lakes \& Reservoirs: Research \& Management 17, 143-159.

Shi, W., and Wang, M. (2009). An assessment of the black ocean pixel assumption for MODIS SWIR bands. Remote Sensing of Environment 113, 1587-1597. 
Shrestha, S., and Kazama, F. (2007). Assessment of surface water quality using multivariate statistical techniques: A case study of the Fuji river basin, Japan. Environmental Modelling \& Software 22, 464-475.

Sickman, J. O., Melack, J. M., and Clow, D. W. (2003). Evidence for nutrient enrichment of high-elevation lakes in the Sierra Nevada, California. Limnology and Oceanography, 1885-1892.

Siddiqui, A. Q. (1979). Changes in fish species composition in Lake Naivasha, Kenya. Hydrobiologia 64, 131-138.

Simeonov, V., Simeonova, P., Tsakovski, S., and Lovchinov, V. (2010). Lake water monitoring data assessment by multivariate statistics. Journal of Water Resource and Protection 2, 353-361.

Simons, T. J. (1974). Verification of numerical models of Lake Ontario: Part I. Circulation in spring and early summer. Journal of Physical Oceanography 4, 507-523.

Singh, K. P., Malik, A., Mohan, D., and Sinha, S. (2004). Multivariate statistical techniques for the evaluation of spatial and temporal variations in water quality of Gomti River (India)-a case study. Water Research 38, 3980-3992.

Sivakumaran, K., Brown, P., Stoessel, D., and Giles, A. (2003). Maturation and Reproductive Biology of Female Wild Carp, Cyprinus carpio, in Victoria, Australia. Environmental Biology of Fishes 68, 321-332.

Smart, A. C., Harper, D. M., Malaisse, F., Schmitz, S., Coley, S., Gouder de Beauregard, and Anne-Christine (2002). Feeding of the exotic Louisiana red swamp crayfish Procambarus clarkii; (Crustacea, Decapoda), in an African tropical lake: Lake Naivasha, Kenya. Hydrobiologia 488, 129-142.

Smith, B. B., and Walker, K. F. (2004). Spawning dynamics of common carp in the River Murray, South Australia, shown by macroscopic and histological staging of gonads. J ournal of Fish Biology 64, 336-354.

Smith, S. (1984). Phosphorus versus nitrogen limitation in the marine environment. LIMNOLOGY.

Son, S., and Wang, M. (2012). Water properties in Chesapeake Bay from MODIS-Aqua measurements. Remote Sensing of Environment 123, 163-174.

Søndergaard, M., Kristensen, P., and Jeppesen, E. (1992). Phosphorus release from resuspended sediment in the shallow and wind-exposed Lake Arresø, Denmark. Hydrobiologia 228, 91-99.

Spasojevic, M., and Holly, F. (2000). Field data and 3D mobile-bed modeling: Help or hindrance? In "Proc 4th Int Conf on Hydroinformatics, Iowa".

Spataru, P. (1978). Food and feeding habits of Tilapia zillii (Gervais)(Cichlidae) in Lake Kinneret (Israel). Aquaculture 14, 327338.

Ssebuggwawo, V., Kitamirike, J., Khisa, P., Njuguna, H., Myanza, O., Hecky, R., and Mwanuzi, F. (2005). Hydraulic/Hydrodynamic Conditions of 
Lake Victoria. LAKE VICTORIA ENVIRONMENT MANAGEMENT PROJECT (LVEMP) WATER QUALITY AND ECOSYSTEM STATUS, 42.

Stager, J. C., Cumming, B., and Meeker, L. (1997). A high-resolution 11,400yr diatom record from Lake Victoria, East Africa. Quaternary research 47, 81-89.

Stoof-Leichsenring, K., Junginger, A., Olaka, L., Tiedemann, R., and Trauth, M. (2011). Environmental variability in Lake Naivasha, Kenya, over the last two centuries. J ournal of Paleolimnology 45, 353-367.

Talling, J. F., and Driver, D. (1961). Some problems in the estimation of chlorophyll a in phytoplankton. Proc. Conf. Primary Production Measurement Marine Freshwater, p. 142-146.

Tarafdar, S., and Harper, D. (2008). Anti-persistence in levels of Lake Naivasha: Assessing effect of human intervention through time-series analysis. Physica A: Statistical Mechanics and its Applications 387, 296-302.

Tariq, S. R., Shah, M. H., Shaheen, N., Khalique, A., Manzoor, S., and Jaffar, M. (2005). Multivariate analysis of selected metals in tannery effluents and related soil. J Hazard Mater 122, 17-22.

Tarras-Wahlberg, H., Everard, M., and Harper, D. M. (2002). Geochemical and physical characteristics of river and lake [2pt] sediments at Naivasha, Kenya. Hydrobiologia 488, 27-41.

Teeter, A. M., Johnson, B. H., Berger, C., Stelling, G., Scheffner, N. W., Garcia, M. H., and Parchure, T. (2001). Hydrodynamic and sediment transport modeling with emphasis on shallow-water, vegetated areas (lakes, reservoirs, estuaries and lagoons). Hydrobiologia 444, 1-23.

Tempero, G. W., Ling, N., Hicks, B. J., and Osborne, M. W. (2006). Age composition, growth, and reproduction of koi carp (Cyprinus carpio) in the lower Waikato region, New Zealand. New Zealand J ournal of Marine and Freshwater Research 40, 571-583.

Tyler, A. N., Svab, E., Preston, T., Présing, M., and Kovács, W. A. (2006). Remote sensing of the water quality of shallow lakes: A mixture modelling approach to quantifying phytoplankton in water characterized by high-suspended sediment. International Journal of Remote Sensing 27, 1521 - 1537.

United Nations ( 2007). "Glossary of environment statistics, studies in methods," New York.

Van Oel, P. R., Mulatu, D. W., Odongo, V. O., Meins, F. M., Hogeboom, R. J., Becht, R., Stein, A., Onyando, J. O., and van der Veen, A. (2013). The Effects of Groundwater and Surface Water Use on Total Water Availability and Implications for Water Management: The Case of Lake Naivasha, Kenya. Water resources management 27, 3477-3492.

Vega, M., Pardo, R., Barrado, E., and Debán, L. (1998). Assessment of seasonal and polluting effects on the quality of river water by exploratory data analysis. Water Research 32, 3581-3592. 
Verbesselt, J., Hyndman, R., Newnham, G., and Culvenor, D. (2010). Detecting trend and seasonal changes in satellite image time series. Remote sensing of Environment 114, 106-115.

Verschuren, D. (1999). Influence of depth and mixing regime on sedimentation in a small, fluctuating tropical soda lake. Limnology and Oceanography 44, 1103-1113.

Verschuren, D., Laird, K. R., and Cumming, B. F. (2000a). Rainfall and drought in equatorial east Africa during the past 1,100 years. Nature 403, 410-414.

Verschuren, D., Tibby, J., Sabbe, K., and Roberts, N. (2000b). Effects of depth, salinity, and substrate on the invertebrate community of a fluctuating tropical lake. Ecology 81, 164-182.

Vincent, C., Davies, T., and Beresford, A. (1979). Recent changes in the level of Lake Naivasha, Kenya, as an indicator of equatorial westerlies over East Africa. Climatic Change 2, 175-189.

Wang, F., Wang, X., Zhao, Y., and Yang, Z. (2012). Long-term Changes of Water Level Associated with Chlorophyll a Concentration in Lake Baiyangdian, North China. Procedia Environmental Sciences 13, 12271237.

Wang, M., and Shi, W. (2008). Satellite-observed algae blooms in China's Lake Taihu. Eos, Transactions American Geophysical Union 89, 201.

Wang, M., Shi, W., and Tang, J. (2011). Water property monitoring and assessment for China's inland Lake Taihu from MODIS-Aqua measurements. Remote Sensing of Environment 115, 841-854.

Wang, M., Tang, J., and Shi, W. (2007). MODIS-derived ocean color products along the China east coastal region. Geophysical Research Letters 34, L06611.

Wang, Q., Li, S., Jia, P., Qi, C., and Ding, F. (2013). A review of surface water quality models. The Scientific World J ournal 2013.

Weghorst, P. L. (2008). "MODIS algorithm assessment and principal component analysis of chlorophyll concentration in Lake Erie," Kent State University.

Welcomme, R. (1967). Observations on the biology of the introduced species of Tilapia in Lake Victoria. Rev. Zool. Bot. Afr 76, 249-279.

Wenchuan, Q., Dickman, M., and Sumin, W. (2001). Multivariate analysis of heavy metal and nutrient concentrations in sediments of Taihu Lake, China. Hydrobiologia 450, 83-89.

Wenning, R. J., and Erickson, G. A. (1994). Interpretation and analysis of complex environmental data using chemometric methods. TrAC Trends in Analytical Chemistry 13, 446-457.

Wetzel, R. G. (2001). "Limnology: lake and river ecosystems," Access Online via Elsevier.

Wilkerson, F. P., Lassiter, A. M., Dugdale, R. C., Marchi, A., and Hogue, V. E. (2006). The phytoplankton bloom response to wind events and 
upwelled nutrients during the COOP WEST study. Deep Sea Research Part II: Topical Studies in Oceanography 53, 3023-3048.

Wolfgang, R. (2006). DNS and LES of some engineering flows. Fluid Dynamics Research 38, 145.

You, B.-s., Zhong, J.-c., Fan, C.-X., Wang, T.-c., Zhang, L., and Ding, S.-m. (2007). Effects of hydrodynamics processes on phosphorus fluxes from sediment in large, shallow Taihu Lake. Journal of Environmental Sciences 19, 1055-1060.

Zhu, Y., Yang, J., Hao, J., and Shen, H. (2009). Numerical Simulation of Hydrodynamic Characteristics and Water Quality in Yangchenghu Lake. In "Advances in Water Resources and Hydraulic Engineering", pp. 710715. Springer Berlin Heidelberg.

Zinabu, G.-M. (2002). The effects of wet and dry seasons on concentrations of solutes and phytoplankton biomass in seven Ethiopian rift-valley lakes. Limnologica - Ecology and Management of Inland Waters 32, 169-179.

Zinabu, G., and Pearce, N. J. (2003). Concentrations of heavy metals and related trace elements in some Ethiopian rift-valley lakes and their inflows. Hydrobiologia 492, 171-178. 


\section{Appendix 1}

\section{Idealized study of wind-driven flow scenario in Lake Naivasha}

\section{Model formulation}

\subsection{Geometry and force}

To define the geometry and force, consider a rectangular basin of length ( $2 L$ ) and width ( $2 B$ ). Let $\quad X$ and $y$ be the along-basin and crossbasin coordinates, such that the basin boundaries are located at $x=-L, L$ and, $y=-B, B$. The vertical coordinate $z$ points upward, with $Z=\eta$ denoting the free surface elevation with respect to the undisturbed water level $z=0$ and the bed level at $z=-h$. In general, $h$ is a function of $x, y$ but for simplicity we take $h=h(y)$. We look for steady flow $(\partial / \partial t=0)$ and solve the linearized mass and momentum equations, assuming the pressure is hydrostatic.

Let $u=\left(u^{*}, v^{*}, w^{*}\right)$ represent the flow velocity vector, with components $u, v, w$, in the $x, y$ and $z$ - direction, respectively. In terms of dimensional variables, the governing equations and boundary conditions are (A.1):

$$
\frac{\partial u^{*}}{\partial x^{*}}+\frac{\partial v^{*}}{\partial y^{*}}+\frac{\partial w^{*}}{\partial z^{*}}=0
$$

The steady, linearized momentum equations is

$$
\text { -" } p^{*}+\rho^{*} K_{v}^{* * 2} u^{*}=0
$$

$p^{*}$ represent the pressure, with differential operator " , the first term indicate the pressure gradient. It will be balanced by shear stress, result from the divergence of the gradient of velocity, where " *2 is the Laplace operator, $\rho^{*}$ is the density of water, and $K_{v}^{*}$ is the vertical diffusivity. Linearized surface boundary condition are applied at $z=0$. 


$$
\frac{\partial u^{*}}{\partial x^{*}}=\frac{\tau_{s}^{x}}{\rho^{*} K_{v}^{*}}, \frac{\partial v^{*}}{\partial x^{*}}=\frac{\tau_{s}^{y}}{\rho^{*} K_{v}^{*}}, p^{*}=\rho^{*} g^{*} \eta^{*} \text { and } w^{*}=0
$$

In this study, the wind stress is taken to be blowing along the $X$-axis, with the maximum amplitude $\tau^{*}$. The $y$-direction wind drives a cross-basin circulation which will be given later. Due to the linearity, the case where wind blows in arbitrary direction is just the superposition of the solutions of the wind blowing along $X$-direction and $y$-direction, respectively.

\section{$1.2 \quad$ Non-dimensional model}

If $L^{*}$ and $B^{*}$ are characteristic lengths in the $X$ and $y$ direction, and $H^{*}$ is the maximum vertical depth $(L>B \quad H)$, then:

$$
\begin{aligned}
& x^{*}=L^{*} x, y^{*}=B^{*} y, z^{*}=H^{*} z, u^{*}=\frac{\tau^{*} H^{*}}{\rho^{*} K_{v}^{*}} u, \\
& v^{*}=\frac{\tau^{*} H^{*}}{\rho^{*} K_{v}^{*}} \alpha v, w^{*}=\frac{\tau^{*} H^{*}}{\rho^{*} K_{v}^{*}} \frac{H^{*}}{L^{*}} w
\end{aligned}
$$

Unstarred variables are non-dimensional. The horizontal aspect ratio can be expressed as: $\alpha=B^{*} / L^{*}$. Assuming the vertical momentum balance to be hydrostatic then for a constant density the dimensional balance is:

$$
p^{*}=-\int \rho^{*} g^{*} \mathrm{~d} z^{*}=-\rho^{*} g^{*} z^{*}+\text { constant }=\rho^{*} g^{*}\left(\eta^{*}-z^{*}\right)
$$

Assuming that the momentum is the sum of the pressure, and shear forces is zero, then, the linearized problem reduces to:

$$
\frac{\partial u}{\partial x}+\frac{\partial v}{\partial y}+\frac{\partial w}{\partial z}=0
$$

The momentum equation can be simplified as:

$$
\frac{\partial^{2} u}{\partial z^{2}}=\frac{\partial \eta}{\partial x}
$$




$$
\alpha^{2} \frac{\partial^{2} v}{\partial z^{2}}=\frac{\partial \eta}{\partial y}
$$

The remaining boundary conditions are:

$$
\frac{\partial u}{\partial z}=\tau, \frac{\partial v}{\partial z}=0, w=0 \text { at } z=0 ; u=v=w=0 \text { at } z=-h
$$

To represent the trough-like structure, the following term is introduced:

$$
h=1-|y|
$$

\subsection{Horizontal velocity and transport}

Horizontal and vertical transport can be calculated as:

$$
u=\eta_{x} h^{2} \frac{\tilde{z}^{2}-1}{2}+\tau h(\tilde{z}+1), \quad \alpha^{2} v=\eta_{y} h^{2} \frac{\tilde{z}^{2}-1}{2}
$$

where $\quad \tilde{z}=z / h$ is the local relative depth. The first term on the right of the solution for $U$ (the downwind velocity) is the velocity forced by the pressure gradient (negative because $\tilde{z}^{2}$ is always less than 1 ), and the second term is the velocity driven by the wind stress. The subscript indicates a derivative, e.g $\eta_{x}$ means $\frac{\partial \eta}{\partial x}$. If $h$ is very small, then the second term in the expression for $U$ dominates over the first. The horizontal transport can be expressed as:

$$
[u]=\int_{-h}^{0} u \mathrm{~d} z=\tau \frac{h^{2}}{2}-\eta_{x} \frac{h^{3}}{3}
$$

While vertical transport is:

$$
\alpha^{2}[v]=\int_{-h}^{0} v \mathrm{~d} z=-\eta_{y} \frac{h^{3}}{3}
$$

and mass conservation integration is expressed as:

$$
[u]_{X}+[v]_{y}=0
$$




\subsection{Equation for stream function}

Stream function $(\varphi)$ is then introduced as defined:

$$
[u]=-\varphi_{y} \quad ;[v]=\varphi_{x}
$$

Substituting stream function into equation 12 and 13 results in:

$$
\eta_{x}=\tau \frac{3}{2 h}+\frac{3}{h^{3}} \frac{\partial \varphi}{\partial y}, \quad \eta_{y}=-\frac{3 \alpha^{2}}{h^{3}} \frac{\partial \varphi}{\partial x}
$$

Cross differentiating, the above equation results in:

$$
\frac{\partial}{\partial x}\left(\frac{1}{h^{3}} \frac{\partial \varphi}{\partial x}\right)+\alpha^{-2} \frac{\partial}{\partial y}\left(\frac{1}{h^{3}} \frac{\partial \varphi}{\partial y}\right)=\alpha^{-2} \frac{\partial}{\partial y} \frac{\tau}{2 h}
$$

The stream function was assumed to be equal around the boundary (as the boundary condition).

\section{Solution}

Away from the closed ends of the basin, $\varphi$ is expected to depend only on $y$.

A.17 can be integrated once in $y$ to give:

$$
\frac{\partial \varphi}{\partial y}=-\frac{\tau h^{2}}{2}+\frac{C h^{3}}{3}
$$

Considering equation 12, the down-wind component of the sea level gradient is taken to be constant. If the basin is closed, the stream function must have the same values on both sides, setting the laterally averaged transport to zero as shown below:

$$
0=-\frac{\tau}{2}<h^{2}>+\frac{\eta_{x}}{3}<h^{3}>
$$

where the $<>$ brackets denotes integrals across the width of the basin. Far from where the up and down-wind ends, the axial sea level gradient is:

$$
\eta_{x}=\frac{3 \tau}{2} \frac{<h^{2}>}{<h^{3}>}
$$

In this case, the bottom profile is a trough, $h=1-|y|$, then $\left\langle h^{2}>=2 / 3\right.$ and $<h^{3}>=1 / 2$ then $\eta_{x}=2$. Thus the horizontal transports are:

$$
[u](y)=\tau \frac{h^{2}}{2}-2 \frac{h^{3}}{3} ; \quad[v]=0
$$


Incorporating stream function yields:

$$
\varphi(y)=\frac{y}{6|y|^{2}}\left[(1-|y|)^{3}-(1-|y|)^{4}\right]
$$

In case wind blowing in $y$-direction, only circulation in cross-basin is formed. The depth integrated transport is $\alpha^{2}[v]=\frac{\alpha h^{2}}{2} \tau-\frac{h^{3}}{3} \eta_{y}$, where surface gradient $\eta_{y}=2 \alpha \tau$ balance the wind stress in $y$-direction.

Where $h=h(y)$ then equation 17 can be solved as:

$$
\alpha^{2} \varphi_{x x}+h^{3}\left(\frac{\varphi_{y}}{h^{3}}\right)_{y}=\frac{h h_{y}}{2}
$$

Near the mid-basin, the solution is $\varphi^{\infty}$ as Equation 22 shows. In the rest of the basin, we seek a solution in the form of an expansion in terms of eigen function of $y$ :

$$
\varphi(x, y)=\sum_{n=0}^{\infty} a_{n} X_{n}(x) Y_{n}(y)
$$

One way to do this is to define the $Y_{n}$ 's as:

$$
\frac{d}{d y}\left(\frac{Y_{n, y}}{h^{3}}\right)+\frac{\lambda_{n}}{h^{3}} Y_{n}=0
$$

Consider $y \geq 0$ is then $1-y$, for odd eigenvectors(as required to match $\varphi$ at mid-basin) with homogenous conditions $Y_{n}(0)=Y_{n}(1)=0$, the solutions are Bessel functions of

$$
Y_{n}(y)=(1-y)^{2} J_{2}\left(\sqrt{\lambda_{n}}(1-y)\right)
$$

where $\sqrt{\lambda_{n}}$ represent the zeros of $J_{2}$. Similar result is obtained for $y \leq 0$ :

$$
Y_{n}(y)=-(1+y)^{2} J_{2}\left(\sqrt{\lambda_{n}}(1+y)\right)
$$

Using the orthogonality properties of Bessel functions, we choose coefficient $a_{n}$ to be

$$
a_{n}=-\frac{1}{\lambda_{n}} \int_{-1}^{1} \frac{h_{y} Y_{n}}{2 h^{2}} \mathrm{~d} y
$$


Then we obtain the following equation for the $X_{n}$ :

$$
\alpha^{2} X_{n^{\prime \prime}}-\lambda_{n} X_{n}+\lambda_{n}=0
$$

When the boundary conditions are $X_{n}=0$ at $x= \pm 1$, the solution for $X_{n}$ becomes:

$$
X_{n}(x)=1-\frac{\cosh \left(\sqrt{\lambda_{n}} / \alpha x\right)}{\cosh \left(\sqrt{\lambda_{n}} / \alpha\right)}
$$

Over shallow areas, the wind stress dominates the circulation, forms downwind depth-intergrated (flow Figure A.1), whereas over deep areas the surface level gradient dominates and the depth-integrated flow is upwind. Mathieu et al (2002).

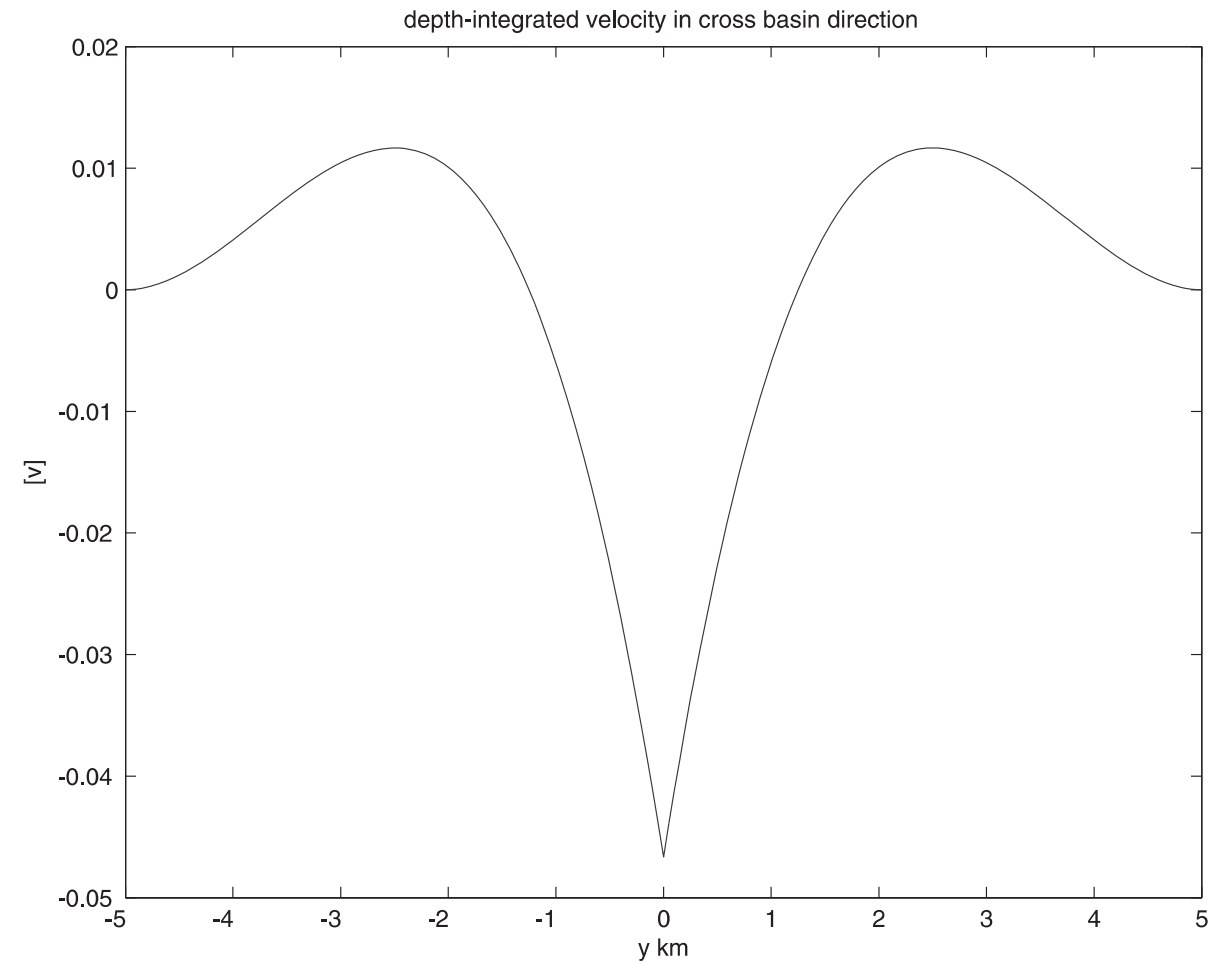

Figure A.1. Wind blowing in $y$-direction, the $\mathrm{x}$-horizontal transport (depth-integrated) is zero everywhere. 


\section{Appendix 2}

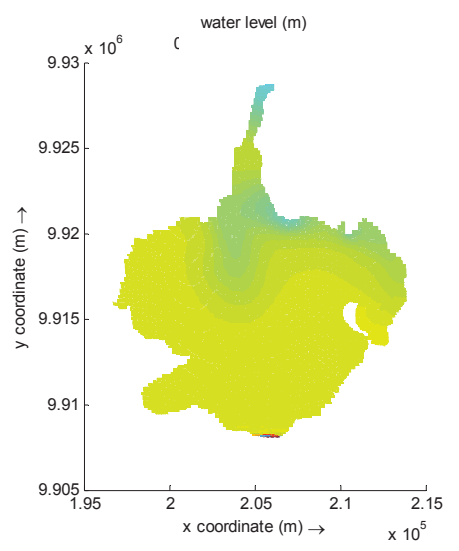

(a)

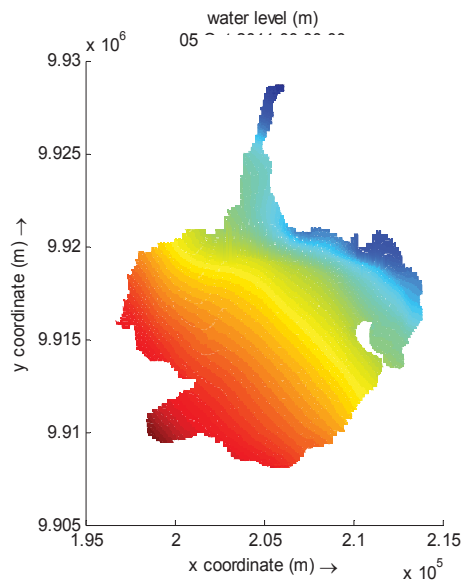

(c)

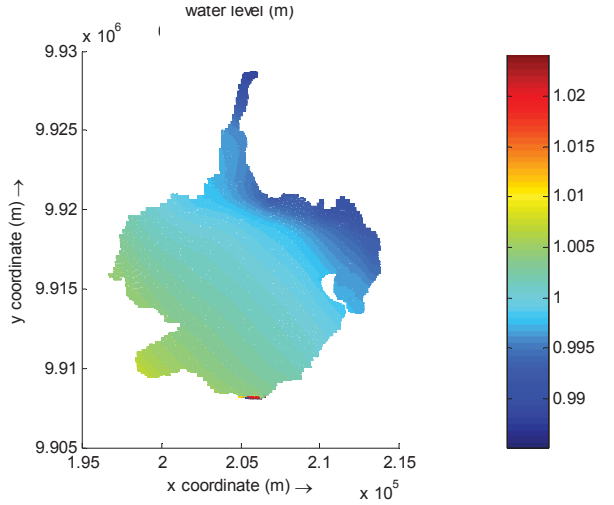

(b)
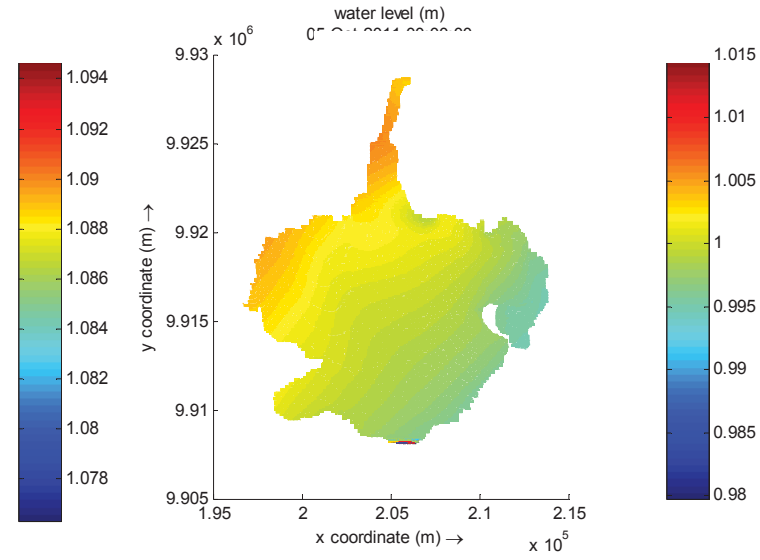

(d)

Water level setup at zero wind $\operatorname{speed}(a), 45^{\circ}(\mathrm{b}), 90^{\circ}(\mathrm{c})$, and $135^{\circ}(\mathrm{d})$ wind directions. 


\section{Samenvatting}

De waterkwaliteit van aquatische systemen is belangrijk omdat het van invloed is op de ecologische processen. Een verslechterde kwaliteit van het water als gevolg van milieuverstoringen bedreigt de biotische integriteit en belemmert de functies van aquatische ecosystemen. Dit onderzoek richt zich op het bestuderen van de waterkwaliteit in Lake Naivasha in Kenia. Een groot aantal milieuverstoringen in het Lake Naivasha ecosysteem hebben het meer getransformeerd van een helder naar een troebel eutroof systeem, wat heeft geresulteerd in een afname van de ecologische kwaliteit die effect heeft op de visstand en het toerisme. Hoewel de waterstand en visvangst regelmatig gemeten worden, zijn er relatief weinig metingen gedaan aan de waterkwaliteit in Lake Naivasha. De specifieke doelstellingen van dit onderzoek zijn daarom: het bepalen van de algemene waterkwaliteit in het meer; het vaststellen van de mate van eutrofiëring; het reconstrueren van de waterkwaliteit in het afgelopen decennium; het bestuderen van de veranderingen in de vispopulaties; en het onderzoeken van de mechanismen die de waterkwaliteit in Lake Naivasha beïnvloeden.

Deze doelstellingen zijn bereikt door een combinatie van veldmetingen, geoinformatie en aardobservatie en systeemmodellering. De veldmetingen werden wekelijks verzameld van januari tot juni en tweewekelijkse van juli tot november 2011 op zeven verschillende locaties in het meer. Watertemperatuur, $\mathrm{pH}$, geleidbaarheid, Secchi diepte en troebelheid werden in-situ gemeten terwijl andere parameters werden bepaald uit de analyse van watermonsters in het laboratorium. Aardobservatie met de Moderate Resolution Imaging Spectroradiometer (MODIS-Aqua) satelliet werden gebruikt bij het verkrijgen van chlorofyl-a concentraties van juni 2002 tot juni 2012. Voor het bepalen van de mechanismen die de waterkwaliteit beïnvloeden is gebruik gemaakt van Delft3D en een eenvoudig gemengde reactor model.

Hoofdcomponentenanalyse en clusteranalyse zijn gebruikt om de ruimtelijke variabiliteit in fysisch-chemische parameters, nutriënten en de belangrijkste ionen te bepalen. Het noordelijke deel van het meer, het centrale en zuidelijke deel van het meer en Crescent Lake, een min of meer geïsoleerd kratermeer, waren duidelijk verschillend. De analyses geven aan dat het noorden van het meer (in de omgeving waar de twee belangrijkste rivieren, de Malewa en Gilgil in het meer uitmonden) het meest wordt beïnvloed door agrarische activiteiten. De waterkwaliteit in het noordoostelijk deel van het meer wordt gedomineerd door de lozing van huishoudelijk afvalwater en de interactie met Crescent Lake, waarvan de minerale samenstelling verband houdt met de vulkanische oorsprong. 
Deze studie toont aan dat de mate van eutrofiëring in Lake Naivasha ligt tussen eutroof en hypereutroof. In vergelijk met eerdere waterkwaliteitstudies is de eutrofiëring in het meer toegenomen. Uit discriminantanalyse van de trofische staat indices (TSI) zijn dezelfde drie regio's te onderscheiden: het noordelijke deel van het meer, het centrale en zuidelijke deel en Crescent Lake. De grafische weergave van de verschillen tussen de trofische staat index van chlorofyl-a (TSI-CHL) en totaal fosfor (TSI-TP) geeft aan dat het meer voornamelijk fosfor gelimiteerd is (TSI-CHL $>$ TSI-TP). Daarnaast blijkt dat dicht bij de monding van de Malewa rivier, het noordoostelijk deel (dichtbij het lozingspunt van de afvalwaterzuiveringsinstallatie en Kihoto sloppenwijk) en Kamere Beach (nabij Kamere nederzetting) de troebelheid voornamelijk veroorzaakt wordt door sedimenten of organisch materiaal en minder door chlorofyl-a (TSI-CHL $<$ TSI-SD (SD=Secchi diepte)). In Crescent Lake was de TSI-CHL groter dan de TSI-SD (TSI-CHL > TSI-SD), wat een indicatie is voor de aanwezigheid van algensoorten met een meer draadvormige of koloniale structuur dan in de rest van het meer.

Deze studie bevestigt de mogelijkheid van retrospectieve analyse van de ruimtelijke variaties en temporele trends in de chlorofyl-a-concentratie met behulp van de MODIS-Aqua satelliet, die data verstrekt op momenten dat routinematige metingen aan de grond ontbreken. De samengestelde maandelijkse kaarten van de chlorofyl-a-concentraties laten een grote ruimtelijke variatie zien binnen een jaar die wordt veroorzaakt door seizoensinvloeden zoals klimaat (neerslag) en seizoensgebonden landbouwpraktijken. De lange termijn trend in de chlorofyl-a-concentratie bleek een duidelijke omgekeerde correlatie te vertonen met de waterstand in het meer wat kan duiden op verdunning en concentratie-effecten.

Modelsimulaties met Delft3D laten zien dat de stroming in Lake Naivasha vooral windgedreven is. Deze stroming zorgt voor circulatie van water in het grootste gedeelte van het meer en zo voor spreiding en herverdeling van stoffen zoals zwevende deeltjes en opgeloste stoffen. De stroming kan de waterkolom verrijken met nutriënten en daardoor de algengroei bevorderen en de troebelheid vergroten. Modellering van de waterkwaliteit laat zien dat het ongeveer 40 jaren duurt voordat een nieuwe evenwichtsconcentratie is bereikt na een verandering van de (constante) invoerconcentratie. Wegzijging van water uit het meer naar het grondwater is mogelijk de belangrijkste reden waarom het water in Lake Naivasha nog steeds zoet is, al is deze term in de waterbalans moeilijk te meten.

Uit de evaluatie van de trends in vispopulaties bleek dat de toename van de Cyprinus carpio niet alleen heeft geleid tot eliminatie van roofsoorten die jagen op zicht zoals Tilapia zilli, maar waarschijnlijk ook heeft bijgedragen 
aan de toename van de chlorofyl-a concentratie doordat nutriënten vrijkomen bij het wroeten in de sedimentlaag. Micropterus salmoides bleek relatief tolerant voor troebele omstandigheden. Cyprinus carpio heeft de laagste prijs per eenheid gewicht, maar omdat deze soort het meest gevangen wordt zorgt deze vis voor het grootste deel van het inkomen van de vissers in Lake Naivasha.

Deze studie heeft laten zien dat de integratie van veldmetingen, geoinformatie en modellering nuttig is voor het verkrijgen van belangrijke informatie over de waterkwaliteit van Lake Naivasha. 


\section{Biography}

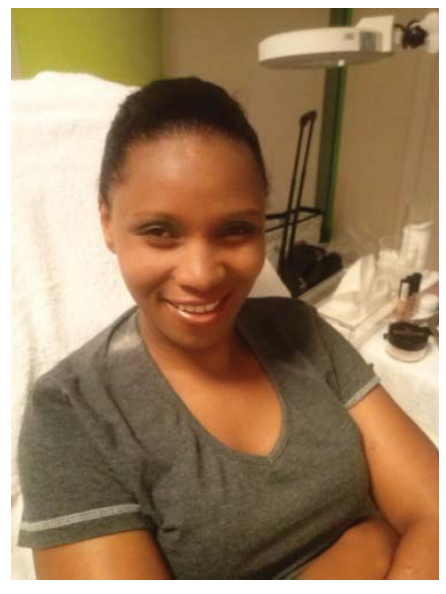

Jane Ndungu was born in Kiambu County in a small village called Kaguongo. She went to Kaguongo primary school and later joined St. Francis Girls' high school Mang'u. She undertook her bachelor's studies in Egerton University in Bachelor of Science in Environmental Science and graduated in 2004. In 2007, she enrolled for a Master of Science Degree in Geo-information and Earth Observation in Natural Resources Managements in Faculty of Geo-information and Earth Observation (ITC) in University of Twente and graduated in March 2009.

Since April 2010, she has been working on her $\mathrm{PhD}$ research at University of Twente under Earth Observation-and Integrated Assessment Approach (EOIA) to the governance of Lake Naivasha project among other four $\mathrm{PhD}$ researchers. The project is a collaborative initiative between Egerton University, University Nairobi and University of Twente. Her study focus is on integration of field measurements, remote sensing and modelling in assessment of water quality issues in Lake Naivasha.

Jane is a research scientist in Kenya Marine and Fisheries Research Institute since 2005. She has been involved in execution of European Union Research Projects such as Western Indian Ocean Satellite Project (WIOSAP), African Monitoring of the Environment for Sustainable Development (AMSED) and Ocean Data and Information Network for Africa (ODINAFRICA). She has participated in other MASMA (Marine Science for Management projects) as a remote sensing expert. Her keen research interest are in environmental sciences and natural resource management specifically in ecology, water quality, GIS and bulk remote sensing data processing, limnology, and aquatic sciences.

\section{List of publications}

Ndungu, J.N., Monger, B.C., Augustijn, D.C.M., Hulscher, S.J.M.H., Kitaka, N. \& Mathooko, J.M. (2013). Evaluation of spatio-temporal variations in chlorophyll-a in Lake Naivasha, Kenya: remote-sensing approach. International journal of remote sensing, 34(22), 8142-8155.

Ndungu, J.N, Augustijn, D.C.M., Hulscher, S.J.M.H., Kitaka, N., and Mathooko, J. (2013) Spatio-temporal varwiations in the trophic status of Lake Naivasha, Kenya Lakes and Reservoirs: Research and Management 18, 1-12. 
Ndungu, J.N., Augustijn, D.C.M., Hulscher, S.J.M.H., Bernard Fulanda, Kitaka, N. \& Mathooko, J.M. (2013). Multivariate approach in the assessment of the status of water quality in Lake Naivasha. Accepted in Marine and Fresh Water Research J ournal.

Van Oel P.R., Odongo V.O., Mulatu D.W., Muthoni F.K, Ndungu J.N,, Van der Veen A., Supporting IWRM through Spatial Integrated Assessment for the Lake Naivasha basin, Kenya (Accepted in International Journal of Water Resources Development)

Ndungu, J.N., Augustijn, D.C.M., Hulscher, S.J.M.H., Kitaka, N. \& Mathooko, J.M Relationship between fish community succession, water quality and livelihood: case study in Lake Naivasha, Kenya (Submitted).

Ndungu, J.N., Augustijn, D.C.M., Hulscher, S.J.M.H., Bernard Fulanda, Kitaka, N. \& Mathooko, J.M., Hydrodynamics modelling in Lake Niavasha. (To be submitted).

Ndungu, J.N., Augustijn, D.C.M., Hulscher, S.J.M.H., A simplified water quality model of Lake Naivasha (In preparation)

\section{Other publications}

Clerici, M., Hoepffner, N., Diop, M., Ka, A., Kirugara, D., and Ndungu, J. (2009) SST derivation from MSG for PUMA Pilot Projects in Fisheries. International Journal of Remote Sensing 30(8), 1941-1959.

\section{Proceedings}

Oel, P.R. van, Odongo, V.O., Mulatu, D.W., Ndungu, J.N., Muthoni, K., Ogada, J., Khroda, G., Mathooko, J., Becht, R., Kitaka, N., Onyando, J.O. \& Veen, A. van der (2012). An earth observation and integrated assessment (EOIA) approach for the sustainable governance of a socio - ecological system : the case of the Lake Naivasha basin, Kenya. In Proceedings of Water Management Issues in Africa : Scientific conference of the NASACKNAW collaboration initiative in collaboration with MAST and Leopoldina on 28-31 March 2012, Réduit, Mauritius. (pp. 21 p.). Réduit: NASAC-KNAW.

\section{Conference abstracts}

Ndungu, J.N., Augustijn, D.C.M. \& Hulscher, S.J.M.H. (2013). A remote sensing approach in evaluation of spatio-temporal variation in chlorophyll-a concentrations in Lake Navaisha, Kenya. In 4th International multidisciplinary conference on hydrology and ecology (HydroEco'2013): emerging patterns, breakthroughs and challenges, 13-16 May 2013, Rennes, France (pp. 165165). Rennes, France. 
Ndungu, J.N. (2013). Multivariate approach in the assessment of the status of water quality in Lake Navaisha. In Z. Heiszler \& R. Hohol (Eds.), Book of Abstracts 32nd Congress of the International Society of Limnology, 4-9 August 2013, Budapest, Hungary (pp. 207-207). Tihany, Hungary: Balaton Limnological Institute.

\section{Prices}

Ndungu, J.N., Augustijn, D.C.M. \& Hulscher, S.J.M.H. (2013). Best Poster Award: A remote sensing approach in evaluation of spatio-temporal variation in chlorophyll-a concentrations in Lake Navaisha, Kenya. 4th International multidisciplinary conference on hydrology and ecology: emerging patterns, breakthroughs and challenges, 13-16 May 2013, Rennes, France: Rennes, France (2013,May 13 - 2013, May 16). Prijs / Beurs. 